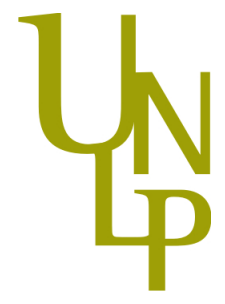

Facultad de Informática Universidad Nacional de La Plata

Tesis de maestría en Redes de Datos

\title{
Un modelo de integrabilidad con SOA y BPM
}

\author{
Lic. Patricia Bazán
}

Directores: Dra. Roxana Giandini, Lic. F. Javier Diaz 
"En verdad os digo que, si el grano de trigo no cae en la tierra y muere, quedará solo; pero si muere llevará mucho fruto" (San Juan 12-24) 


\section{Prólogo}

Para quien escribe estas líneas, es un honor prologar el presente trabajo de tesis para la Maestría en Redes de Datos de la Facultad de Informática de la Universidad Nacional de La Plata (UNLP), cuya autora es la Licenciada en Informática Patricia Bazán.

La Licenciada Bazán es Miembro del Laboratorio de Investigación en Nuevas Tecnologías Informáticas (LINTI), Profesor Titular en la cátedra de Desarrollo de Software en Sistemas Distribuidos de la carrera de Licenciatura en Sistemas de la Facultad de Informática de la UNLP, Directora de Estadística de la Facultad de Informática de la UNLP, Consejera Superior Titular por el claustro de profesores de la Facultad de Informática de la UNLP e Integrante del Proyecto "Avances en redes de transmisión de datos y en seguridad", con un cargo de Profesor Titular con Dedicación Exclusiva, desempeñando funciones en la Facultad de Informática de la UNLP. Este proyecto se encuentra enmarcado dentro del Programa de Incentivos a la Investigación del Ministerio de Educación de la Nación.

En los últimos años, la autora ha venido profundizando en los temas que son objeto de estudio en esta tesis, tarea que ha quedado plasmada en diferentes publicaciones de trabajos de investigación y en las tesis de grado que ha dirigido como docente de las carreras de Licenciatura en Sistemas y Licenciatura en Informática de la Facultad de Informática de la UNLP.

La obra presente apunta fundamentalmente a concebir un modelo de integración de aplicaciones dentro de una organización, problemática que desvela a los responsables de las mismas, visto que el impacto que producen los cambios en las nuevas tecnologias y la velocidad con la que éstos se suceden, no siempre permiten un crecimiento ordenado, armonioso y eficiente de sus estructuras.

El enfoque abordado en este trabajo está orientado al diseño de procesos y servicios, promoviendo la reutilización de código, la mejora continua de los procesos y la especificación de requerimientos, comprometiendo todo el ciclo de vida de los proyectos e integrando funcionalidades nuevas y existentes. El marco metodológico propuesto se orienta a servicios y a procesos de negocio gestionados por tecnologías SOA y BPM.

La autora presenta, como objeto de estudio, un interesante ejemplo de un caso real de reingeniería de negocio y tecnológica, que tuvo como fin la implementación de una ventanilla única de trámites en una repartición pública. Esta temática permitió aplicar en gran medida los enunciados expuestos en el presente trabajo.

Podemos decir, finalmente, que el lector encontrará en las páginas siguientes un análisis exhaustivo y fundamentado de lo que representa en nuestros días la problemática referida a la integración de aplicaciones en las organizaciones y sus posibles soluciones.

Virginia Chedrese 


\section{Agradecimientos}

En primer lugar quiero agradecer a mis directores, el Lic. Javier Díaz con quien he crecido académica y profesionalmente desde hace veinte años y a la Dra. Roxana Giandini, quien además de ser mi amiga, aportó toda su experiencia como postgraduada; sin ella hubiera sido mucho más arduo este camino.

A la Facultad de Informática, y dentro de ella al Laboratorio de Investigación en Nuevas Tecnologías Informáticas (LINTI), que me cobijan desde siempre.

A Virginia Chedrese, mi amiga y compañera, que minuciosamente revisó este trabajo y escribió el prólogo que lo presenta.

A Luciano Lorenzón, quien ha sido para mi otra fuente de inspiración para este trabajo y que favoreció mi desarrollo como profesional fuera del ámbito académico.

A la DCV Ariadna Alfano, que aportó un mejor aspecto visual a este trabajo y realizó una y mil veces cada gráfico que venía a mi mente.

A mi hermosa y queridísima familia. Mi esposo, Darío, compañero insuperable y enorme puntal de mi vida. A mis hijos, Sabrina, quien por ser la primera me enseñó a ser mamá y me transformó como persona. A Candela, que por ser la más chiquita me enternece con su presencia y me acompañó haciendo dibujos en mis largas jornadas frente al teclado. A Santiago, mi musa celestial, que con su partida me enseñó que en realidad se fue para quedarse eternamente.

A mis padres, Beba y César, a quien les debo ni más ni menos que mi propia existencia y que son un verdadero ejemplo a seguir.

A Dios, mi Señor, por las abundantes bendiciones que derrama sobre mi vida. 


\section{Índice general}

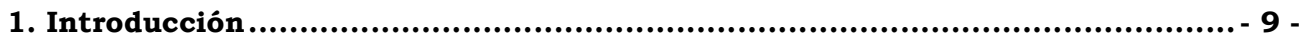

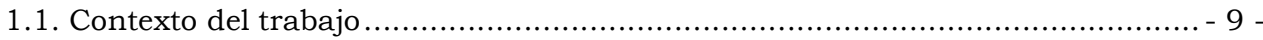

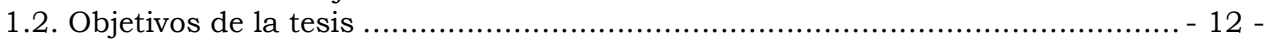

1.3. Aportes de esta tesis .............................................................. - 13 -

1.4. Publicaciones relacionadas con esta tesis .......................................... 13 -

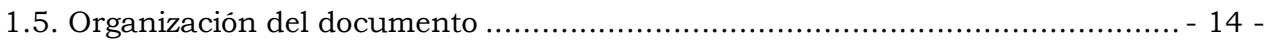

2. Procesos de negocios................................................................. 16 -

2.1. Definiciones y generalidades ....................................................... 16 -

2.2 BPMN, BPD y el modelado de los procesos de negocios .............................. 18 Importancia de BPMN ................................................................ 19 -

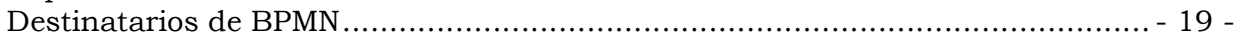

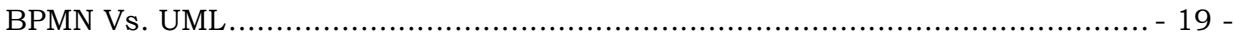

Elementos del lenguaje ........................................................................... 20 -

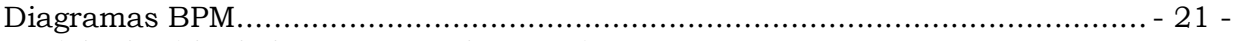

2.3. Ciclo de vida de los procesos de negocios......................................... 24 -

2.4. Clasificación de los procesos de negocios...................................... 27 -

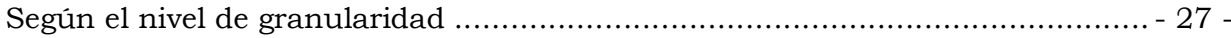

Según el alcance corporativo ............................................................ 27 -

Según el grado de automatización ............................................... - 27 -

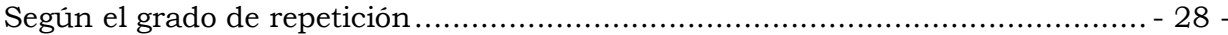

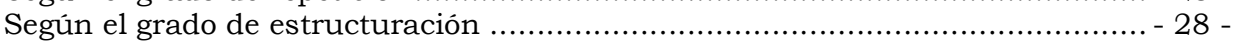

2.5. Orquestación y coreografia de los procesos de negocios ......................... 28 -

2.6. Conclusiones ................................................................................. 29 -

3. Arquitectura Orientada a Servicios ............................................... 31 .

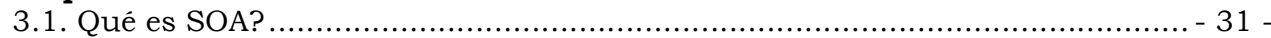

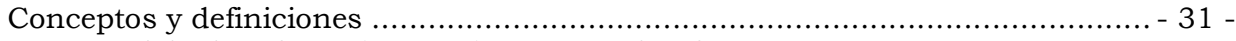

SOA: modelo de referencia, arquitectura y plataforma.............................. - 32 -

SOA y el modelo de interacción............................................................. 33 -

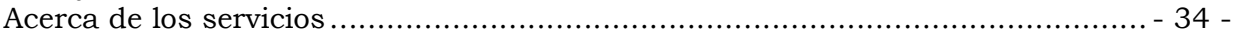

3.2. Evolución desde los objetos distribuidos a los servicios ............................. 34 -

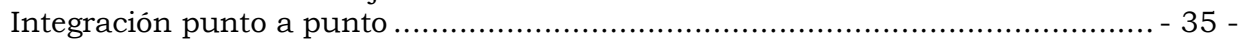

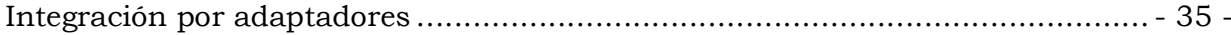

Mediador de mensajes ................................................................. 36 -

CORBA como estándar de objetos distribuidos ..................................... $37-$

Modelo de integración por servicios ....................................................... 38 -

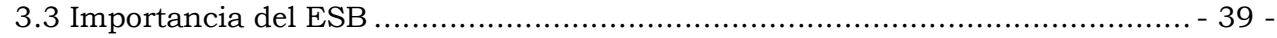

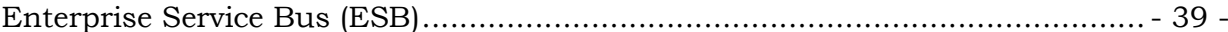

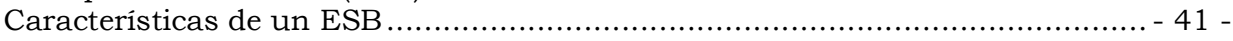

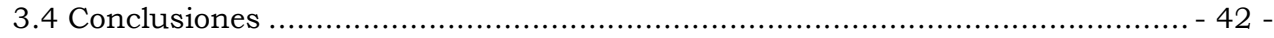

4. Modelos de integración existentes ........................................................ - 43 -

4.1. Evolución tecnológica de las aplicaciones ...................................... $43-$

4.2. Alternativas de integración de aplicaciones......................................... 45 -

EAI tradicional ..................................................................................... 45 -

Sistemas de Workflow y la integración de aplicaciones ............................... - 46 -

Integración basada en SOA con BPM .................................................... 47 -

4.3. Elementos de un modelo de integración ................................................. 49 -

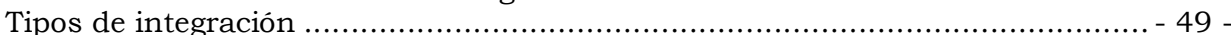

Escenarios de integración dirigida por procesos ........................................ 49 -

Método para la integración basada en servicios.......................................... 50 -

Componentes de infraestructura para la integración................................. 50 -

Actores que participan en la integración .............................................. $52-$

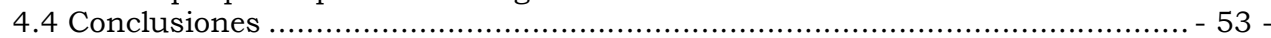

5. Marco Metodológico con SOA y BPM ............................................. 55 -

5.1. Marco metodológico: etapas y su interacción ........................................ 56 -

5.2. Etapa de organización y plan estratégico ............................................. 58 -

5.3. Etapa de identificación y especificación de requisitos …......................... 59 -

5.4. Etapa de modelado del negocio......................................................... 61 -

5.5. Etapa de modelado de procesos ...................................................... 63 -

5.6. Etapa de modelado de servicios ........................................................ - 64 -

5.7. Etapa de definición de componentes........................................... 68 -

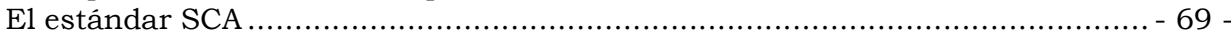


5.8 Etapa de implementación de componentes ......................................... - 71 -

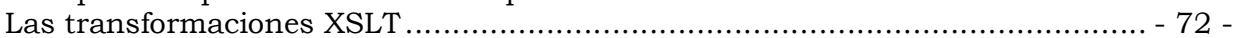

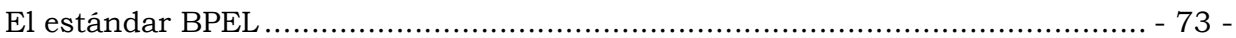

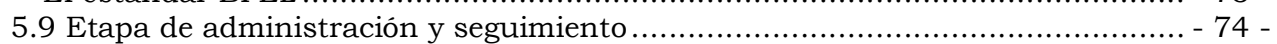

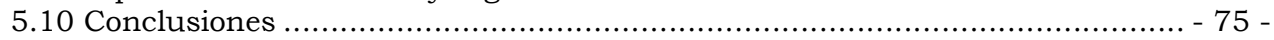

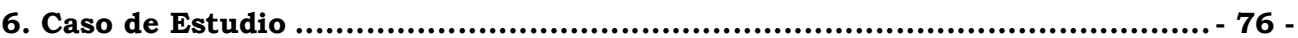

6.1 Planteo del problema................................................................... 76 -

6.2 Aplicación de la metodología al caso de estudio .................................... 78 -

Generalidades resultantes de aplicar las etapas de 1-OPE y 2-IER del marco

metodológico

$-78-$

Etapa de modelado del negocio 3-MN …............................................. 81 -

Etapa de modelado de procesos 4-MP ............................................... 89 -

Etapa de modelado de servicios 5 -MS ............................................ 93 -

Etapa de definición de componentes 6 -DC ............................................. 95 -

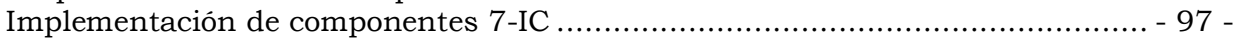

6.2 Lecciones aprendidas y estado actual de la tecnología .............................. 99 -

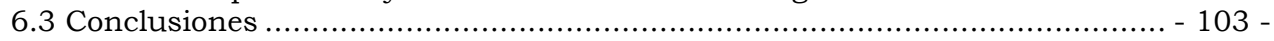

7. Conclusiones y trabajos relacionados......................................... - 105 -

7.1. Trabajos relacionados ............................................................... - $105-$

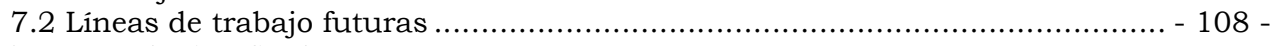

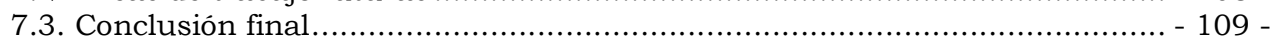

Referencias............................................................................. - 111 -

Anexo 1. Contexto Global ............................................................. 114 -

A.1.1 Aspectos Conceptuales ...................................................... - 114 -

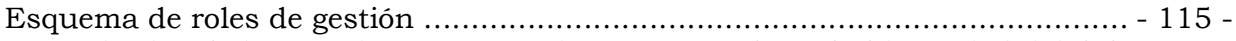

A.1.2. Criterios de interacción con usuarios en que se basa la hipótesis inicial de

ventanillas que da lugar al diagrama de contexto. .................................... - 117 -

A.1.3. Criterios tecnológicos y de procesos en que se basa el diagrama de contexto - 118

A.1.4. Criterios derivados de las politicas ........................................... 118 -

A.1.5. Diagrama de contexto ............................................................. 120 -

Anexo 2. Modificaciones Propuestas ................................................ - 122 -

A.2.1 Modificaciones generales.......................................................... - 122 -

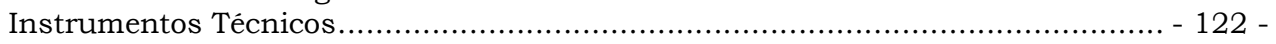

Mejora en las reglas de negocio de los procesos ..................................... - 123 -

A.2.2. Modificaciones específicas....................................................... - 124 - 


\section{Índice de Figuras}

Figura 1.1 Esquema general de la orientación a servicios con procesos de negocio.... - 12 -

Figura 2.1. Representación gráfica de un proceso de compra simple ..................... 17 -

Figura 2.2. Interacción entre procesos de negocios ..................................... 18 -

Figura 2.3. Ejemplo de un proceso simple ................................................ 24 -

Figura 2.4. Segmento de un proceso con detalle ............................................ 24 -

Figura 2.5. Ciclo de vida de los procesos de negocio........................................ 25 -

Figura 3.1. Marco general entre modelo de referencia, arquitectura de referencia y

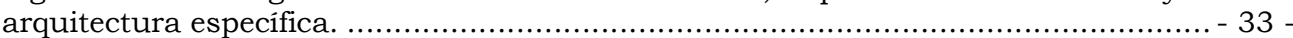

Figura 3.2. Modelo de Interacción triangular de SOA .................................... 33 -

Figura 3.3. Mecanismo de integración punto a punto ...................................... 35 -

Figura 3.4. Mecanismo de integración por adaptadores................................. 36 -

Figura 3.5. Mecanismo de integración por Broker de Mensajes .......................... - 37 -

Figura 3.6 ESB como una infraestructura distribuida con control centralizado ......... - 41 -

Figura 4.1. Evolución de tecnológica de aplicaciones ................................ 44 -

Figura 4.2. Componente Workflow de aplicación simple ................................... 47 -

Figura 4.3. Componente Workflow de aplicación múltiple. .............................. 47 Figura 4.4. SOA alinea negocios con IT, llevando las aplicaciones tradicionales hacia las

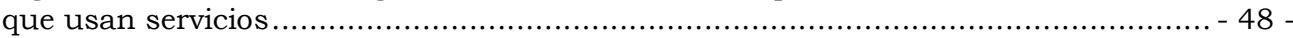

Figura 4.5. Escenario de un modelo de integración y sus actores ....................... 53 -

Figura 5.1. Ortogonalidad de procesos y servicios ........................................ 55 -

Figura 5.2. Marco metodológico propuesto: etapas superpuestas en cada ciclo de vida - 58

Figura 5.3. Marco metodológico propuesto: interacción de etapas .......................... 58 -

Figura 5.4. De la maraña original a la red de trabajo rediseñada......................... 61 -

Figura 5.5 Caso de uso "Identificación de usuario" ...................................... 63 -

Figura 5.6. Formulario para registrar el diccionario de datos ............................. 64 -

Figura 5.7. Simbolo de servicio como un círculo con cuerda ............................... - 64 -

Figura 5.8. Composición de servicios expresada con círculos con cuerda ................. 65 -

Figura 5.9. Los servicios como encapsulamiento de la lógica.............................. 66 -

Figura 5.10. Componente calculadora ............................................... 68 -

Figura 5.11. Inventario de servicios ................................................... 69 -

Figura 5.12. Representación gráfica de un componente SCA................................. 69 -

Figura 5.13. Proceso de registro de una orden de compra en DB2 ....................... - 70 -

Figura 5.14. Proceso modularizado de registro de una orden de compra en SAP....... - 70 -

Figura 5.15. Ciclo para cerrar las etapas de Administración y Seguimiento ............... - 75 -

Figura 6.1. Casos de uso del negocio - Proceso "Permiso de Funcionamiento"........... - 85 -

Figura 6.2. Formulario de caso de uso del negocio "Solicitud de Permiso de

Funcionamiento"

Figura 6.3. Mapa de procesos y arquitectura de los componentes de la solución ........ - 88 -

Figura 6.4. Diagrama de Casos de Uso del Subproceso "Solicitud de Permiso de

Funcionamiento"

Figura 6.5. Formulario de Caso de Uso "Nueva Solicitud de Permiso de Funcionamiento"

con Diccionario de datos...

-91 -

Figura 6.6. Formulario de Caso de Uso "Imprimir Solicitud de Permiso de Funcionamiento y DDJJ" con Diccionario de Datos ........................................................... 93 Figura 6.7. Diagrama BPMN del Proceso de "Nueva Solicitud de Permiso de

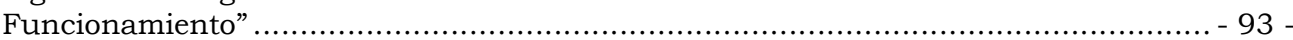

Figura 6.8. Diagrama de servicios identificados y categorizados ......................... - 94 -

Figura 6.9. Servicio Trámite con la especificación de su interfaz ............................. 95 -

Figura 6.10. Diagrama BPEL del proceso de "Permiso de Funcionamiento" ............... - 96 -

Figura 6.11. Diagrama de ensamblado de componentes del proceso Permiso de

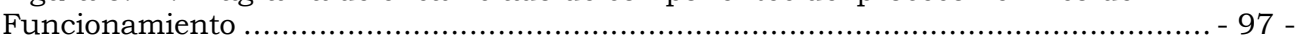

Figura 6.12. Diagrama de implementación de componentes.............................. 98 -

Figura 6.13. Componentes de JBoss Enterprise SOA Platform ........................... - 100 -

Figura 6.14. Componentes de Oracle BPM ............................................ 101 -

Figura 6.15. Componentes de IBM WebSphere BPM ...................................... - 102 - 


\section{Índice de Tablas}

Tabla 2.1 - Elementos rotacionales de BPMN............................................... 21 -

Tabla 2.2 - Sub-tipos de mensajes en la modelización por eventos........................ - 22 -

Tabla 2.3 - Actores involucrados, tareas que realizan y su intervención en las etapas del

ciclo de vida de los procesos de negocio ..................................................... 26 -

Tabla 2.4 - Comparación de conceptos de orquestación y coreografia ..................... - 28 -

Tabla 3.1 - Qué NO es SOA ............................................................................. 32 -

Tabla 5.1 - Actividades de la Disciplina Diseño ...................................... - 67 -

Tabla 5.2 - Comparación de cuatro BPMS …........................................... 74 -

Tabla 6.1 - Etapas del marco metodológico y su abreviatura............................. - 77 -

Tabla 6.2 - Procesos modificados para aplicar una mejora .............................. - 80 -

Tabla 6.3 - Relación entre modificaciones aplicadas y criterios enunciados............... - 80 -

Tabla 6.4- Comparación de herramientas (1era parte).................................... 102 -

Tabla 6.5 - Comparación de herramientas (2da parte) .................................. - 103 - 


\section{Introducción}

\subsection{Contexto del trabajo}

En los origenes de la ciencia de la computación todo el énfasis estuvo puesto en desarrollar sistemas que automatizaran tareas que se hacian manualmente. Este era suficiente desafio.

En la actualidad, se han automatizado muchas tareas y el gran desafio es cómo mejorar la capacidad de los sistemas para alcanzar nuevos requerimientos: agregar nuevas interfaces, combinar múltiples fuentes de datos en una sola, interactuar con dispositivos móviles y reemplazar viejas aplicaciones con nuevas.

La tendencia hoy es hacia un paradigma orientado a procesos, donde las aplicaciones cubren la actividad global de la empresa y las herramientas son los BPMS (Business Process Management Systems o Sistemas de Gestión de Procesos de Negocio).

Los modelos actuales resultan insuficientes porque son pobres en su integración y se orientan a describir datos y transacciones.

El cambio de enfoque en el modo de diseñar aplicaciones e implementar soluciones radica en:

- Explicitar el conocimiento de un proceso de negocio ayudando a documentarlo, a definirlo y a implementarlo.

- Proveer interoperabilidad de las soluciones

- Resolver la dinámica de los problemas en términos declarativos y cubriendo todas las etapas del ciclo de vida del software.

BPM (Business Process Management o Gestión de procesos de negocio) ha adquirido una atención considerable recientemente tanto por las comunidades de administración de negocios como las de ciencia de la computación.

Los miembros de estas comunidades están identificados por diferentes soportes e intereses educacionales; entre ellos encontramos los analistas de negocios, que están interesados en mejorar las operaciones de las compañias. Hechos como incrementar la satisfacción de los clientes, reducir los costos de operación, y establecer nuevos productos y servicios a bajo costo, son aspectos importantes del manejo de procesos de negocio desde el punto de vista de un analista del negocio.

La comunidad de software, por su parte, está interesada en proveer sistemas robustos y escalables. Como los procesos de negocios son realizados en espacios de información tecnológica compleja, la integración de los sistemas de información existentes se convierte en una base importante para la implementación técnica de los procesos de negocio.

BPM se basa en la observación de cada producto que la compañía provee al mercado, lo cual genera como resultado un número de actividades ejecutadas. Los procesos de negocio son la clave para organizar estas actividades, y mejorar el entendimiento de sus interrelaciones.

La tecnologia de la información en general y los sistemas de información en particular, merecen un rol importante en BPM, porque cada vez más actividades que realizan las compañias son soportadas por sistemas de información. Las actividades de los procesos pueden ser ejecutadas manualmente por empleados de la compañía, o con la asistencia de aplicaciones dedicadas a tal fin. También puede ocurrir que las actividades sean directamente ejecutadas por sistemas sin intervención humana. 


\section{Introducción}

Una compañia puede alcanzar sus objetivos de manera eficiente sólo si su gente y los sistemas de información se conducen en la misma dirección, siendo los procesos de negocio quienes facilitan esta colaboración.

En las compañias suele haber una brecha entre los aspectos organizacionales del negocio y la tecnología de información. Es importante hacer mínima esta brecha porque el mercado suele forzar a dar más y mejores productos a los clientes. Los productos que son exitosos hoy, pueden no serlo mañana. El mercado puede inclinarse hacia quien ofrezca el mejor producto y que sea más barato.

En un nivel organizacional, los procesos de negocio son esenciales para comprender cómo opera una organización. Aunque también son importantes para el diseño e implementación de sistemas de información flexibles. Estos sistemas proveen la base para la creación rápida de nueva funcionalidad que cree nuevos productos, y también para adaptar rápidamente funcionalidad existente a requerimientos del negocio.

BPM es entonces una estrategia para gestionar y mejorar el rendimiento de un negocio optimizando sus procesos a través de la modelización, ejecución y medida de rendimiento dentro de un ciclo de mejora continua [29].

Es una disciplina que va mucho más allá de la arquitectura de software que la implementa, pero éste es, sin lugar a dudas, un elemento muy importante.

SOA (Service Oriented Architecture o Arquitectura Orientada a Servicios) no es un concepto nuevo, sino un enfoque diferente para el diseño y construcción de sistemas que sean flexibles y adaptables a apoyar un entorno empresarial dinámico. La arquitectura SOA permite diseñar, construir, desplegar e integrar los servicios independientes de los lenguajes en los que estén codificados y de las plataformas en las que se ejecutan. Estos servicios están vinculados entre sí y se definen a través de procesos de negocio formando servicios compuestos que llevan a cabo las funciones empresariales. Algunos ejemplos de servicios que se pueden enumerar dentro del mundo real son: la localización de la información de facturación para el paciente, solicitud de transacciones recientes de cuenta financiera, identificación del propietario de un vehículo registrado, control de inventario de almacén para un determinado rubro, o solicitud de una lista de vuelos disponibles para un determinado destino [26].

En este marco, los servicios pueden compartirse y reutilizarse en varios procesos de negocio. El resultado es un entorno altamente adaptable, con menores costos para el desarrollo de aplicaciones, mejoras en la integración y despliegue rápido. Una simple SOA basada en servicios puede, de hecho, ser reutilizada ampliamente a lo largo de una empresa por muchos procesos de negocio. Y estos procesos de negocio pueden ser cambiados en cualquier momento a solicitud de otros nuevos y diferentes servicios. Una vez que se despliega SOA para las funciones principales del negocio, la capacidad de añadir dinámicamente nuevas capacidades a través de servicios pueden ayudar a reducir los costos de desarrollo y casi eliminar el tradicional ciclo de desarrollo más rápidamente, para ofrecer nuevos servicios al cliente y abrir nuevos canales de mercado.

Un error común es creer que una SOA es una nueva versión de los Web Services. SOA define un modelo para la ejecución de un determinado proceso. Los Web Services, por otra parte, pueden facilitar la aplicación táctica del modelo SOA. De este modo, los Web Services son esencialmente sólo una de las muchas maneras en que puede construirse una SOA.

El desarrollo de software orientado a servicios y BPM están vinculados con el manejo de workflow. El logro principal que se busca alcanzar aquí es la representación explícita de las estructuras de los procesos a través de modelos, y la representación controlada de los procesos basándonos en los modelos creados con anterioridad.

La aproximación a través del manejo de modelos facilita un mayor grado de flexibilidad, debido a que los modelos pueden ser adaptados a nuevos 


\section{Introducción}

requerimientos, y las modificaciones resultantes se pueden usar inmediatamente para representar los procesos de negocio.

El término workflow consiste en la automatización de un proceso de negocio, en su totalidad o en parte, y en el cual se intercambian documentos, información o tareas de un participante a otro, para provocar la acción de acuerdo a un conjunto de reglas procedimentales [6].

Un sistema de manejo de workflow permite definir, crear y manejar la ejecución de flujos de trabajo a través del uso de software, puede correr en uno o más motores, y es capaz de interpretar la definición del proceso, interactuar con los participantes del workflow y, donde sea requerido, invocar el uso de herramientas y aplicaciones de tecnología de la información.

La tecnologia de workflow no sólo es capaz de soportar procesos de negocio dentro de un sistema dado o dentro de un conjunto de aplicaciones, lo que permite efectivamente integrar estos sistemas, sino que posibilita también representar procesos en los que hay seres humanos activamente involucrados, y asî mejorar la colaboración entre los trabajadores con conocimiento.

Sin embargo según se afirma en [31], el factor conductor de los BPMS no fue el workflow en mayor medida que lo fue el desarrollo rápido de formularios gráficos o las interfaces de los sistemas. BPM es una respuesta a requerimientos del negocio, y las tecnologias que forman su suite incluyen workflow. La manera en que se resuelve un problema usando BPM es superior a construir una aplicación usando workflow ya que la conceptualización y manera de abordar el problema ha evolucionado y se requiere la integración de varias tecnologias para resolverlo.

Las aplicaciones construidas con BPM no son diferentes a las que se construyen escribiendo código, la diferencia es la capacidad de otorgar escalabilidad a la solución. El avance está dado por el trabajo colaborativo de los actores intervinientes, la modularidad de los componentes de la aplicación y la habilidad para fijar el conocimiento previo que se requiere para aplicar cambios en el medio de un proceso.

Para obtener verdaderos beneficios de los enfoques SOA y BPM, se deben reformular roles y responsabilidades en la definición, especificación e implementación de los proyectos dentro de una organización. El equipo técnico debe reorientarse a resolver el trabajo en forma no monolitica, identificando componentes verticales. Aparece la figura de arquitecto, que ensambla cada una de las piezas e interactúa con el analista de negocios, otro actor preponderante en este escenario que debe participar activamente en todas las etapas de la concreción del proyecto.

Según M. Imaz en [57] se pueden encontrar características distintivas entre la concepción de una organización orientada a funciones en contraposición con una orientada a procesos.

El enfoque orientado a funciones se caracteriza por:

- Los roles y responsabilidades están alineados por áreas

- No hay una visibilidad clara del proceso a través de las áreas funcionales

- El control de costos se realiza por centros de costo alineados a áreas funcionales

- Se pierde el valor del proceso al dar más peso a la búsqueda de eficiencia de las áreas funcionales

El enfoque orientado a procesos, por su parte, presenta las siguientes particularidades:

- Los roles y responsabilidades están alineados por procesos de negocios

- Se tiene una visibilidad del proceso de negocio desde el principio hasta el fin

- El control de costos se alinea según los pasos en los procesos

- Se centra en la eficacia, sin perder la eficiencia, facilitando la generación de valor de quienes consumen los servicios 


\section{Introducción}

Este cambio de punto de vista en la manera de abordar los problemas representa una verdadera innovación en las políticas de una organización. No se trata de un enfoque meramente tecnológico, si bien no sólo lo alcanza sino que lo beneficia.

El enfoque de procesos de negocios identificados, modelados y monitoreados que se comporten como consumidores de servicios verticales dentro de una organización, es aplicable sin lugar a dudas tanto a la formulación de proyectos nuevos como a la integración de sistemas de software existentes, así como también a una verdadera reingeniería de los procesos de negocios.

La Figura 1.1 [25] muestra las distintas capas o niveles de abstracción que se presentan en un enfoque orientado a servicios con procesos de negocios.

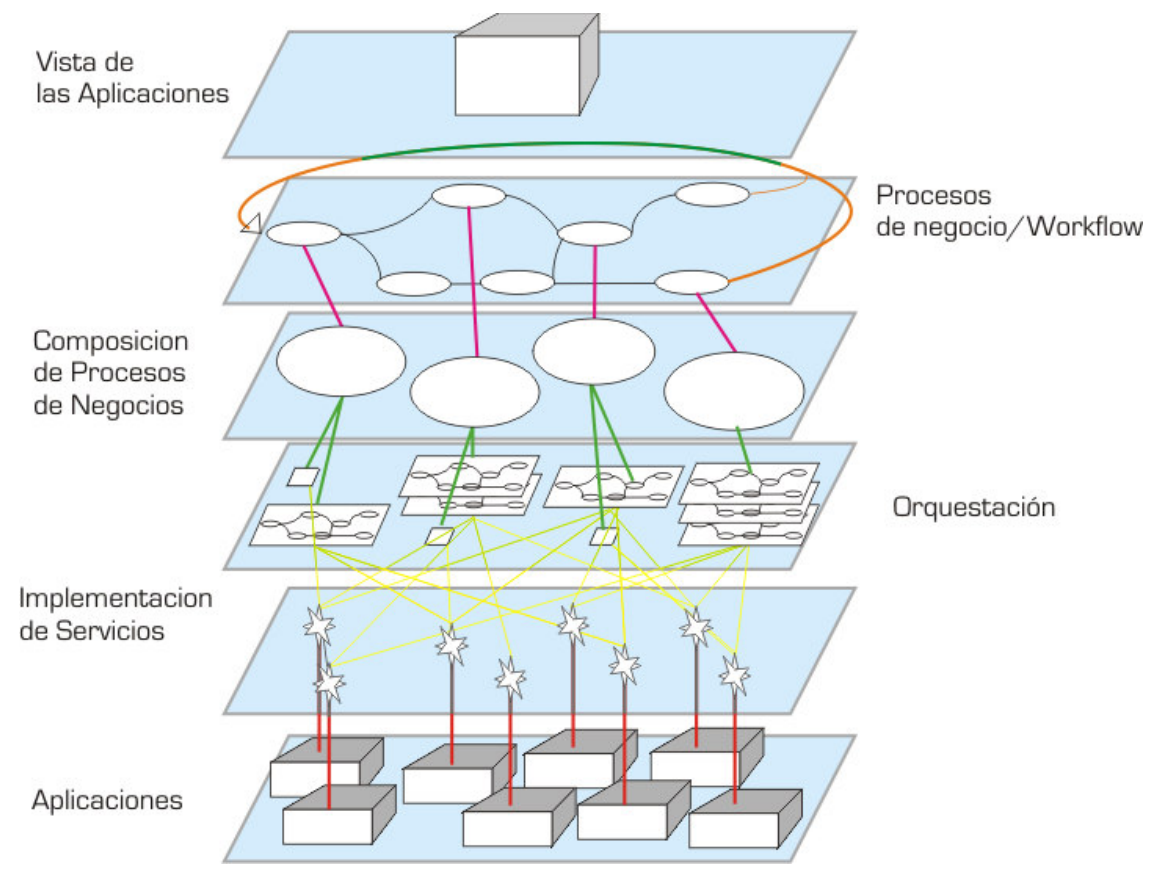

Figura 1.1 Esquema general de la orientación a servicios con procesos de negocio

\subsection{Objetivos de la tesis}

El objetivo de esta tesis es definir una metodología general y abarcativa para desarrollar proyectos con enfoque SOA y BPM.

Además, esta tesis provee un modelo para la integración de aplicaciones, realizando un estudio evolutivo de las distintas estrategias destinadas a tal fin, buscando puntos de contacto entre ellas y eligiendo los elementos a componer para lograr una integración completa, segura y confiable de los sistemas de software existentes, optimizando su reusabilidad y minimizando los costos de mantenimiento, tanto técnicos como económicos.

El trabajo se diferencia de otras propuestas en el sentido que cubre todas las etapas del ciclo de vida del software, aún la especificación de requisitos. Es un marco contextual que pretende identificar las etapas del ciclo de vida de los procesos en conjunción con el desarrollo de software buscando puntos de contacto para utilizar la metodología más adecuada en cada fase.

Además, este trabajo hace hincapié en la importancia de modelar la organización en términos de los procesos que ella ejecuta. Estos procesos se comportan como consumidores de los servicios, que se identifican como piezas de software que implementan una determinada funcionalidad. Así, mientras los procesos de 


\section{Introducción}

negocio atraviesan la estructura organizativa y definen sus reglas independientemente del proceso de desarrollo, los servicios resuelven funcionalidades concretas requeridas dentro de cada unidad organizativa y se componen para realizar los procesos de negocio a través de su orquestación y coreografia.

En este trabajo se delinea una nueva visión global que identifica las etapas y su interacción, para cubrir tanto el ciclo de vida de los procesos de negocio como del software de una manera unificada. Esta propuesta metodológica tiene como objetivo final facilitar la construcción de procesos de mejora continua y flexibilidad ante los cambios.

\subsection{Aportes de esta tesis}

Uno de los aportes de esta tesis es de índole pedagógico ya que integra conceptos de mundos aparentemente distintos (SOA y BPM) con una visión unificada poniendo en blanco y negro muchas nociones vinculadas a la integración de aplicaciones y sus alternativas de implementación, los patrones de diseño existentes y su aplicación en los entornos productivos, realizando un recorrido sobre temas tradicionales del desarrollo del software y de los sistemas de comunicación, para descubrir en ellos las raíces de las tecnologías más modernas.

Orto aporte, desde el punto de vista académico, representa una línea de trabajo dentro de las carreras de grado de la Facultad de Informática (Licenciatura en Sistemas y Licenciatura en Informática) siendo fuente de varias tesis de graduación de alumnos avanzados de la carrera, así como del dictado de materias optativas. Asimismo, esta línea de trabajo contribuye a la formación de recursos humanos y la interacción con docentes investigadores formados que estén incorporando estas ideas como linea de acción.

Durante los años 2008 y 2009 se iniciaron cuatro tesinas de grado de las carreras de Licenciatura en Sistemas y Licenciatura en Informática de la Facultad de Informática de la Universidad Nacional de La Plata, dos de las cuales estarán concluidas al término de esta Tesis de Maestría.

- "Evaluación de plataformas que proveen soporte BPM". Alumnos Gabriel Gotelli y Facundo Rodríguez. En codirección con la Lic. Claudia Queiruga.

- "Arquitectura Orientada a Servicios y su impacto en el desarrollo de aplicaciones". Alumno Román Rollie.

- "Análisis metodológico de la plataforma IBM WebSphere BPM, y sus equivalentes funcionales en herramientas de licenciamiento de código fuente abierto". Alumno José Martínez Garro. En codirección con el Ing. Emilio Lorenzón.

- "Análisis comparativo de lenguajes notacionales para el modelado de procesos”. Alumna Pilar Vázquez. Dirección a cargo de la Dra. Roxana Giandini y codirección de quien suscribre.

Por último, otro de los aportes de esta tesis es realizar un análisis de los requisitos exigidos a las herramientas de soporte para BPM con vistas a su utilización en cada una de las etapas del marco metodológico propuesto.

\subsection{Publicaciones relacionadas con esta tesis}




\section{Introducción}

Durante los años 2007 y 2009 se generaron y publicaron artículos en diferentes congresos que se mencionan a continuación:

- "Modelos de procesos y modelos de servicios: una visión unificada". [Bazán P., Giandini R, Díaz J.] Jornadas Chilenas de Computación 2009. XXI Encuentro Chileno de Computación (ECC). Santiago de Chile. Noviembre 2009. Con referato. http://jcc2009.usach.cl/?page_id=15

- "Elements of process-based design in service orientation" [Díaz J. Bazán P.] aceptado para su publicación como póster en CENTERIS 2009 - Conference on ENTERprise Information Systems. Portugal. Octubre 2009. Con referato. http://centeris.eiswatch.org/

- "Entornos para usar BPM en aplicaciones JAVA: un análisis comparativo" [Díaz J, Bazán P., Queiruga C, Gotelli G, Rodríguez F.] publicado en XI Workshop de Investigadores en Ciencias de la Computación WICC. Universidad Nacional de San Juan. Argentina. Mayo 2009. Con referato. http://www.wicc2009.com.ar/index.php?option=com_content\&view= article\&id=61\&Itemid=74. ISBN 978-950-605-570-7

- "BPEL: una propuesta para el uso de Web Services" [Bazán] publicado CACIC Congreso Argentino en Ciencias de la Computación 2007. Argentina. Octubre 2007. Con referato. ISBN 978-950-656109-3

\subsection{Organización del documento}

El presente documento, que corresponde al informe del trabajo de tesis de maestría realizado, se organiza de la siguiente manera:

En el Capitulo 2 se presentan los conceptos principales de procesos de negocios, incluyendo las definiciones que han elaborado los autores de mayor referencia en el tema, acompañadas de ejemplos que ilustran estas ideas. Luego, se define en forma exhaustiva la notación estándar para representar los procesos de negocios, su importancia y sus destinatarios, así como una comparación con otro estándar como es UML. En la sección 2.3 se presenta el ciclo de vida de los procesos de negocios y luego, en la sección 2.4 se clasifican los procesos de negocios en base a la taxonomía de Weske en [6]. Por último, en la sección 2.4 se definen los conceptos de orquestación y coreografía de procesos de negocios como el mecanismo de composición de servicios para dar respuesta a los objetivos de los procesos de negocios.

En el capítulo 3 se abordan los conceptos de Arquitecturas Orientadas a Servicios (SOA) como el sustento tecnológico más importante para los procesos de negocios. Se presenta SOA como modelo de referencia, como arquitectura y como plataforma, así como su modelo de interacción, uno de sus conceptos subyacentes más importantes. En la sección 3.2 se realiza un análisis evolutivo de los servicios partiendo de los objetos distribuidos. Por último, se plantea la importancia del ESB (Enterprise Service Bus o Bus de Servicios Empresarial) como solución tecnológica para los servicios, sus funciones, sus tendencias de implementación y sus características distintivas.

En el capítulo 4 se exponen los modelos de integración sustentados en el análisis de las alternativas existentes de integración de aplicaciones, los tipos de integración posibles y los componentes que deben estar presentes en un modelo de estas características. Se identifican también los roles o actores más 


\section{Introducción}

importantes que entran en juego dentro de un modelo de integración que sigue el enfoque de SOA y BPM.

En el capítulo 5 se presenta el marco metodológico con enfoque SOA y BPM que ha sido el objeto de investigación de esta tesis. La construcción de dicho marco metodológico tiene alcance durante todo el ciclo de vida del proyecto y abarca a toda la organización en su conjunto, incluyendo una etapa de identificación y especificación de requisitos abordada también desde el punto de vista de los procesos de negocio.

En el capítulo 6 se aplican las diferentes técnicas y métodos planteados en el capítulo 5 sobre un caso real, vinculado con el circuito de trámites para gestionar permisos de funcionamiento de comercios e industrias dentro de una organización pública.

Por último, en el capítulo 7 , se incluyen las conclusiones y los trabajos relacionados con esta investigación y líneas de trabajo a futuro.

Finalmente se presentan las referencias bibliográficas consultadas para la realización de este trabajo.

Los anexos I y II presentan el contexto global y las modificaciones propuestas, respectivamente, del Sistema de Ventanilla Única y que constituyen las especificaciones iniciales del problema a resolver. 


\section{Procesos de negocios}

Este capítulo presenta definiciones básicas acerca de los procesos de negocios, su gestión y la manera de modelarlos. También describe el ciclo de vida de los mismos, mostrando las etapas involucradas cuando se trabaja en el análisis y diseño de problemas con enfoque de procesos de negocios. Muestra asimismo una clasificación de dichos procesos.

El campo que abarca la gestión de los procesos de negocios incluye dos comunidades: la de la administración del negocio (analistas de negocio) y las de la IT (Information Technology o Tecnología de la Información).

Los profesionales del área de negocios tienden a considerar al área de tecnología como subordinados a los aspectos del negocio. Mientras que el área de tecnologia considera que los objetivos de negocio y las regulaciones organizacionales no merecen mucho análisis ni un alto nivel de abstracción.

Uno de los principales objetivos que persigue el enfoque de resolución de problemas orientado a procesos de negocios, es conciliar estos puntos de vista y lograr modelizar e implementar procesos de negocios correctos y robustos en un software adecuado, contribuyendo a la mejora continua de los procesos y a una ágil absorción de los cambios de la realidad.

\subsection{Definiciones y generalidades}

La gestión de procesos de negocio se basa en la idea de que cada producto es el resultado de un conjunto de actividades realizadas para obtenerlo.

La tecnología de la información en general y los sistemas de información en particular, juegan un rol importante en la gestión de procesos de negocio dado que muchas de las actividades son soportadas por sistemas de información.

El éxito en el alcance de los objetivos y su logro eficaz y eficiente depende del trabajo coordinado de los recursos que intervienen (sean estos humanos o tecnológicos).

Mientras que en el ámbito organizacional los procesos de negocio sirven para entender cómo opera la compañia, también juegan un rol importante en la construcción de sistemas de información más flexibles. Esta flexibilidad se mide en su capacidad de adaptarse rápidamente a los cambios y para absorber velozmente el ritmo del mercado.

Según Mathias Weske en [6], un proceso de negocio es un conjunto de actividades que se realizan en coordinación en un ambiente organizacional y técnico. Estas actividades alcanzan el objetivo del negocio. Cada proceso de negocio representa una única organización, pudiendo interactuar con otras.

La gestión de procesos de negocio incluye conceptos, métodos y técnicas para soportar el diseño, administración, configuración, representación y análisis de los procesos de negocio. Su objetivo último es representar el proceso de negocio con sus actividades y las restricciones de ejecución entre ellas.

Los procesos de negocio son representados manualmente, guiados por el conocimiento del personal de la organización y asistidos por regulaciones organizacionales y procedimientos previamente instalados.

Los sistemas de gestión de procesos de negocios (BPMS) son softwares utilizados como herramientas para representar y coordinar las actividades involucradas en un proceso de negocio.

Ejemplo: un proceso de seguimiento de orden de compra simple. En tal proceso, se recibe la orden, se emite la factura, se recibe el pago y se envian los productos comprados. 
Esta representación textual de actividades no otorga un orden a las mismas siendo más apropiado representar este ordenamiento gráficamente.

Esta representación gráfica del proceso muestra un conjunto de actividades realizada en forma coordinada.

La coordinación entre las actividades se realiza por una representación explícita del proceso usando las restricciones de ejecución.

Para representar esta situación es preciso acordar una notación posible de modo que cada símbolo tenga un significado univoco. Esta notación se conoce como BPMN (Business Process Modeling Notation) [6].

Esta representación gráfica constituye un molde para el proceso de negocio. Todos los procesos de órdenes de compra se instanciarán con este molde. La Figura 2.1 [6] muestra el diagrama del proceso de negocio (BPD Business Process Diagram) para un proceso de seguimiento de orden compra simple.

En el apartado 2.2 se describen en detalle los conceptos relevantes de BPMN y BPD.

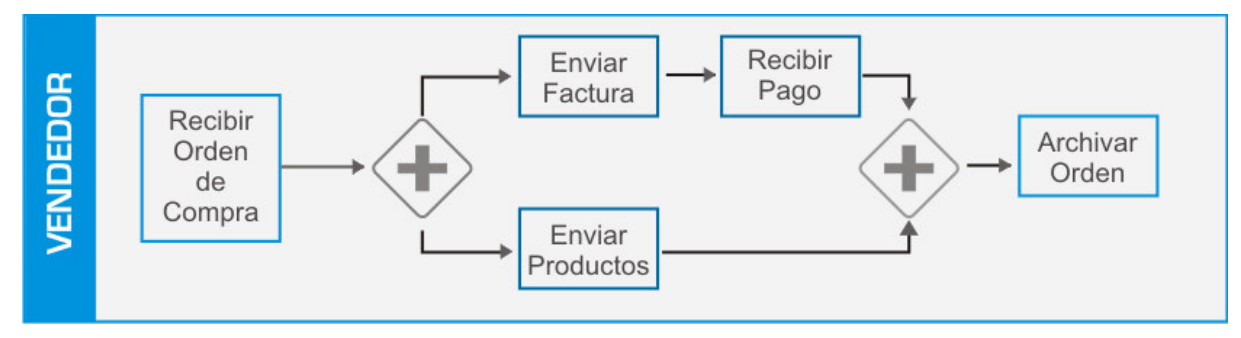

Figura 2.1. Representación gráfica de un proceso de compra simple

Siguiendo con las definiciones dadas por M.Weske en [6], un modelo de proceso de negocio constituye un conjunto de modelos de actividades y las restricciones de ejecución entre ellas. Una instancia de proceso de negocio representa un caso concreto dentro de los procesos operativos de una compañia. Estos procesos se componen de un conjunto de instancias de actividades.

Cada modelo de proceso de negocio es un molde para múltiples instancias de tales procesos y cada modelo de actividad, lo es también para múltiples instancias de actividades.

Por abuso de lenguaje suele denominarse proceso de negocio y actividad tanto al modelo como a la instancia de cada uno de ellos.

Un modelo de proceso de negocio, como se muestra en la Figura 2.1, puede usarse para configurar un BPMS que asegurará que todas las instancias del modelo se ejecuten según la especificación del mismo.

Muchas organizaciones plasman en un BPMS todas sus actividades como un componente de software centralizado. Este control centralizado es conocido como orquestación de procesos.

La figura 2.1 representa las actividades del proceso que lleva a cabo un vendedor cuando recibe la orden de compra.

El proceso de negocio del comprador se inicia con la ubicación de una orden de compra. Luego, en paralelo, se recibe la factura y el producto. A continuación de la recepción de la factura se abona la misma.

Los procesos de negocio pueden interactuar entre sí. La Figura 2.2 [6] muestra la interacción entre los procesos llamados distribuidor y comprador, representados cada uno de ellos por sus respectivos swimlanes o andariveles (Ver sección Elementos del Lenguaje de este mismo capítulo) 


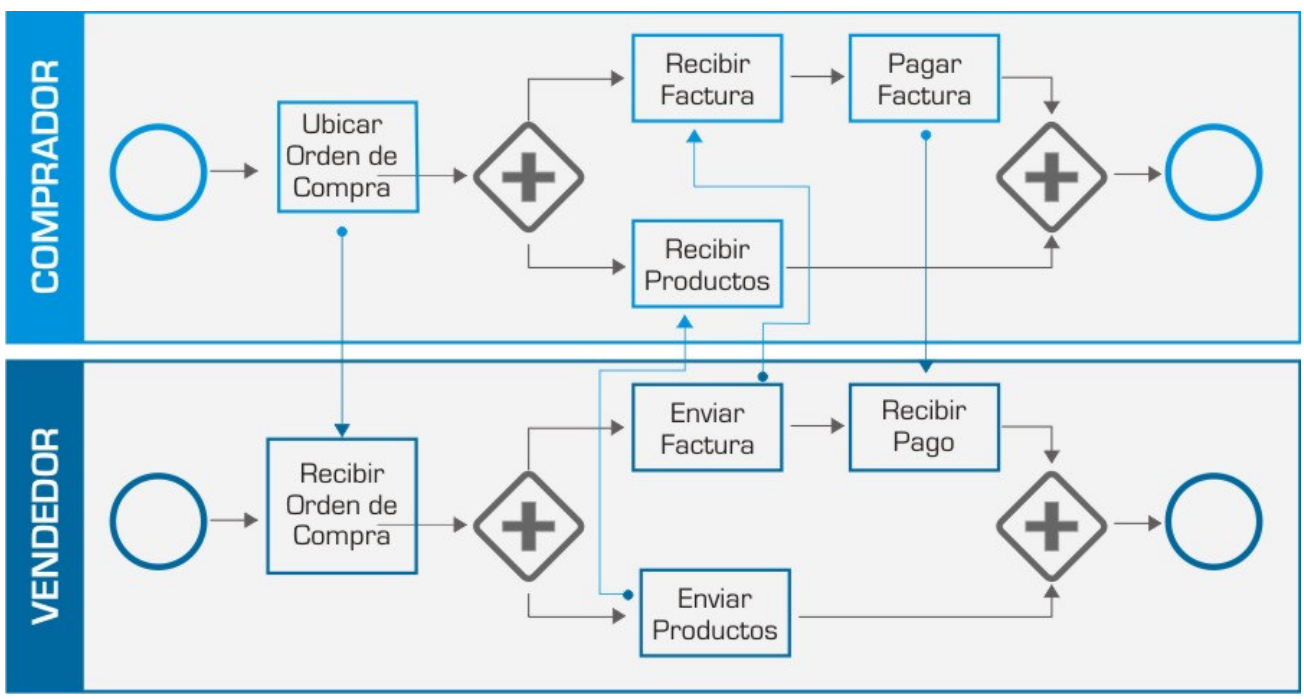

Figura 2.2. Interacción entre procesos de negocios

La interacción entre los distintos procesos de negocio se denomina coreografía. Este término indica la ausencia de un agente central que controle las actividades involucradas en el proceso. La interacción solamente envía y recibe mensajes. Para realizar una interacción correcta los procesos deben acordar la coreografia (Ver apartado 2.5).

La realización de los procesos de negocio vistos desde el punto de vista de sus participantes, permiten aplicar cambios a sus actividades sin que cambie el proceso en sí mismo.

Por ejemplo: supongamos que se quiere aplicar como regla del negocio para el proceso de orden de compra del vendedor, el hecho de que el producto no es enviado hasta tanto se abone la factura. En este caso, el modelo de proceso del vendedor y su interacción con el comprador, prácticamente no cambian. Lo que cambia es la orquestación interna del proceso del vendedor.

\subsection{BPMN, BPD y el modelado de los procesos de negocios}

BPMI (Business Process Management Initiative) es un organismo sin fines de lucro que ha desarrollado el estándar BPMN (Businnes Process Modeling Notation). La primera especificación de dicho estándar fue publicada en Mayo del 2004. Luego, en junio de 2005, la BPMI se fusionó con la OMG para trabajar en conjunto sobre temas de BPM (http://www.bpmi.org/).

El objetivo primario de BPMN fue proveer una notación que sea legible y entendible para todos los usuarios de negocios, desde los analistas que realizan el diseño inicial de los procesos y los responsables de desarrollar la tecnología que ejecutará estos procesos, hasta los gerentes de negocios encargados de administrar y realizar el monitoreo de los procesos. BPMN también soporta un modelo interno que permite generar ejecutables BPEL4WS [21]. Así, BPMN crea un puente estandarizado para cubrir el hueco provocado por las diferencias entre el diseño de los procesos de negocios y su implementación.

BPMN define un diagrama de procesos de negocio (BPD) basado en una técnica adaptada de diagramas de flujo para la creación de modelos gráficos de operaciones de procesos de negocio. Un modelo de procesos de negocio, es una red de objetos gráficos que representan las actividades (por ejemplo tareas) y los controles de flujo que definen su orden de ejecución [7]. 


\section{Importancia de BPMN}

El mundo de los negocios ha cambiado drásticamente en los últimos años. Los procesos son coordinados dentro de los limites naturales de las organizaciones y a su vez pueden interactuar con procesos de otras organizaciones. Actualmente un proceso de negocio abarca múltiples participantes y la coordinación puede ser compleja.

Hasta la aparición de BPMN no existía un estándar sobre técnicas de modelado desarrollado para estos fines. BPMN ha sido desarrollado para proveer a los usuarios de una notación estándar de forma análoga a como UML estandarizó el mundo de la ingeniería del software [23].

\section{Destinatarios de BPMN}

BPMN está dirigido a los analistas de negocios en el alto nivel y a los implementadores de procesos en el bajo nivel. Los analistas de negocio deberían entender fácilmente un diagrama de proceso de negocio en BPMN. Los implementadores de procesos deberian poder complementar el diagrama de proceso de negocio con mayor detalle con la intención de representar el proceso en una implementación ejecutable.

BPMN está dirigido a usuarios y proveedores de servicios que requieren comunicar los procesos de negocio de una forma estándar [7] [8] [23].

\section{BPMN Vs. UML}

El advenimiento de BPMN, BPMS y sus lenguajes de ejecución no deja obsoleta la necesidad de desarrollos de sistemas, como los que se logran utilizando UML (Unified Modeling Languaje). Los desarrollos de sistemas siguen teniendo un rol importante en la arquitectura de procesos en el ámbito empresarial.

UML es un lenguaje que facilita a los desarrolladores la especificación, visualización y documentación de modelos de sistemas de software. Está dirigido en lineas generales a los arquitectos de software e ingenieros de software. Fue desarrollado como un medio para mejorar el proceso de desarrollo de software, desde el diseño de la arquitectura hasta la implementación de la aplicación, para ser utilizado por personas con conocimientos técnicos (analistas de sistemas y programadores) [9].

BPMN está dirigido a los analistas de negocio, arquitectos de sistemas e ingenieros de software. Fue desarrollado para mejorar todo el ciclo de vida del desarrollo de procesos desde el diseño de los mismos.

Por su parte, UML es un lenguaje desconocido para la mayoria de los analistas de negocio.

UML define un número de diagramas que se pueden clasificar en las siguientes categorías: estructura estática de la aplicación, comportamiento dinámico y administración y organización de soluciones de software.

De estas tres categorias, el comportamiento dinámico es el utilizado para modelar los procesos de negocio; los diagramas asociados son el de actividad UML y los de casos de uso. BPMN está emparentado con UML por el hecho que ambos definen una notación gráfica para los procesos de negocio similar a los diagramas de comportamiento de UML. Sin embargo, BPMN y UML usan enfoques muy diferentes para modelar procesos de negocio.

Si bien los diagramas de actividad constituyen la herramienta UML para modelar actividades de procesos, UML, en general, ofrece un enfoque orientado a objetos para modelar aplicaciones. Mientras que BPMN toma un enfoque centrado en los procesos. Este enfoque es mucho más natural e intuitivo para los analistas de negocios. Con BPMN, el control y los mensajes de flujo entre procesos son primeramente modelados. Luego, se definen implícitamente los modelos de objetos para los procesos en vez de hacerse explícitamente como en UML. BPMN también ofrece la opción de explicitar el modelado de objetos de negocio que pueden ser expuestos a través de servicios de negocio en el flujo del proceso. 
Otro aspecto que marca una fuerte diferencia es que UML no posee una vista de implementación de los modelos de negocios.

UML es un ensamblado de diagramas que conforman un conjunto de buenas prácticas colectivas. Desafortunadamente, esto significa que sus diagramas no fueron diseñados específicamente para trabajar conjuntamente unos con otros. Como consecuencia, los desarrolladores sólo pueden modelar una parte de sus aplicaciones con UML, el nivel de implementación detallado no está cubierto.

En contraste, BPMN define un único tipo de diagrama que posee múltiples vistas derivadas del mismo meta-modelo de ejecución del proceso. Como resultado, la implementación es una vista lógica del proceso en un lenguaje de ejecución de procesos de negocio (BPML) [7] [22].

\section{Elementos del lenguaje}

Un diagrama de proceso de negocio está compuesto por un conjunto de elementos gráficos. Los elementos utilizados para construir los diagramas fueron elegidos para ser distinguibles unos de otros y utilizar las figuras que son familiares a la mayoria de los diseñadores. Por ejemplo, las actividades se representan mediante rectángulos y las decisiones mediante rombos. Cabe destacar que uno de los objetivos del desarrollo de BPMN fue crear un mecanismo sencillo para la creación de modelos de procesos de negocio y al mismo tiempo ser capaz de manejar la complejidad inherente de los mismos. El enfoque adoptado para manejar estos dos requisitos fue la organización de la gráfica de los aspectos de la notación en categorias específicas. Éste provee un pequeño conjunto de categorias de notación que permite al lector del diagrama de procesos de negocio reconocer fácilmente los elementos básicos y comprender el diagrama.

Dentro de las categorias básicas de elementos se pueden incluir variaciones adicionales o información para soportar requerimientos complejos sin tener un cambio drástico en la mirada y sentido básico del diagrama.

Las cuatro categorias básicas de elementos son:

- flow objects (objetos que representan el flujo)

- connecting objects (objetos conectores)

- swimlanes (andariveles)

- $\quad$ artifacts [7] (artefactos)

y se encuentran representadas en la Tabla 2.1 [7] [22] 
Tabla 2.1 - Elementos rotacionales de BPMN

\begin{tabular}{|c|c|c|c|}
\hline Categoria & Elemento & Descripción & Gráfica \\
\hline \multirow{3}{*}{ Flujos } & Evento & $\begin{array}{l}\text { Es algo que sucede durante el curso del proceso } \\
\text { de negocio. Afectan al flujo del proceso. } \\
\text { Normalmente tienen una causa [disparador] o } \\
\text { un impacto [resultado). Dependiendo de cuando } \\
\text { afectan al flujo serán eventos iniciales, } \\
\text { intermedios o finales. }\end{array}$ & \\
\hline & Actividad & $\begin{array}{l}\text { Es un termino genérico para el trabajo que } \\
\text { realiza una compañía. Puede ser atómica (tarea] } \\
\text { o compuesta [sub-proceso]. Para indicar la no } \\
\text { atomicidad se coloca un signo + en la esquina } \\
\text { del símbolo de actividad. }\end{array}$ & \\
\hline & Gateway & $\begin{array}{l}\text { Se utiliza para controla la convergencia o } \\
\text { divergencia de flujos. Representa una decisión } \\
\text { para mezclar o unir caminos. }\end{array}$ & \\
\hline \multirow{3}{*}{ Conexiones } & $\begin{array}{l}\text { Flujo de } \\
\text { secuencia }\end{array}$ & $\begin{array}{l}\text { Se utiliza para mostrar el orden o secuencia en } \\
\text { que las actividades se realizan en un proceso }\end{array}$ & \\
\hline & $\begin{array}{l}\text { Flujo de } \\
\text { mensajes }\end{array}$ & $\begin{array}{l}\text { Se utiliza para mostrar el flujo de mensajes } \\
\text { entre dos participantes separados. }\end{array}$ & \\
\hline & Asociación & $\begin{array}{l}\text { Se utiliza para mostrar entradas y salidas de } \\
\text { actividades. }\end{array}$ & \\
\hline \multirow{2}{*}{ Swimlanes } & $\begin{array}{l}\text { Pool } \\
\text { [fondo común }\end{array}$ & $\begin{array}{l}\text { Representa un participante en un proceso. } \\
\text { Actúa como contenedor grafico para particionar } \\
\text { un conjunto de actividades. }\end{array}$ & Nombre \\
\hline & $\begin{array}{l}\text { Lane } \\
\text { [sendero] }\end{array}$ & $\begin{array}{l}\text { Es una sub-particion dentro de un pool y puede } \\
\text { extenderse a todo lo largo o ancho del pool. Se } \\
\text { utilizan para organizar y categorizar actividades. }\end{array}$ & \\
\hline \multirow{3}{*}{ Artefactos } & $\begin{array}{l}\text { Objetos } \\
\text { de datos }\end{array}$ & $\begin{array}{l}\text { Mecanismo para mostrar como los datos son } \\
\text { requeridos y producidos por las actividades. Se } \\
\text { conectan a las actividades por asociaciones. }\end{array}$ & $\begin{array}{l}\square \text { Nombre } \\
\text { (estado) }\end{array}$ \\
\hline & Grupos & $\begin{array}{l}\text { Se utiliza para documentación o para propósitos } \\
\text { de análisis, pero no afecta al Flujo de Secuencias }\end{array}$ & $\vdots \cdots$ \\
\hline & Anotaciones & $\begin{array}{l}\text { Mecanismo para que quien esta modelando } \\
\text { provea información adicional para el lector del } \\
\text { diagrama. }\end{array}$ & \\
\hline
\end{tabular}

\section{Diagramas BPM}

La notación BPM permite construir diagramas fáciles de leer y que además manejen la complejidad traduciendo el diagrama en algún lenguaje de ejecución [22].

Para modelar un flujo sólo se modelan los eventos que ocurren. Las decisiones entre flujos se modelan con gateways.

El modelado está centrado en flujos y eventos, pero principalmente en eventos, que son los elementos disparadores de determinadas situaciones.

Un proceso en el flujo puede contener subprocesos que cuando son atómicos se denominan tareas.

Los eventos se dividen en iniciales, intermedios y finales según se desencadene al inicio, durante o al finalizar el flujo del proceso.

Además, se puede especificar "quién hace qué", ubicando los procesos en pools que denotan quién hace la tarea pudiendo particionar el pool en lanes o senderos. Típicamente un pool representa a toda la organización mientras que el 


\section{Procesos de Negocios}

lane representa un departamento dentro de la misma. Puede extrapolarse esto mismo a funciones, aplicaciones y sistemas.

Para mejorar el poder expresivo, a estos tres tipos de eventos básicos se los divide a su vez en eventos más complejos en función de la tarea que realizan. Esta sub-clasificación agrega restricciones al modelo. Ejemplo: un evento "timer" nunca finaliza un flujo.

La tabla 2.2 contiene los distintos sub-tipos de mensajes que pueden utilizarse para modelizar los eventos.

Tabla 2.2 - Sub-tipos de mensajes en la modelización por eventos

\begin{tabular}{|l|l|l|l|l|}
\hline Exepciòn & $\begin{array}{l}\text { Un evento de excepción } \\
\text { final informa a la } \\
\text { máquina de ejecución } \\
\text { que el proceso finalizo } \\
\text { anormalmente o } \\
\text { también puede ser } \\
\text { captado por un evento } \\
\text { intermedio. Un evento } \\
\text { de excepción nunca } \\
\text { inicia un proceso }\end{array}$ & NO & SI & SI \\
\hline Compensación & $\begin{array}{l}\text { Un evento de } \\
\text { compensación final } \\
\text { informa a la máquina } \\
\text { de ejecución que el } \\
\text { proceso debe ser } \\
\text { compensado. Se utiliza } \\
\text { como evento } \\
\text { intermedio cuando el } \\
\text { proceso requiere un } \\
\text { roll-back. }\end{array}$ & NO & SI & SI \\
\hline "kill" & $\begin{array}{l}\text { Un evento de } \\
\text { cancelación final indica } \\
\text { que el usuario cancelo } \\
\text { el proceso. }\end{array}$ & NO & NO & \\
\hline Cancelación & $\begin{array}{l}\text { Un evento "Kill" final } \\
\text { indica que un error } \\
\text { fatal y que todas las } \\
\text { actividades dentro del } \\
\text { proceso deben ser } \\
\text { finalizadas. El proceso } \\
\text { es finalizado con } \\
\text { compensación o con } \\
\text { manejo de errores }\end{array}$ & NO & SI \\
\hline
\end{tabular}




\begin{tabular}{|c|c|c|c|c|c|}
\hline Tipo de Evento & Gráfico & Descripción del evento & Inicio & Intermedio & Fin \\
\hline Mensaje & & $\begin{array}{l}\text { Proviene de un } \\
\text { participante y dispara el } \\
\text { inicio de un proceso o } \\
\text { continúa otro en el } \\
\text { caso de ser un evento } \\
\text { intermedio. El mensaje } \\
\text { de fin denota el } \\
\text { mensaje generado al } \\
\text { finalizar el proceso. }\end{array}$ & SI & SI & SI \\
\hline Timer & & $\begin{array}{l}\text { Se puede establecer } \\
\text { una hora o ciclo para el } \\
\text { disparar el inicio de un } \\
\text { proceso o continuarlo } \\
\text { si es un evento } \\
\text { intermedio. No puede } \\
\text { ser un evento de } \\
\text { finalización. }\end{array}$ & SI & SI & NO \\
\hline Regla & & $\begin{array}{l}\text { Una regla se dispara } \\
\text { cuando su condición se } \\
\text { cumple al inicio o } \\
\text { durante un proceso. No } \\
\text { puede ser un evento de } \\
\text { finalización }\end{array}$ & SI & SI & NO \\
\hline Enlace & & $\begin{array}{l}\text { Es un mecanismo para } \\
\text { conectar el evento final } \\
\text { de un proceso con el } \\
\text { inicial de otro. }\end{array}$ & SI & SI & SI \\
\hline Múltiple & & $\begin{array}{l}\text { Un evento múltiple } \\
\text { indica que hay varias } \\
\text { maneras de iniciar un } \\
\text { proceso o continuarlo } \\
\text { en el caso de un evento } \\
\text { intermedio. Solamente } \\
\text { una de esas maneras } \\
\text { será requerida. Los } \\
\text { atributos del evento } \\
\text { definen cual se aplica. } \\
\text { Para la finalización de } \\
\text { un evento múltiple hay } \\
\text { múltiples } \\
\text { consecuencias del } \\
\text { proceso, las cuales } \\
\text { ocurrirán TODAS. } \\
\text { [Ejemplo, se enviaran } \\
\text { múltiples mensajes]. }\end{array}$ & SI & SI & SI \\
\hline
\end{tabular}

Las Figuras 2.3 y 2.4 obtenidas de [7] muestran el grado de detalle que puede obtenerse a través de un diagrama BPM en función del nivel de abstracción que los modeladores deseen reflejar. 


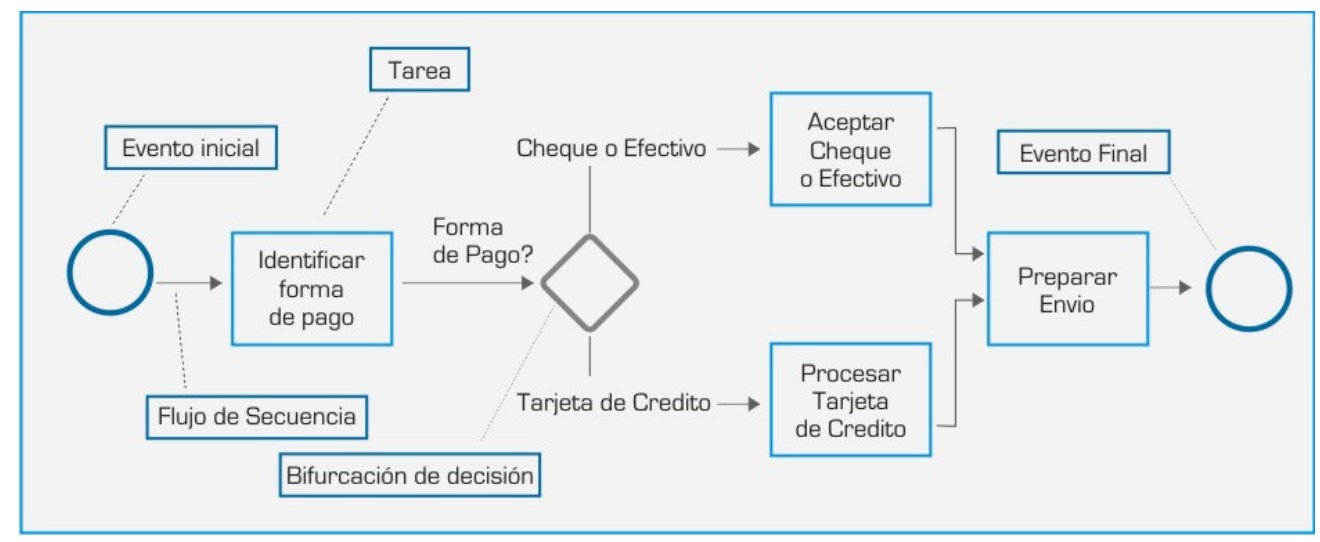

Figura 2.3. Ejemplo de un proceso simple

El proceso graficado en la Figura 2.3 representa el proceso de recepción del pago de un cliente. El proceso se inicia con la actividad de Identificar la forma de pago. Se prevén dos posibles formas de pago: en efectivo o con tarjeta de crédito. En cada caso se aplica la actividad de aceptar el pago según la forma del mismo y se pasa a la actividad de empaque de la mercadería, finalizando así el proceso.

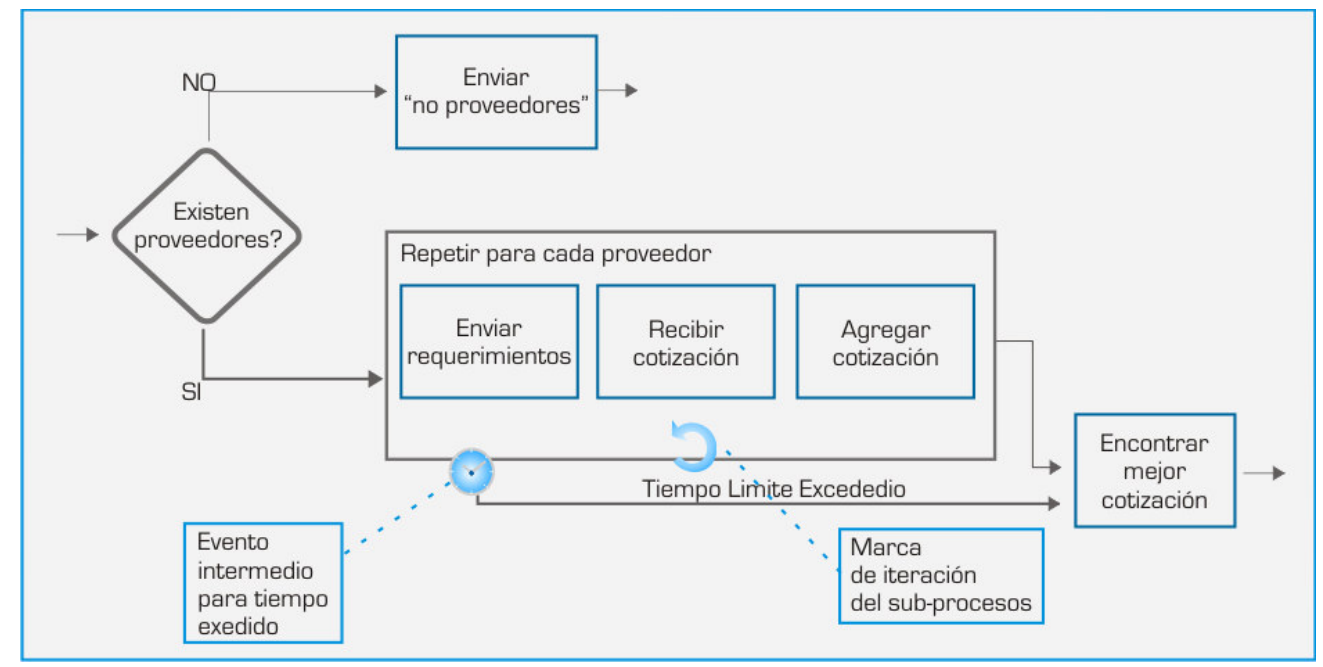

Figura 2.4. Segmento de un proceso con detalle

En la Figura 2.4, se representa una porción del proceso de "evaluación de presupuestos", mostrando el lazo iterativo de análisis de cada proveedor. Como se ve, se detallan las sub-actividades consideradas dentro del proceso de "análisis del proveedor" que encierra las actividades "Enviar requerimientos", "Recibir cotización" y "Agregar cotización". Además intervienen eventos intermedios que consideran el tiempo dentro de dicho proceso.

\subsection{Ciclo de vida de los procesos de negocios}

El ciclo de vida de los procesos de negocios se compone de fases cíclicas que no implican necesariamente un orden temporal, pero sí una dependencia lógica, según lo define M.Weske en [6].

Muchas de las actividades de diseño y desarrollo se llevan a cabo dentro de cada fase. Es frecuente también que varias actividades concurrentes se realicen dentro de cada etapa en forma gradual y evolutiva. 


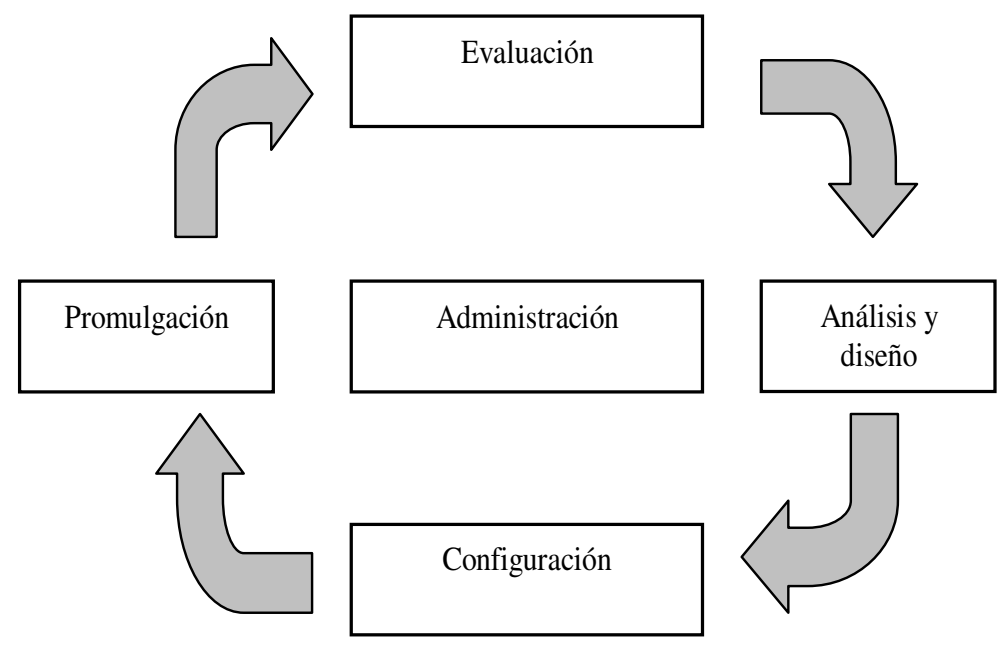

Figura 2.5. Ciclo de vida de los procesos de negocio

En la Figura 2.5 [6] se observa claramente un lazo iterativo sin fin donde ninguna de las fases graficadas con rectángulos presenta un orden ni tampoco una condición de salida. La administración como etapa central, sin flujo que la atraviese, pone de manifiesto la presencia de esa fase en cualquiera de las anteriores.

La fase de Diseño y Análisis consiste en el estudio de la situación tanto desde el punto de vista técnico como organizacional. Sobre la base de este estudio, se identifican, revisan, validan y representan los procesos de negocios en un modelo. Sobre la base de este modelo se valida, se simula y se verifica el proceso, siendo éstas las actividades de análisis.

En la etapa de Configuración entra en juego la elección o no de un BPMS para dar soporte a la implementación y despliegue de los procesos. En el caso de no utilizar un BPMS las políticas y procedimientos (reglas del negocio) que deban cumplirse, tendrán que ser desarrolladas como un componente más de la solución de software.

La configuración y sobre todo la integración con los sistemas operacionales, es un aspecto de mucha importancia ya que muchos procesos de negocio están soportados actualmente sobre sistemas de software existentes.

Por otra parte, la configuración de un BPMS también puede incluir aspectos transaccionales en el sentido estricto de la palabra y el cumplimiento de las propiedades ACID (Atomicity, Consistency, Isolation, Durability). Éste, si bien es un tópico resuelto en los sistemas de gestión de bases de datos, no lo es aún en un BPMS.

La Promulgación del sistema se asocia por analogía con la promulgación de una ley o disposición, que consiste en hacer pública la misma. Esto otorga al proceso de negocio un carácter diferente al del simple despliegue de una pieza de software que implementa un proceso de negocio. Las instancias generadas con cada modelo de un proceso de negocio, se ejecutan de una manera única y repetitiva cumpliendo siempre las mismas restricciones y ejecutando la misma lista de actividades. El BPMS controla y monitorea la ejecución de cada instancia de proceso de negocio. Esta etapa requerirá de un BPMS necesariamente.

La Evaluación de los modelos de procesos de negocios constituye una etapa imprescindible para completar el ciclo de mejora continua de los procesos. Requiere disponer de los registros de ejecución de dichos procesos y la posibilidad de evaluar y simular cambios.

Por último, la Administración es una fase permanente, por lo tanto se visualiza en el centro del ciclo ya que posee una mirada directa a cada etapa y su 
complejidad variará en función del soporte de software con que se cuente, el número de procesos que se modelen y las características propias de la organización.

Este modelo de ciclo de vida, pone de manifiesto cinco etapas que marcan la necesidad de contar con varios participantes, cada uno de ellos con perfiles bien marcados. M.Weske enumera algunos de dichos perfiles como: dueño del proceso, diseñador, participante, responsable, arquitecto del sistema, experto en el negocio y desarrollador.

Lo importante de este ciclo de vida es facilitar que los participantes cooperen en el diseño y despliegue de una solución que represente el proceso de negocio.

Sin duda este es un ciclo de vida muy vasto que amerita la necesidad de esbozar un marco metodológico para su aplicación en la construcción de software.

En una arquitectura orientada a servicios, la funcionalidad de los aplicativos se provee a través de servicios. Éstos se especifican de modo tal que puedan estar desacoplados de la implementación.

Este esquema es muy utilizado en arquitecturas para integración de aplicaciones ya que torna reusable gran parte del código escrito con anterioridad. Además, potencia la funcionalidad de las aplicaciones ocultando sus detalles tecnológicos, una característica muy útil a la hora de disponer de funcionalidad básica "vía Web".

Siguiendo con la definición de Weske, se describen a continuación los actores o roles que intervienen en la definición del modelo del proceso de negocio. En función de estas definiciones, se construye la Tabla 2.3. En esta tabla se analiza la intervención de cada actor en cada una de las etapas del ciclo de vida de los procesos de negocios.

Es claro que el Dueño del Proceso tiene una participación permanente, mientras que los demás actores presentan intervenciones especificas.

Es importante destacar la diferencia entre el Ingeniero del Negocio y el Diseñador del Proceso. El primero presenta un perfil más analítico y no participa, al menos en forma directa, de la fase de Configuración. Por su parte el Diseñador del Proceso adquiere una intervención un poco más vinculada a lo técnico, si bien mantiene un perfil conceptual.

Los perfiles que ocupan la etapa de Promulgación como los Trabajadores del Conocimiento, Responsables del proceso, Arquitectos y Desarrolladores, adquieren un rol un poco más vinculado al área de IT, no llegando a ser eminentemente técnicos, salvo el caso de los Desarrolladores.

Tabla 2.3 - Actores involucrados, tareas que realizan y su intervención en las etapas del ciclo de vida de los procesos de negocio

\begin{tabular}{|c|c|c|c|c|c|c|}
\hline \multirow[b]{2}{*}{ Rol o Actor } & \multirow[b]{2}{*}{ Descripción de sus tareas } & \multicolumn{5}{|c|}{ Ciclo de vida de los procesos de negocio } \\
\hline & & Evaluación & $\begin{array}{c}\text { Análisis y } \\
\text { Diseño }\end{array}$ & Configuración & Promulgación & Administración \\
\hline $\begin{array}{l}\text { Dueño del } \\
\text { proceso }\end{array}$ & $\begin{array}{l}\text { Responsable de la estandarización } \\
\text { del proceso y de su evolución }\end{array}$ & & & & & \\
\hline $\begin{array}{l}\text { Ingeniero del } \\
\text { negocio }\end{array}$ & $\begin{array}{l}\text { Expertos en el dominio del negocio } \\
\text { que marcan los objetivos de la } \\
\text { compañía y de los procesos de } \\
\text { negocios operacionales }\end{array}$ & & & & & \\
\hline \begin{tabular}{|l} 
Diseñador del \\
proceso
\end{tabular} & $\begin{array}{l}\text { Crea el modelo de procesos de } \\
\text { negocio }\end{array}$ & & & & & \\
\hline $\begin{array}{l}\text { Participante del } \\
\text { proceso }\end{array}$ & $\begin{array}{l}\text { Conducen el trabajo operacional } \\
\text { durante la promulgación de las } \\
\text { instancias de procesos de negocio. }\end{array}$ & & & & & \\
\hline
\end{tabular}




\begin{tabular}{|l|l|l|l|l|l|l|}
\hline \multirow{2}{*}{ Rol o Actor } & \multirow{2}{*}{ Descripción de sus tareas } & \multicolumn{4}{|c|}{ Ciclo de vida de los procesos de negocio } \\
\cline { 3 - 7 } & & Evaluación & $\begin{array}{c}\text { Análisis y } \\
\text { Diseño }\end{array}$ & Configuración & Promulgación & Administración \\
\hline $\begin{array}{l}\text { Responsable del } \\
\text { proceso }\end{array}$ & $\begin{array}{l}\text { Corrige y mejora la ejecución de } \\
\text { cada instancia de un modelo de } \\
\text { procesos de negocio. }\end{array}$ & & & & & \\
\hline $\begin{array}{l}\text { Arquitecto del } \\
\text { sistema }\end{array}$ & $\begin{array}{l}\text { Desarrolla y configura el BPMS que } \\
\text { promulga los modelos de procesos } \\
\text { de negocios. }\end{array}$ & & & & & \\
\hline Desarrollador & $\begin{array}{l}\text { Crea las interfases para comunicar } \\
\text { los distintos procesos de negocios }\end{array}$ & & & & & \\
\hline
\end{tabular}

\subsection{Clasificación de los procesos de negocios}

Los procesos de negocio pueden clasificarse utilizando diversos enfoques. Describimos en esta sección una taxonomía planteada por M.Weske en [6] que aborda una gama bastante amplia de casos.

\section{Según el nivel de granularidad}

Desde este punto de vista, los procesos de negocios pueden calificarse como organizacionales, cuando describen en el ámbito global los procesos de la organización y marcan o delinean grandes objetivos, en contraposición con los procesos operacionales que presentan un mayor nivel de detalle y suelen concluir en un modelo completo del proceso de negocio.

Claramente los procesos organizacionales representan el primer nivel de abstracción posible en el análisis y los procesos operacionales son la explotación del nivel anterior.

La aplicación de metodologías iterativas y evolutivas sobre estos dos tipos de procesos constituiría un modelo de procesos de negocio altamente detallado.

\section{Según el alcance corporativo}

Este aspecto permite clasificar a los procesos de negocios según se circunscriban a la organización en sí misma, o la trasciendan hacia otras organizaciones.

Esta clasificación identifica procesos intraorganizacionales e interorganizacionales, marcando la diferencia existente entre orquestación y coreografia de procesos como se describe en 2.5 .

Los procesos interorganizacionales son soportados generalmente por sistemas de gestión de workflow en su versión tradicional o, en versiones más modernas, implementados o desplegados como un conjunto de servicios ejecutados bajo un motor de orquestación.

Los procesos interorganizacionales requieren una coreografia de procesos donde se requiere establecer contratos entre las partes que interactúan.

En el caso en que se deba interactuar con otras organizaciones, estamos en presencia de coreografia de procesos donde se requiere establecer contratos con las partes con las que se interactúa.

\section{Según el grado de automatización}

El grado de automatización de un proceso de negocio permitiria clasificarlos en totalmente automatizados, parcialmente automatizados o manuales.

Este aspecto también marca el grado de interacción humana que requiere la promulgación del proceso.

Los Trabajadores del Conocimiento (actores involucrados en la etapa de administración) permiten marcar claramente el próximo paso a seguir para 
llevar a cabo un proceso, por lo tanto, a la hora de construir un software es el indicado para determinar el flujo de la interacción con el usuario.

\section{Según el grado de repetición}

Este aspecto permite tener una medida temprana del ROI (Return Of Investment) de la aplicación de metodologías con enfoque en los procesos de negocio.

Cuando el grado de repetición es alto, la inversión hecha en su modelización y promulgación esta justificada ya que habrá muchas instancias que cumplen el mismo modelo.

En el caso en que no exista un alto grado de repetición, como puede suceder con procesos como el diseño de un avión, se duda acerca de la justificación de la inversión. En estos casos se puede poner el foco en modelizar la interacción entre personas mediante procesos de negocio colaborativos, donde el objetivo de modelar y promulgar no está en la eficiencia sino en obtener una traza de su ejecución para analizar los datos arrojados por la misma.

\section{Según el grado de estructuración}

Un proceso de negocio estructurado es el que prescribe las actividades a realizar $\mathrm{y}$ las restricciones de ejecución de una única manera. Las decisiones que se toman durante la promulgación del proceso fueron tomadas en tiempo de diseño. Los workflow de producción son un ejemplo de tales procesos.

Los procesos estructurados no permiten saltear actividades no requeridas o ejecutar concurrentemente actividades definidas como secuenciales.

Para dar soporte a estas ideas surge el concepto de actividades ad-hoc, donde el Trabajador del Conocimiento decide el orden y el momento de su ejecución dentro de un proceso. Es en estos casos que adquiere mayor relevancia el uso de BPMS, sobre todo aquellos que incluyen herramientas para realizar monitoreo de procesos (BAM Business Activity Monitoring).

\subsection{Orquestación y coreografia de los procesos de negocios}

Los procesos de negocio atraviesan la estructura organizativa y definen sus reglas independientemente del proceso.

Los servicios resuelven funcionalidades concretas requeridas dentro de cada unidad organizativa y se componen para realizar los procesos de negocio a través de su orquestación y coreografia [21].

En la tabla 2.4 se presenta una comparación entre ambos conceptos fijando como patrones a contrastar, el objetivo de cada uno, el modelo o metáfora que siguen, el enfoque que se le da y el fundamento para su uso.

La orientación a procesos implica independizarse de la estructura organizativa, pensar las actividades según la manera en que se ejecutan en lugar de dónde se realizan.

Los servicios resuelven aspectos funcionales directamente vinculados a la ubicación de la unidad funcional dentro de la estructura.

Una buena resolución de procesos garantiza una buena solución orientada a servicios y no viceversa.

Tabla 2.4 - Comparación de conceptos de orquestación y coreografia

\begin{tabular}{lll}
\hline & Orquestación & Coreografia \\
\hline Objetivo & $\begin{array}{l}\text { Componer servicios para } \\
\text { cumplir con un proceso de } \\
\text { negocio dentro de una } \\
\text { organización }\end{array}$ & $\begin{array}{l}\text { Componer servicios para } \\
\text { colaboración entre } \\
\text { organizaciones }\end{array}$ \\
\hline Modelo & Jerárquico. Pregunta- & Peer - to -Peer \\
\hline
\end{tabular}




\begin{tabular}{lll}
\hline & Respuesta & \\
\hline Enfoque & $\begin{array}{l}\text { Componer servicios y el } \\
\text { orden en que son } \\
\text { ejecutados para alcanzar el } \\
\text { objetivo de un proceso de } \\
\text { negocio }\end{array}$ & $\begin{array}{l}\text { Definir la manera en que } \\
\text { múltiples partes colaboran para } \\
\text { conformar una transacción de } \\
\text { negocio }\end{array}$ \\
\hline Fundamento & $\begin{array}{l}\text { Constituye un servicio en sí } \\
\text { mismo }\end{array}$ & Define la interacción del negocio \\
\hline
\end{tabular}

La noción de una aplicación o servicio compuesto se basa en la idea de la construcción de nuevas aplicaciones o servicios, interconectando las partes existentes. La orquestación juega un papel importante en esto, ya que es quien aglutina estas partes al coordinar la ejecución de cada servicio discreto.

La orquestación resuelve el problema de la ejecución de la aplicación de forma centralizada. En ella debe existir un mecanismo que dirige las actividades. Estas actividades son en realidad interacciones entre servicios, es decir, servicios que se invocan unos a otros, pero no de forma desordenada, sino de manera controlada por el orquestador que es quien conoce el detalle de todas las tareas que se deben llevar a cabo para completar el proceso.

La construcción del proceso de negocio se realiza en dos pasos: primero se publican los servicios y luego se orquestan, es decir, se integra cada servicio al proceso en su lugar y momento adecuado.

En la orquestación de servicios hay varios actores involucrados. Entre ellos encontramos la especificación del proceso de negocio, un motor de ejecución de procesos que contiene los procesos de negocios y sus reglas, y los consumidores de los servicios que se exponen.

A diferencia de la orquestación, la coreografia plantea un esquema en donde no hay un control centralizado del proceso, sino un control "declarativo" que sólo especifica cuáles son las interacciones permitidas entre dos pares. De esta forma, dadas las reglas correctas, las partes interactuarán unas con otras en un estilo "peer-to-peer" y el proceso de negocio estará definido de forma implícita. De ahí su nombre (coreografia), ya que se asemeja a un estilo en donde cada parte hace su trabajo bajo ciertas reglas y se obtiene un resultado final conjunto.

Para implementar coreografia se puede usar BPEL aún cuando éste está pensado para orquestación. La diferencia reside en que se especifica una serie de procesos entre cada par que interactuará y cada uno de estos procesos especificados representa la interacción válida entre dichos pares [28].

Los estándares para orquestación de procesos incluyen [17]:

- WSBPEL: cada proceso WSBPEL se expone como un Web Service usando WSDL que describe la entrada de datos y los puntos de salida del proceso.

- BPEL4People: es una extensión del estándar WSBPEL que inserta tareas humanas en la orquestación.

- BPMN: una notación visual para modelar procesos. Fue diseñado para ilustrar los procesos y mapearlos a los lenguajes de ejecución como BPEL El estándar número uno para ejecutar procesos de negocios y controlar en forma centralizada (orquestar) servicios, es BPEL (Business Process Execution Language). BPEL es un lenguaje ejecutable que especifica la interacción entre Web Service. El estándar fue construido por un comité y hoy es mantenido por OASIS. Dicho comité se planteó ciertos objetivos, tales como usar Web Service, usar XML, poder administrar el ciclo de vida del proceso y poder manejar transacciones a largo plazo [21].

\subsection{Conclusiones}




\section{Procesos de Negocios}

Los procesos de negocio tienen principio y final y pueden tener varias instancias. Un diagrama de procesos de negocio (BPD) describe el funcionamiento del proceso, mientras que el mapa del proceso de negocio es una representación gráfica en términos del funcionamiento de la organización y describe cómo se articula el funcionamiento de la empresa para dar lugar al objetivo del negocio.

Los procesos de negocios trascienden la estructura organizativa y la atraviesan. Son las actividades que se realizan a través de las unidades organizativas de la empresa y comandan los procesos de cada área cuidando que éstas hagan lo que les corresponde.

El enfoque orientado a procesos de negocios implica un fuerte énfasis en cómo el trabajo es realizado dentro de una organización o entre organizaciones en contraste al acento en el qué, en el enfoque orientado a producto.

Las actividades de los procesos son responsabilidad de personas o áreas de empresas, incluso si son automatizadas.

Las politicas empresariales y las reglas de negocio se establecen para determinar cómo debe actuar la empresa para cumplir sus objetivos, respondiendo a estrategias preestablecidas. Estas reglas son de aplicación en los distintos pasos de un proceso.

La definición de un proceso conlleva a identificar indicadores que puedan medir su rendimiento, favoreciendo el análisis y la mejora continua de dicho proceso.

Los objetivos de la gestión de los procesos de negocio pueden resumirse en los siguientes puntos:

- Explicitar los procesos de negocios para entender las operaciones realizadas en una organización y sus relaciones.

- Identificar actividades y representarlas en un modelo de procesos de negocio como medio de comunicación entre los participantes, además de permitir analizar el modelo y mejorarlo.

- Facilitar la mejora continua de los procesos de negocio, cuyo repositorio constituye un activo para la organización y su gestión.

- Reducir la brecha existente entre el proceso de negocio en sí mismo y su realización en un software.

En este capítulo hemos presentado las nociones básicas acerca de los procesos de negocio y su gestión, poniendo énfasis en su ciclo de vida ya que será el aspecto sobre el que se basa una parte importante de nuestra propuesta. 


\section{Arquitectura Orientada a Servicios}

En este capítulo se presentan los conceptos más importantes que definen una Arquitectura Orientada a Servicios (SOA Software Oriented Architecture) como una de las iniciativas tecnológicas más importantes de la década.

La evolución de las aplicaciones desde los objetos distribuidos hacia la orientación a servicios, es un aspecto abordado en este capítulo para encontrar diferencias y similitudes en este sentido.

Desde el punto de vista tecnológico, se presenta el concepto de Bus de Servicios Empresarial (ESB) y su importancia en una Arquitectura Orientada a Servicios.

\subsection{Qué es SOA?}

Según lo afirma Hurwicz en [18], SOA representa un cambio radical en la relación entre el mundo del negocio y el área de tecnología de la información. SOA constituye mucho más que un conjunto de productos aglutinados por una tecnología. Es un nuevo enfoque en la construcción de sistemas de IT que permite a las empresas aprovechar los activos existentes y abordar fácilmente los inevitables cambios en el negocio [26].

Si bien la industria del software ha venido enfocándose en una arquitectura orientada a servicios desde hace más de 20 años con la noción de reusabilidad y su aplicación a la construcción de software, lo cierto es que en los últimos años esto se ha fortalecido con la definición de estándares y la conformación de consorcios que participan en su definición.

\section{Conceptos y definiciones}

Comenzaremos definiendo el concepto de una arquitectura de software para poder comprender mejor la idea de una Arquitectura Orientada a Servicios.

Según IEEE una arquitectura de software es la organización fundamental de un sistema, reflejado por sus componentes, relaciones entre ellos y entorno, así como los principios que regirán su diseño y evolución (1471-2000). [28]

Según OASIS, se define como la estructura o estructuras de un sistema de información formado por entidades y sus propiedades externamente visibles, así como las relaciones entre ellas (Modelo de Referencia para SOA 1.0 - Agosto de 2006). [28]

Adaptándose a la definición de OASIS, se define SOA como un paradigma capaz de organizar y utilizar las capacidades distribuidas, que pueden estar bajo el control de distintas organizaciones, y de proveer un medio uniforme para publicar, descubrir, interactuar y usar los mecanismos oportunos para lograr los efectos deseados.

Podemos resumir los conceptos subyacentes fundamentales en este paradigma en los siguientes:

- Proveedor: entidad (organización o persona) que ofrece el uso de capacidades mediante servicios.

- Necesidad: carencia de una empresa para resolver la actividad de su negocio.

- Consumidor: entidad (organización o persona) que busca satisfacer una necesidad particular a través de las capacidades ofrecidas por servicios.

- Capacidad: tarea que el proveedor de un servicio puede proporcionar al consumidor. 
- Servicio: mecanismo que permite el acceso a una o más capacidades alcanzables por medio de una interfaz preestablecida, y que se llevará a cabo de forma consistente con las normas establecidas para él.

- Descripción del servicio: información necesaria para hacer uso del servicio.

- Interacción: actividad necesaria para hacer uso de una capacidad con el objeto de obtener efectos deseados.

La tabla 3.1 enuncia los puntos más importantes que ayudan a entender qué es $\mathrm{SOA}$ en función de lo que NO es.

Tabla 3.1 - Qué NO es SOA

\begin{tabular}{|l|l|}
\hline NO es una tecnología & JEE, .NET, Web Services \\
\hline NO es un producto & ESB, SOA Fabrics \\
\hline NO es un protocolo & SOAP, HTTP, etc. \\
\hline NO es un estándar & Es un modelo de referencia \\
\hline NO es una solución & $\begin{array}{l}\text { SOA no es ejecutable y por lo tanto no } \\
\text { produce resultados. }\end{array}$ \\
\hline
\end{tabular}

\section{SOA: modelo de referencia, arquitectura y plataforma}

SOA es un modelo de referencia para entender las relaciones más significativas dentro del dominio de un problema concreto y facilitar el desarrollo de estándares o especificaciones. Se fundamenta en un pequeño número de conceptos para explicar el modelo a profanos y busca producir una semántica sin ambigüedades.

SOA es un modelo de referencia para:

- La creación y utilización de servicios a lo largo de su vida útil

- La definición de la infraestructura que permita intercambiar datos entre diferentes aplicaciones

- La participación de los servicios en los procesos de negocios independientemente del sistema operativo, los lenguajes de programación y si los procesos son internos o externos a la organización

Los conceptos y sus relaciones, definidas en el modelo de referencia SOA, deben ser la base para describir la arquitectura.

Una arquitectura SOA concreta será el producto de aplicar la arquitectura de referencia desarrollada según el modelo de referencia y los patrones ${ }^{1}$ de esa arquitectura, asi como los requerimientos necesarios, incluyendo los impuestos por los entornos tecnológicos.

La aplicación de un modelo de referencia para lograr una arquitectura completa, equivale a pasar de una etapa de análisis a una de diseño en analogia con las etapas del ciclo de vida del software. Implica dar un paso más en el nivel de detalle y comenzar a buscar metodologias para aplicar sobre los conceptos analizados.

Una arquitectura concreta se desarrolla en un contexto predefinido donde se fijan protocolos, perfiles, especificaciones y estándares. La plataforma SOA combina estos elementos a los efectos de generar un producto operativo.

La Figura 3.1 [28] presenta un marco general entre la noción de marco de referencia, arquitectura de referencia y arquitectura especifica, que muestra qué aporta y en qué consiste cada una de ellas, así como el paso de lo más abstracto hacia lo más concreto.

\footnotetext{
${ }^{1}$ Un patrón es una forma de realizar una tarea concreta basada en una generalización.
} 


\section{Arquitectura Orientada a Servicios}

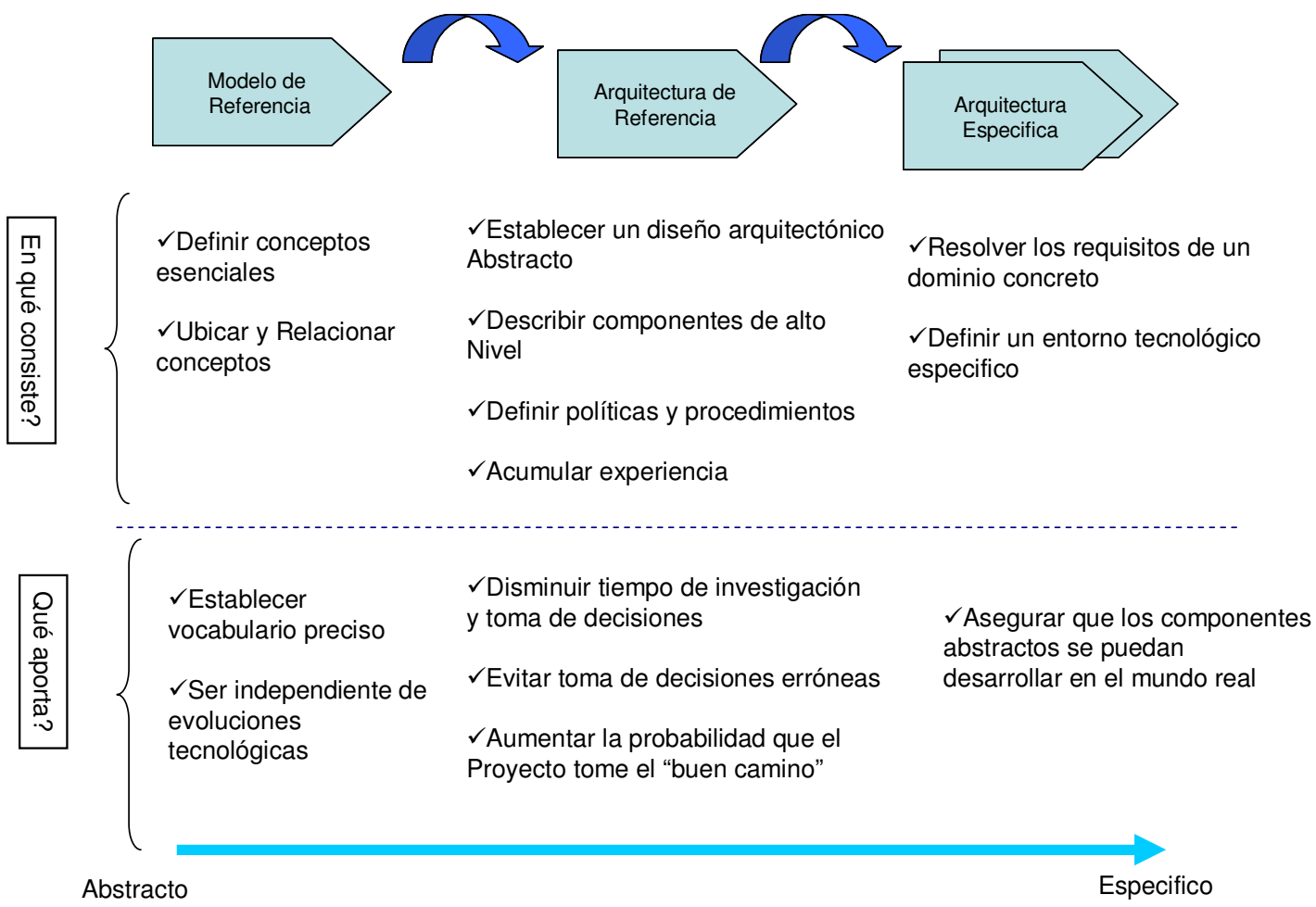

Figura 3.1. Marco general entre modelo de referencia, arquitectura de referencia y arquitectura especifica.

\section{SOA y el modelo de interacción}

Según los conceptos subyacentes a SOA descriptos con anterioridad, el modelo de interacción es uno de los más relevantes dado que aporta la manera en que los servicios se comunican entre sí.

Este modelo de interacción sigue el paradigma triangular de Publicar-LigarEjecutar como se muestra en la Figura 3.2 [28].

En este paradigma, los proveedores registran sus servicios en un registro público. Los consumidores utilizan este registro para buscar servicios que cumplan con cierto criterio. Si el registro posee tal servicio, el mismo provee al consumidor con un contrato y un punto de acceso para el servicio.

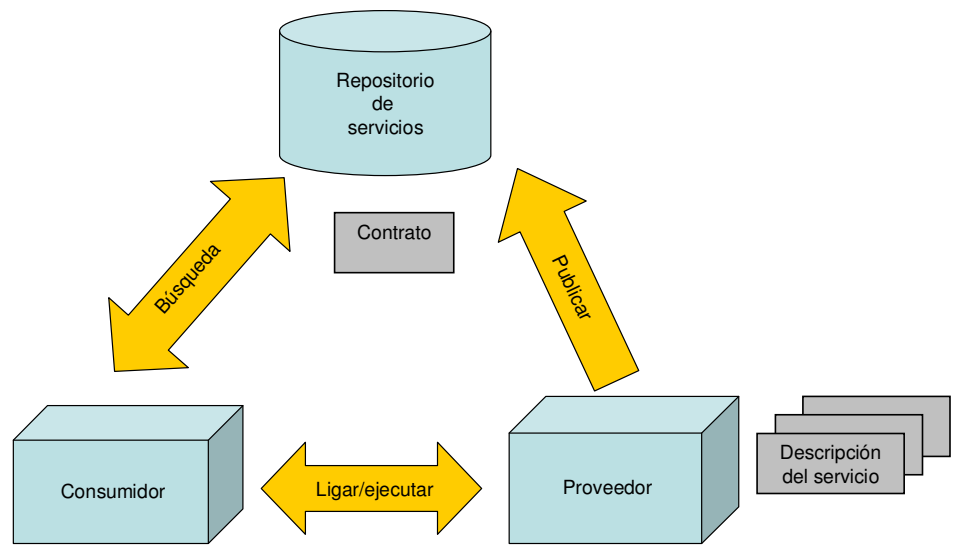

Figura 3.2. Modelo de Interacción triangular de SOA 
- Publicar: para que un servicio sea usado, su descripción de servicio debe ser publicada

- Descubrir / Encontrar: el consumidor busca una descripción de servicio directamente, o hace una búsqueda de servicios. La operación se puede hacer en dos puntos del ciclo de vida del cliente: durante el diseño o durante la ejecución

- Enlazar: el cliente del servicio invoca o inicia la interacción con el mismo durante la ejecución, contando con los detalles en la descripción del servicio para localizarlo, contactarlo e invocarlo

\section{Acerca de los servicios}

Un servicio es un elemento que se comprende en términos de la utilidad que brinda, por lo tanto, no puede apartarse del negocio o problema para el cual debe ser útil.

Los servicios son tareas computacionales débilmente acopladas que se comunican vía una red (en el caso de los web services por Internet), y que juegan una relación cada vez más creciente en las interacciones B2B.

Un servicio captura funcionalidad con un valor de negocio, y está listo para ser usado. Es provisto por servidores, para lo cual requiere de una descripción que pueda ser accedida y entendida por potenciales clientes. Los servicios de software son servicios provistos por sistemas de software. [3]

Con estas definiciones podemos decir que el conjunto de conceptos que describen los servicios son: descripción del servicio, contratos y normas y contexto de ejecución.

A través de la descripción del servicio se obtiene la información que un consumidor necesita para considerar si usa o no el servicio.

Con esta información se puede informar al consumidor: si el servicio existe (alcanzabilidad), qué funciones realiza (funcionalidad), qué restricciones se aplican a su uso y cómo se debe interactuar con el servicio (interfaz) tanto en cuanto a formato como a secuencias.

Los contratos $\boldsymbol{y}$ normas representan el acuerdo entre las partes, las condiciones de uso, las restricciones y el despliegue de los servicios.

El contexto de ejecución es el conjunto de elementos técnicos y de negocios que conforman la via para que proveedores y consumidores puedan interactuar.

La posibilidad de extender sistemas anexándole nuevos servicios y haciendo reuso de los ya existentes, con el objetivo de lograr interoperabilidad entre tecnologías y aplicaciones heterogéneas, nos permite prolongar la vida de los sistemas. Los beneficios de SOA son a largo plazo. La existencia de un único servicio, no tendrá valor si no tiene forma de complementarse con otros servicios.

Este estilo de arquitectura nos permite el desarrollo de aplicaciones débilmente acopladas, las cuales pueden ser accedidas a través de la red.

\subsection{Evolución desde los objetos distribuidos a los servicios}

Las arquitecturas de sistemas empresariales cubren los sistemas de información en su conjunto, ya sean de índole administrativa o de tipo de control de dispositivos.

El problema es siempre el mismo, encontrar mecanismos para manejar la complejidad.

La abstracción se identifica como uno de los mecanismos más adecuados para manejar la complejidad: pensar los problemas de modo que puedan ser descompuestos funcionalmente por sucesivos refinamientos. 
Una arquitectura de software define una estructura que organiza los elementos de software y los recursos de un sistema de software. Estos dos elementos son representados por subsistemas. Los detalles internos de cada subsistema son tratados por la arquitectura de software de los mismos.

La idea de construcción de aplicaciones integradas permitió que las organizaciones desarrollaran software que resuelva cada parte de su negocio y se integre con aplicaciones que gestionen la parte administrativa de dicho negocio. En este sentido la idea de integración de aplicaciones comienza a cobrar un sentido muy relevante.

En este contexto surgen los sistemas ERP (Enterprise Resource Planning) que proveen variada funcionalidad integrada por un único repositorio de datos.

No se tardó demasiado en intentar agregar valor a los desarrollos de las organizaciones aportando sistemas de CRM (Customer Relationship

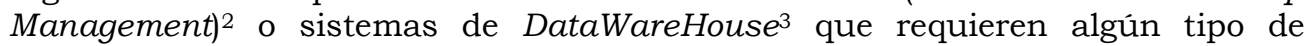
integración con los sistemas de índole operativa o propia del negocio.

Esta integración se enfoca principalmente en la integración vía el modelo de datos.

Este tipo de integración ha sufrido una evolución e incluye diversas variantes que se describen a continuación, con miras a llegar a la noción de servicio como un enfoque posible de integración, pero también como el elemento básico en una SOA [21].

\section{Integración punto a punto}

Se basa en integración uno a uno sustentada generalmente por un middleware asincrónico basado en colas de mensajes. Si bien es un esquema de alta disponibilidad, dada por el mecanismo de comunicación, es rígido y difícil de adaptar a los cambios, además de resultar muy costoso de gestionar, monitorear y extender. Es una arquitectura accidental, completamente sincrónica, de grano grueso y poco escalable.

La Figura 3.3, presentada por M.Weske en [6], grafica el escenario de una integración con el mecanismo punto a punto.

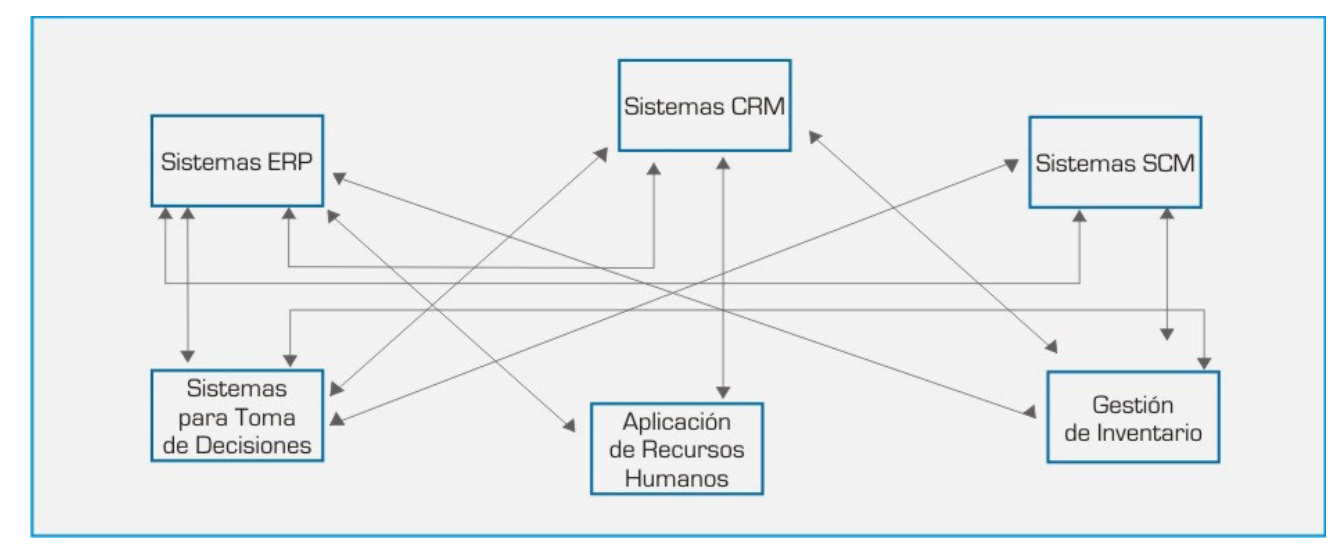

Figura 3.3. Mecanismo de integración punto a punto

\section{Integración por adaptadores}

\footnotetext{
${ }^{2}$ Sistemas informáticos de apoyo a la gestión de las relaciones con los clientes, a la venta y al marketing (Wikipedia)

${ }^{3}$ Es una colección de datos orientada a un determinado ámbito (empresa, organización, etc.), integrado, no volátil y variable en el tiempo, que ayuda a la toma de decisiones en la entidad en la que se utiliza (Wikipedia)
} 
La interacción se realiza por un " $h u b$ " donde se conecta cada elemento a integrar previa construcción del adaptador correspondiente para poder "enchufarse". Cada uno de los elementos está desconectado y no requiere utilizar el mismo lenguaje ya que existen adaptadores para establecer la comunicación.

La complejidad esta en la construcción del adaptador.

La Figura 3.4, también obtenida de [6], presenta una evolución de la Figura 3.3 hacia un mecanismo de integración por adaptadores.

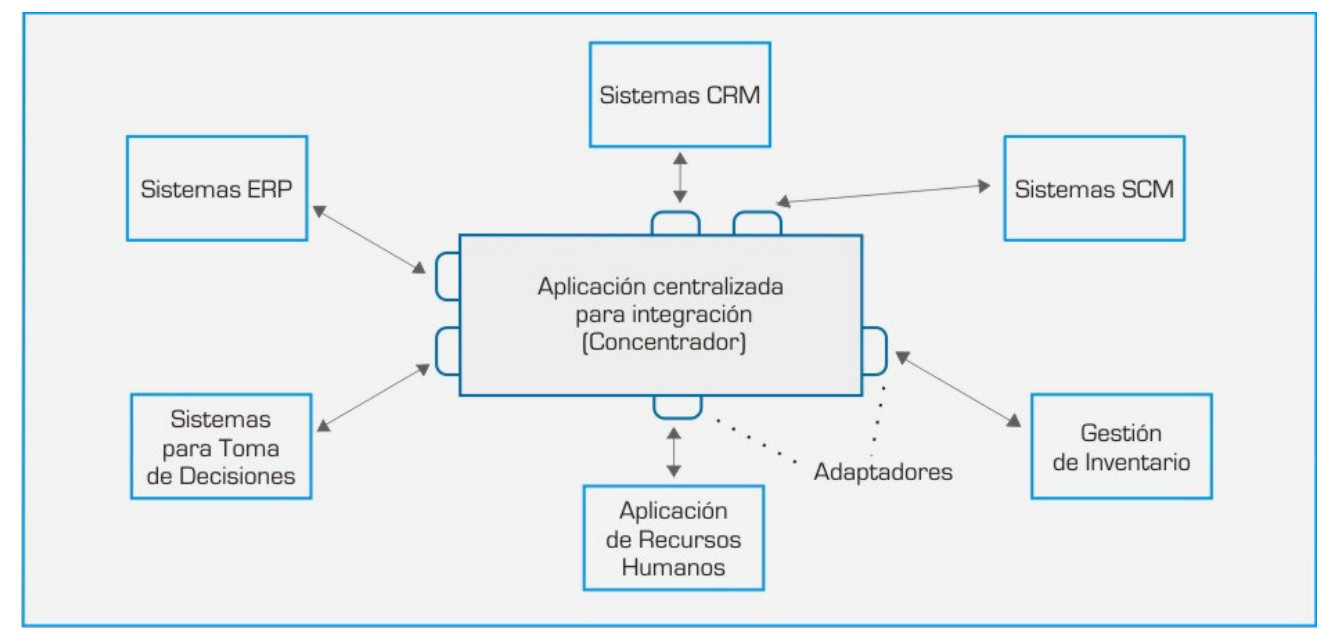

Figura 3.4. Mecanismo de integración por adaptadores

\section{Mediador de mensajes}

Este mecanismo de integración representa una evolución del modelo anterior hacia una generalización del hub permitiendo extraer la lógica de la integración fuera de las aplicaciones.

Se define declarativamente la forma de comunicación de las aplicaciones y se traslada al mediador o "broker" la lógica necesaria para producir las transformaciones que generen salidas válidas para el otro extremo.

Utiliza colas para garantizar la distribución de los mensajes, que se manejan con un esquema de publicador/suscriptor. Esto asegura que el tráfico que se genera sea solamente el requerido.

La Figura 3.5 [6] muestra el próximo paso evolutivo desde la Figura 3.4 donde se muestra la integración a través de un broker de mensajes. 


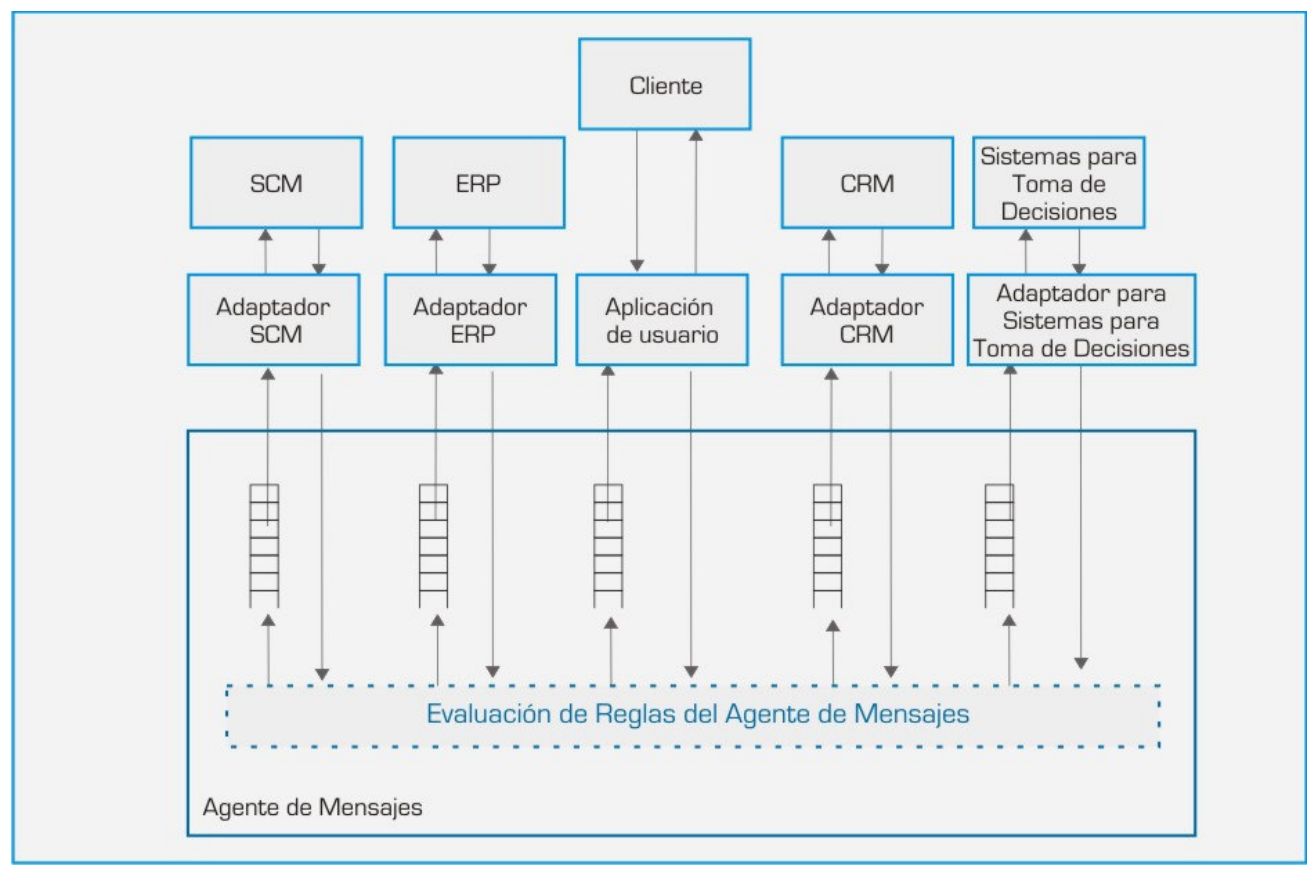

Figura 3.5. Mecanismo de integración por Broker de Mensajes

\section{CORBA como estándar de objetos distribuidos}

El mecanismo de integración vía un broker de mensajes es el marco conceptual sobre el que se sustenta CORBA.

CORBA (Common Object Request Broker Architecture) ha sido el proyecto de middleware más importante y ambicioso de la industria de la computación de fines de la década del ' 90 . Es producto de un consorcio que aglutinó a 650 compañias (entre las que NO se encuentra Microsoft que compitió con DCOM (Distributed Componente Object Model).

El bus de objetos de CORBA define la forma de los componentes que viven dentro de él y cómo interoperan.

CORBA constituye un estándar de la $\mathrm{OMG}^{4}$ que establece una plataforma de desarrollo de sistemas distribuidos facilitando la invocación de métodos remotos bajo un paradigma orientado a objetos.

CORBA fue diseñado para permitir que componentes inteligentes (pensadas en términos de objetos) se descubran unas a otras e interoperen. Pero trasladar el paradigma de la orientación a objetos a un entorno distribuido implica sin duda agregar conceptos que están ausentes en un entorno único o local como lo son:

- Transaccionalidad

- Seguridad

- Cerramiento y/o Aislamiento

- Persistencia

Para alcanzar los objetivos de interoperabilidad se definió el IDL (Interface Definition Language). Es un lenguaje puramente declarativo, no provee detalles de implementación y provee independencia del lenguaje de programación y del sistema operativo. Un IDL se usa para:

- Especificar atributos de los componentes

- Heredar clases de un padre

- Levantar excepciones

- Emitir eventos tipificados

${ }^{4}$ http://www.omg.org/technology/documents/corba_spec_catalog.htm\#CCM 


\section{Arquitectura Orientada a Servicios}

- Declarar los métodos que soporta el componente

La gramática IDL es un subconjunto de $\mathrm{C}++$ con palabras claves adicionales para soportar conceptos distribuidos.

El ORB (Object Request Broker) es el middleware que establece la relación solicitud/proveedor entre objetos distribuidos.

Las interfaces mediante las cuales especificar los servicios que se proveen, están definidas en el lenguaje IDL de OMG y los objetos distribuidos son identificados por medio de referencias que implementan la interfaz remota.

Por último, CORBA define un conjunto de servicios distribuidos, definidos en el nivel superior del ORB, para soportar la integración e interoperabilidad de objetos distribuidos. Estos servicios resuelven los aspectos mencionados anteriormente acerca de los objetos distribuidos como lo son la transaccionalidad, seguridad, cerramiento y/o aislamiento y persistencia.

\section{Modelo de integración por servicios}

Sin lugar a dudas, CORBA ha constituido una base conceptual muy importante en la aparición de los conceptos de SOA.

El concepto de objeto y el de servicio guardan muchas similitudes en lo que se refiere a su modularidad y capacidad de reuso, pero también se diferencian, fundamentalmente en el modelo de interacción que presentan.

Los objetos se definen con gran cohesión, en el sentido que existe gran asociación entre los métodos que atienden el objeto y una fuerte ligadura funcional, pero con bajo acoplamiento para minimizar el impacto de los cambios de una clase.

Los servicios, por su parte, necesitan un menor acople y no requieren que se conozca su nombre para utilizarlos porque poseen abundante meta-información. Dentro de un servicio existen operaciones, no habiendo, a priori, asociaciones entre ellos, por lo tanto existe menos cohesión que en los objetos.

A cambio, se hace imprescindible contar con un marco de referencia o arquitectura, que facilite su registro y publicación para conocer su existencia [13] [14].

Un servicio difiere de un objeto o un procedimiento porque se define en función de los mensajes que intercambia con otros servicios.

Por último, los Web Services surgieron en forma paralela a la idea de SOA. La plataforma SOA ordenó su uso sistemático combinando protocolos, perfiles, especificaciones y estándares [15][20].

En términos generales, cuando se habla de integración de aplicaciones nos referimos tanto a datos como a procesos.

Los datos pueden integrarse o puede resolverse su integración contando con cualquiera de los esquemas anteriormente planteados. Cualquiera de ellos implica el desencadenamiento de un flujo o cadena de mensajes que quedan incrustados dentro del esquema de integración mismo.

Así, los sistemas de gestión de workflow surgen como ciudadanos de primera clase a la hora de realizar una integración de aplicaciones eficiente y fácil de mantener y actualizar.

Gran parte del esfuerzo de implementar SOA y BPM se ha centrado sobre la integración de aplicaciones y el workflow. Sin embargo existe una preocupación de los arquitectos de software acerca de la incapacidad para acceder a datos de negocios y administrarlos de una manera ágil tal como sucede con la lógica de negocio en las aplicaciones

La integración de datos dirigida por procesos puede ayudar a enriquecer los servicios de negocios SOA y los procesos BPM a través de una secuencia de servicios de datos combinados de manera reusable que incorpora la intervención de tareas humanas transformando la información en exacta, consistente y oportuna. 
Desde el punto de vista de Ovum en [17], muchos de los procesos sustentados por una arquitectura SOA, son inherentemente dirigidos por datos. La arquitectura SOA sin un nivel de servicio de datos, hace proliferar los sistemas aislados que no se integran y dificultan la agilidad del negocio.

\subsection{Importancia del ESB}

El enfoque SOA busca construir aplicaciones mediante la combinación poco acoplada de servicios interoperables. Tal como se afirma en [28], el hecho de que un servicio pueda utilizarse ampliamente en toda la empresa por muchas aplicaciones, implicaria dar lugar a los siguientes riesgos para la infraestructura de IT de una organización:

- Tiempos de respuesta poco aceptables tanto para los usuarios como para procesos de negocio.

- Infracciones de seguridad.

- Pérdida de niveles de servicio para funciones críticas del negocio.

- Incumplimiento de normas de la industria y regulaciones gubernamentales.

- Gestión de servicios insuficiente.

El área de tecnología de una organización se ha centrado desde hace mucho tiempo en la gestión de la infraestructura como un activo para apoyar las aplicaciones y las unidades de negocio. Con SOA la atención se enfoca hacia la gestión de los servicios que prestan apoyo a los procesos de negocio.

\section{Enterprise Service Bus (ESB)}

En función de las motivaciones presentadas en el apartado anterior, resulta evidente la necesidad de contar con una infraestructura de IT que apoye la gestión de los servicios.

Sobre una arquitectura SOA se puede definir un bus de servicios empresariales (Enterprise Service Bus o ESB) como una plataforma de software que da soporte a muchas funcionalidades resueltas a nivel de la capa de aplicación en los enfoques tradicionales de construcción de aplicaciones.

Tales funcionalidades son:

- La comunicación: el ESB se ocupa del ruteo de los mensajes entre los servicios.

- La conectividad: el ESB resuelve la conectividad entre extremos mediante la conversión de protocolos entre solicitante y servicio.

- La transformación: es responsabilidad del ESB resolver la transformación de formatos de mensajes entre solicitante y servicio.

- La portabilidad: los servicios serán distribuidos independientemente del lenguaje de programación en el que estén escritos y del sistema operativo subyacente.

- La seguridad: el ESB posee la capacidad de incorporar los niveles de seguridad necesarios para garantizar servicios que puedan autenticarse, autorizarse y auditarse.

Actualmente existen dos tendencias mayoritarias para la implementación de un ESB: los que requieren un servidor de aplicaciones y los que son totalmente distribuidos y, por lo tanto, no lo requieren [28].

Funcionalmente, cualquiera de las dos tendencias conserva sus propias características según se detalla en el cuadro "Servidores de aplicaciones Vs ESB", pero se puede afirmar que un ESB totalmente distribuido que no requiere de un servidor de aplicaciones tendrá mayor independencia de la plataforma y será capaz de ofrecer una mayor ubicabilidad de los servicios que gestiona. 


\section{Arquitectura Orientada a Servicios}

\section{Servidores de aplicaciones Vs ESB}

Los servidores de aplicaciones manejan gran parte de las interacciones entre la capa cliente y la capa de persistencia a datos en un modelo de 3capas. Proveen una colección de servicios de middleware junto con un ambiente de ejecución para desplegar las componentes de lógica de negocios (el container). La mayoría de los servidores de aplicaciones soportan Web Services, ORB's, sistemas de mensajes, manejo transaccional, seguridad, balanceo de carga y gestión de los recursos. Proveen una solución integral a las necesidades de los sistemas de información empresariales (a gran escala).

Constituyen una excelente plataforma de integración. Hoy la mayoría de los productos comerciales posicionan sus servidores de aplicaciones como máquinas de integración o los especializan agregando conexiones a back-end y sistemas legados posicionando sus productos como servidores de integración.

$\mathrm{Si}$ bien este tipo de servidores puede facilitar considerablemente la configuración de los diferentes productos de middleware, todavía vale la pena pensar en lo que hay debajo. Sean utilizado para desarrollo de aplicaciones o para integración, los servidores de aplicaciones son plataformas de software: la combinación de tecnologías de software necesarias para ejecutar aplicaciones. En este sentido, ellos definen la infraestructura de todas las aplicaciones desarrolladas y ejecutadas en los mismos.

Un ESB, por su parte, es una infraestructura de software en sí misma, que actúa como middleware intermediario y que dirige los requerimientos extendidos que generalmente no pueden ser cubiertos por los Web Services, como la integración entre los mismos y la inclusión de otras tecnologias de middleware y servicios de valor agregado como robustez, seguridad, gestión y control de servicios.

Un ESB dirige estos requerimientos y agrega flexibilidad para la comunicación entre servicios, haciendo posible conectar los servicios implementados en diferentes tecnologías (tales como EJB, sistemas de mensajes, componentes CORBA y sistemas legados).

Más allá de la estructura interna, el concepto de bus, lo componen los mecanismos de comunicación que hacen que todos los elementos conectados al ESB puedan conectarse entre sí, sin necesidad de conocerse unos a otros.

Un ESB centraliza el control y distribuye el procesamiento [35]. Para lograr este objetivo los ESB evolucionaron desde la integración por adaptadores, donde se centralizaba tanto el control como el procesamiento. Los ESB representan una suerte de federación de adaptadores a gran escala donde la configuración centralizada es un concepto que se implementa de manera distribuida. 


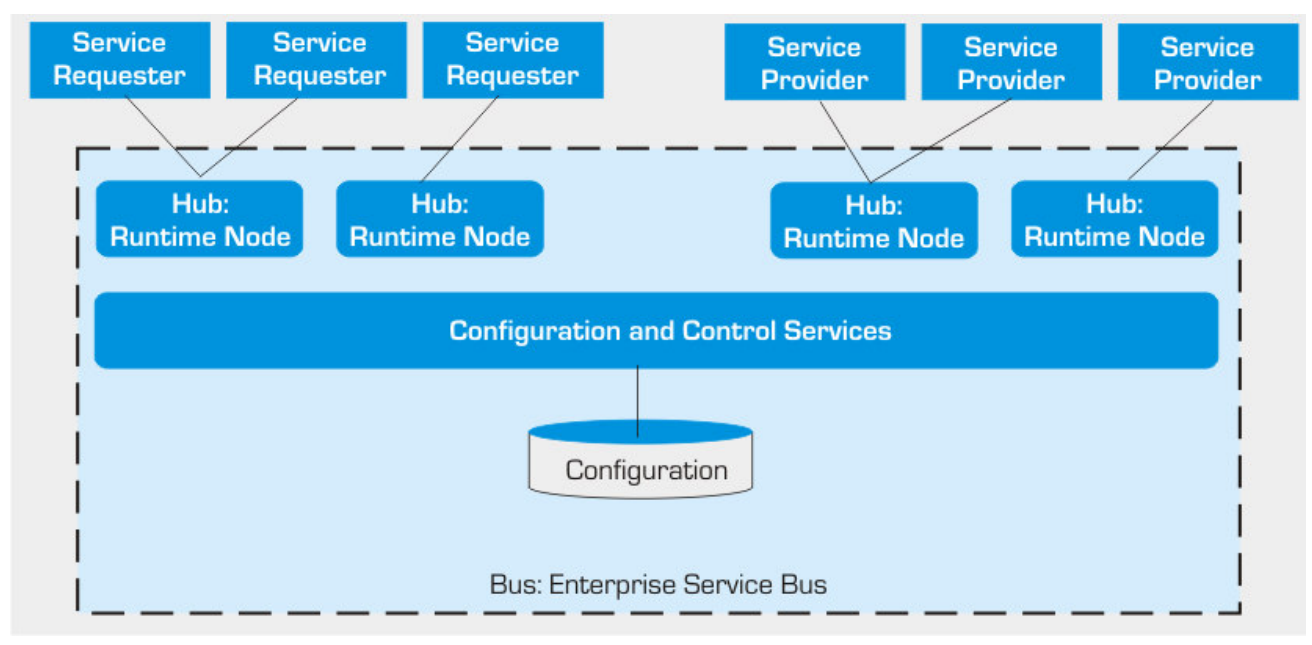

Figura 3.6 ESB como una infraestructura distribuida con control centralizado

En la Figura 3.6 [33] se muestra el resultado de la implementación de un ESB. El nodo de Configuración y Control de Servicios tiene línea punteada para ilustrar su construcción lógica.

Cuando las soluciones tecnológicas brindan herramientas completas para gestionar los servicios desde los procesos de negocios, los ESB están dirigidos por los servidores de procesos donde se definieron los procesos de negocios y es dicho servidor quien gestiona y orquesta las solicitudes a través del ESB. Tal es el caso de la solución de IBM mediante su línea de WebSphere BPM.

En este marco, podemos afirmar que, hoy por hoy, los Web Services no constituyen un ESB por sí mismos, pero sí pueden ser parte de él.

\section{Caracteristicas de un ESB}

El conjunto de características que se enuncian a continuación representa un aporte a la hora de determinar qué es y qué no es un ESB.

- Está desarrollado sobre una arquitectura orientada a servicios, por lo tanto, es una implementación de SOA.

- Se basa en la utilización de estándares en un $100 \%$, pero admite también elementos propietarios.

- Normalmente son multi-plataforma y multi-lenguaje.

- Son netamente distribuidos en el sentido de que no es necesario conocer la ubicación física de los servicios y que un mismo servicio puede existir en más de una localización en forma simultánea.

- Presenta un mecanismo de comunicación basado en mensajes con enrutamiento inteligente (basado en reglas o basado en contenido)

- Implementa un modelo se seguridad estandarizado con lo que se denomina nivel C2 de seguridad garantizando autenticación, autorización y auditoría.

Según la opinión de algunos analistas como Mike Gilpin (Forrester), “... el ESB ayuda a las compañias a obtener las ventajas de SOA incrementando la conectividad, añadiendo una flexibilidad capaz de acelerar los cambios y proporcionando un mayor control sobre el uso del recurso sobre el que actúa." 


\section{Arquitectura Orientada a Servicios}

\subsection{Conclusiones}

En este capítulo se han resumido y vinculado los conceptos más relevantes de una SOA. En realidad podemos decir que no hay elementos radicalmente nuevos ya que la orientación a servicios, tal como esta descripta, se ha venido aplicando a lo largo de los años.

Las diferencias principales radican entonces en la forma en que los servicios se comunican (que ha presentado una gran evolución desde las comunicaciones punto a punto), en que los servicios dejan de usarse de manera aislada, en el uso de estándares que sin duda son parte esencial del éxito y en que se utilizan técnicas exitosas en términos de experiencias pasadas.

Los beneficios más importantes a la hora de implementar un SOA pueden resumirse en los siguientes:

- Es adaptable en el sentido de que se articula fácilmente a los cambios del negocio, facilita la integración de sistemas, es independiente de la plataforma y de los lenguajes de programación.

- Es ágil puesto que es fácil agregar funcionalidad y hacerla llegar a los canales, sean nuevos o existentes. Además facilita la creación de nuevos servicios.

- Permite ahorrar costos mediante la reutilización como también por la facilidad de mantenimiento.

Más allá de todo, es cierto también, que la implementación de una SOA no es una tarea simple ni mucho menos gratuita. Una práctica recomendable puede ser usar SOA para integración en una primera instancia y luego, en otro paso de madurez, ir descomponiendo las aplicaciones para descubrir los servicios.

Según una estadística de Gartner Group, "para el año 2008, SOA será la práctica de ingeniería de software más extendida, terminando con 40 años de dominación de las arquitecturas monoliticas ( 0.7 de probabilidad)" 


\section{Modelos de integración existentes}

En este capitulo se realiza un análisis evolutivo del estado del arte respecto a la integración de aplicaciones y se estudian las características principales de esta evolución para poder plantear en el próximo capítulo, un nuevo modelo de integrabilidad entre SOA y BPM. Este modelo se basa en la premisa de obtener soluciones a los problemas de las organizaciones, que cuenten con una integración completa y esté guiada por una metodología.

Como vimos en el capitulo 3, SOA es una metodología de desarrollo de software que se enfoca en crear una arquitectura más flexible que pueda atravesar múltiples dimensiones mientras que BPM, por su parte, se enfoca puramente en optimizar la manera de trabajo real [24].

En el capítulo 2, al describir BPM, vimos que representa una manera de analizar y medir el negocio o la realidad, en términos de procesos de negocios que atraviesan la organización y los límites de los sistemas.

$\mathrm{Si}$ bien los primeros esbozos de realizar reingenieria de procesos fueron un aporte importante en el sentido de que se basaban en la idea de la mejora de los mismos, no dejaban de enfocarse en la automatización de la tarea y no en la optimización de la misma. Además tenían la particularidad de que los procesos se gestionaban por herramientas construidas ad-hoc.

La evolución natural fue entonces hacia la definición de una estrategia para gestionar y mejorar el rendimiento de un negocio a través de la optimización continua de sus procesos dentro de un ciclo de modelado, ejecución y medida. BPM es tal estrategia o disciplina.

BPMS (Sistemas o Suite para BPM) proveen un conjunto de herramientas integradas que soportan el diseño, media, monitoreo, análisis y mejoras continuas al proceso de negocio.

BPM es el complemento natural de SOA, y un mecanismo a través del cual una organización puede aplicar SOA a sus procesos de negocio.

BPM aporta valor en el mundo real mientras que SOA facilita la integración de soluciones y provee tecnologías para gestionar los componentes técnicos de un proceso de negocio.

Los analistas de procesos de negocio usan BPM para crear y optimizar modelos de procesos de negocio, encontrar servicios de negocio que implementen las actividades modeladas, volcándolos en un BPMS.

Lo deseable es que el resultado de esta producción culmine en procesos desplegados como servicios, registrados en un repositorio y expuestos a los consumidores.

El modelo de integración que se presenta y que surge de un análisis del estado del arte en términos de integración de aplicaciones, define un conjunto de componentes tanto tecnológicos como de negocios, que dan una visión unificada e integradora de la solución alcanzada. Sobre este análisis se construye el modelo propuesto en esta tesis, que se presentará en los próximos capitulos.

\subsection{Evolución tecnológica de las aplicaciones}

Los sistemas de información tradicionales que sustentan su modelado en un enfoque netamente dirigido a los datos han dominado la industria por largo tiempo. En los últimos tiempos subyace, cada vez con más ímpetu, la idea de que los procesos son igualmente importantes y deben ser considerados de una manera sistemática. 
Por otra parte, el paradigma de desarrollo orientado a servicios está llevando el mundo de la tecnología de información a un cambio de enfoque en la manera de resolver problemas y también a una nueva visión de integración de aplicaciones. En la década del 70 el paradigma era el cálculo, las aplicaciones eran de estadisticas/contabilidad y balística y la herramienta los lenguajes de programación procedurales sin entornos de desarrollo.

En la década del 90 el paradigma era la construcción de los sistemas de información, aplicaciones de gestión generalmente de índole administrativa y las herramientas eran los RDBMS, TP, Workflow y DataWarehouse.

La tendencia actual es hacia un paradigma orientado a procesos cuyo enfoque se ha sustentado en los conceptos de workflow pero que encontró en BMP un soporte de la idea de procesos mucho más amplio incluyendo simulación, verificación y monitoreo.

Además, el enfoque orientado a procesos actual ordena la arquitectura de integración accidental originada por la integración punto a punto, proveyendo un mayor nivel de abstracción donde existen procesos que orquestan servicios, que a su vez, resuelven la funcionalidad.

La tecnología de Servicios Web representa el estándar de computación distribuida más adoptado de la historia de la industria y son la plataforma ideal para la Arquitectura Orientada a Servicios (SOA).

Asimismo, la orquestación y coreografia de los Servicios Web como workflow son partes esenciales de las definiciones de trabajo actuales.

La orquestación impone el orden y el ritmo individual a un conjunto de Servicios Web. La coreografia define el comportamiento variado entre los Servicios Web.

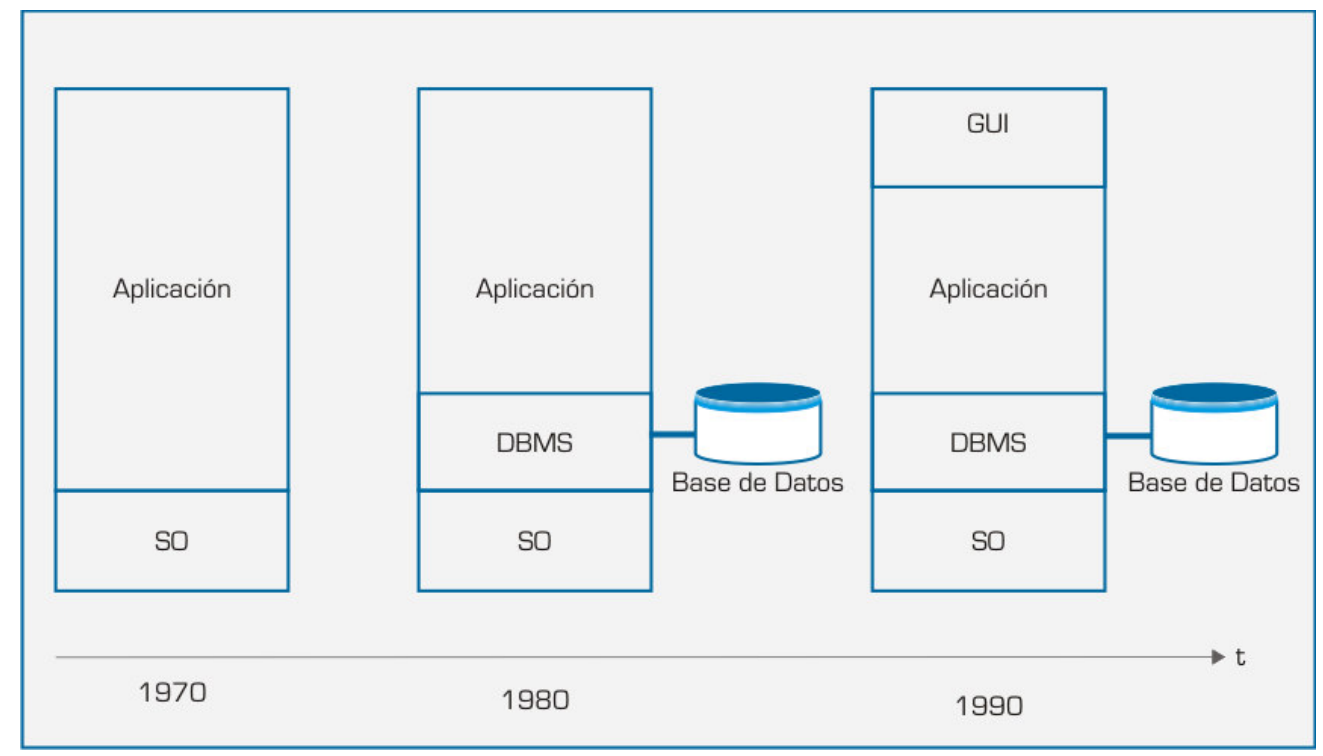

Figura 4.1. Evolución de tecnológica de aplicaciones

Como se muestra en la figura 4.1 extraida de [6], la evolución marca la tendencia de otorgarle primero una gran independencia al componente de manipulación de datos con la aparición de los DBMS. Luego de ello se dio mayor relevancia a la interfaz con el usuario, dejando la lógica de la aplicación como un elemento o componente separado y que debería tender a no mezclarse con los otros dos elementos. 


\subsection{Alternativas de integración de aplicaciones}

Al referir el término "integración de aplicaciones" surge naturalmente la noción de EAI o Enterprise Application Integration 5 .

Enterprise Application Integration emergió como una iniciativa de la industria de la computación con el advenimiento del año 2000 y la caducidad de muchos viejos sistemas no compatibles Y2K.

La era Y2K provocó una nueva iniciativa, con un fuerte foco en el uso de la tecnología para establecer relaciones de tipo productor-consumidor entre las organizaciones.

El objetivo de la EAI no es nuevo, comenzó ya con la distribución de datos desde los mainframes hacia los procesadores front-end, sin embargo, los datos atrapados entre distintas compañias y formatos tornaron dificil la tarea [21].

EAI se enfoca en el desarrollo de sistemas que proveen funcionalidad de negocios fluida donde la integración está en la capacidad de intercambiar y compartir datos sin saber dónde están ubicados y qué formato tienen.

Las siguientes dos definiciones obtenidas de [50] son las que mejor se adaptan a la idea de integración de aplicaciones que se quiere trasmitir:

"La integración fluida de procesos de negocio con el propósito de conducirlos electrónicamente"

"La integración es compartir y/o intercambiar datos entre los sistemas con el propósito de proveer una interfaz unificada"

La integración de aplicaciones presenta una evolución descripta parcialmente en el Capítulo 3 cuando se menciona la evolución desde los objetos distribuidos hacia los servicios. Allí se menciona la integración punto a punto como una de las primeras aproximaciones donde (existe) la misma se encontraba embebida en el código con serias dificultades para su modificación y gestión y haciendo imposible su administración y monitoreo.

Esto provocó enormes frustraciones tanto en las áreas de IT como de negocios de las organizaciones y comenzó a esbozar las definiciones de EAI enunciadas más arriba.

Surge así la EAI tradicional como primera alternativa que dará lugar a los modelos basados en workflow y más tarde al uso de modelos de procesos que utilizan servicios dentro de una SOA.

\section{EAI tradicional}

Este modelo se basa en la construcción de un nodo central y un conjunto de repetidores directamente asociados a éste, aunque los repetidores no se encuentran conectados entre sí. De esta manera, el middleware está representado por la integración centralizada de aplicaciones, y las aplicaciones que deben ser integradas son reflejadas por los repetidores. Las mismas interactúan entre ellas por medio de la integración centralizada de aplicaciones [6].

Las aplicaciones pueden interactuar de formas muy diversas, desde invocaciones simples hasta interacciones complejas entre múltiples aplicaciones. Estas últimas consisten en una serie de actividades representadas por una invocación a una aplicación, además de existir restricciones de ejecución entre las mismas. Este esquema de agentes y mensajes tiene ciertos inconvenientes. El primero de ellos es que el agente contiene cierta lógica, oculta en las reglas. La programación de éstas puede volverse una labor compleja debido a las dependencias que pueden darse entre las mismas, y el hecho de cambiar una regla puede tener implicancias en el comportamiento global del sistema.

\footnotetext{
${ }^{5}$ Uso de software y sistemas informáticos para integrar un conjunto de aplicaciones en una organización.(Wikipedia)
} 
La razón principal de estos problemas es la "pérdida" conceptual que se da en la integración de aplicaciones, ya que la integración de datos y de procesos requiere gran actividad de programación y configuración de bajo nivel, tanto de adaptadores como de los agentes de mensajes.

La integración de datos suele darse mediante actividades de mapeo, lo cual requiere un modelo de datos acordado entre todas las aplicaciones y que reside en los agentes. Este modelo global suele no ser explícitamente desarrollado, pero es común encontrarlo oculto en las reglas de mapeo de datos efectuadas por los adaptadores.

\section{Sistemas de Workflow y la integración de aplicaciones}

El término workflow consiste en la automatización de un proceso de negocio, en su totalidad o en parte, en el cual se intercambian documentos, información o tareas de un participante a otro, para provocar la acción de acuerdo a un conjunto de reglas procedimentales [6].

Un sistema de manejo de workflow es un sistema que permite definir, crear y manejar la ejecución de flujos de trabajo a través del uso de software, que corre en uno o más motores, y que es capaz de de interpretar la definición del proceso, interactuar con los participantes del workflow y, donde sea requerido, invocar el uso de herramientas y aplicaciones IT.

La integración de aplicaciones es efectuada por el sistema de manejo de workflow, usando adaptadores similares a los que se usan en un ambiente tradicional de aplicaciones empresariales.

La tecnología de workflow es capaz de soportar procesos de negocio dentro de un sistema dado o dentro de un conjunto de aplicaciones, lo que permite efectivamente integrar estos sistemas. Sin embargo esta tecnología posibilita también representar procesos en los que hay seres humanos activamente involucrados, y así mejorar la colaboración entre los trabajadores con conocimiento.

La tecnología de manejo de workflow puede ser utilizada para facilitar la modificación de la lógica del proceso realizado por aplicaciones. Las funciones de una aplicación son pasos en el workflow, y cada componente usa un modelo de workflow para representar las funciones. Por la modificación de la lógica del proceso especificada en los modelos de workflow, se puede modificar el comportamiento de las aplicaciones sin codificar.

Hoy en dia, la mayor cantidad de aplicaciones empresariales, como las aplicaciones de planeamiento, poseen un componente workflow que facilita la adaptación flexible de los procesos de negocio dentro de estos sistemas. Observar que usamos el término "componente de workflow" además de "sistema de manejo de workflow", debido a que un componente no es un sistema aislado sino que está embebido en la aplicación.

Podemos concluir que una aplicación de workflow única consiste de actividades y su correspondiente ordenamiento causal y temporal, donde las mismas son realizadas por un sistema común (tal como se muestra en la Figura 4.2 [6]). Los workflow de aplicación múltiple contienen actividades que son realizadas por sistemas de múltiples aplicaciones, proveyendo así una integración de las mismas (tal como se muestra en la Figura 4.3 [6].) 


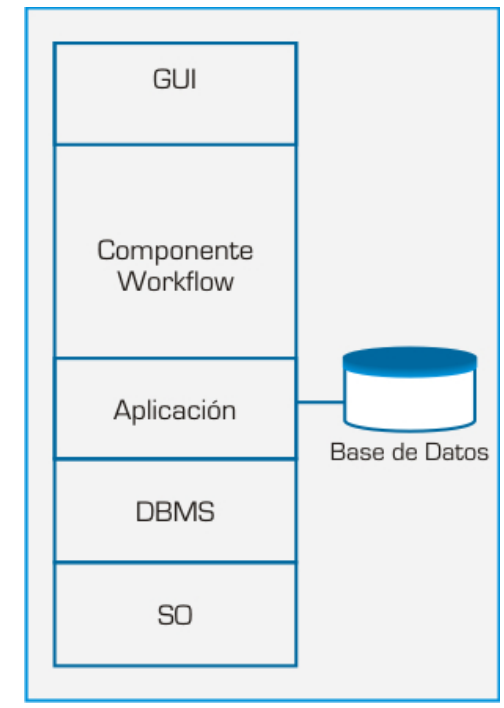

Figura 4.2. Componente Workflow de aplicación simple

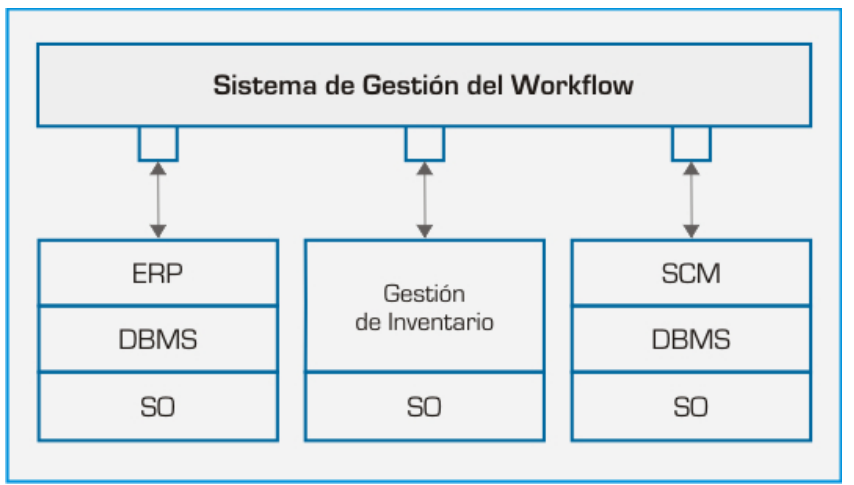

Figura 4.3. Componente Workflow de aplicación múltiple.

\section{Integración basada en SOA con BPM}

El software de workflow utilizado para integrar aplicaciones, puede cubrir cuatro aspectos:

1. Ser un componente de aplicaciones verticales. Un software de workflow es ágil a la hora de adaptarse a los cambios de procesos y cambios organizacionales. Esta es una realidad en muchas aplicaciones verticales.

2. Son adecuados para utilizar como APIs. Esto es así si cuenta con soporte para Java que permite integrarse tanto para aplicaciones Web como para otras aplicaciones de IT.

3. Constituye el elemento unificador para aplicaciones colaborativas, tanto desde el punto de vista de aplicaciones que se construyen como composición de otras bajo la filosofia de Web Services, como del de la automatización de procesos basados en reglas.

4. Se ajustan a la implementación de Web Services.

Pero en una aplicación donde el proceso de negocio sea realmente un conjunto de tareas cuyos participantes son Servicios Web, provoca inevitablemente un 
desorden dentro del workflow y surge la necesidad de interoperar y describir procesos ejecutables.

La interoperabilidad se logra a través de la adopción de estándares como XML y WSDL, mientras que la descripción de procesos ejecutables se puede llevar a cabo a través de BPEL [21] [28].

Los desarrollos en arquitectura de software empresarial y en BPM están relacionados con el manejo de workflow. El logro principal que se busca alcanzar aquí es la representación explícita de las estructuras de los procesos a través de modelos, y la representación controlada de los procesos basada en los modelos creados con anterioridad [6].

Para la realización de aplicaciones de composición en un ambiente de orientación a servicios, se utilizan técnicas de composición de servicios.

El middleware de integración de aplicaciones en general, y el middleware de bus de servicios empresariales en particular, proveen una base técnica aceptable para realizar composición de servicios, debido a que proveen interfaces estándar que pueden ser utilizadas en desarrollos de composición. El middleware típico para la integración de aplicaciones empresariales presenta un componente de workflow de sistema, que puede o bien usar un código propietario o bien usar código BPEL (Lenguaje de ejecución de procesos de negocio para Web Services).

La composición de servicios es una idea de especial interés para el desarrollo de nuevas aplicaciones, basándose en funcionalidad ya existente. Así, la composición describe la forma en que se relacionan los distintos servicios, es decir que se están describiendo estructuras de proceso. Como resultado, una composición posee un conjunto de servicios, cada uno de los cuales realiza una actividad.

La Figura 4.4 muestra la analogía entre aplicaciones tradicionales, que conllevan un mecanismo de integración tradicional, con las aplicaciones basadas en servicios [29] [30].

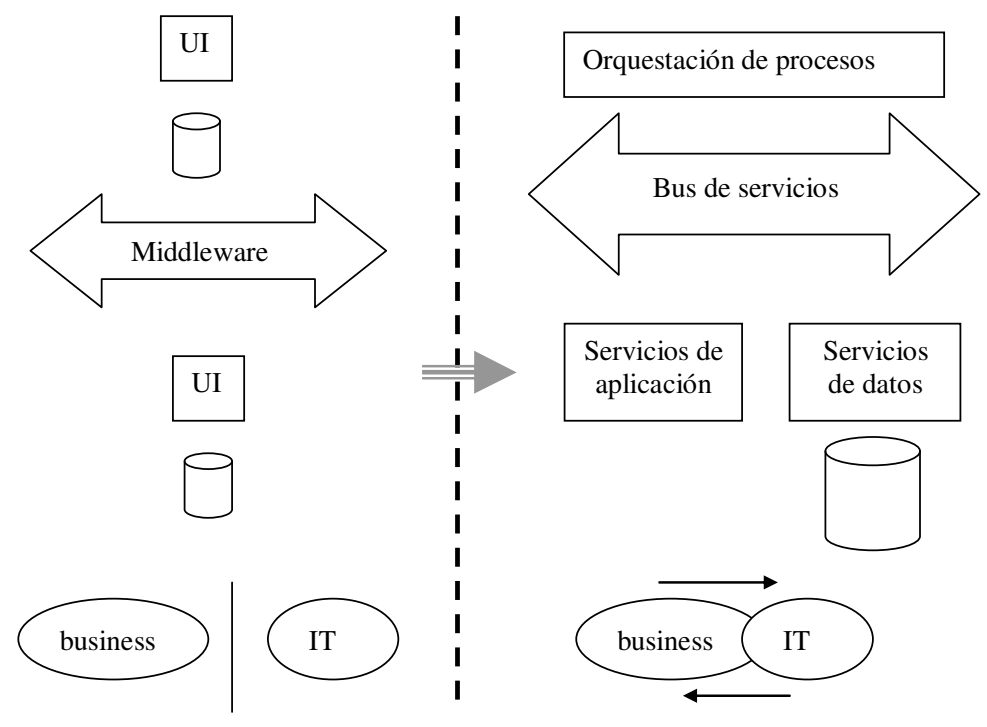

Figura 4.4. SOA alinea negocios con IT, llevando las aplicaciones tradicionales hacia las que usan servicios

BPM como la nueva metodología para satisfacer los objetivos de una organización a través de la gestión de procesos de negocio, no plantea una visión completamente renovadora y de empezar de cero, sino que es necesario contemplar todo el trabajo realizado con anterioridad dentro de la empresa, de manera de apuntar a la integración. Aquí es donde se insertan los conceptos de 
SOA, Web Services y BPEL, de manera tal de lograr construir una aplicación real, integrada e insertada en un entorno B2B, y por sobre todo, orientada a procesos.

\subsection{Elementos de un modelo de integración}

El modelo de integración tiene por objetivo lograr una integración completa, segura y confiable de un conjunto de sistemas de software existentes, maximizando la reutilización de código, manteniendo un bajo acoplamiento y favoreciendo el mantenimiento ágil y a bajo costo.

Los elementos de este modelo de integración llevan a analizar los tipos de integración posible, los métodos aplicados para llevar a cabo la integración, los componentes de infraestructura requerida y los actores que participan. Este análisis realizado tiene por finalidad aportar criterios a la hora de decidir cuáles de todos los elementos se elegirán para componer un modelo de integración.

\section{Tipos de integración}

Si bien existen diversas taxonomías acerca de los posibles tipos de integración existentes [21], los más frecuentes, teniendo en cuenta el enfoque que se abordará, se refieren a la integración desde dos aspectos posibles:

- Integración a nivel de datos: se enfoca en el movimiento de datos entre aplicaciones con el objetivo de compartirlos. Es una integración relativamente simple si se comparten formatos y estructuras, de lo contrario se establecen protocolos o acuerdos entre las partes para poder realizar la integración. (Ejemplo: integración por XML)

- Integración a nivel de aplicaciones: se basa fundamentalmente en compartir funcionalidad. Es una integración basada en APIs que exponen su funcionalidad a través del uso de interfaces que serán tanto más portables dependiendo del lenguaje utilizado para definirse. (Ej: IDL de CORBA o WSDL de los Web Services)

Tanto desde el punto de vista de los datos como de las aplicaciones, el modelo de integrabilidad aborda cualquiera de estos tipos de integración con la visión de los mismos como servicios coordinados por procesos.

La integración de datos dirigida por procesos [17] ayuda a enriquecer los servicios de negocios SOA y los procesos BPM a través de una secuencia de servicios de datos combinados de manera reusable que incorpora la intervención de tareas humanas transformando la información en exacta, consistente y oportuna.

La integración de aplicaciones tiene por objetivo entender y usar las interfaces para acceder a la funcionalidad requerida y enmascarar u ocultar las diferencias tecnológicas usadas por cada interfaz en su acceso. Esto último se lleva a cabo con servicios que exponen sus interfaces [21].

La idea subyacente es que los procesos de integración se encuentren separados de los procesos de negocio en sí mismos. Esto requiere examinar los sistemas existentes, extraer datos y procesos y obtener una manera de meta-anotación que permita crear una definición centralizada del elemento de negocio.

\section{Escenarios de integración dirigida por procesos}

Entre las particularidades que presenta un escenario de integración dirigido por procesos podemos encontrar: mantenimiento de la integridad transaccional, manejo de tareas de larga duración o múltiples pasos, colaboración entre las personas y las actividades de integración y el soporte para integración de datos analitica.

- Manejo del rechazo o datos inválidos, para mantener la integridad transaccional. Los procesos o aplicaciones deben tener en cuenta cómo 
responden los procesos de integración de datos ante entradas erróneas o respuestas recibidas fuera de tiempo. Sin duda el manejo de excepciones consume cerca del $80 \%$ del tiempo en la construcción de los procesos de negocios.

- Manejo de tareas de integración de datos de larga duración y múltiples pasos. La integración no puede hacerse en un único paso y necesita ser modelada como un workflow orquestado.

- Promover mejor colaboración entre las personas y las actividades de integración de datos. La integración de datos basada en procesos puede ayudar a coordinar esfuerzos a través de múltiples grupos. La orquestación junto con el workflow humano puede asistir con la revisión y aprobación de ciertos datos que caen bajo la responsabilidad de varias personas.

- Soporte para BI e integración de datos analítica. Cuando un KPI que se monitorea en una consola de BI atraviesa ciertos umbrales, se requiere la intervención de humanos que tomen acciones correctivas.

- Soporte para integración B2B.

\section{Método para la integración basada en servicios}

La orientación a servicios es una filosofía de diseño que hace que los recursos de IT estén disponibles sobre una red en forma independiente de su ubicación [29]. Existen dos maneras de introducir esta filosofia de orientación a servicios en una organización.

- Dirigida por procesos o top-down: capacidad de la organización de modelarse a si misma como proveedor de servicio. Incluye:

1. Identificar procesos de negocios y eventos

2. Reunir los requerimientos de negocios para cada proceso

3. Descomponer los procesos hasta un grado de detalle que los haga autocontenidos e independientes (servicios)

4. Coordinar la descomposición dentro de un flujo de procesos transversales a la organización

- Dirigida por aplicaciones bottom-up: sobre aplicaciones existentes, se detectan áreas de bajo acoplamiento y reusabilidad antes de desarrollar el "core" de servicios.

1. Identificar la funcionalidad dentro de las aplicaciones para ser publicados como servicio

2. Exponer y publicar los servicios

3. Orquestar los servicios expuestos de modo que logren alcanzar la funcionalidad de las aplicaciones existentes

4. Reevaluar la cartera de aplicaciones para eliminar redundancias Si bien el enfoque bottom-up pareciera ser el más apto en el modelo de integrabilidad que se está definiendo, cabe señalar que el enfoque top-down, también será aplicable por los analistas de negocios para identificar procesos y sus interdependencias explicitando el conocimiento implícito en cada uno de dichos procesos.

\section{Componentes de infraestructura para la integración}

Los componentes de la infraestructura son un conjunto de servicios agrupados según la funcionalidad que resuelven y que conforman la base sobre la que se construirá el modelo de integrabilidad.

Analizamos cada uno en detalle dando una idea de su implementación posible.

\section{- Comunicación}


La comunicación asegura a los desarrolladores un nivel de abstracción tal, que pueden independizarse de los detalles de bajo nivel asegurando que proveedor y consumidor de servicio puedan encontrarse.

Pueden utilizarse sistemas de comunicación asincrónicos basados en mensajería o bien sincrónicos vía un broker de objetos o bien un ESB.

Estos middleware usan protocolos estándar como SOAP (Simple Object Access Protocol), HTTP, TCP/IP, IIOP (Internet Inter-ORB Protocol) [21].

\section{- Ruteo y mediación}

El ruteo y mediación es un nivel que adapta el nivel de comunicación entre aplicaciones de tal modo que las mismas puedan interoperar [21]. Entre las responsabilidades que tiene este nivel está la de lograr que datos provenientes de distintas fuentes representen un concepto de negocio.

Este nivel utiliza metadatos para definir las aplicaciones participantes, los métodos, los mensajes, las interfaces y las secuencias de operación invocados.

\section{- Transformación}

La transformación de las estructuras de datos ha sido siempre un problema resuelto de manera puntual, escribiendo código ad-hoc que leía y transformaba al formato destino de manera puntual.

La aparición de los lenguajes de marcado y en particular el XML como estándar de facto para el intercambio de datos, otorgaron un mayor nivel de madurez a la transformación de los datos [21].

La transformación hoy puede considerarse como un servicio provisto por las máquinas de transformación basadas en XSLT (EXtensible Stylesheet Language for Transformations) que producen transformaciones independientes del lenguaje y la plataforma.

\section{- Coordinación/Orquestación}

En un enfoque dirigido por procesos es preciso sincronizar las actividades de integración definiendo formalmente los servicios que requieren los procesos y las aplicaciones, secuenciándolos en una orquestación.

En este sentido, una infraestructura de integración debe contar con algún mecanismo de coordinación inter-procesos o intra-procesos que ordene los pasos a seguir para conducir los servicios.

La orquestación ha evolucionado desde el enfoque manual al automatizado. En el primer caso, se reducía a código inyectado en las aplicaciones que resolvía integración punto a punto y que tenía embebida la lógica del workflow. Esto resultaba dificil de mantener y de modificar. El enfoque automático provee una mayor flexibilidad, desacoplando procesos de datos y produciendo un servicio de datos independiente que inicia una tarea de integración de datos de bajo nivel como parte del proceso de workflow.

Este último enfoque, el automático, es solamente posible si los servicios están construidos de modo adecuado como módulos autocontenidos sin las dependencias típicas de la programación procedural.

\section{- Transacción}

Uno de los principales aportes al definir una infraestructura de integración es la de proveer un mecanismo para llevar a cabo las operaciones de modo transaccional, esto es, la capacidad de invocar operaciones sobre diferentes sistemas soportando la semántica del modelo transaccional bajo las propiedades ACID (Atomicity, Consistency, Isolation, Durability) [21]. 
Estas propiedades garantizan la preservación de la consistencia del sistema, aíslan las operaciones entre sí, otorgan persistencia a los cambios y además son atómicas.

En [49] se presenta una solución al manejo transaccional de Web Services provista por WebSphere Process Server de IBM.

\section{- Seguridad}

Desde el punto de vista de la integración, la seguridad conlleva los mismos conceptos tradicionales: autorización, autenticación y auditoría. En este sentido, la infraestructura de la integración debe proporcionar los medios para limitar el acceso al sistema, hacerlo de una manera unificada y dejar rastros de dichos accesos.

\section{Actores que participan en la integración}

Los actores que participan en un modelo de integrabilidad tienen la finalidad de instanciar los componentes del modelo, elegir un tipo de integración posible, identificar el escenario y aplicar el método elegido.

Los actores pueden o no estar representados por seres humanos, pudiendo reemplazarse actores no humanos por humanos cuando la solución tecnológica del modelo de integración así lo requieran.

Los actores principales son:

- Analista de negocio: identifica los procesos, dentro del modelo de integración, que deben llevarse a cabo para alcanzar el objetivo de integrar sistemas de software en el marco un una visión de procesos de la organización. Eventualmente, modela los procesos en alguna herramienta de diseño basada en BPMN.

- Arquitecto del sistema: a partir de los procesos definidos por el analista, trabaja en conjunción con el área de tecnología de la información para identificar funcionalidades existentes y transformarlas en insumos para los procesos a cubrir. También refina los modelos realizados por el analista mejorando los detalles que se requieren para identificar componentes.

- Coordinador de servicios: este actor puede ser reemplazado por un software, en función de las herramientas utilizadas para realizar la integración e incluso puede ser un actor mixto (parte con participación humana y parte con participación automática). Su responsabilidad radica en aplicar los flujos y condiciones que deben cumplirse para que los servicios y componentes identificados por el arquitecto trabajen en forma coordinada (orquestada) para alcanzar el objetivo del negocio.

- Desarrollador de componentes y servicios: este actor se ocupa de codificar las interfaces necesarias y desarrollar los componentes o servicios que se requieran según lo han delineado los procesos identificados y descriptos dentro del modelo de integración.

Como se muestra en la figura 4.5, los actores del modelo de integración trabajan de manera colaborativa en cada nivel. Esta figura se apoya sobre los fundamentos para la integración con SOA planteada en [32] y se complementa con los actores que participan en ese modelo de integración.

Los Analistas de Negocios definen el modelo de procesos y sus instancias, en el contexto de la composición de servicios y transformaciones de datos.

Los Arquitectos del Sistema trabajan sobre los servicios a nivel de composición y luego articulan con el Desarrollador de Componentes al momento de realizar la orquestación BPEL y definir el transporte y publicación de los servicios. 
El Coordinador de Servicios realiza y da soporte al despliegue a nivel de Operación y Gestión y también trabaja junto al Desarrollador de Componentes a nivel de orquestación y transformación XML.

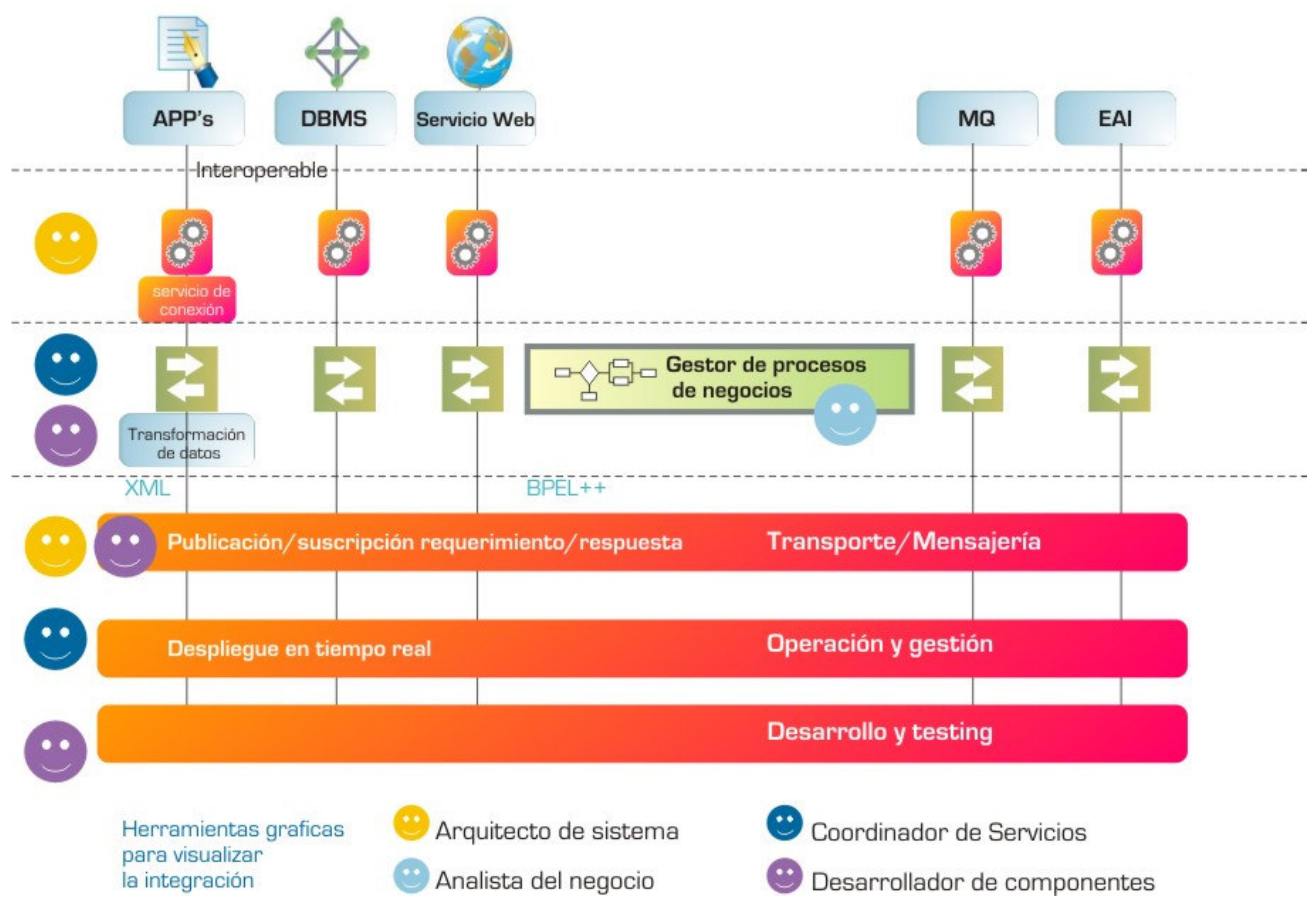

Figura 4.5. Escenario de un modelo de integración y sus actores

\subsection{Conclusiones}

En escenarios típicos de integración de aplicaciones, la funcionalidad de los sistemas de integración está organizada en forma de un proceso. Este proceso consiste en la ejecución de un conjunto de actividades con restricciones de ejecución, apuntando a la obtención de un objetivo. En estos escenarios la representación de los procesos está embebida en las reglas que los agentes manejan, y parece ser más apropiado alcanzar una representación explícita del mismo.

La integración por línea de base siempre es posible, pero hacer una verdadera integración significa reconocer que la orquestación de servicios y la gestión de procesos de negocios no son lo mismo y que usar adaptadores para integrar a modo de APIs directamente desde el modelo de procesos, es diferente a usar servicios de negocios gestionados por tecnología SOA, como lo es un bus de servicios o la registración de servicios. También significa reconocer que la tarea humana juega un importante rol en muchos procesos de negocios y que cualquier plataforma de BPM debe incluir soporte para workflow e interacción humana.

En este capítulo hemos analizado y descripto los elementos principales que componen un modelo de integración posible con enfoque a procesos y a servicios.

Sin embargo, el desarrollo de aplicaciones con este enfoque comparte la mayoria de los conceptos vertidos en este modelo de integración, pero aplicado a la definición, especificación, desarrollo, puesta en marcha y seguimiento de proyectos, cuyo objetivo es modelar una organización en términos de los procesos que ejecuta. 
Un modelo con enfoque a procesos y a servicios cuenta con el valor agregado de que sus conceptos se pueden utilizar para el desarrollo de soluciones computacionales nuevas o bien como mecanismos de integración de aplicaciones existentes, además de permitir capturar el conocimiento subyacente en la manera en que se ejecutan los procesos de negocio.

Según se afirma en [34], de acuerdo a investigaciones de Gartner, la integración de aplicaciones representa un 35\% del costo total en diseño, desarrollo y mantenimiento de software en una organización típica, sea esta grande, mediana o pequeña. Por lo tanto, el aspecto crucial ya no es si se debe integrar sino directamente cómo hacerlo.

En este sentido y a la luz de lo expuesto en este capítulo, resulta natural pensar en un marco metodológico que aborde problemas con un enfoque de SOA y BPM. En el próximo capítulo se presenta dicho marco metodológico, que propone dar respuesta al "cómo" tomando como premisa que la construcción de aplicaciones integradas y con un alto grado de reusabilidad, está fuera de discusión. 


\section{Marco Metodológico con SOA y BPM}

En este capítulo se presenta el modelo propuesto para abordar la solución de problemas con una visión integradora de procesos y servicios, a través de la definición de un marco metodológico.

Un marco metodológico debe proveer un conjunto de etapas y sus actividades, que acompañen el ciclo de vida de los procesos y el ciclo de vida del software con miras a reducir la brecha entre la conceptualización del problema (en las etapas iniciales del ciclo de vida) y la pieza de software que resuelve dicho problema.

Para definir este marco metodológico se deben tener presentes dos puntos que pueden resultar diferentes: por un lado, el carácter ortogonal de los servicios respecto de los procesos y viceversa; por el otro, la convivencia de un modelo de ciclo de vida iterativo con uno en cascada, correspondientes a la gestión de procesos de negocio y los servicios respectivamente, que comparten caracteristicas comunes.

La noción de ortogonalidad de los procesos respecto de los servicios se fundamenta en el hecho de que los procesos atraviesan las áreas funcionales de la organización y alcanzan el objetivo para el que fueron definidos, como una coordinación de las funcionalidades que cada área resuelve.

Los servicios, por su parte, son elementos que se comprenden por la utilidad que brindan $\mathrm{y}$, por lo tanto, no pueden apartarse del problema que resuelven. Los servicios resuelven funcionalidades concretas de cada unidad funcional y, como se mencionó en el Capítulo 2, cuando esta coordinación se realiza dentro de una misma organización, se habla de orquestación y cuando trasciende la organización para integrarse con otra, estamos en presencia de coreografia.

La Figura 5.1 presenta un ejemplo donde se muestra la ortogonalidad de los procesos respecto de los servicios dentro de una organización.

Servicios

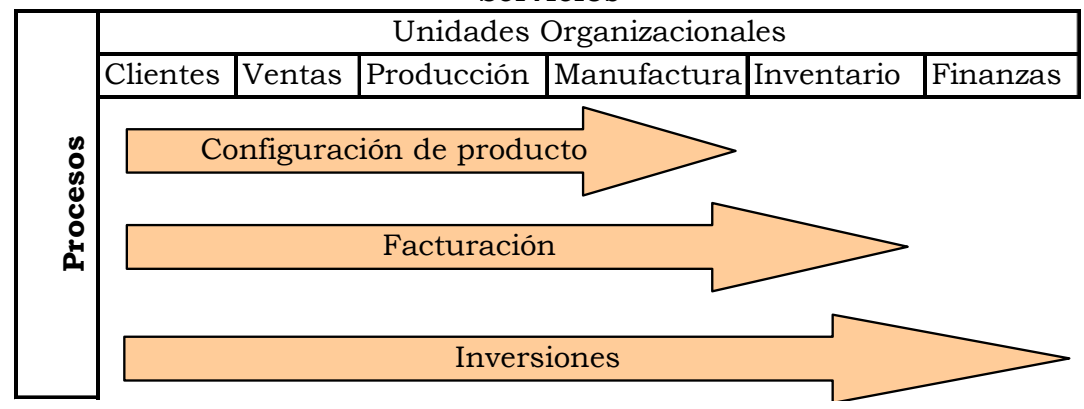

Figura 5.1. Ortogonalidad de procesos y servicios

El ciclo de vida de los procesos de negocio se caracteriza porque cada etapa es recorrida en forma cíclica, sin tener un orden temporal, aunque sí un orden lógico. Este ciclo puede recorrerse entrando en cualquier fase, pero una vez dentro del ciclo, se debe continuar con la próxima etapa, sin contar necesariamente con una condición de finalización. Es muy similar a un ciclo de vida en espiral.

Por otro lado, el ciclo de vida de los servicios como el del software, en general tiende a tener un comportamiento en cascada. Si bien las nuevas metodologías de desarrollo de software, incluso ágiles, han marcado una evolución en la manera de construir software, su resistencia a la absorción de cambios sigue 


\section{Marco Metodológico con SOA y BPM}

siendo una característica. Sin ir más lejos, es difícil entrar al ciclo en cualquier etapa por la sencilla razón de que dicho ciclo no está girando en forma permanente.

\subsection{Marco metodológico: etapas y su interacción}

Esta propuesta metodológica pone el foco en la definición de un conjunto de etapas y la determinación de su alcance, la forma de interacción de las mismas y su aplicación a la resolución de problemas en términos de procesos y servicios.

Es una propuesta que aborda el proyecto en su conjunto, trascendiendo los aspectos tecnológicos y aportando una visión diferente para resolver los problemas a la luz de la identificación transversal de procesos de negocio. Estos procesos de negocio se transforman en consumidores de servicios que pueden tener o no una implementación tecnológica.

El objetivo es comprender a la organización en su conjunto y establecer claramente una serie de fases que ordenen las actividades a llevar a cabo de manera permanente, para alcanzar el propósito de contar con un ciclo de mejora continua de procesos, capaces de absorber los cambios que propone la realidad.

Se describen a continuación las etapas propuestas, las actividades que abarcan y el alcance de las mismas para el desarrollo de proyectos con enfoque en los procesos de negocio.

1. Etapa de Organización y Plan Estratégico. Esta etapa cubre toda la vida del proyecto $\mathrm{y}$, al igual que la última de las etapas, tiene un comportamiento "envolvente" en el sentido de que está siempre presente en cada una de las etapas sucesivas que se describen a continuación.

2. Etapa de Identificación y Especificación de Requisitos. Esta etapa incluye el análisis de requisitos como una actividad muy importante en el desarrollo de todo el ciclo de vida del software que siempre ha sido parcialmente considerada en muchas metodologías. Se incluye en esta propuesta una metodología basada en al idea del Diseño Participativo de Procesos, extraído de [12].

3. Etapa de Modelado del Negocio. En esta etapa se identifican los procesos de negocio y sus principales restricciones. Los procesos de negocio se describen como un conjunto de tareas en el que los actores participan según un flujo de trabajo determinado. Estos procesos pueden organizarse en forma jerárquica hasta con dos o tres niveles de anidamiento. Se representa cada proceso del negocio como un caso de uso del negocio, que inicialmente será descripto en forma textual. Para tener una visión general de los diferentes procesos de negocio de la organización, puede construirse un diagrama de casos de uso del negocio, en el cual aparece cada proceso del negocio como un caso de uso [9]. Este diagrama permite mostrar los límites y el entorno de la organización bajo estudio y obtener un mapa de proceso.

4. Etapa de Modelado de Procesos. En esta etapa se modela cada uno de los procesos identificados y detallados en los casos de uso del negocio mediante BPMN [7][8], obteniendo un diagrama del proceso de negocio. Acompañando a este modelo de procesos se aplican restricciones y objetos de información que quedan incompletamente detallados en el BPD (Business Process Diagram), por lo tanto resulta conveniente que se expliciten mediante un formulario genérico que acompañe el BPD.

Este formulario incluirá al menos los siguientes puntos:

- Formulario para los objetos de información: nombre del objeto de información, atributos, restricciones y clase del dominio que lo representa.

- Formulario para las actividades: nombre de la actividad, origen (actividad que la origina), agente involucrado, pre-condiciones, post-condiciones, caso de uso del sistema que lo representa. 
5. Etapa de Modelado de Servicios. Definición de servicios, especificación de los mismos y su categoría. En esta etapa se incluye la investigación de servicios existentes.

Esta fase es el siguiente paso de refinamiento en el modelado de procesos. Los elementos de diseño que la guían están dados por la utilización de la metodología basada en la notación de círculos con cordones de Erl en [3], junto con la disciplina de diseño propuesta por Delgado en [1].

Lo más importante de esta etapa está dado por la definición del grado de granularidad de la pieza diseñada como para que se pueda considerar un servicio, con autonomía y atomicidad.

6. Etapa de Definición de los Componentes. Define componentes de software en términos de los servicios identificados y su modo de interacción (orquestación). Un componente es una pieza de software lo suficientemente pequeña para crear y mantener, lo suficientemente grande para distribución y soporte y con interfaces estándar para interoperabilidad. Claramente los Web Services y su modo de orquestación en una arquitectura SOA pueden ser una solución tecnológicamente válida en esta etapa [4] [5].

7. Etapa de Implementación de los Componentes. En esta etapa se lleva a cabo el despliegue, en la plataforma elegida, del resultado de las etapas anteriores. En ella no pueden faltar el desarrollo de prototipos, la retroalimentación con los actores de las etapas anteriores, la integración con los sistemas existentes y los aspectos no funcionales como robustez y rendimiento.

8. Etapa de Administración y Seguimiento. Esta etapa se vincula con las etapas de promulgación y administración del ciclo de vida de los procesos de negocio. Los productos obtenidos serán tanto más fáciles de construir cuanto más apropiada sea la solución tecnológica adoptada. Los BPMS o bien los sistemas de gestión de workflow, proveen las salidas pertinentes para poder realizar una adecuada lectura de indicadores.

En la figura 5.2, se muestran las etapas ubicadas de manera superpuesta sobre las fases de los ciclos de vida de los procesos y del software. La figura 5.3, muestra el modo de interacción de dichas etapas. Se graficaron de manera independiente para facilitar su visualización, pero consideraremos su descripción de manera conjunta.

En la figura 5.2, las etapas de Organización y Plan Estratégico, así como la de Administración y Seguimiento, engloban a las etapas internas marcando una presencia permanente a lo largo de todo el ciclo de vida, mientras que las flechas de la figura 5.3 señalan la interacción y retroalimentación entre ellas. En ambas figuras las lineas punteadas marcan el solapamiento entre las etapas clásicas del ciclo de vida del software y las de los procesos, respecto de las fases propuestas en esta metodología.

La etapa 2 (Identificación y Especificación de Requisitos) trasciende la etapa de Análisis y Diseño del ciclo de vida de los procesos, abarcando incluso toda la etapa de Configuración. Como se mencionó, la etapa de Configuración cubre aspectos más bien tecnológicos, pero sin embargo se propone continuar aplicando las actividades propias de la etapa 2 a la hora de elegir herramientas y realizar consideraciones que se vinculen a la integración de sistemas de software existente.

Como también se observa en la figura 5.2, la etapa 3 (Modelado del Negocio) posee un alcance casi totalmente delimitado a las etapas de Análisis y Diseño del ciclo de vida de los procesos, como así también la etapa 4 (Modelado de Procesos) abarca la de Configuración tomando parte de la etapa de Promulgación, sobre todo en lo que respecta al despliegue de los procesos modelados en un BPMS. 


\begin{tabular}{|c|c|c|}
\hline \multicolumn{3}{|c|}{ Ciclo de Vida del Software } \\
\hline Identificación & Especificación & Despliegue \\
\hline
\end{tabular}
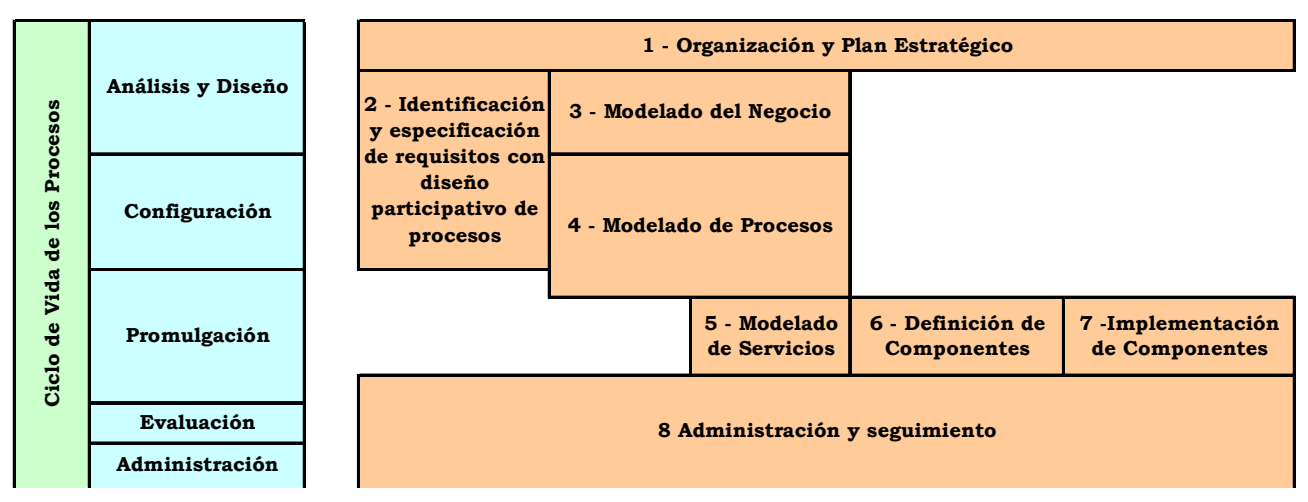

Figura 5.2. Marco metodológico propuesto: etapas superpuestas en cada ciclo de vida

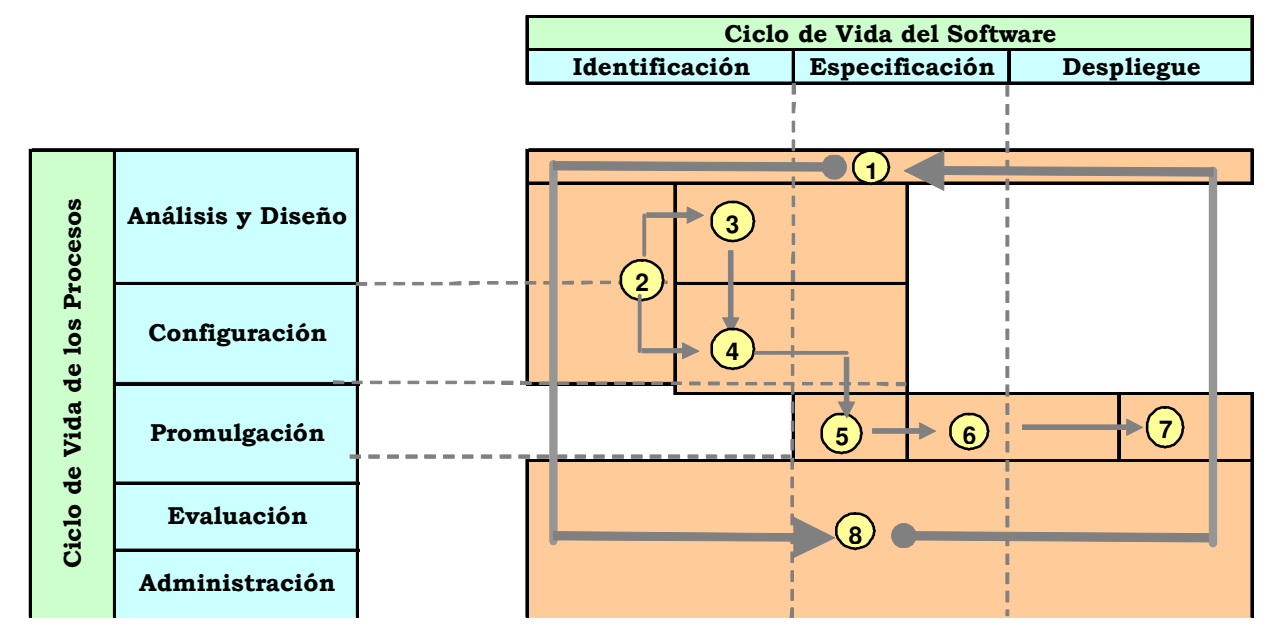

Figura 5.3. Marco metodológico propuesto: interacción de etapas

En las próximas secciones se detallan cada una de las etapas del marco metodológico propuesto y se describe la metodologia utilizada para llevar a cabo cada una de ellas.

\subsection{Etapa de organización y plan estratégico}

Como se mencionó anteriormente, esta etapa alcanza todas las etapas del marco metodológico propuesto. Si bien es la etapa con la cual se inicia el abordaje del problema, contiene actividades que continuarán siendo desarrolladas durante todo el ciclo de vida del proyecto.

El fin principal de esta etapa es delinear el perfil de la solución y fijar objetivos y estrategias claras que serán conservadas a lo largo de todo el proyecto.

En esta etapa juega un rol muy importante el liderazgo ya que debe abordar la resistencia cultural de todos los involucrados, desde la conducción de la organización hasta los usuarios finales que desempeñan su actividad diaria dentro de cada área funcional. El líder realiza una tarea de "evangelización" resaltando el valor de la actividad que se desarrolla en cada área y muestra la capacidad de la misma de reutilizarse para resolver varios problemas de negocio. 


\section{Marco Metodológico con SOA y BPM}

Esto fomenta la colaboración y reduce la tendencia a apropiarse de las actividades, encerrándolas en compartimientos estancos.

La organización del proyecto debe incluir los objetivos, una consideración de alternativas, el análisis financiero, un plan de proyecto y una revisión de los riesgos asumidos.

El plan estratégico, por su parte, es un documento evolutivo que irá cambiando en la medida en que se incorporen procesos al proyecto. Este documento otorga una visión arquitectónica del diseño y también incluye consideraciones de riesgo, seguridad y gestión de los procesos involucrados.

Es un documento esencial para la socialización de los procesos a través de toda la organización y para crear un vocabulario organizacional común.

Cumplida la etapa de organización y plan estratégico del proyecto, comienza la etapa de modelado que en nuestra propuesta se divide en dos etapas: la identificación y especificación de requisitos y el modelado del negocio propiamente dicho. Si bien como se menciona en [35] el modelado de procesos de negocios forma parte de la mayoría de las aproximaciones de ingenieria de requisitos basadas en modelado organizacional, nuestra propuesta incluye una etapa previa al modelado de los procesos de negocio que denominamos "modelado del negocio" y cuya finalidad es aplicar técnicas particulares en cada etapa y llevar adelante un esquema round-trip (ida y vuelta) que permita desmenuzar las necesidades y modelar un contexto global por refinamientos sucesivos.

En las próximas dos secciones se describen las etapas mencionadas junto con la metodologia propuesta para llevarlas a cabo.

\subsection{Etapa de identificación y especificación de requisitos}

La etapa de identificación y especificación de requisitos constituye una pieza muy importante en el desarrollo de un proyecto con enfoque en los procesos y los servicios. Como se mencionó anteriormente este enfoque tiende a reducir la brecha existente entre el área de tecnología y el área del negocio procurando obtener la mejor parte de cada uno de ellos.

La inclusión temprana de estos conceptos en las etapas de desarrollo de un proyecto asegura una intervención completa de cada uno de los actores. Según Giorgetti en [12], "...en todo proyecto exitoso, lo técnico y lo humano se articulan y adaptan, por prueba y error, en un proceso de aproximaciones sucesivas basado en el apoyo de la conducción y en el aprendizaje de los protagonistas.". No se trata entonces de un proceso lineal simple, sino de etapas simultáneas de análisis y aprendizaje, acompañadas de articulación y evaluación.

Es habitual encontrar como etapa dentro del ciclo de vida del software a la especificación de requisitos, perdiendo de vista que para especificar un requisito (sea este funcional o no funcional), es preciso primero identificarlo como tal.

En este sentido, el diseño participativo de procesos planteado en [12], resulta un enfoque muy apropiado para ayudar a esta tarea de identificación. La especificación, luego, podrá ser realizada mediante la simple redacción de un documento, la utilización de mecanismos de especificación basados en los casos de uso de UML, o utilizando un enfoque orientado a aspectos como se plantea en [16].

La base conceptual del diseño participativo de procesos se puede resumir en la siguiente idea [12]: "Muestra una metodología de intervención que asegura "lograr cambios con sentido", mutando el rol de las personas involucradas de meros espectadores al de generadores y conductores del cambio, que mediante la exclusiva exposición de las necesidades de los clientes y utilizando, sin exponer, el conocimiento distribuido de los involucrados, logra que los nuevos procesos surjan como una consecuencia natural, sin siquiera pensar en procesos." 


\section{Marco Metodológico con SOA y BPM}

El origen del problema que plantea un cambio en el enfoque para identificar y especificar requisitos, está dado por el enfoque funcional con que muchas organizaciones desarrollan su actividad. En el Capitulo 1 se enunciaron las particularidades de la concepción de una organización orientada a funciones, contra una orientada a procesos.

Es suficiente observar el organigrama tradicional de muchas organizaciones para advertir que se fundamenta en al idea de la jerarquía y la división del trabajo. Este esquema no tiene inconvenientes per-se siempre que no se pierda de vista al proceso en sí mismo.

La identificación de los procesos es la actividad que pone de manifiesto "cómo" se alcanzan los objetivos de la organización, siendo sus áreas funcionales el apoyo para poder sustentar el flujo de dichos procesos.

Se trata entonces de encontrar una metodologia para identificar y especificar requisitos con una marcada tendencia al enfoque orientado a procesos, diluyendo las fronteras funcionales y comprometiendo a todos los actores en esta tarea.

La metodología planteada por [12] para el diseño participativo de procesos será tomada como método para llevar a cabo la identificación y especificación de requisitos en el marco metodológico que se propone en este trabajo.

Esta metodología parte de la identificación del proceso a desarrollar, la delimitación de sus alcances y la estructura de roles que lo desarrollan. En nuestro caso, estas actividades fueron resueltas en la etapa 1 (Organización y Plan Estratégico) y tienen un alcance organizacional.

La metodología introduce el rol de facilitador, que coordinará las reuniones de trabajo, los propósitos de trabajo y las reglas de juego.

El facilitador le solicitará a cada participante que dibuje a mano alzada un diagrama que muestre las interrelaciones con el resto de los participantes en una relación persona/persona. Se realiza esta actividad sobre una hoja grande de papel, en silencio y alentando a los participantes a que anoten todos sus intercambios. Esta mecánica permite a todos expresarse libremente.

El resultado de esta actividad es lo que se denomina "Informe de Radiografia" porque muestra la situación actual del proceso bajo estudio. Transparenta las interacciones formales e informales entre las áreas internas e incluso con actores externos. Los desacuerdos entre interlocutores pueden marcarse en color rojo para reflejar las posibles inconsistencias.

El próximo paso es comenzar a desenredar la "maraña" tendiendo a acercar las áreas involucradas para simplificar y agilizar el proceso.

Como vemos, es una metodología altamente colaborativa donde la definición de las necesidades con la participación de los usuarios clave y los expertos del sistema, coordinados por un facilitador, hace innecesario el exceso de consideraciones y comparaciones con los procesos actuales. La clave será la concurrencia de todos los participantes en cada proceso y su intervención activa [12].

Pero en esta metodología no solamente tiene lugar la participación activa de los involucrados sino que aporta algo más: la idea de identificar las necesidades desde quien las tiene, sin pensar en el proceso. Partiendo de las necesidades y sumando las mismas con los aportes de cada participante, se obtiene el proceso. Este esquema se denomina "trazabilidad" de las necesidades. Si conocemos las necesidades y el objetivo del proceso está claramente definido por todas sus piezas, entonces al desarmarlo surgirá todo lo necesario para construirlo.

En [12] se presenta la aplicación de esta metodología con una herramienta informática donde se vuelca el resultado de las reuniones participativas (dibujo de la "maraña") y se obtiene el árbol de necesidades y el flujograma del proceso. 
En nuestro caso sólo utilizaremos la idea de diseño participativo como método para favorecer la intervención de los actores principales de la etapa de identificación de requisitos, para su especificación con un enfoque orientado a procesos y servicios. Consideramos que esta metodología refleja muy bien la idea de considerar los procesos como suma de funcionalidades, muchas de ellas existentes, que sólo deben ordenarse, documentarse y explicitarse.

La utilización de una herramienta de dibujo para capturar el conocimiento de los usuarios o expertos en el problema, aumenta la capacidad expresiva y aporta un documento con el cual se puede trabajar y refinar hasta llegar al modelo deseado.

Por último, este proceso de identificación de necesidades permite una construcción bottom-up del proceso, obteniendo fácilmente la traza de ejecución del mismo para ser volcada en una notación tipo BPMN y obtener el diagrama del proceso.

Para graficar lo expuesto, se muestra la Figura 5.4 donde se visualiza el resultado al que se puede arribar partiendo de la "maraña" original y llegando a la red de trabajo rediseñada, tomado de un caso real de la referencia citada.

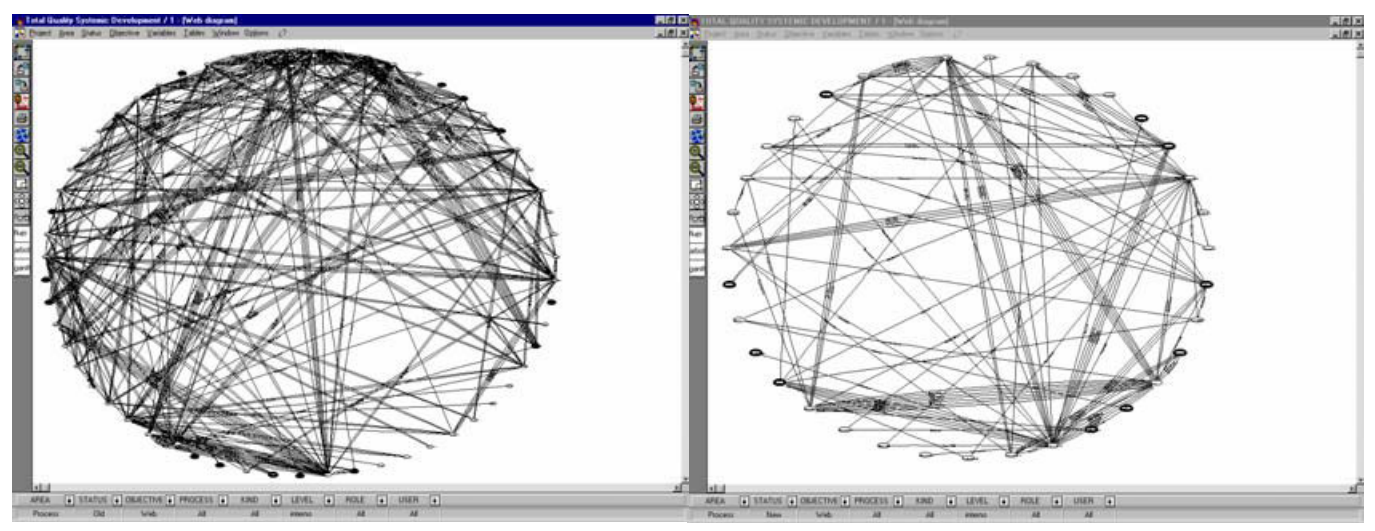

Figura 5.4. De la maraña original a la red de trabajo rediseñada

Esta metodología para identificación y especificación de requisitos explicita las actividades realizadas en la organización y quienes las llevan a cabo, propiciando el desarrollo de la próxima etapa de la metodología que consiste en el modelado del negocio, a partir de sus tareas y actores involucrados.

\subsection{Etapa de modelado del negocio}

La etapa del modelado del negocio consiste principalmente en la identificación de las principales actividades del negocio, los actores involucrados en las mismas y el contexto global en el cual se enmarca el negocio.

Esta etapa del marco metodológico que se plantea, fuerza a la organización a visualizar los procesos de negocios como un conjunto de componentes enlazados que contemplan los aspectos técnicos, estratégicos, operativos y organizativos.

El modelado del negocio permite construir el mapa de procesos a través de la definición del diagrama de procesos, la identificación de los roles y la definición de los casos de uso del negocio que aportan la funcionalidad que requiere el mapa de procesos.

Tal como se mencionó en el Capítulo 2, un mapa de procesos es una representación gráfica en términos del funcionamiento de la organización y describe como se articula el funcionamiento de la empresa para dar lugar al objetivo del negocio. 


\section{Marco Metodológico con SOA y BPM}

En sintonía con la idea utilizada en la etapa de identificación de requisitos a través del diseño participativo de procesos, para modelar el negocio es necesario que la organización identifique los componentes de negocio.

El propósito de un componente de negocio se define por el valor que provee a otros componentes y realiza un conjunto excluyente de actividades para llevar a cabo su cometido, proveyendo y recibiendo servicios de negocio.

Los componentes requieren recursos-personas, conocimiento y bienes tangibles que soporten sus actividades.

El modelado de procesos mediante identificación de componentes, requiere detallar las mismas como el conjunto de tareas o actividades que llevan a cabo, realizadas en determinadas condiciones y bajo un determinado rol. Existen tareas automáticas, manuales o mixtas y son la unidad indivisible en términos de modelado.

Los subprocesos agrupan tareas interrelacionadas que pueden ser realizadas por varios roles y constituyen un producto intermedio para el proceso.

Como se mencionó anteriormente, esta etapa debe producir un mapa de procesos acompañado de la descripción de los casos de uso y su respectivo diagrama para dar cuenta de la funcionalidad.

Para la construcción de los casos de uso y sus diagramas puede utilizarse cualquier herramienta que soporte este perfil de UML o bien valerse de formularios prediseñados para volcar dicha información.

En la Figura 5.5 se muestra un ejemplo de formulario de caso de uso para una actividad muy frecuente en dentro de cualquier proceso como lo es la de "Identificación de usuario".

\begin{tabular}{|l|l|}
\hline Proceso: Código-Descripción & Subproceso: Código - Descripción \\
\hline Actividad: Código-Descripción & $\begin{array}{l}\text { Caso de Uso: } 02 \text { - Identificar Usuarios del } \\
\text { Sistema }\end{array}$ \\
\hline Fecha de Emisión: $13 / 06 / 2008$ & Autor: Marpel \\
\hline Revisión: $1.1-13 / 06 / 2008$ & Revisado por: Marpel \\
\hline $\begin{array}{l}\text { Descripción: } \\
\text { Permite al usuario identificarse y obtener clave de acceso al Sistema. }\end{array}$ \\
\hline $\begin{array}{l}\text { Actores: } \\
\text { Usuario del sistema. }\end{array}$ \\
\hline $\begin{array}{l}\text { Precondiciones: } \\
\text { No aplica. }\end{array}$
\end{tabular}

Regla del Negocio:

La identificación del usuario y la clave no caducan.

El usuario no tendrá restricciones sobre la cantidad de trámites a ingresar.

\section{Flujo Normal:}

1. El Actor accede ingresando un nombre de usuario.

2. El Sistema comprueba que nombre de usuario no exista y requiere ingreso y confirmación de clave privada.

3. El Sistema verifica que la clave ingresada cumpla requisitos de generación de claves y asigna clave de acceso al solicitante.

4. El Sistema informa su clave al actor. 
Flujo Alternativo:

El sistema comprueba la validez de los datos, si los datos no son correctos, se avisa al actor de ello permitiéndole que los corrija o abandone la opción.

Poscondiciones:

Actor con usuario y clave de acceso al Sistema asignados.

Figura 5.5 Caso de uso "Identificación de usuario"

\subsection{Etapa de modelado de procesos}

A partir del mapa de procesos ya construido en etapas anteriores, las necesidades y requisitos identificadas y especificadas y los casos de uso del negocio descriptos en la etapa de modelado del negocio, se puede comenzar la etapa de modelado de procesos de negocio.

Si bien el modelado de los procesos de negocio constituye una de las piezas fundamentales para desarrollar soluciones con enfoque en los procesos de negocios, resulta insuficiente abordar solamente el aspecto funcional de tales procesos, debiendo completarse la perspectiva de los datos que circulan en los flujos. Más aún, desde la óptica de un enfoque basado también en servicios, es indudable que tales servicios conformarán componentes de software donde los datos deben no solamente ser modelados sino también persistidos e intercambiados entre servicios.

En este marco, se propone desarrollar esta etapa mediante un diagrama de procesos de negocio (BPD) que se obtiene utilizando BPMN, pero enriquecido con la documentación que aportan dos formularios: el de los casos de uso del sistema y el de descripción de los objetos de información.

A los efectos de formalizar y en cierta medida contar con alguna herramienta de software que ayude a documentar la etapa, definiremos los dos formularios anteriormente mencionados como diagramas de casos de uso del UML y diagramas de clase de UML respectivamente. En cuanto a los BPD pueden documentarse con cualquier herramienta de modelado que soporte BPMN. Existe una gran variedad de estas herramientas en cuanto al modelado concretamente, muchas de código abierto (la más popular es JBPM de JBoss, https://www.jboss.com/products/jbpm/), muchas otras propietarias que incluyen soporte completo para BPM (ver Tabla 5.14 de este capitulo), hasta las que pueden descargarse como freeware como es el caso de BizAgi Process Modeler (http://www.bizagi.com/) que será utilizada en el próximo capitulo para mostrar el caso de estudio.

Los diagramas de casos de uso documentarán lo que denominaremos "casos de uso del sistema" que constituyen un próximo nivel de refinamiento de los casos de uso del negocio construidos en la etapa anterior, por lo tanto se utilizará el mismo formulario de la figura 5.5.

El objetivo de la construcción de estos casos de uso es lograr una descomposición del proceso en un conjunto de tareas e identificar los objetos de información y/o documentos que circulan entre las tareas. La definición de roles y flujos que del caso de uso aportan documentación textual al BPD.

Por su parte, los diagramas de clase de UML describen y estructuran los objetos de información que fluyen entre las actividades de un proceso de negocio y representan datos del dominio. Estos datos del domino constituyen una buena base para crear el modelo de datos conceptual inicial. Este modelo incluirá las entidades y sus relaciones y se describirá mediante un diagrama de clases UML, en el que las entidades se representan mediante clases (clases del dominio). 


\section{Marco Metodológico con SOA y BPM}

Así, cada objeto de información del diagrama de proceso se convertirá en una clase del sistema informático. A partir de la especificación de un objeto de información obtendremos la definición de la entidad asociada, es decir, sus atributos, relaciones con otras clases y restricciones.

Para apoyar la construcción de estos diagramas de clase, se extiende el formulario para describir casos de uso y se incluye el diccionario de datos involucrado en el caso de uso. Este diccionario será el insumo principal en la construcción del diagrama de clases y permitirá conocer, en una etapa temprana, los atributos más importante de cada dato, además de garantizar su unicidad. La figura 5.6 muestra un ejemplo de formulario para documentar dicho diccionario de datos.

\begin{tabular}{|c|l|l|l|l|}
\hline Código & \multicolumn{1}{|c|}{ Descripción } & Tipo de Dato & \multicolumn{1}{c|}{ Dominio } & \multicolumn{1}{|c|}{ Validación } \\
\hline UsrName & $\begin{array}{l}\text { Nombre de usuario } \\
\text { del sistema }\end{array}$ & Alfanumérico & 8 caracteres. & $\begin{array}{l}\text { Comienza siempre } \\
\text { con letra y } \\
\text { minúscula }\end{array}$ \\
\hline UsrPass & $\begin{array}{l}\text { Clave de acceso al } \\
\text { sistema }\end{array}$ & Alfanumérico & 8 caracteres. & $\begin{array}{l}\text { Combinación } \\
\text { aleatoria de letras y } \\
\text { números no } \\
\text { consecutivos }\end{array}$ \\
\hline
\end{tabular}

Figura 5.6. Formulario para registrar el diccionario de datos

Por último los diagramas de procesos de negocio representan gráficamente las actividades de un determinado proceso, los actores que las desempeñan y el flujo de mensajes que intercambian las actividades.

Una vez obtenido el modelo de procesos se encuentra el terreno propicio para identificar los elementos (servicios) que realizarán los procesos de negocios, transformándose estos últimos en consumidores de dichos servicios.

\subsection{Etapa de modelado de servicios}

La idea de un servicio es identificar un ámbito bien definido de funcionalidad y hacerlo accesible de forma uniforme y completa, independientemente de dónde se use [28].

Los servicios incorporan reglas de negocios, además de información y operaciones. Este es uno de los puntos que los diferencian de los objetos.

Como ya se mencionó en el Capítulo 3, un servicio es un objeto con mucha más información y un menor grado de acoplamiento dado que no existe una asociación entre ellos, sino que su comportamiento es desencadenado por la meta-información que posee, básicamente en cuanto contrato de servicio y contexto de ejecución. Pero su similitud con los objetos admite que sean modelados en términos de clases.

Inspirado en las clases del UML, Erl define en [3] el símbolo de servicios como un círculo comprendido por dos áreas: una para el nombre del servicio y otra para las capacidades del mismo, tal como se ve en la figura 5.7. Este círculo fue denominado "círculo con cuerda" por Paul Zablosky de la Universtiy of British Columbia.

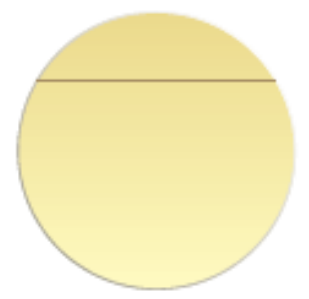

Figura 5.7. Simbolo de servicio como un círculo con cuerda 
El fundamento de uso de este símbolo se inspira en la idea geométrica de círculo como reflejo de autonomía, independencia e individualidad, estableciendo una unidad lógica denominada servicio.

Tal como se expresa en [3], el término "círculo con cuerda" se inspira también en el plano de la geometría donde ya en el siglo XVI, el matemático Robert Recorde dijo que "si una línea cruza un círculo y pasa más allá de su centro, se denomina una cuerda".

La utilización de un círculo con cuerda o cualquier otra notación complementaria implica que se están considerando ciertas connotaciones:

- El círculo con cuerda es una expresión abstracta e independiente de la implementación del servicio.

- El círculo con cuerda es complementario al UML.

- El círculo con cuerda representa un elemento del inventario de servicios.

- El círculo con cuerda es útil en la etapa de análisis en la que se modelan los servicios y se bosquejan servicios candidatos y colaborativos.

- El círculo con cuerda es una notación extensible ya que pueden agregarse etiquetas adicionales para definir patrones de intercambio, modelos de servicios y caracteristicas de encapsulamiento.

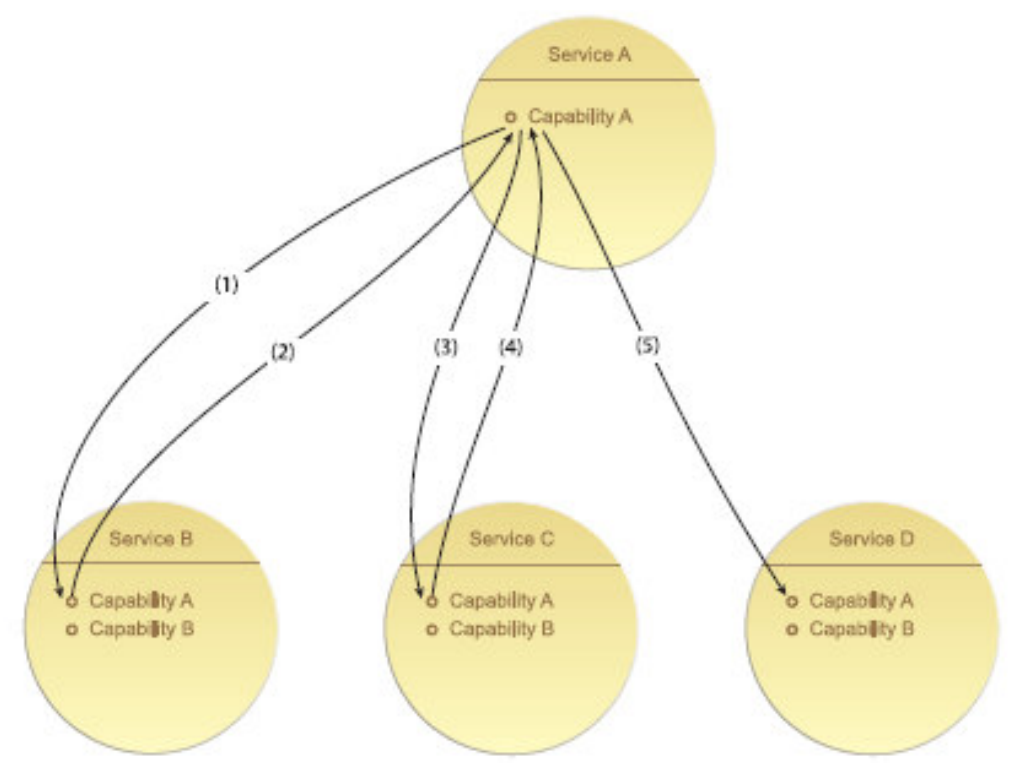

Figura 5.8. Composición de servicios expresada con círculos con cuerda

Más allá de la forma de representación que se adopte para los servicios, es importante considerar la correcta granularidad de los mismos, asi como su categorización para evitar lo que se denomina "síndrome de servicio".

Si bien los servicios son los bloques constructivos de los procesos de negocios, no todos los servicios se categorizan como servicios de negocio.

Por ejemplo, un servicio centralizado que informa condiciones de excepción o un servicio que establece la conexión con una base de datos relacional en forma genérica, son servicios que pueden utilizarse en muchos procesos de negocio y se los denomina servicios de infraestructura o servicios de tecnología.

Los servicios de negocio abarcan los servicios de entidad, donde su alcance funcional son las entidades de negocio. Son de alta reusabilidad dado que son agnósticos a muchos procesos de negocios.

El otro aspecto que abarcan los servicios de negocios son los servicios de tareas que son servicios de negocio con limites funcionales directamente asociados con una tarea o proceso de negocio. Es un servicio que tiene menos reuso potencial y 


\section{Marco Metodológico con SOA y BPM}

es generalmente responsable de controlar la composición de otros servicios, por lo tanto, entre sus capacidades, encapsula lógica de negocio.

Los servicios, para mantener su independencia, deben encapsular la lógica dentro de un contexto que puede ser una tarea, una entidad de negocio o algún otro agrupamiento. Para que los servicios puedan participar de la lógica que encapsulan, pueden intervenir en la ejecución de las actividades del negocio, para lo cual deben poder establecerse relaciones con aquellos que quieren usarlos. La Figura 5.9 muestra en forma esquemática como se lleva a cabo el encapsulamiento de la lógica de un servicio.

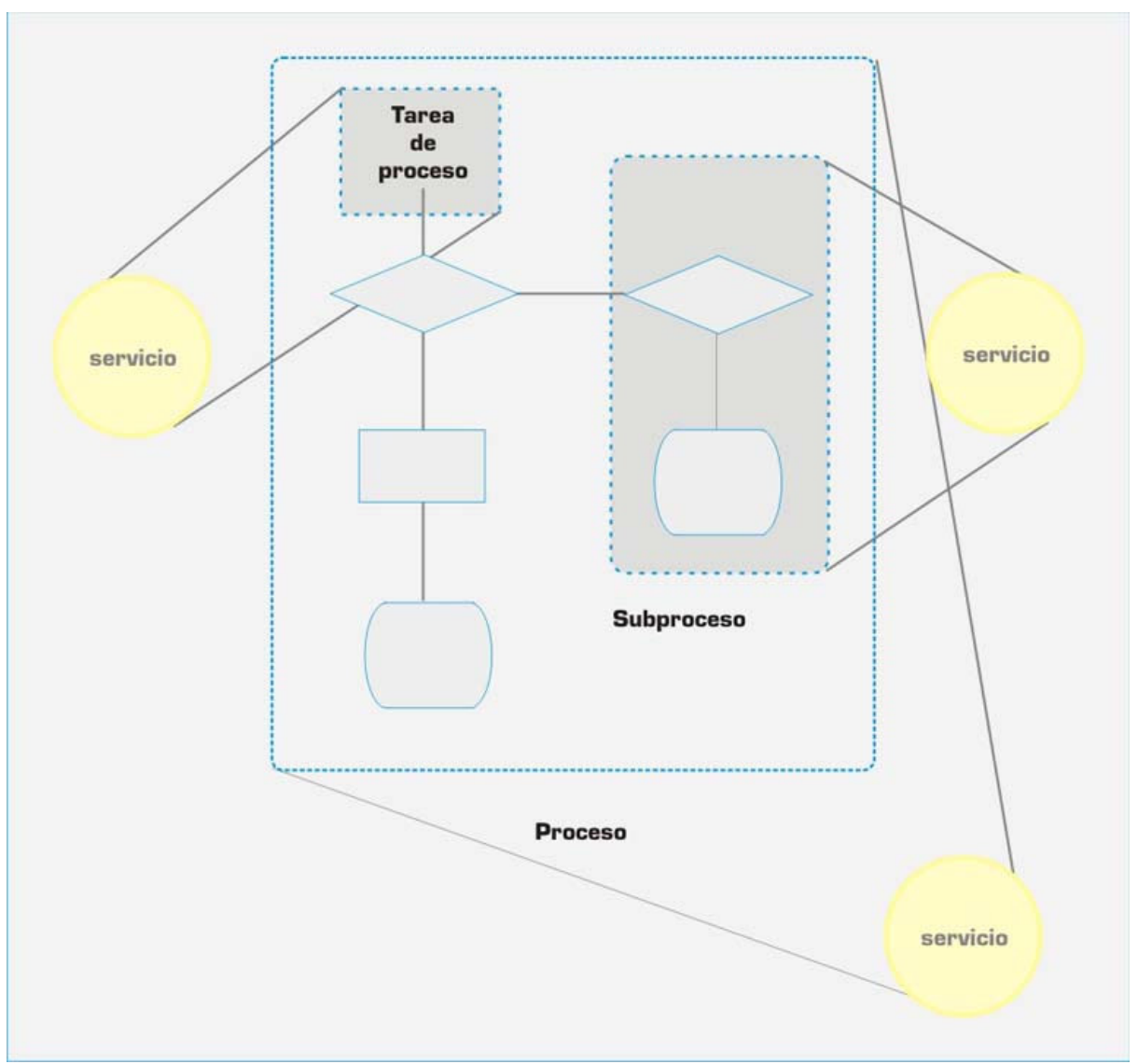

Figura 5.9. Los servicios como encapsulamiento de la lógica

Los contratos de servicio indican claramente las interfaces que proveen, sus operaciones y sus parámetros, favoreciendo la catalogación de los servicios y su consecuente composición para ampliar las funcionalidades.

Por último, otro aspecto muy importante es la secuencia de interacción entre servicios que se puede mostrar mediante diagramas de secuencia de UML.

La Disciplina para Diseño de Servicios de A.Delgado en [1], presenta una lista de actividades a realizar en este proceso de diseño, explicitando el objetivo de actividad, su entrada, su salida y los roles involucrados en la misma, tal como se presenta en la tabla 5.1. 


\section{Marco Metodológico con SOA y BPM}

Tabla 5.1 - Actividades de la Disciplina Diseño

\begin{tabular}{|c|l|l|l|l|}
\hline Actividad & Objetivo & Entradas & Salidas & Roles \\
\hline \hline $\begin{array}{c}\text { Identificar y } \\
\text { categorizar } \\
\text { servicios (D1) }\end{array}$ & $\begin{array}{l}\text { Definir y clasificar los } \\
\text { servicios para realizar } \\
\text { los procesos de } \\
\text { negocio y } \\
\text { funcionalidades }\end{array}$ & $\begin{array}{l}\text { Arquitectura SW, } \\
\text { Docs. Procesos de } \\
\text { negocio, servicios } \\
\text { y requisitos }\end{array}$ & $\begin{array}{l}\text { Documento de } \\
\text { servicios, } \\
\text { Arquitectura de } \\
\text { SW }\end{array}$ & $\begin{array}{l}\text { Arquitecto, } \\
\text { Analista, } \\
\text { Implemen- } \\
\text { tador }\end{array}$ \\
\hline $\begin{array}{c}\text { Especificar } \\
\text { servicios (D2) }\end{array}$ & $\begin{array}{l}\text { Definir contratos de } \\
\text { servicios, operaciones, } \\
\text { etc. }\end{array}$ & $\begin{array}{l}\text { Documento de } \\
\text { servicios }\end{array}$ & $\begin{array}{l}\text { Documento de } \\
\text { servicios }\end{array}$ & $\begin{array}{l}\text { Arquitecto, } \\
\text { Analista }\end{array}$ \\
\hline $\begin{array}{c}\text { Investigar } \\
\text { servicios } \\
\text { existentes (D3) }\end{array}$ & $\begin{array}{l}\text { Reutilizar servicios, } \\
\text { funponentes o } \\
\text { funcionalidades }\end{array}$ & $\begin{array}{l}\text { Documento de } \\
\text { servicios, } \\
\text { Catálogo de } \\
\text { servicios }\end{array}$ & $\begin{array}{l}\text { Documento de } \\
\text { servicios, } \\
\text { Catálogo de } \\
\text { servicios }\end{array}$ & $\begin{array}{l}\text { Arquitecto, } \\
\text { Analista }\end{array}$ \\
\hline $\begin{array}{c}\text { Asignar servicios } \\
\text { a componentes } \\
\text { D4) }\end{array}$ & $\begin{array}{l}\text { Definir } \\
\text { implementación de } \\
\text { servicios }\end{array}$ & $\begin{array}{l}\text { Documentos de } \\
\text { servicios y de }\end{array}$ & $\begin{array}{l}\text { Documento de } \\
\text { servicios y de }\end{array}$ & $\begin{array}{l}\text { Arquitecto, } \\
\text { Implemen- } \\
\text { Diseño }\end{array}$ \\
$\begin{array}{c}\text { Definir } \\
\text { Interacción de } \\
\text { servicios (D5) }\end{array}$ & $\begin{array}{l}\text { Definir las secuencias } \\
\text { servicios que realizan } \\
\text { procesos denegocio }\end{array}$ & $\begin{array}{l}\text { Docs. Procesos de } \\
\text { negocio, servicios } \\
\text { yequisitos }\end{array}$ & $\begin{array}{l}\text { Documento de } \\
\text { servicios y de } \\
\text { Implementación }\end{array}$ & $\begin{array}{l}\text { Arquitecto, } \\
\text { Analista, } \\
\text { Implemen- } \\
\text { tador }\end{array}$ \\
\hline
\end{tabular}

SoaML (Service oriented architecture Modeling Language) [10] es un perfil de UML y un metamodelo para el diseño de servicios bajo el enfoque de desarrollo dirigido por modelos. Este perfil puede ser incorporado como herramienta en esta etapa pero sin perder de vista el enfoque orientado a procesos de nuestra propuesta.

Lo más importante de esta etapa está dado por la definición del grado de granularidad de la pieza diseñada como para que se pueda considerar un servicio, con autonomía y atomicidad.

El proceso de transformación entre las etapas 4 y 5 sin duda puede ser automatizado por herramientas construidas para tal fin. Ejemplos de herramientas para tal transformación podemos encontrarlos en [45] [46].

La etapa de modelado e identificación de servicios implica acompañar el cambio de estado de dicho servicio desde lo intangible a lo físico, tal como se afirma en [19]. Alli el autor afirma que el modelado orientado a servicios es una disciplina guiada por la metamorfosis de los servicios, donde el curso normal comienza con la inspección de los mismos que emergen como concepto, continua a través de su análisis y diseño y culmina como una solución ejecutable.

También sostiene que esta práctica de modelado orientado a servicios evoca la transformación de un servicio de un estado a otro para maximizar la flexibilidad en el análisis, el diseño y la arquitectura. Esta elasticidad facilita la agilidad del negocio debido al modelo de metamorfosis del servicio.

Concluida esta etapa de modelado de servicios y de la identificación de los mismos, se sucede la etapa de definición de componentes, es decir el empaquetado de servicios como componentes de grano grueso para dar respuesta a los requisitos funcionales y no funcionales identificados en la etapa inicial y encuadrados en los procesos de negocios que los requieren. 


\subsection{Etapa de definición de componentes}

La etapa de definición de componentes se entiende como un conjunto de servicios empaquetados que admiten una única entrada y pueden contar con varias salidas. Un ejemplo muy ilustrativo de un componente se visualiza en la figura 5.10 que representa la funcionalidad llevada a cabo por una calculadora.

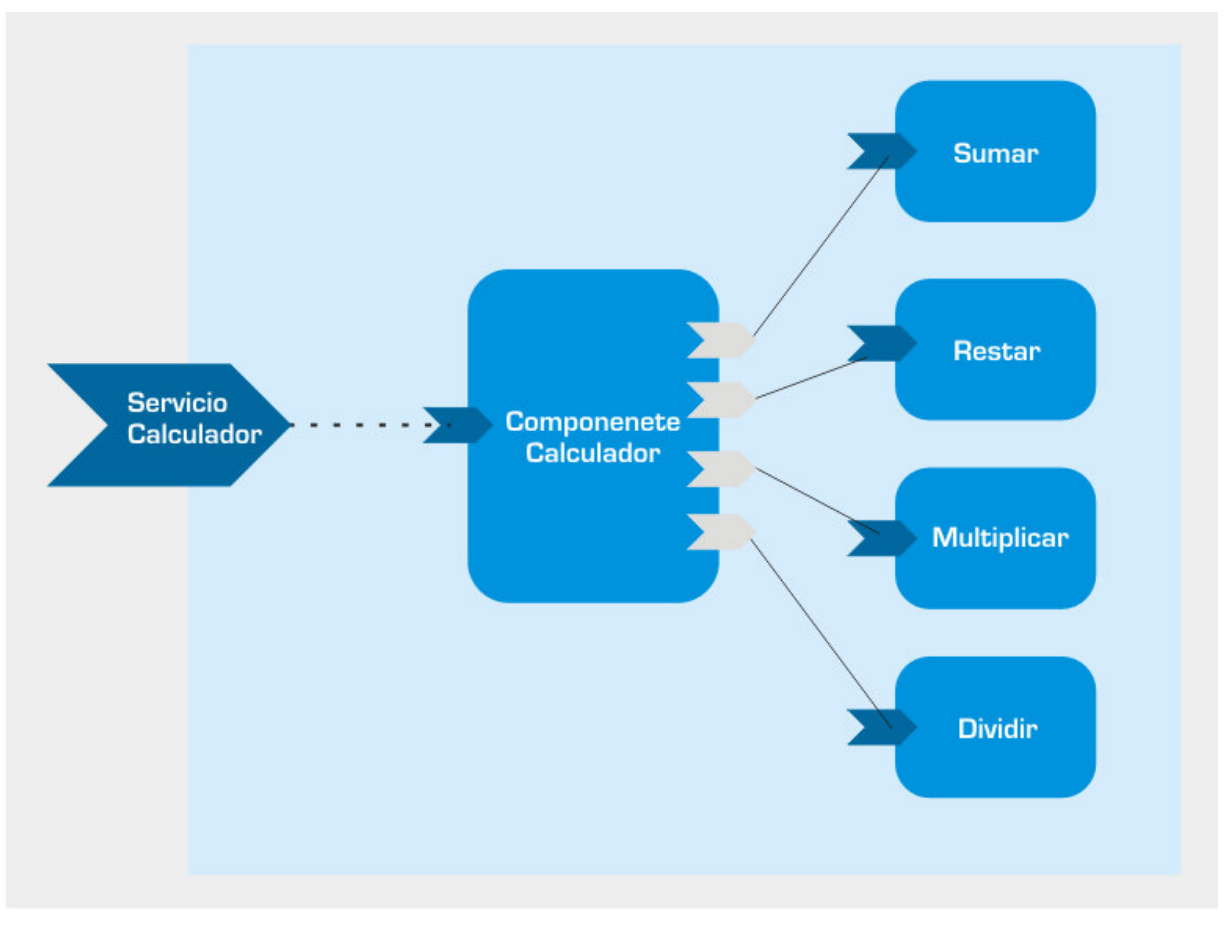

Figura 5.10. Componente calculadora

La particularidad del servicio empaquetado radica en el hecho de que debe ser capaz de utilizar cualquier interfaz nativa que tenga la implementación de la funcionalidad existente. Si bien en apariencia un componente de servicios es como cualquier otro componente que provee funcionalidad a través de sus interfaces, la diferencia radica en la noción de accesibilidad y estabilidad [28].

La accesibilidad está relacionada con la capacidad del componente de estar disponible independientemente de la tecnologia y la implementación, lo que evita la duplicación de funcionalidad.

La estabilidad hace que la interfaz de un servicio sea una invariante en el contexto de los sistemas de información y los procesos de negocio que están en permanente evolución.

En esta etapa de definición de componente se trata entonces de definir la manera en que se componen y empaquetan funcionalidades, sean estas existentes (en sistemas heredados o en paquetes de software adquiridos por la organización) o nuevas, para construir piezas funcionales que puedan registrarse en un repositorio común.

Esta forma de cómputo orientado a servicios representa una nueva generación de plataformas de computación que acompaña a las arquitecturas orientadas a servicios cuyo fin último es crear y ensamblar un inventario de los mismos [3]. La Figura 5.11 muestra cómo un inventario de servicios establece un pool de servicios agnósticos que pueden ser reutilizados a través de múltiples composiciones. 


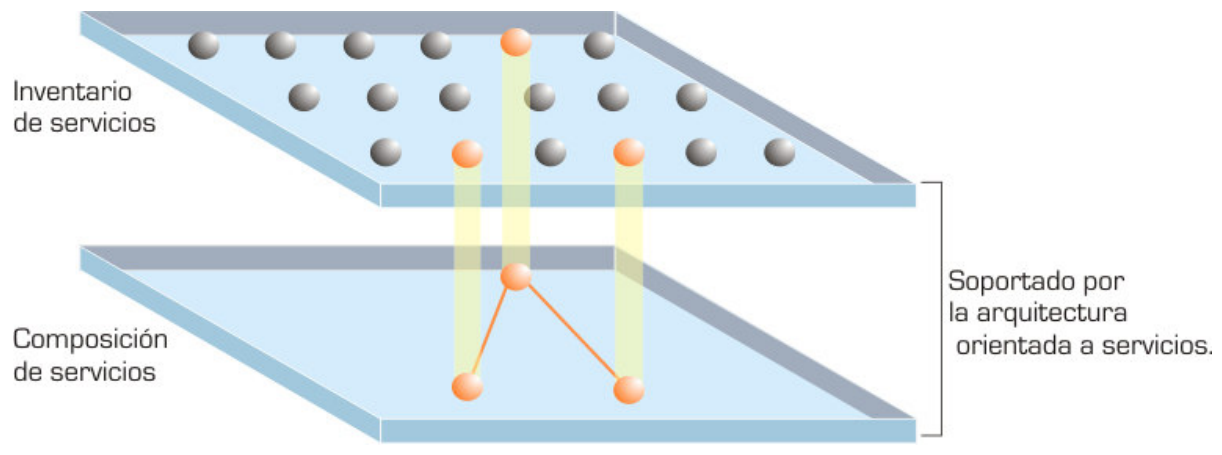

Figura 5.11. Inventario de servicios

Una composición de servicios es un conjunto de servicios ensamblados para proveer una funcionalidad que requiere automatizar una tarea o un proceso.

Una colección estandarizada de servicios conforma la base de un inventario de servicios que puede ser administrado en forma independiente dentro de su propio entorno de ejecución.

\section{El estándar SCA}

El estándar SCA (Service Component Architecture o Arquitectura de Componentes de Servicios) está siendo desarrollado por Open SOA Collaboration www.osoa.org [51] y adhieren a él la mayoría de las empresas proveedoras de herramientas con enfoque SOA y BPM (BEA, IBM, Oracle, SAP, Siebel, Fiorano, Sun), junto con el estándar para intercambiar datos entre servicios SDO (Service Data Objects o Servicios de Objetos de Datos).

Este estándar utiliza la idea de componentes del UML y se utiliza para ensamblar, componer y ejecutar aplicaciones orientadas a servicios.

Del mismo modo que los servicios contenían operaciones o capacidades, en SCA un componente contiene otros servicios.

En la figura 5.12 se visualiza un componente como un elemento que posee un único punto de entrada o interfaz que indica cómo invocarla y posee varios puntos de salida que constituyen referencias a los servicios que invoca. Estos pueden ser una invocación a un web service o a un stored procedure o bien a una función accesible vía una DLL, e incluso acceder a una cola de mensajes.

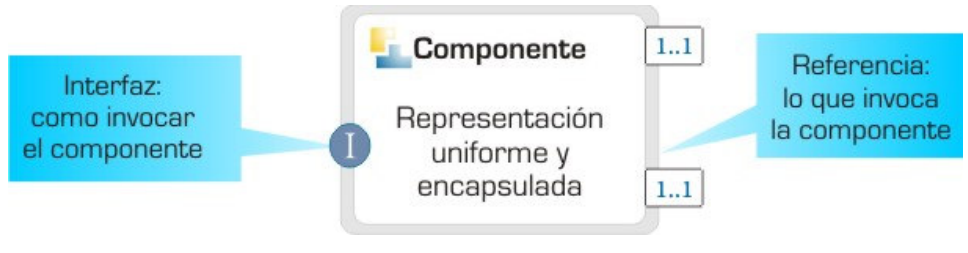

Figura 5.12. Representación gráfica de un componente SCA.

La Figura 5.13 extraída de [39] muestra un esquema de composición de servicios para llevar a cabo un proceso de orden de compra que accede a una base de datos relacional DB2 y luego, en la Figura 5.14, se muestra el mismo proceso pero dividido en distintos módulos y finalizando el flujo accediendo a SAP. 


\section{Marco Metodológico con SOA y BPM}

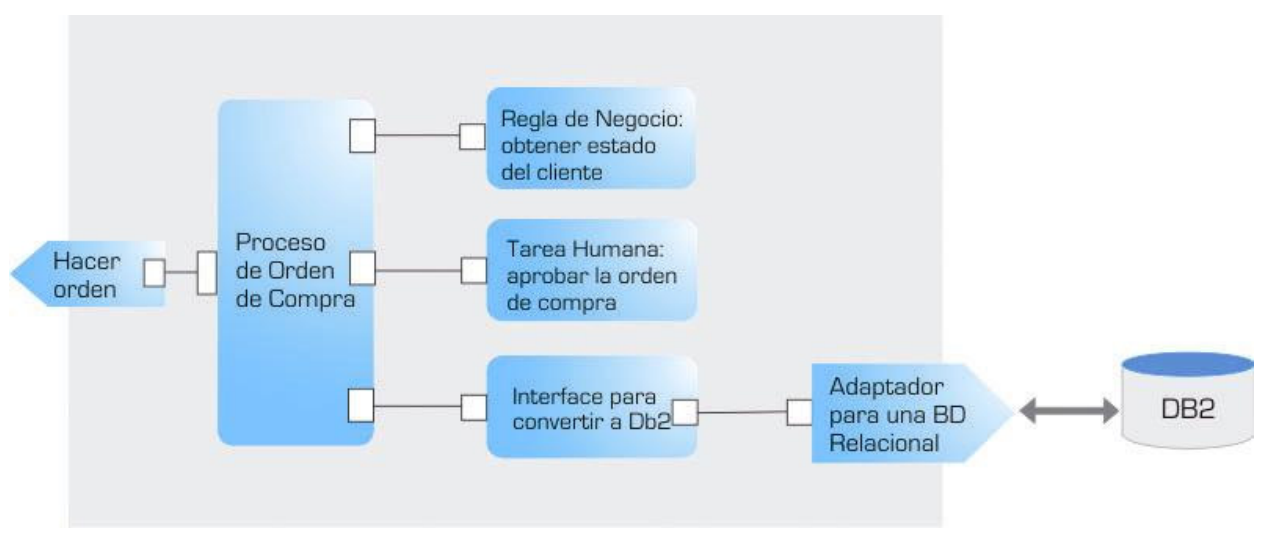

Figura 5.13. Proceso de registro de una orden de compra en DB2

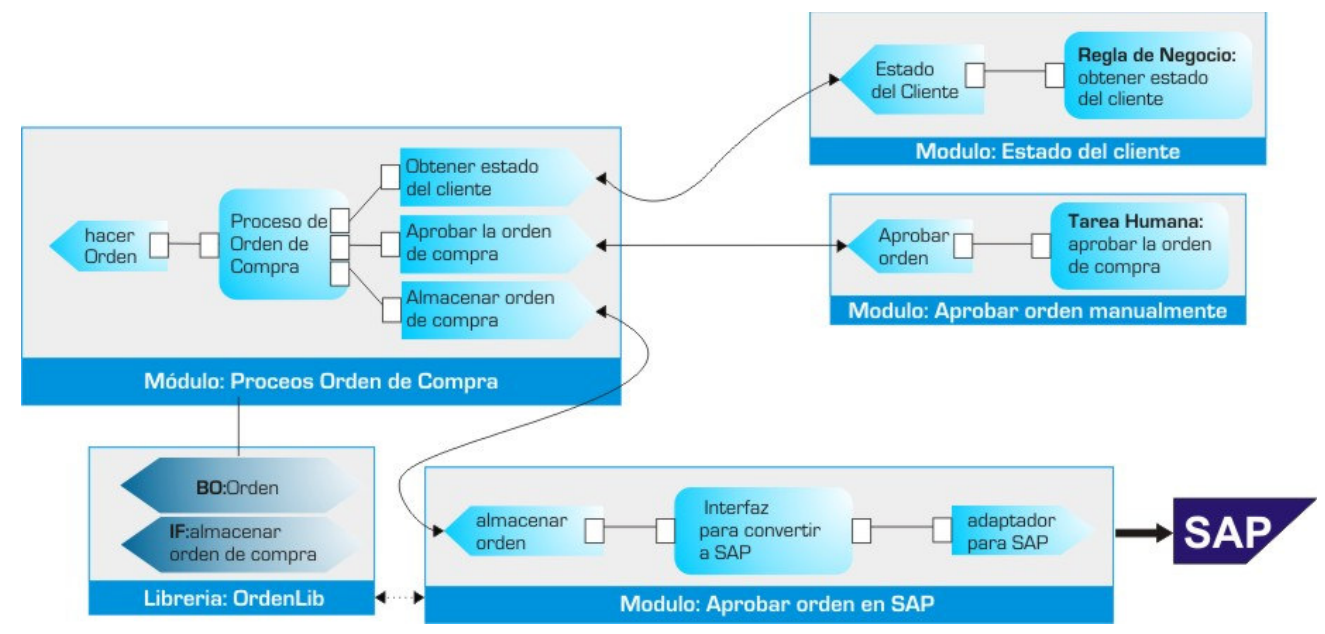

Figura 5.14. Proceso modularizado de registro de una orden de compra en SAP

Más allá de que se dispone de estándares y ayudas tecnológicas para implementar servicios, está claro que esto requiere una complejidad adicional. Al trabajo adicional del diseño se le añade el overhead de la ejecución de los servicios.

Esto nos lleva a concluir que no cualquier pieza de software requiere funcionalidad de servicio. Algunas de las pautas a tener en cuenta son enunciadas por Imaz en [28]:

- La cantidad de trabajo realizada por el servicio debe ser acorde al trabajo adicional provocado por su diseño más el overhead de ejecución que provoca.

- La funcionalidad del servicio debe ser utilizada por dos o más clientes.

- La implementación del servicio evoluciona mientras que la funcionalidad que aporta se mantiene relativamente estable.

En esta etapa de definición de componentes se utilizan los conceptos vertidos en este apartado para identificar y componer servicios con el objetivo de dar respuesta a procesos de negocio con alta reusabilidad.

El estándar SCA marca una fuerte tendencia que se encuentra absorbida por la mayoria de los productos comerciales existentes, pero también otorga un marco conceptual para el ensamblado y composición de servicios a nivel de diseño, como es el objetivo de esta etapa. 


\section{Marco Metodológico con SOA y BPM}

En la próxima etapa se aborda la fase de implementación de estos componentes $\mathrm{y}$ alli se enaltecen aún más las ventajas de adherir a estándares para el ensamblado y la composición de servicios.

\subsection{Etapa de implementación de componentes}

Sustentado en la idea de ensamblado de componentes, la etapa de implementación será tanto más directa de abordar en la medida en que la etapa de definición de las mismas haya sido capaz de componer servicios.

En esta etapa de implementación de componentes es donde adquieren mayor protagonismo las particularidades tecnológicas y se aprecian las ventajas de cada herramienta.

Nuestro enfoque para esta etapa es encuadrar los estándares de mercado como herramientas para completar la composición y realizar el despliegue de los componentes de servicios.

Según [37] los activos existentes de una organización que podrian componerse y desplegarse como servicios pueden clasificarse de la siguiente manera:

- Adaptadores. Los servicios concebidos como adaptadores constituyen una de las más tradicionales formas de integración tal como se mencionó en el Capítulo 4. En este caso podemos definir adaptadores de tecnología (acceso a bases de datos o a archivos planos) o adaptadores de aplicación (conectividad con SAP, por ejemplo).

- Web Services. La tecnologia de Web Services es otra alternativa para componer y desplegar servicios basado en estándares y que cubren un espectro particular del paradigma orientado a servicios. Entre las variantes más populares podemos encontrar SOAP [4] (Simple Object Access Protocol) sobre HTTP, como el mecanismo de interacción para aplicaciones basadas en Web con invocación de páginas dinámicas y SOAP sobre JMS (Java Message Service) como variante en el caso de software basado en el estándar de mensajería de Java.

- Mensajería. El intercambio de mensajes en los sistemas de comunicación asincrónica ha sido un esquema válido de implementación de sistemas distribuidos desde la época del Cliente/Servidor. En términos de servicios, la mensajería continúa estando vigente y las variantes de implementación pueden variar desde la adhesión al estándar de mensajería de Java como lo es JMS (para el caso de usar tecnología de código abierto), hasta la utilización de los productos comerciales que dan soporte para mensajeria como WebSphere MQ de IBM. En un camino intermedio existen los esquemas de comunicación punto a punto basado en los mecanismos de publicación y suscripción como se describió en el Capitulo 4.

- HTTP. El HTTP (HyperText Transfer Protocol) es un protocolo de comunicación basado en el intercambio de archivos que tiene sus raíces en el FTP y que constituyó la evolución ideal de dicho protocolo para sostener el esquema de comunicación de los servidores Web, dando origen a la posibilidad de desarrollos de aplicaciones basadas en Web que dotaron de dinamismo a la estaticidad del código HTML. Sustentando esta idea y considerando al XML como el estándar de facto para el intercambio genérico de información, resulta apropiado contar con tecnología capaz de utilizar dos estándares para resolver la comunicación necesaria de los servicios en el enfoque orientado a servicios que estamos formulando. 


\section{Marco Metodológico con SOA y BPM}

- EJB. Los EJB (Enterprise Java Beans) son una de las API que forman parte del estándar de construcción de aplicaciones de la plataforma J2EE y cuya especificación describe cómo proveer funcionalidad de objetos del lado del servidor con capacidades de control de transacciones, seguridad, concurrencia y eventos basados en JMS, entre otras. En este contexto, resultan una solución tecnológica muy importante para implementar y desplegar servicios y su composición, cuando se utiliza la variante de EJB de sesión. El otro enfoque de uso de EJBs lo abordan los EJB de entidad que encapsulan objetos del dominio como lo son las entidades del modelo entidad-relación.

- SCA: el estándar SCA descripto en la etapa anterior como mecanismo para identificar componentes alcanza también la etapa de despliegue o implementación de dichos componentes. La utilización de este estándar en la etapa de implementación conlleva a conectar módulos unos a otros exponiendo una interfaz.

La implementación de un componente SCA queda descripta con los siguientes atributos [28]:

- Servicios, que describen la funcionalidad de cada componente.

- Referencias, que describen las dependencias del componente para poder funcionar.

- Propiedades, que definen los parámetros de configuración que controlan cómo se comporta la lógica del programa.

- Políticas, que describen supuestos acerca del comportamiento en sus dos variantes: de implementación y de interacción. Las primeras impactan en el comportamiento de una implementación (Por ejemplo: transacciones) y las segundas definen cómo interactúan los componentes entre sí (Por ejemplo: seguridad).

La implementación de un componente puede realizarse en cualquier lenguaje. Una alternativa es BPEL [21] [28] para los procesos de negocio o XSLT para las transformaciones o Java.

\section{Las transformaciones XSLT}

Con la creciente popularidad de XML como medio de interacción entre distintos sistemas, se comenzó a adoptar para resolver la interoperabilidad e incluso para realizar una clara separación entre la interfaz de usuario y la lógica de negocios, con lo cual ganó preponderancia el XSL(Extensible Stylesheet Language) [21], familia de lenguajes basados en el estándar XML que permite describir cómo la información contenida en un documento XML cualquiera, debe ser transformada o formateada para su presentación en un medio.

XSLT o Transformaciones XSL es un estándar de la organización W3C que presenta una forma de transformar documentos XML en otros e incluso a formatos que no son XML. Las hojas de estilo XSLT realizan la transformación del documento utilizando una o varias reglas de plantilla. Estas reglas de plantilla unidas al documento fuente a transformar, alimentan un procesador de XSLT, el que realiza las transformaciones deseadas poniendo el resultado en un archivo de salida, o, como en el caso de una página web, las hace directamente en un dispositivo de presentación tal como el monitor del usuario.

EL XSL puede agregar nuevos elementos en el archivo de salida, remover otros, reorganizar los existentes y testear y tomar decisiones acerca de cuáles elementos mostrar. 


\section{Marco Metodológico con SOA y BPM}

Por su filosofia, las transformaciones XSLT constituyen un lenguaje válido para la implementación de componentes, básicamente las que se utilizan para llevar a cabo politicas de interacción.

\section{El estándar BPEL}

En nuestro enfoque basado en procesos y servicios, los procesos de negocios son colecciones de actividades a través de las cuales se invocan servicios. Podemos decir entonces que un proceso de negocios ejecutable es un servicio que puede interactuar con otros servicios de manera intra-organizacional o interorganizacional.

Para poder dar respuesta a estos conceptos se requiere contar con un lenguaje ejecutable para especificación, orquestación y coreografia (Ver Sección 2.5 de este trabajo) de los procesos de negocios.

BPEL (Business Process Execution Language) es un lenguaje de programación a gran escala específicamente diseñado para composición de servicios y enfocado sobre los procesos de negocios [21].

Si bien la implementación de procesos usando cualquier lenguaje tradicional como Java o C\# para componer servicios es posible, se debe realizar una tarea adicional para mantener la composición de los servicios a lo largo de todo el proceso considerando aspectos de la lógica de transición de estados de un sistema, generando una pobre o baja separación entre el flujo del proceso y la lógica del negocio.

BPEL es el lenguaje para definir procesos de negocios que componen servicios y además externalizan su funcionalidad como servicios. Es un lenguaje basado en XML y se apoya en los estándares WSDL, XLM Schema y XPath.

Desde el punto de vista histórico nació como la convergencia entre WSFL (Web Service Flow Language) de IBM y XLANG de Microsoft.

BPEL define procesos de negocios ejecutables que se despliegan y ejecutan en una máquina o motor de ejecución BPEL, generalmente denominado Process Server o Servidor de Procesos. Este Servidor de Procesos generalmente se monta sobre un ESB (Ver Sección 3.3 de este trabajo), pero esto depende fuertemente de la implementación de cada producto, sea éste propietario o de código abierto.

Esta idea de Servidor de Procesos como entorno propio de ejecución de procesos de negocios, sumado a su característica de estándar, hacen de BPEL una de las herramientas más adecuadas para esta etapa de implementación de componentes.

Por otra parte, la derivación automática de código BPEL a partir de BPMN [42], ha sido y continúa siendo uno de los aspectos más buscados en los sistemas de gestión de procesos de negocios o BPMS [44].

Como corolario de esta etapa de implementación de componentes, se incluye la tabla 5.2 de [43] que muestra una comparación entre cuatro BPMS en función de ciertos criterios previamente definidos. 


\section{Marco Metodológico con SOA y BPM}

Tabla 5.2 - Comparación de cuatro BPMS

\begin{tabular}{|c|c|c|c|c|c|c|}
\hline & Hardware & Licenciamiento & \multicolumn{2}{|c|}{ Ciclo de vida } & Soporte SOA & Integración con IDEs JAVA \\
\hline \multirow{3}{*}{ JBPM } & \multirow{3}{*}{$\begin{array}{l}768 \mathrm{MB} \text { de RAM } \\
800 \mathrm{MB} \text { de espacio en el disco } \\
\text { rígido para la versión full [platform] } \\
0220 \mathrm{Mb} \text { de espacio en disco }\end{array}$} & \multirow{3}{*}{$\begin{array}{l}\text { Lesser } \\
\text { General } \\
\text { Public }\end{array}$} & Modelado & $\checkmark$ & \multirow{3}{*}{$\begin{array}{l}\text { Cuenta con componentes } \\
\text { "ESB service" dentro del } \\
\text { diseñador de procesos } \\
\text { para utilizar servicios que }\end{array}$} & \multirow{3}{*}{$\begin{array}{l}\text { Eclipse con plug- } \\
\text { inhttp://www.eclipse- } \\
\text { plugins.info/eclipse/plugin_d } \\
\text { etails.jsp?id=1028 } \\
\text { http://sourceforge.net/proje }\end{array}$} \\
\hline & & & \begin{tabular}{|l|} 
Ejecución \\
Despliegue
\end{tabular} & $\checkmark$ & & \\
\hline & & & Monitoreo & $\checkmark$ & & \\
\hline \multirow{3}{*}{ Bonita } & \multirow{3}{*}{$\begin{array}{l}\text { Procesador de } 1 \mathrm{GHZ} \text { es } \\
\text { recomendado, con un mínimo de }\end{array}$} & \multirow{3}{*}{$\begin{array}{l}\text { Lesser } \\
\text { General } \\
\text { Public License } \\
\text { [LGPL] }\end{array}$} & Modelado & $\checkmark$ & \multirow[t]{3}{*}{ No provee } & \multirow{3}{*}{$\begin{array}{l}\text { Eclipse con plug-in } \\
\text { http://forge.objectweb.org/ } \\
\text { project/showfiles.php?group } \\
\text { _id=56 }\end{array}$} \\
\hline & & & \begin{tabular}{|l|} 
Ejecución \\
Despliegue
\end{tabular} & $\checkmark$ & & \\
\hline & & & Monitoreo & $\checkmark$ & & \\
\hline \multirow{3}{*}{ GPA } & \multirow{3}{*}{$\begin{array}{l}\text { Procesador: PC Pentium } 233 \\
\text { MHz o superior Pentium III } \\
\text { recomendado. } \\
128 \text { MB de RAM [o superior] } \\
\text { Disco Rigido: } 245 \mathrm{MB} \text { de espacio }\end{array}$} & \multirow{3}{*}{$\begin{array}{l}\text { Licencia } \\
\text { Consist-GPA }\end{array}$} & Modelado & $\checkmark$ & \multirow{3}{*}{$\begin{array}{l}\text { Posee un mecanismo } \\
\text { propio para definir un } \\
\text { adaptador y un } \\
\text { componente para } \\
\text { ejecutar un servicio web }\end{array}$} & \multirow{3}{*}{$\begin{array}{l}\text { No posee un entorno de } \\
\text { desarrollo. Ofrece una } \\
\text { plantilla de modelado sobre } \\
\text { Microsoft Visio: } \\
\text { http:// office.microsoft.com/e }\end{array}$} \\
\hline & & & \begin{tabular}{|l|} 
Ejecución \\
Despliegue
\end{tabular} & $\checkmark$ & & \\
\hline & & & Monitoreo & $\checkmark$ & & \\
\hline Oracle Business & \multirow{3}{*}{$\begin{array}{l}\text { Procesador Intel Pentium IV } 3.0 \\
\text { Ghz, 2GBRAM, } \\
\text { Tarjeta gráfica con resolución de } \\
1024 \text { x } 768 \text { con al menos } 256 \\
\text { colores } \\
\text { Red de alta velocidad ( } 100 \text { Mbit) }\end{array}$} & \multirow{3}{*}{$\begin{array}{l}\text { OTN License } \\
\text { Agreement }\end{array}$} & \begin{tabular}{|l|} 
Modelado \\
\end{tabular} & Crable BPA 10g & \multirow{3}{*}{$\begin{array}{l}\text { Utiliza como lenguaje de } \\
\text { ejecución a BPEL. }\end{array}$} & \multirow[t]{3}{*}{ JDeveloper 10g } \\
\hline Suite $10 \mathrm{~g}$ & & & $\begin{array}{l}\text { Ejecución } \\
\text { Despliegue }\end{array}$ & $V_{\text {Jderelat }}$ & & \\
\hline $\begin{array}{l}\text { Oracle SOA } \\
\text { Suite } 10 \mathrm{~g}\end{array}$ & & & Monitoreo & 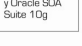 & & \\
\hline
\end{tabular}

Cumplida esta etapa de implementación de componentes, se sucede una etapa de durabilidad a lo largo de todo el ciclo de vida de los procesos, que es la de administración y seguimiento de los procesos definidos, diseñados y desplegados a lo largo de las etapas anteriores.

\subsection{Etapa de administración y seguimiento}

La etapa de Administración y Seguimiento es, sin duda, la etapa que mayor relevancia toma luego de cumplidas todas las etapas anteriores. Sin embargo, la hemos graficado con un alcance a todas las etapas del ciclo de vida del software tal como la etapa inicial de Organización y Plan Estratégico. Esto es así teniendo en cuenta que ambas etapas tendrán una permanente realimentación a medida que se desarrollan las otras etapas.

La etapa que nos ocupa en este apartado en particular, cubre las actividades relacionadas con la capacidad del sistema de adaptarse a los cambios, sean estos provocados por cambios regulatorios del mercado o por mejoras que deseen aplicarse a los mismos.

En este contexto y como ya se mencionó, el enfoque basado en procesos y servicios aporta no solo agilidad para adaptarse al cambio sino flexibilidad para absorber las mejoras que impone el entorno en un esquema de mejora continua. Entre las prestaciones típicas de un BPMS, se puede enumerar: definición de procesos en forma estandarizada con BPMN, ejecución de los mismos de manera directa con BPEL y su motor de ejecución, y su monitorización en tiempo real a través de un BAM (Business Activity Monitoring).

Sin lugar a dudas, es posible llevar adelante esta etapa sin contar con un BAM, pero será sin duda mucho más dificultoso, requerirá mayor esfuerzo de programación y difícilmente se logrará el grado de integración que representa contar con un monitor de procesos dentro del mismo contexto de desarrollo.

Un BAM permite monitorear los procesos de negocio en tiempo real obteniendo información de los KPI (Key Perfomance Indicator) que se hayan definido desde las etapas más tempranas, incluso pueden definirse en el modelado del negocio y surgir de la identificación de requisitos. Estos indicadores también ayudan a generar simulaciones de la ejecución de los procesos evaluando distintos escenarios en función de dichos indicadores que pueden ser por ejemplo: tiempos, costos, calidad, satisfacción del cliente, etc.

La Figura 5.15 [42] muestra un esquema del ciclo que debe cumplirse para lograr contar con un monitor y simulador de procesos de negocio. 


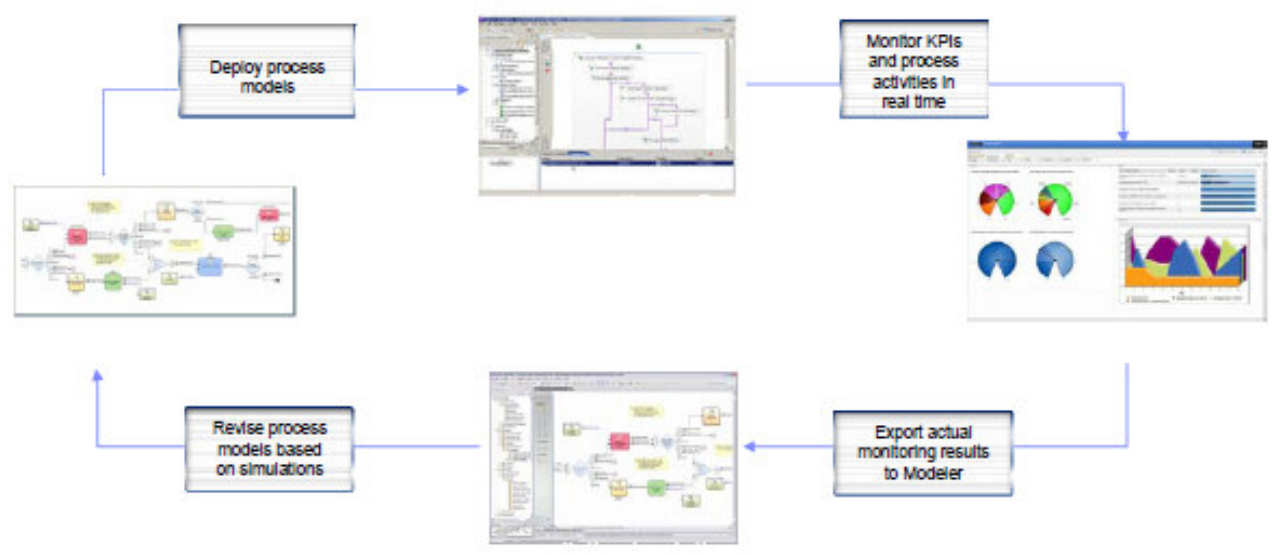

Figura 5.15. Ciclo para cerrar las etapas de Administración y Seguimiento

\subsection{Conclusiones}

La construcción de soluciones con enfoque de procesos y de servicios constituye una nueva manera de abordar los problemas fomentando ampliamente el reuso, la agilidad y flexibilidad para absorber los cambios y la idea de mejora continua de los procesos como consecuencia de lo anterior.

La descripción de las etapas de este marco metodológico propuesto, si bien conlleva una lectura secuencial, fomenta una permanente realimentación entre ellas incluso desde las etapas más tempranas como lo es la Identificación de Requisitos, la que también se propone abordar desde un enfoque basado en el diseño de procesos.

Otro objetivo del enfoque de procesos y servicios es el acortamiento de la brecha entre el área de negocios y el de tecnología. Las etapas descriptas fomentan la conformación de roles que son capaces de intercambiar información en un lenguaje común y que además los compromete con el proyecto como una solución unificada e integrada a la organización.

En el próximo capítulo se presentará un caso real abordado hacia mediados de 2008 y que constituyó una tarea conjunta de reingeniería del negocio y tecnológica para poder dar una solución a una organización pública que requería poner en funcionamiento el concepto de Ventanilla Única de Trámites. 


\section{Caso de Estudio}

En este capítulo se presenta un caso de estudio que ha sido objeto de aplicación del marco metodológico presentado en el Capítulo 5. El problema abordado será planteado de modo completo en la sección 6.1. Por cuestiones de volumen y al solo efecto de facilitar la comprensión de la aplicación del modelo propuesto, se considerarán al resolverlo, algunas simplificaciones sobre el caso real.

\subsection{Planteo del problema}

El caso de estudio que se plantea para la aplicación del marco metodológico propuesto está inspirado en un caso real que se desarrolló durante el segundo semestre de 2008 y que fue fuente de inspiración de este trabajo.

El desarrollo del caso real no contó con todas las particularidades enunciadas en esta presentación, dado que muchas de ellas surgieron como elementos de mejora sobre el trabajo realizado.

El objetivo del proyecto fue diseñar un modelo integral y viable de Ventanilla Única Empresarial para una organización pública, que permita gestionar el asesoramiento, registro de la actividad económica, permiso de funcionamiento y fiscalización de empresas comerciales, industriales y de servicios, con el objeto de promover el desarrollo económico local en un marco de legalidad y formalidad a través de la facilitación y simplificación de trámites empresariales y del fortalecimiento del poder de contralor de la región.

El modelo deberá contemplar los lineamientos estratégicos emanados del gobierno regional con relación a la politica de desarrollo económico-productivo y territorial de la región y orientarse por los principios de la simplificación, unificación, agilización y automatización de procesos y servicios, conteniendo e integrando las propuestas de reformas necesarias para su implementación e incluyendo un plan de acción para su implantación definitiva.

Entre los objetivos específicos del proyecto, se encuentran:

1. Proponer el diseño del Modelo Integral para la gestión de los servicios de asesoramiento, registro, permisos de funcionamiento y control de las actividades económicas sobre la base de la tecnología de gestión y metodologia de Ventanilla Única Empresarial, incluyendo el rediseño de los servicios, la reingeniería de los procesos involucrados, las propuestas de reformas normativas, y los aspectos organizativos, tecnológicos $\mathrm{e}$ informáticos, de infraestructura fisica y la correspondiente evaluación de impacto financiero y tributario.

2. Proponer el Código Único de Habilitaciones Comerciales e Industriales de la región, de potestad reglamentaria regional, conteniendo criterios generales y particulares para cada actividad económica involucrada y considerando y referenciando a las normativas provinciales y nacionales correspondientes de manera de reglamentar conforme a derecho.

3. Realizar el diseño de detalle del modelo integral para su implementación y puesta en marcha en las distintas delegaciones municipales.

Se entiende por Ventanilla Única un sistema de organización funcional, que sirve de principal enlace entre los usuarios internos y externos de una organización con el objetivo de hacer ágiles, confiables y agradables los trámites internos requeridos por los usuarios, simplificar los trámites, disminuir los puntos de atención, mejorar la oportunidad de la información, personalizar la 
atención al usuario y aprovechar el gran soporte tecnológico disponible en la actualidad.

A la luz de esta definición y con este objetivo, tanto el general como los específicos en mente, se identificaron los siguientes alcances para el proyecto:

1. Reingeniería de los procesos de regulación de la actividad económica de la región con el objetivo de:

a. Definir tipos de trámites y encuadrarlos según el grado de regulación requerido a partir del nivel de riesgo.

b. Flexibilizar el grado de regulación permitiendo modificar el tipo de trámite correspondiente a cada rubro considerando las reglas de negocio a cumplirse.

c. Establecer compatibilidades entre rubros que minimicen o simplifiquen la necesidad y frecuencia de trámites de tipo "modificación".

d. Establecer claramente los requisitos y disminuir aquellos que no impliquen prevención de riesgos para minimizar la complejidad del trámite.

2. Identificación de roles y actores intervinientes en los procesos estableciendo la actividad que desempeñan.

3. Definición del escenario tecnológico requerido para el funcionamiento de una Ventanilla Única siguiendo las siguientes premisas:

a. Contar con una base de datos registral única de trámites.

b. Poseer acceso al sistema informático desde cualquier punto geográfico.

c. Integrar el sistema con sistemas legados existentes en la organización y que requieran ser invocados para la concreción del trámite.

En este marco, podemos decir que encontramos un terreno propicio para abordar el problema con un enfoque orientado a procesos y a servicios bajo el concepto de un modelo de integrabilidad.

El enfoque orientado a procesos permitirá satisfacer el alcance fijado como reingeniería de los procesos de regulación de actividad económica logrando, además, explicitar el conocimiento implícito en dichos procesos (estén estos vigentes o surjan como resultado de la reingenieria) e insertar el circuito de trámites en un proceso de mejora continua capaz de absorber los cambios regulatorios que pudieran producirse.

Por su parte, el enfoque orientado a servicios nos permitirá identificar funcionalidades transversales y reusar gran parte del activo de la organización existente en sistemas legados, definiendo un modelo de integración que facilite el acceso desacoplado a dichos activos.

Para agilizar la lectura se definen en la Tabla 6.1 las abreviaturas para cada una de las etapas del marco metodológico que serán utilizadas para referir las mismas durante el desarrollo de este capítulo.

Tabla 6.1 - Etapas del marco metodológico y su abreviatura

\begin{tabular}{|l|l|}
\hline \multicolumn{1}{|c|}{ Etapa } & \multicolumn{1}{c|}{ Abreviatura } \\
\hline Etapa de Organización y Plan Estratégico & 1-OPE \\
\hline Etapa de Identificación y Especificación de Requisitos & 2-IER \\
\hline Etapa de Modelado del Negocio & 3-MN \\
\hline Etapa de Modelado de Procesos & 4-MP \\
\hline Etapa de Modelado de Servicios & 5-MS \\
\hline Etapa de Definición de los Componentes & 6-DC \\
\hline Etapa de Implementación de los Componentes & 7-IC \\
\hline Etapa de Administración y Seguimiento & 8-AS \\
\hline
\end{tabular}




\subsection{Aplicación de la metodologia al caso de estudio}

\section{Generalidades resultantes de aplicar las etapas de 1-OPE y 2-IER del marco metodológico}

Las etapas de 1-OPE y 2-IER arrojaron como resultado un conjunto de documentos que se describen en este apartado y se presentan en forma completa como anexos (Anexo 1 - Contexto Global y Anexo 2 - Modificaciones Propuestas), y que constituyeron el punto de partida para iniciar la etapa de modelado del negocio según el modelo propuesto.

Si bien el mayor aporte de estas etapas está dado por su práctica, contiene un conjunto de heurísticas vinculadas a la etapa 2-IER donde se llevaron a cabo entrevistas, trabajos grupales con la intervención de un moderador y diversas actividades orientadas a quitar ambigüedades, realizar un relevamiento de base cero de la situación, definir criterios comunes y aplicarlos para definir las modificaciones generales y específicas que el problema requirió.

Ente las conclusiones más importantes a las que se abordó luego de la ejecución de la etapa 2-IER, se encuentran una lista de criterios derivados de politicas definidas por la organización y que pueden resumirse en los siguientes:

1. Gestión según tipos de trámite definidos de acuerdo al grado de regulación requerido a partir del nivel de riesgo, que el Estado tiene la obligación de prevenir, a fin de garantizar las condiciones del medio ambiente y la seguridad de las personas.

2. Flexibilidad en el grado de regulación establecido, mediante la posibilidad de cambiar, siempre que las circunstancias lo aconsejen y la normativa lo permita, el tipo de trámite que corresponda a cada tipo de comercio o industria (ámbito), sin por ello cambiar la lógica de las reglas de negocio del sistema.

3. Establecimiento de compatibilidades en ámbitos que minimice o simplifique la necesidad y frecuencia de trámites del tipo modificación. Al igual que el anterior, este criterio es llevado a la práctica mediante el análisis de los riesgos inherentes y la razonabilidad de cada tipo de compatibilidad, pudiendo existir distintos niveles en esta relación, los que modifican la aplicación de este criterio.

4. No disminuir requisitos cuando ello implique la no prevención de riesgos, más allá del grado de complejidad del trámite resultante.

A partir de estos criterios identificados, pueden definirse algunas modificaciones requeridas, las que pueden ser clasificadas, según sus características, en los siguientes grupos:

- Modificaciones generales, que impactan a todos los procesos y trámites, que tendrán principalmente implicancias normativas, ya que son las que fijan la lógica general de los procesos y para su implementación requerirán de ajustes normativos.

- Modificaciones específicas, asociadas a un determinado proceso

Estas modificaciones tendrán implicancias de índole administrativa que también se describen en este apartado.

\section{a. Modificaciones generales}

Entre las modificaciones de índole general surgidas de la etapa 2-IER encontramos un grupo de modificaciones aplicable a los trámites propiamente dichos y otras a las reglas que dirigen los procesos de negocio. 
Entre las primeras surge la necesidad de crear un Clasificador de la Especie o Género de la Actividad desarrollada por los comercios e industrias (EACyI) que se desarrollará y que debe ser capaz de cubrir los siguientes aspectos:

- Identificación de los ámbitos que son objeto de regulación en los comercios e industrias a los efectos normativos y operativos.

- Aplicación según el ámbito de las regulaciones que resultan de las normas territoriales vigentes en la región (p.e. Código de Ordenamiento Urbano).

- Calificación de riesgo ambiental y social asignado por el Estado regional a cada ámbito según sus dimensiones, a los efectos de la regulación de la actividad.

- Establecimiento de los aspectos a fiscalizar y exigencias de prevenciones y medidas precautorias para las actividades económicas según su nivel de riesgo.

- Exigencia de requisitos a cargo del actor que desea realizar una actividad económica en la región.

- Vinculación del clasificador con las regulaciones de tipo tributario.

Otra de las necesidades surgidas de la identificación de requisitos es la de fijar un Clasificador de Tipos de Trámites que considere los siguientes aspectos:

- Nivel de exigencia de requisitos según fases del proceso (viabilidad legal, permisos de funcionamiento, modificaciones a los permisos de funcionamiento y finalización del trámite).

- Nivel de exigencia de requisitos según nivel de riesgo ambiental y socioeconómico.

Por último, dentro de las modificaciones generales relativas a los trámites surge la necesidad de crear un instrumento de evaluación del riesgo contextual que regule los siguientes aspectos:

- Variables e indicadores con los que deberá ser evaluado el nivel de riesgo ambiental y social intrínseco de los rubros según las dimensiones para el desarrollo de la actividad económica.

- Niveles máximos admisibles de riesgo en cada variable y medidas específicas de prevención exigibles para garantizar que dicho nivel no sea superado.

- Peso relativo de las variables de riesgo en caso de que algún aspecto de política u otro se regulara según el índice de riesgo.

Entre las modificaciones generales aplicables a las reglas de negocio que dirigen los procesos, surge la siguiente lista de necesidades:

- Distinción entre procesos propios de la regulación de la actividad económica frente a otras gestiones de la región. Se requiere distinguir entre las gestiones propias de la regulación y las de otras gestiones de la región (ordenamiento territorial, gestión tributaria, fiscalización e inspección, entre otras). El sector encargado de la regulación, deberá solicitar información a otras áreas del organismo y, sobre la base de dicha información, la normativa correspondiente, tomar decisiones respecto de los procesos que tiene a su cargo. Esto no implica que no deba existir colaboración entre áreas, los responsables por la regulación deberán poner a disposición de terceras áreas cualquier información disponible que permita facilitar sus tareas.

- Eliminar pases improductivos. Se trata de eliminar aquellos pases improductivos o formales, que actualmente se realizan por meros requerimientos formales (Normas de reglamentación de procesos administrativos), pero que no tienen justificación técnica. Para ellos se intenta que las gestiones que implican solicitudes de información entre 
áreas del municipio se realicen previamente a la confección del expediente.

- Reducción del número de interacciones del solicitante. Se trata de evitar que el solicitante del trámite deba realizar gestiones en distintas áreas del organismo, para ello, todas las gestiones con terceras áreas serán resueltas de manera interna o incorporadas al espacio físico de la ventanilla única.

\section{b. Modificaciones especificas}

Este tipo de modificaciones, como se dijo, está asociado a cada proceso, por lo que resultaría muy extenso enumerarlas todas.

Una vez más, a los efectos de dar una dimensión acorde al alcance de este informe, se simplifican algunas descripciones.

En este sentido, se muestran en la Tabla 6.2 un par de ejemplos de procesos que requieren algún tipo de mejora específica y cómo la misma será aplicada. E1 detalle completo de las modificaciones se presenta en el Anexo 2 a este informe.

Tabla 6.2 - Procesos modificados para aplicar una mejora

\begin{tabular}{|l|l|l|}
\hline \multicolumn{2}{|c|}{ Situación Actual } & \multicolumn{3}{|c|}{ Modificación aplicada } \\
\hline $\begin{array}{l}\text { El trámite es iniciado en distintos } \\
\text { lugares según se trate de comercio o } \\
\text { industria y requiere la interacción del } \\
\text { solicitante con varias áreas del } \\
\text { organismo. }\end{array}$ & $\begin{array}{l}\text { El proceso se inicia para todos los } \\
\text { solicitantes en un único lugar y se } \\
\text { gestiona en el mismo espacio físico en } \\
\text { su totalidad. }\end{array}$ \\
\hline $\begin{array}{l}\text { El emprendedor debe comunicarse con } \\
\text { las áreas para hacer el seguimiento del } \\
\text { trámite. }\end{array}$ & $\begin{array}{l}\text { El soguimiento del trámite por medios no } \\
\text { presenciales. }\end{array}$ \\
\hline $\begin{array}{l}\text { El solicitante debe dirigirse a mesa de } \\
\text { entradas para la caratulación de } \\
\text { expedientes. }\end{array}$ & $\begin{array}{l}\text { La solicitud de caratulación es } \\
\text { realizada por el responsable del trámite } \\
\text { vía remisión de los documentos } \\
\text { recibidos a mesa de entradas. }\end{array}$ \\
\hline
\end{tabular}

\section{c. Cuadro de relación entre modificaciones y criterios}

La Tabla 6.3 indica cuál de los cuatro criterios enunciados es cubierto por cada una de las modificaciones (tanto generales como particulares).

Tabla 6.3 - Relación entre modificaciones aplicadas y criterios enunciados

\begin{tabular}{|c|c|c|c|c|c|c|}
\hline \multirow[b]{3}{*}{ Criterios } & \multicolumn{6}{|c|}{ Modificaciones generales } \\
\hline & \multicolumn{3}{|c|}{ Modificaciones aplicables a los trámites } & \multicolumn{3}{|c|}{ Modificaciones aplicables a las reglas de negocio } \\
\hline & $\begin{array}{l}\text { Clasificador } \\
\text { EACyI }\end{array}$ & $\begin{array}{l}\text { Clasificador } \\
\text { Tipos de } \\
\text { Tramite }\end{array}$ & $\begin{array}{c}\text { Evaluación de } \\
\text { Riesgo } \\
\text { Contextual }\end{array}$ & $\begin{array}{c}\text { Distinción entre } \\
\text { procesos propios y } \\
\text { otras gestiones del } \\
\text { organismo }\end{array}$ & $\begin{array}{l}\text { Eliminación de } \\
\text { pases } \\
\text { improductivos }\end{array}$ & $\begin{array}{l}\text { Reducción del } \\
\text { número de } \\
\text { interacciones } \\
\text { del solicitante }\end{array}$ \\
\hline $\begin{array}{l}\text { 1- Gestión de Tipos de } \\
\text { Tramites según Riesgo }\end{array}$ & $\mathrm{X}$ & $\mathrm{x}$ & & $\mathrm{x}$ & $\mathrm{x}$ & $\mathrm{x}$ \\
\hline \begin{tabular}{|l|}
2 - Flexibilidad del \\
Grado de Regulacion
\end{tabular} & & & $\mathrm{X}$ & $\mathrm{x}$ & $\mathrm{x}$ & \\
\hline $\begin{array}{l}\text { 3- Compatibilidad } \\
\text { entre ámbitos }\end{array}$ & $\mathrm{x}$ & & $\mathrm{x}$ & & & $\mathrm{x}$ \\
\hline $\begin{array}{l}\text { 4- Aplicación } \\
\text { exhaustiva de } \\
\text { requisitos }\end{array}$ & $\mathrm{X}$ & $\mathrm{x}$ & & $\mathrm{x}$ & & $\mathrm{x}$ \\
\hline
\end{tabular}




\section{d. Implicaciones de indole administrativa de las modificaciones}

La aplicación de modificaciones conlleva frecuentemente la revisión de cuestiones de indole administrativa que deben considerarse para no omitir regulaciones o procedimientos que se encuentran vigentes y no pueden contradecirse.

Entre estas implicaciones podemos enumerar:

- Cumplimiento de las actuales disposiciones administrativas vigentes La implantación del nuevo esquema debe minimizar los cambios en las actuales normas que incluyan otras áreas del organismo, resultando de interés la mención especial de dos aspectos inherentes a la gestión administrativa: la gestión de expedientes debe ser realizada a través de la administración de los archivos físicos en forma paralela a la soportada informáticamente, de modo acorde a las disposiciones vigentes en la materia y deben generarse soportes en papel con firma hológrafa en todos los casos en que esté establecido y resulte necesario a partir de las nuevas normativas.

\section{- Constancia electrónica entre los actores al interior del municipio}

Sin perjuicio del soporte administrativo antes mencionado, el principio de simultaneidad de actividades presupone la necesidad de considerar válido, en el interior de la gestión de permisos de funcionamiento en todas sus fases y etapas, que tengan validez administrativa para el organismo las decisiones registradas en el sistema informático que soporte la gestión.

En tal sentido, mediante una adecuada administración de la seguridad informática en cuanto a la gestión de usuarios y claves, debería ser suficiente el registro de las decisiones por parte de los actores internos para la continuidad de la secuencia de actividades posteriores, sin prejuicio de la emisión del correspondiente soporte en papel y su integración al archivo físico o al procedimiento administrativo que correspondiera según el caso. Por ejemplo, si para realizar una verificación física determinada fuera requisito necesario la constancia del cumplimiento de determinados requisitos por parte de un solicitante, debería ser suficiente tal registro en el sistema por parte del responsable del mismo, sin necesidad de contar con el soporte en papel firmado, cuya existencia se presupondría.

De la misma manera, la emisión de certificaciones tales como viabilidad legal, permisos de funcionamiento provisorio u otras, al quedar registradas en el sistema del organismo, deberian ser consideradas existentes sin requerirse al responsable del comercio o industria su exhibición para realizar trámites en el mismo organismo relacionados con el permiso de habilitación. Este tipo de decisiones permite, por ejemplo, la notificación electrónica del otorgamiento de diferentes tipos y grados de permisos y el reconocimiento de su validez por parte del Estado regional sin necesidad de presentar el soporte físico en papel (sin perjuicio de su generación en paralelo). Lo aquí mencionado sólo se aplica en el interior de la gestión, manteniéndose la necesidad de constancias en papel ante terceros actores de acuerdo a la normativa vigente.

\section{Etapa de modelado del negocio 3-MN}

El modelado del negocio consiste en identificar los procesos y sus restricciones, describiéndolos como un conjunto de tareas, llevadas a cabo por distintos actores y según un flujo de trabajo.

Como se mencionó, nos valdremos de diagramas de casos de uso para describir la funcionalidad en forma textual y obtener un mapa de procesos. 


\section{a. Identificación de Procesos}

Los procesos principales y globales que se identifican en esta etapa son:

\section{- Proceso de Visibilidad}

Se ofrece información sobre requisitos y normativa para el otorgamiento de permisos de funcionamiento de comercios e industrias. Se ofrecerá información a toda persona que lo solicite presencialmente o a través del acceso al sitio público en Internet. No será requerida la identificación del solicitante para brindarle información. Para la obtención de información sobre un emprendimiento específico el solicitante deberá ingresar datos de la actividad económica a realizarse y de la ubicación prevista para la misma. Podrá obtenerse copia impresa de la información, ya sea desde el acceso a la Web o mediante la presencia del Solicitante en la Ventanilla Única. Complementariamente, el emprendedor podrá acceder en el portal del Municipio al punto "Guía de Trámites", para obtener información sobre la documentación y pasos a seguir en la gestión del permiso de funcionamiento de su emprendimiento. Contará también con un asesoramiento personalizado de agentes del organismo, para su necesidad específica de actividad económica a desarrollar. La etapa de la visibilidad no será un requisito de cumplimiento obligatorio.

\section{- Proceso de Viabilidad Legal de la actividad desarrollada por el comercio o industria}

La Viabilidad Legal es el primer paso de cumplimiento obligatorio para la obtención del permiso de funcionamiento del comercio o industria. El trámite de solicitud de viabilidad legal se realiza en forma presencial por parte del solicitante. Para la etapa de Viabilidad Legal deberán cumplirse los siguientes requisitos o etapas:

1. Presentación de Solicitud de Viabilidad Legal con documentación respaldatoria correspondiente.

2. Pago de tasa por el servicio.

3. Gestión Catastral (informe catastral sobre ubicación del local y cumplimiento de requisitos de registración catastral de planos, en caso de corresponder).

4. Gestión Territorial (informe acerca de la posibilidad de instalación de la actividad en el lugar físico pretendido y requisitos para hacerlo).

5. Gestión Tributaria (informe sobre situación tributaria del local y del solicitante).

6. Evaluación de viabilidad legal, que se realizará en el ámbito de gestión interna de permisos de funcionamiento, sobre la base de los informes recibidos de otras áreas del organismo referidas en los puntos anteriores.

A partir de la evaluación, se genera el informe de Viabilidad Legal, que, en caso de ser aprobado, permitirá al solicitante la continuidad del trámite de permiso de funcionamiento de la actividad económica. El Informe de Viabilidad Legal tendrá un plazo de utilización previo a su vencimiento, de acuerdo a lo que establezca la normativa.

\section{- Proceso de Permisos de Funcionamiento de la actividad desarrollada por el comercio o industria}

Es precondición contar con el Informe de Viabilidad Legal para el inicio del subproceso de Permiso de Funcionamiento de la actividad desarrollada por el comercio o industria. La identificación del Informe de Viabilidad Legal posibilitará la emisión de la Solicitud de Permiso de Funcionamiento. 
Dentro del subproceso de Permiso de Funcionamiento se consideran los siguientes pasos o actividades:

1. Cobro de derechos de permiso de funcionamiento, tasas, sellados y foliados que correspondan.

2. Caratulación del expediente de permiso de funcionamiento.

3. Verificación del cumplimiento de normativas locales, provinciales y/o nacionales.

4. Realización de verificaciones físicas.

5. Inicio de expedientes y trámites por categorizaciones y/o informes complementarios requeridos por el tipo de emprendimiento económico.

A partir de la documentación e informes integrados al trámite, el organismo otorgará certificaciones precarias (licencia precaria de funcionamiento, permiso precario de funcionamiento o empadronamiento) y/o definitivas de la actividad económica.

\section{- Proceso de Modificación de la actividad desarrollada por el comercio $o$ industria}

Es precondición contar con el Certificado de Permiso de Funcionamiento Definitivo para el inicio del subproceso de Modificación de la actividad desarrollada por el comercio o industria. La identificación del Certificado de Permiso de Funcionamiento Definitivo posibilitará la emisión de la Solicitud de Modificación.

Dentro del subproceso de Modificación se consideran los siguientes pasos o actividades:

1. Cobro de tasas.

2. Caratulación del expediente.

3. Verificación del cumplimiento de normativas locales, provinciales y/o nacionales.

4. Realización de verificaciones físicas.

A partir de la documentación e informes integrados al trámite, el organismo otorgará certificaciones precarias y/o definitivas de modificación del permiso de funcionamiento.

\section{- Proceso de Finalización de la actividad desarrollada por el comercio $o$ industria}

Es precondición contar con el Certificado de Permiso de Funcionamiento Definitivo para el inicio del subproceso de Finalización de la actividad desarrollada por el comercio o industria (exceptuando el caso de desistimiento de trámite). La identificación del Certificado de Permiso de Funcionamiento Definitivo posibilitará la emisión de la solicitud de finalización.

Dentro del subproceso de Finalización se consideran los siguientes pasos o actividades:

1. Cobro de tasas

2. Caratulación del expediente.

3. Verificación del cumplimiento de normativas locales, provinciales y/o nacionales.

4. Realización de verificaciones físicas.

A partir de la documentación e informes integrados al trámite, el organismo otorgará certificaciones de desistimiento/baja/cese de la actividad desarrollada por el comercio o industria.

\section{b. Identificación de Roles}


Una vez que se han identificado los procesos de negocio, es preciso encontrar los agentes involucrados en su realización. Cada uno de estos agentes o actores del negocio desempeña cierto papel (juegan un rol) cuando colabora con otros para llevar a cabo las actividades que conforman dicho proceso del negocio. De hecho, identificaremos los roles desempeñados por agentes del propio organismo (que incluyen Agentes, departamentos, sistemas y dispositivos físicos) o agentes externos (como empresas, comercios, ciudadanos, $u$ otros organismos regionales), según lo descripto en el Anexo 1.

\section{c. Identificación de Tareas o Actividades}

Las tareas o actividades pueden describirse funcionalmente en detalle a través de los formularios de casos de uso, que también pueden graficarse mediante un diagrama de casos de uso, que permite mostrar los límites y el entorno de la organización bajo estudio.

Se presenta el diagrama de casos de uso correspondiente al proceso de Permiso de Funcionamiento de la Actividad Económica, y se visualiza en la Figura 6.1.

En la Figura 6.2 se muestra, a modo de ejemplo simplemente, el formulario completo de uno de los casos de uso del negocio del proceso (este mismo ejemplo se utilizará en las sucesivas etapas del marco metodológico para mostrar su uso).

Finalmente la Figura 6.3 muestra un diagrama de componentes que agrupan los procesos desagregados en las principales actividades o subprocesos (en la figura referidos como módulos) y que constituyen una suerte de "mapa de procesos" realizado, en este caso, con una visión arquitectónica además de graficar el funcionamiento de la organización. 


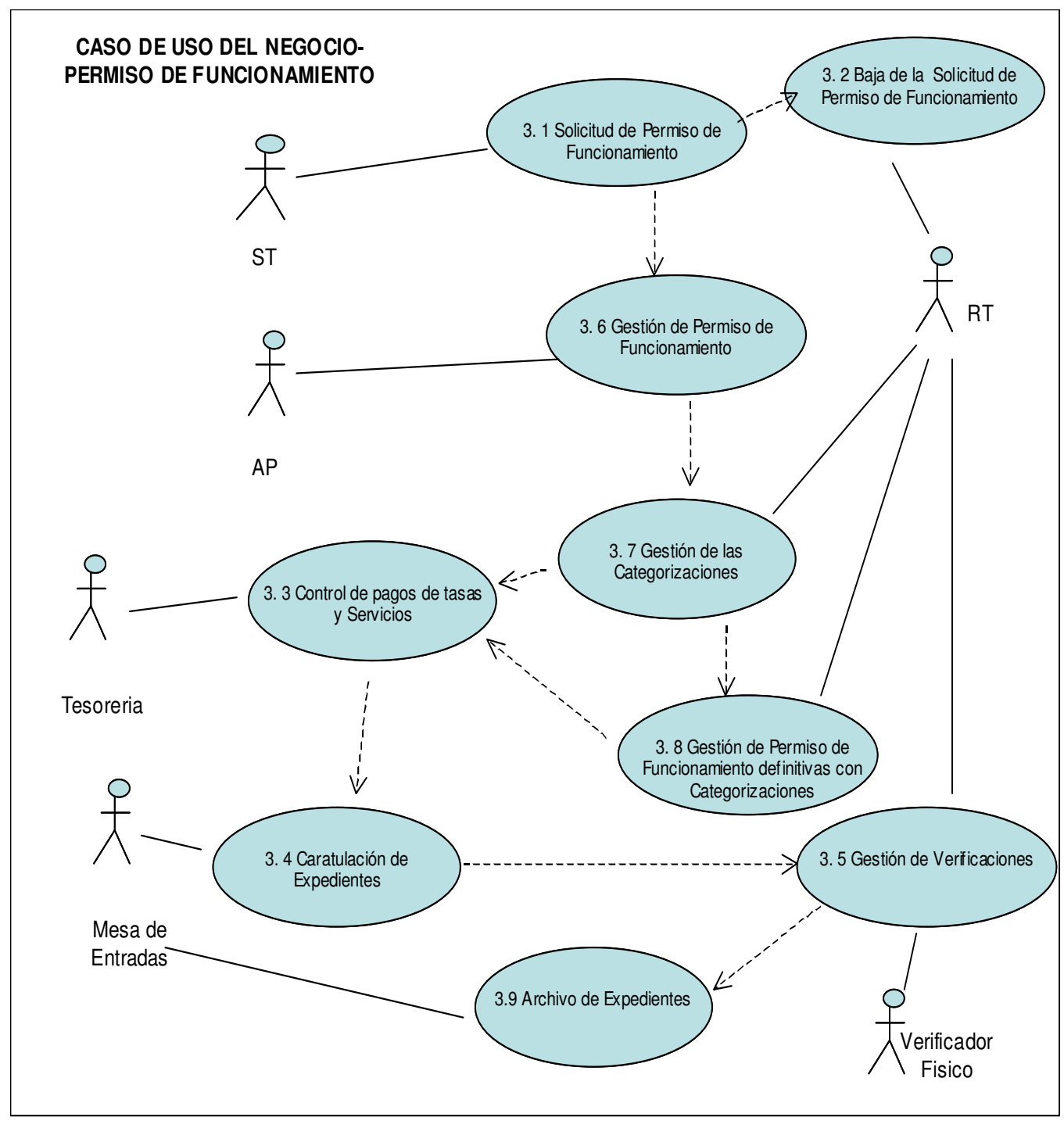

Figura 6.1. Casos de uso del negocio - Proceso "Permiso de Funcionamiento" 


\begin{tabular}{|c|c|}
\hline $\begin{array}{l}\text { Proceso: } 01 \text { - Permiso de } \\
\text { Funcionamiento de Comercios }\end{array}$ & $\begin{array}{l}\text { Modulo: } 03 \text { - Permiso de } \\
\text { Funcionamiento }\end{array}$ \\
\hline Actividad: No aplica & $\begin{array}{l}\text { Caso de Uso: } 3.0 \text { - Solicitud de Permiso } \\
\text { de Funcionamiento }\end{array}$ \\
\hline Fecha de Emisión: $10 / 10 / 2008$ & Autor: Lorel \\
\hline Revisión: 1.2 - 03/12/2008 & Revisado por: \\
\hline \multicolumn{2}{|c|}{$\begin{array}{l}\text { Descripción: } \\
\text { Inicia la solicitud del certificado de permiso de funcionamiento para industr } \\
\text { y comercio }\end{array}$} \\
\hline
\end{tabular}

Actores internos:

Solicitante de trámite (ST).

Atención Primaria (AP).

Precondiciones:

Solicitud de Viabilidad Legal aprobada.

\section{Regla del Negocio:}

Clasificador de la especie o género de la actividad desarrollada por el comercio o industria

\section{Flujo Normal:}

1. El Solicitante del Trámite (ST) se presenta en la ventanilla con su Informe de Viabilidad Legal aprobado, solicitando el inicio del trámite de Permiso de Funcionamiento. El Responsable del Tramite (RT), en base al código de trámite de Viabilidad Legal, verifica en el sistema que el mismo no se encuentre vencido y recupera toda la información asociada al mismo.

2. AP, junto con el ST, verifican la validez de toda la información presentada con la informada por el sistema.

3. Confirmada la validez de los datos, se accede a través del sistema al Clasificador EACyI para identificar el impacto social y ambiental. En base a esta información se determina si es necesaria una solicitud de permiso de funcionamiento o una solicitud de categorización y permiso de funcionamiento. Además, se efectúa el pedido de la documentación necesaria para el tipo de trámite, la cual le fue oportunamente indicada al solicitante en el informe de Viabilidad Legal.

4. Se registra la documentación solicitada.

5. Se asigna un código único de trámite de solicitud de permiso de funcionamiento y el trámite se pondrá en estado "HB Iniciada".

6. Cumplimentada por parte del solicitante la documentación requerida, el sistema registra dicha documentación, genera el remito para su incorporación al legajo correspondiente y cambia al estado "HB Solicitud Emitida Para Cobro de Derechos".

7. El sistema emite, según el tipo de trámite, la Solicitud de Permiso de Funcionamiento o la Solicitud de Permiso de Funcionamiento con la Solicitud de Categorización.

8. Visto en 03.1 se emite "Solicitud de Permiso de Funcionamiento" o "Solicitud de Permiso de Funcionamiento y Solicitud de Categorización para Cobro de Derechos" según corresponda a un determinado tipo de permiso. El formulario de pago incluye el monto (calculado de acuerdo a una tabla de tasas para cada tipo de permiso) y un código de barras con datos identificatorios del mismo. Por cada formulario emitido, el 


\section{Caso de Estudio}

sistema generará para el solicitante un pago pendiente.

9. El pago será incorporado al sistema de permisos de funcionamiento mediante la interfaz con el sistema informático del organismo en la tesoreria. Este pago constituye una condición previa para el seguimiento del trámite de viabilidad legal, y el trámite pasará al estado de "HB Derechos Cobrados".

10. El actor realiza el control de pagos de la tasa de solicitud del permiso de funcionamiento.

11. El sistema permitirá asignar una vigencia a las Solicitudes de Permisos de Funcionamiento mientras se encuentren pendientes por falta de pago.

Flujo Alternativo:

El solicitante cancela su solicitud de permiso de funcionamiento

Poscondiciones:

Solicitud de permiso de funcionamiento pendiente de pago.

Solicitud de permiso de funcionamiento con categorización, pendiente de pago.

Remito para incorporar información en el legajo.

Figura 6.2. Formulario de caso de uso del negocio "Solicitud de Permiso de Funcionamiento" 


\section{Caso de Estudio}

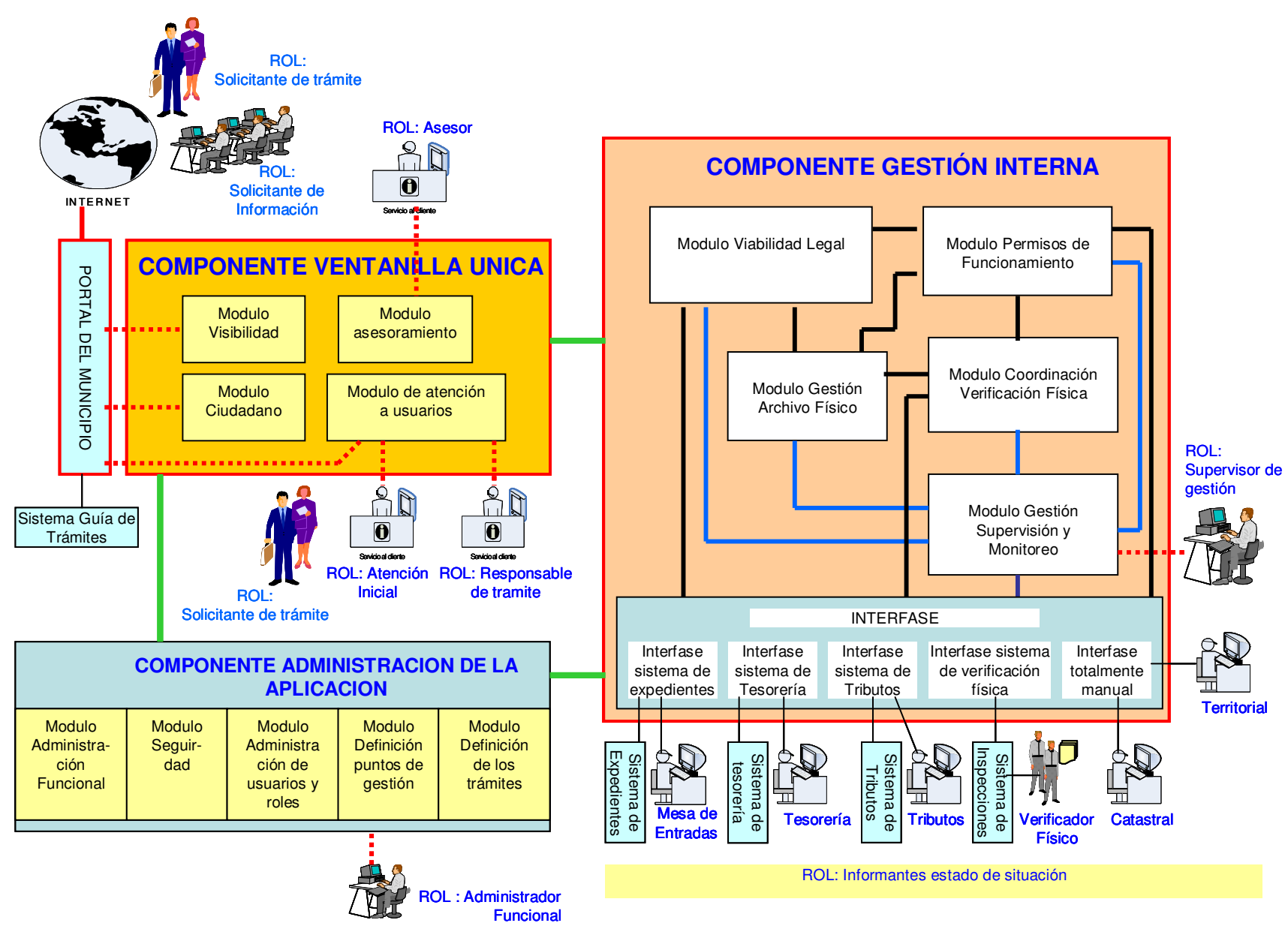

Figura 6.3. Mapa de procesos y arquitectura de los componentes de la solución 


\section{Caso de Estudio}

\section{Etapa de modelado de procesos 4-MP}

En esta etapa se aplican las técnicas de modelado de procesos basado en BPMN y acompañado por los casos de uso del sistema, documentados por los formularios preestablecidos.

Como se mencionó en la sección 6.3 continuaremos trabajando sobre el proceso "Solicitud de Permiso de Funcionamiento" para mostrar la aplicación de las técnicas y pasos definidos para esta etapa.

La Figura 6.4 muestra el diagrama de casos de uso del proceso mencionado y luego se presenta el formulario asociado a cada uno de los casos de uso específicos de este proceso. Los casos de uso numerados con valores distintos de 3.0 se corresponden a los provenientes de otros procesos no modelados en este informe por razones de simplicidad.

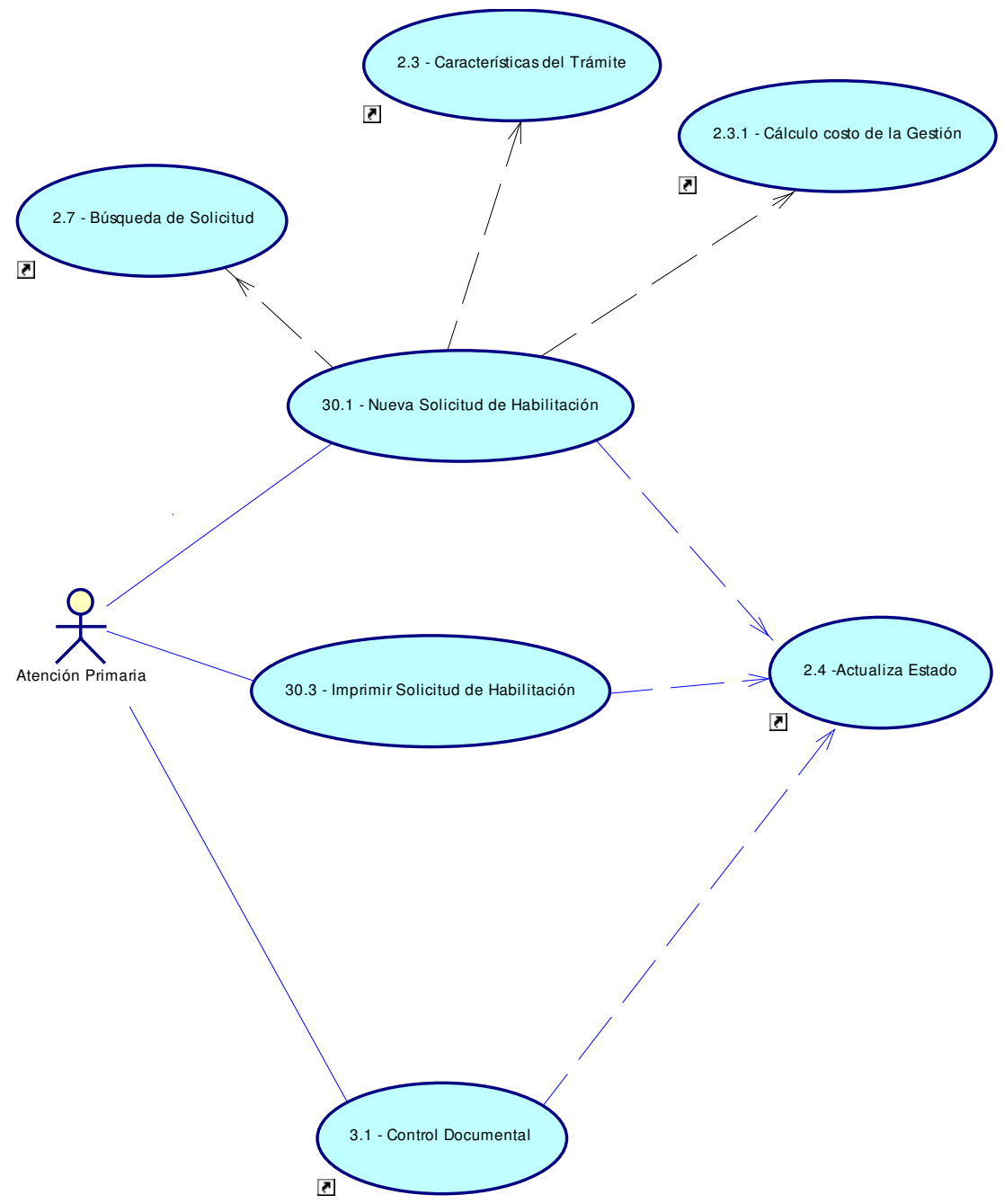

Figura 6.4. Diagrama de Casos de Uso del Subproceso "Solicitud de Permiso de Funcionamiento" 


\section{Proceso: Permiso de Funcionamiento}

Actividad: Solicitud de Permiso de Funcionamiento

Fecha de Emisión: $13 / 06 / 2008$

Revisión: 1.1 - 13/06/2008

Descripción:

Incorpora Solicitudes de Habilitación (SH) con estado "HB Iniciada", para lo cual deberán recuperarse los datos básicos de Viabilidad Legal para luego completarse el resto de datos exigidos.

Actores:

Atención Primaria.

Precondiciones:

1. La Solicitud de Permiso de Funcionamiento se genera a partir de un Certificado de Viabilidad Legal recibido por el Solicitante.

2. El Actor debe ser "Atención Primaria" autenticado del Sistema con perfil habilitado para el ingreso de $\mathrm{SH}$.

Regla del Negocio:

No Aplica

\section{Flujo Normal:}

1. El Actor a través de opción "Nueva Solicitud" del submenú "Administrador Solicitud" del Menú Permiso de Funcionamiento seleccionará el tipo de acceso al Sistema. Si desea iniciar la carga de una nueva Solicitud de Permiso de Funcionamiento (SP) o si requiere al acceso a una SP existente en estado inicial.

2. El Sistema recupera por CASO DE USO “2.7 - Búsqueda de Solicitud" el contenido del trámite de Viabilidad Legal Aprobado (estado SF Informada Aprobada)

3. El Sistema con el trámite clasificado identifica requisitos de documentación, pasos del trámite a cumplimentar y derechos y otros gastos del trámite a través de los CASOS DE USO "2.3 Características del Trámite" y "2.3.1 Cálculo del Costo de la Gestión".

4. El Sistema comprueba y exige el ingreso de los datos especificados como obligatorios por tablas.

5. El actor podrá confirmar el ingreso de la solicitud (botón Grabar).

6. Si los datos no son válidos el sistema informa el motivo al Actor y permite su reingreso.

7. Si la opción es Volver el sistema deja la pantalla de carga (sin guardar)

8. El Sistema asigna número de trámite por la Solicitud de Habilitación.

9. El Sistema registra estado de trámite a través de CASO DE USO "2.4 Actualiza Estado" (SH Iniciada)

10. El Sistema, complementariamente procederá por CASO DE USO “41. Habilitación de Pago" a notificar por Interfaz con Sistema de Gestión Interna del organismo la disponibilidad del derecho de trámite.

11. El Actor complementariamente puede obtener un reporte al seleccionar botón "Imprimir" (CASO DE USO- "3.03 Imprimir Solicitud de Habilitación") y emitirá Comprobante de Pago por CASO DE USO "4.11 Impresión de Comprobante de Pago".

12. Emitido el Comprobante de Pago el Sistema registra estado de trámite a través de CASO DE USO “2.4 Actualiza Estado" como (HB Solicitud Emitida para Cobro de Derechos)

Flujo Alternativo:

Si no se identifica Solicitud de Viabilidad Legal no podrá iniciarse el ingreso de la Solicitud de Permiso de Funcionamiento 


\section{Poscondiciones:}

Solicitud de Permiso de Funcionamiento registrada en el Sistema con estado "HB Iniciada" (fecha de estado inicial y Número de solicitud de permiso de funcionamiento generado)

\begin{tabular}{|c|c|c|c|c|}
\hline Código & Descripción & $\begin{array}{c}\text { Tipo de } \\
\text { Dato }\end{array}$ & Dominio & Validación \\
\hline Tramite Id & $\begin{array}{l}\text { Id. Único del } \\
\text { trámite }\end{array}$ & Numérico & Autoincremental & \\
\hline Tramite FAlta & $\begin{array}{l}\text { Fecha en que se } \\
\text { genera el trámite }\end{array}$ & Fecha & & $\begin{array}{l}\text { Superior a la } \\
\text { fecha actual }\end{array}$ \\
\hline Tramite Codigo & $\begin{array}{l}\text { Código } \\
\text { identificatorio del } \\
\text { trámite }\end{array}$ & Alfanumérico & & \\
\hline Tramite NroExp & $\begin{array}{l}\text { Número de } \\
\text { expediente por el } \\
\text { cual se tramita }\end{array}$ & Alfanumérico & & \\
\hline Tramite Obs & $\begin{array}{l}\text { Observaciones } \\
\text { del trámite }\end{array}$ & Texto & & \\
\hline Tramite RRadio & $\begin{array}{l}\text { Indica si el } \\
\text { trámite posee } \\
\text { restricciones de } \\
\text { radio }\end{array}$ & Booleano & $\mathrm{Si} / \mathrm{No}$ & \\
\hline Tramite RVerif & $\begin{array}{l}\text { Indica si existen } \\
\text { restricciones } \\
\text { verificadas sobre } \\
\text { el trámite }\end{array}$ & Booleano & $\mathrm{Si} / \mathrm{No}$ & \\
\hline Permiso Id & $\begin{array}{l}\text { Identificador } \\
\text { único de Permiso } \\
\text { de } \\
\text { Funcionamiento }\end{array}$ & Numérico & Autoincremental & \\
\hline Tramite PFVig & $\begin{array}{l}\text { Indica si el } \\
\text { permiso está } \\
\text { vigente }\end{array}$ & Booleano & $\mathrm{Si} / \mathrm{No}$ & \\
\hline $\begin{array}{l}\text { Tramite PF } \\
\text { FFVig }\end{array}$ & $\begin{array}{l}\text { Fecha de Fin de } \\
\text { Vigencia del } \\
\text { Permiso de } \\
\text { Funcionamiento }\end{array}$ & Fecha & & $\begin{array}{l}\text { Superior a la } \\
\text { fecha de alta } \\
\text { del trámite }\end{array}$ \\
\hline DocTramite Id & $\begin{array}{l}\text { Identificador de } \\
\text { la documentación } \\
\text { asociada al } \\
\text { trámite }\end{array}$ & Numérico & Autoincremental & \\
\hline $\begin{array}{l}\text { DocTramite } \\
\text { Fecha }\end{array}$ & $\begin{array}{l}\text { Fecha en que se } \\
\text { asocia la } \\
\text { documentación al } \\
\text { trámite }\end{array}$ & Fecha & & $\begin{array}{l}\text { Superior a la } \\
\text { Fecha de } \\
\text { Alta }\end{array}$ \\
\hline $\begin{array}{l}\text { DocTramite } \\
\text { Requerido }\end{array}$ & $\begin{array}{l}\text { Indica si la } \\
\text { documentación } \\
\text { es requerida }\end{array}$ & Booleano & $\mathrm{Si} / \mathrm{No}$ & \\
\hline $\begin{array}{l}\text { DocTramite } \\
\text { Cant Copias }\end{array}$ & $\begin{array}{l}\text { Cantidad de } \\
\text { copias de la } \\
\text { documentación } \\
\text { asociada al } \\
\text { trámite } \\
\end{array}$ & Numérico & & $\begin{array}{l}\text { Número } \\
\text { mayor que } \\
\text { cero. }\end{array}$ \\
\hline $\begin{array}{l}\text { DocTramite } \\
\text { FCaducidad }\end{array}$ & $\begin{array}{l}\text { Fecha de } \\
\text { caducidad de la } \\
\text { documentación }\end{array}$ & Fecha & & $\begin{array}{l}\text { Superior a la } \\
\text { fecha de } \\
\text { asociación. }\end{array}$ \\
\hline
\end{tabular}

Figura 6.5. Formulario de Caso de Uso "Nueva Solicitud de Permiso de Funcionamiento" con Diccionario de datos 


\section{Proceso: Permiso de Funcionamiento}

Actividad: Solicitud de Permiso de Funcionamiento

Fecha de Emisión: $13 / 06 / 2008$

Revisión: $1.1-13 / 06 / 2008$

\section{Descripción:}

Se genera una impresión de la Solicitud de Permiso de Funcionamiento y DDJJ a partir de la definición de tipo de reporte y las características de la impresión

Actores:

Atención Primaria.

\section{Precondiciones:}

1. Estar seleccionado botón "Imprimir SH" de pantalla VUHBP_301.

2. Estado Trámite = "HB Documentación Recibida"

\section{Regla del Negocio:}

No Aplica

\section{Flujo Normal:}

1. El Actor accede a Botón "Imprimir Solicitud" de pantalla VUHBP_301.

3. El Actor selecciona opciones de forma de la impresión.

4. Se dispondrá la impresión de la Solicitud de Habilitación y en la misma acción la impresión de Comprobante de Pago por los derechos específicos del trámite por intermedio de caso de uso "4.11 Emite Comprobante de Pago"

5. El Sistema realiza presentación preliminar del Listado.

6. El Sistema genera salida seleccionada.

\section{Flujo Alternativo:}

$$
\text { No Aplica }
$$

\section{Poscondiciones:}

Estado de Trámite de Permiso de Funcionamiento "HB Solicitud Emitida para el Cobro de Derechos"

\begin{tabular}{|l|l|l|l|l|}
\hline \multicolumn{1}{|c|}{ Código } & \multicolumn{1}{|c|}{ Descripción } & Tipo de Dato & Dominio & Validación \\
\hline $\begin{array}{l}\text { Tramite } \\
\text { Codigo }\end{array}$ & $\begin{array}{l}\text { Código } \\
\text { identificatorio del } \\
\text { trámite }\end{array}$ & Alfanumérico & & \\
\hline $\begin{array}{l}\text { Persona } \\
\text { CUIP }\end{array}$ & $\begin{array}{l}\text { Código Único de } \\
\text { Identificación de } \\
\text { Persona }\end{array}$ & Alfanumérico & & \\
\hline $\begin{array}{l}\text { Persona } \\
\text { NDoc }\end{array}$ & $\begin{array}{l}\text { Número de } \\
\text { documento de la } \\
\text { persona }\end{array}$ & Numérico & & Mayor que \\
\hline $\begin{array}{l}\text { Persona } \\
\text { Apellido }\end{array}$ & $\begin{array}{l}\text { Apellido de la } \\
\text { Persona }\end{array}$ & Alfanumérico & & 1.000 .000 \\
\hline $\begin{array}{l}\text { Persona } \\
\text { Nombres }\end{array}$ & $\begin{array}{l}\text { Nombres de la } \\
\text { persona }\end{array}$ & Alfanumérico & & \\
\hline $\begin{array}{l}\text { Domicilio } \\
\text { Calle }\end{array}$ & $\begin{array}{l}\text { Calle del domicilio } \\
\text { de contacto }\end{array}$ & Alfanumérico & & \\
\hline $\begin{array}{l}\text { Domicilio } \\
\text { Numero }\end{array}$ & $\begin{array}{l}\text { Número de puerta } \\
\text { del domicilio de } \\
\text { contacto }\end{array}$ & Alfanumérico & & \\
\hline $\begin{array}{l}\text { Domicilio } \\
\text { Telefono }\end{array}$ & $\begin{array}{l}\text { Teléfono del } \\
\text { domicilio de }\end{array}$ & Alfanumérico & & \\
\hline
\end{tabular}




\section{Caso de Estudio}

\begin{tabular}{|l|l|l|l|l|}
\hline & contacto & & & \\
\hline $\begin{array}{l}\text { Tramite } \\
\text { Costo }\end{array}$ & Costo del trámite & Monetario & & Mayor que cero \\
\hline
\end{tabular}

Figura 6.6. Formulario de Caso de Uso "Imprimir Solicitud de Permiso de Funcionamiento y DDJJ" con Diccionario de Datos
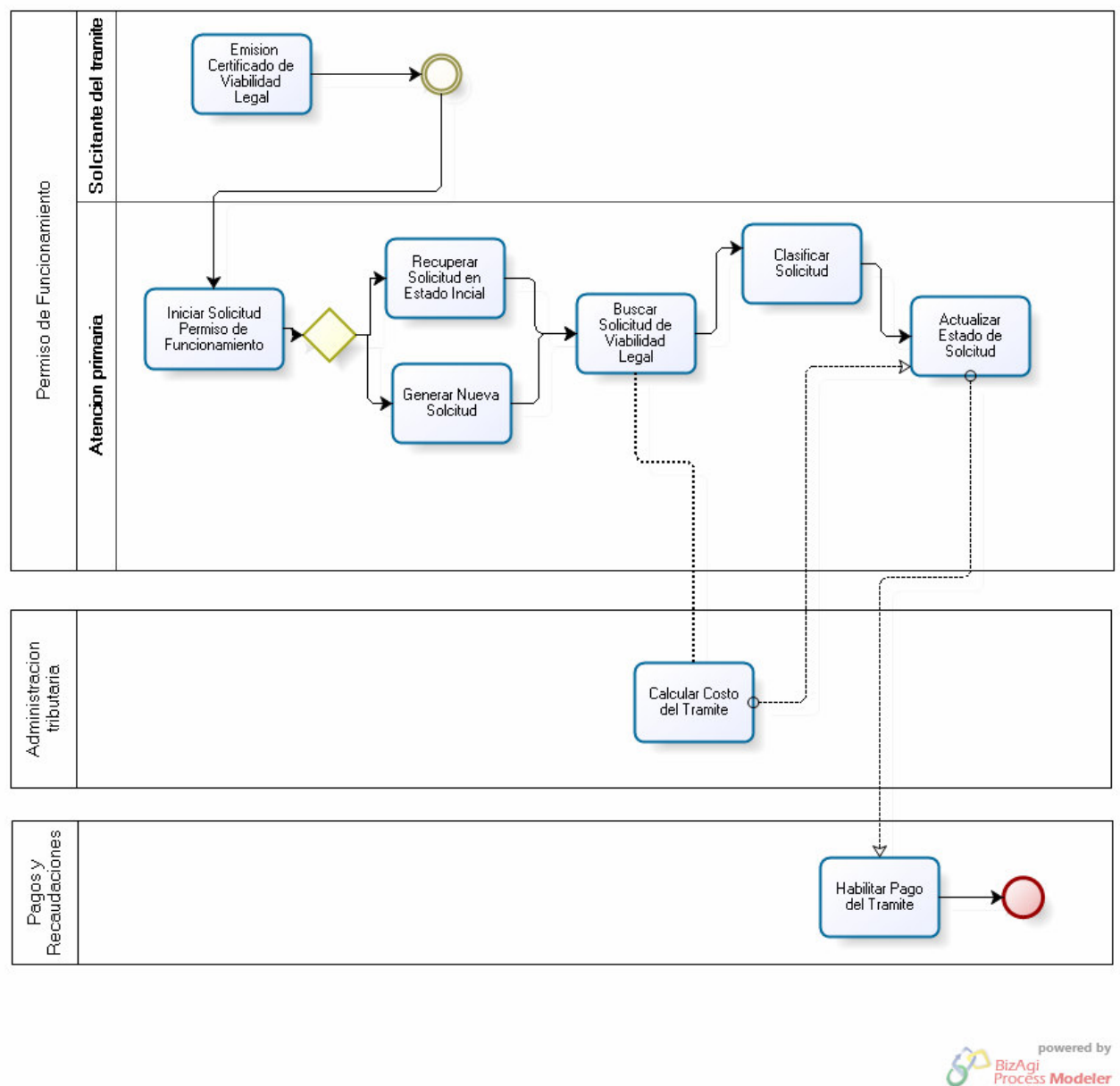

Figura 6.7. Diagrama BPMN del Proceso de "Nueva Solicitud de Permiso de Funcionamiento"

Las Figuras 6.5 y 6.6 muestran los formularios para casos de uso propuestos en la metodología, que contienen la descripción funcional de las actividades.

En la Figura 6.7 se presenta el diagrama de procesos en BPMN, utilizando la herramienta BizAgi Process Modeler. En este diagrama cada proceso se representa por un pool y cada uno de los roles por un lane.

\section{Etapa de modelado de servicios 5-MS}

Continuando con el proceso de "Solicitud de Permiso de Funcionamiento", identificaremos en esta etapa los servicios que resuelven la funcionalidad requerida por los procesos, sean éstos nuevos o resueltos por otras aplicaciones. Como mencionamos en el capítulo 5 utilizaremos la notación de círculos con cordones para el modelado de servicios y completaremos las fases definidas en [1] para el diseño: 
1. identificar y categorizar servicios,

2. especificar los servicios definiendo contratos y operaciones,

3. investigar servicios existentes.

La última fase planteada en [1] como "asignación a componentes" se aborda en la etapa 6-DC de nuestro modelo.

Cabe señalar también que el hecho de utilizar la notación de círculos con cordones conlleva a especificar los servicios incluyendo sus operaciones o capacidades, por lo que para la segunda fase solo restaria definir los contratos.

1. La identificación de servicios y operaciones consiste en definir y especificar los servicios a partir de los procesos de negocios. En este marco, se identifican tres servicios de distinto nivel de abstracción: por un lado el servicio "permiso de funcionamiento" que incluye las capacidades necesarias para dar respuesta al proceso del mismo nombre como son: iniciar la solicitud, clasificar, presupuestar y cobrar y finalmente imprimir el permiso provisorio. Este servicio puede identificarse como un servicio abstracto del cual se derivan dos servicios concretos: "solicitud" y "trámite". Estos dos servicios contienen las capacidades o funcionalidades requeridas por el proceso para poder dar respuesta al servicio de mayor nivel de abstracción.

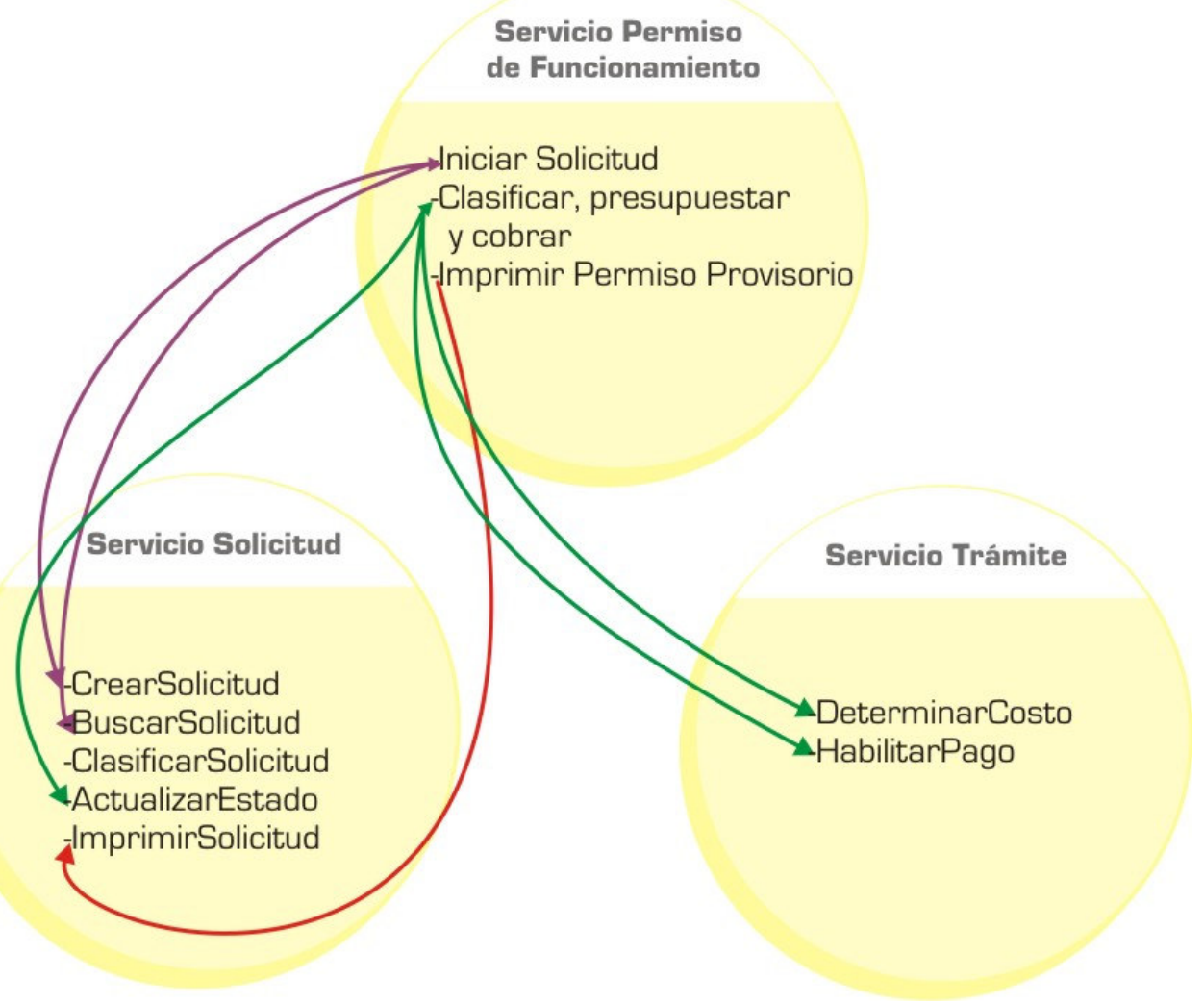

Figura 6.8. Diagrama de servicios identificados y categorizados

A diferencia del paradigma de orientación a objetos, este modelo no representa un sistema funcional. No existe el sentido de flujo, ni descripción de eventos y reglas de negocios. 
En la arquitectura basada en servicios, la coreografia de los procesos, mantenida externamente a los servicios, determina la secuencia y el ritmo de ejecución de las invocaciones a servicios.

2. La definición de contratos consiste en identificar los datos de entrada y salida de cada servicio, que serán utilizados en la etapa de definición de componentes como las interfaces de las mismas.

Como se mencionó en el Capítulo 5, la notación de círculos con cordones es una notación extensible. En este caso, la extenderemos para poder identificar los contratos de cada servicio.

En la figura 6.9 se muestra el servicio Trámite con la definición del contrato indicada entre paréntesis luego de su nombre.

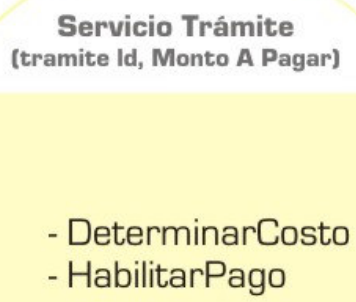

Figura 6.9. Servicio Trámite con la especificación de su interfaz

3. Investigar servicios existentes. Esta fase de la etapa del modelado de servicios, consiste en determinar cuáles de todos los servicios se encuentran funcionalmente resueltos por otras aplicaciones o han sido ya identificados por otros procesos.

En este caso, el servicio Trámite con sus dos capacidades: Determinar Costo y HabilitarPago.

\section{Etapa de definición de componentes 6-DC}

Tal como se definió en el Capítulo 5, en esta etapa se trata de precisar la manera en que se componen y empaquetan funcionalidades, sean éstas existentes o nuevas para construir piezas funcionales que puedan registrarse en un repositorio común.

En el caso de estudio que se plantea, vemos como queda representado el proceso "Permiso de Funcionamiento", en términos de actividades ejecutables. Estas unidades ejecutables se orquestan bajo un diagrama BPEL de procesos ejecutables, como se muestra en la Figura 6.9. 


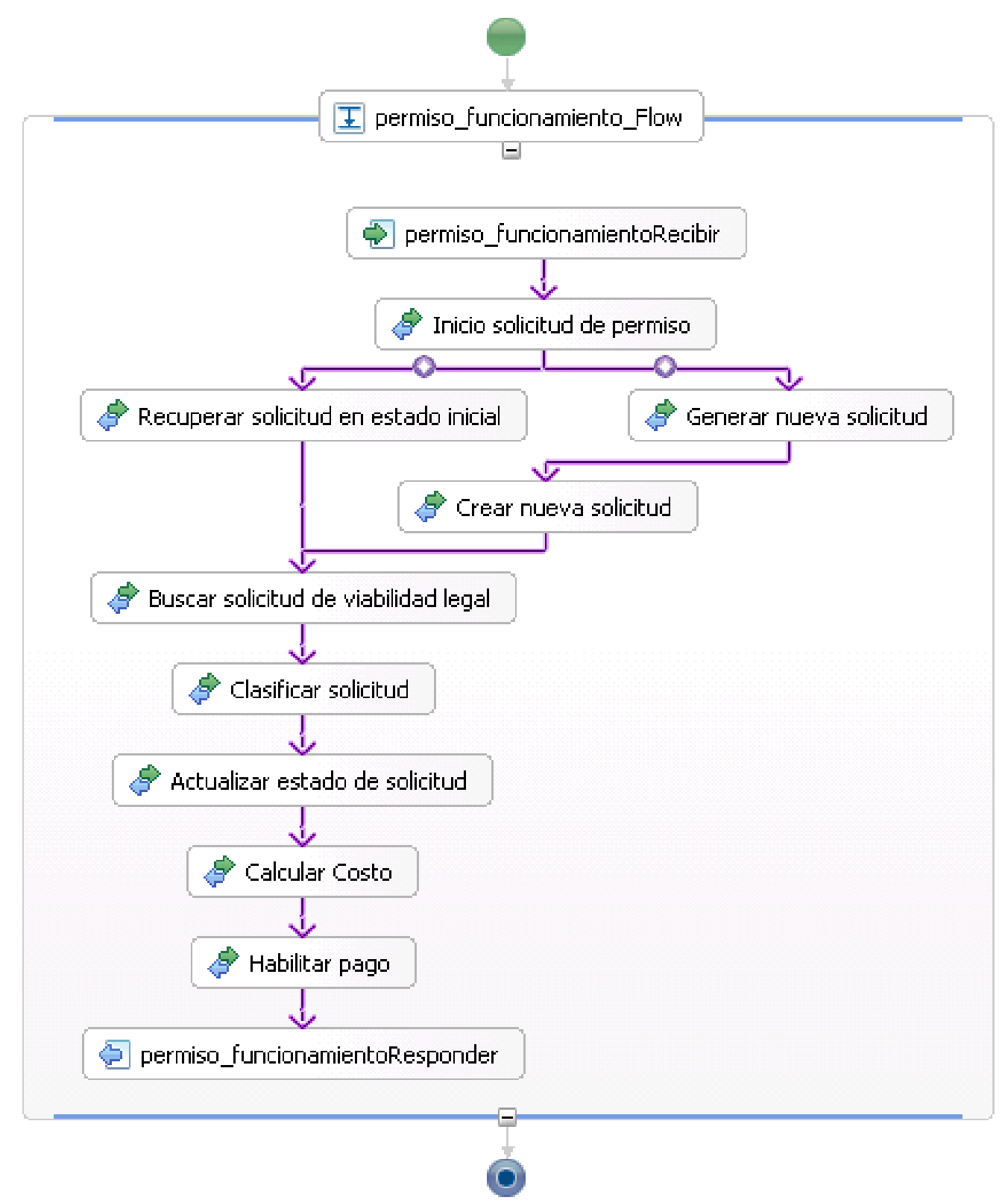

Figura 6.10. Diagrama BPEL del proceso de "Permiso de Funcionamiento"

La construcción de este diagrama corresponde a un mapeo directo que puede realizarse entre un diagrama de procesos en BPMN y BPEL. Por lo tanto, es una actividad de la etapa 6-DC que contará con el nivel de automatización que provea la herramienta elegida para llevar a cabo esta metodologia.

La derivación automática de código BPEL a partir de BPMN [42], ha sido y continúa siendo uno de los aspectos más buscados en los sistemas de gestión de procesos de negocios o BPMS [44].

En este caso, el proceso de negocio BPEL que se utiliza es un proceso abstracto dado que BPEL es un lenguaje de ejecución de procesos para Web Service y nuestra metodología se basa en el concepto de servicios genéricos, donde los Web Services pueden ser una implementación posible (como se verá en la siguiente sección). 


\section{Caso de Estudio}

El paso siguiente a este diagrama BPEL se corresponde con la identificación de los componentes funcionales del proceso en cuestión según el estándar SCA, tal como se muestra en la Figura 6.11

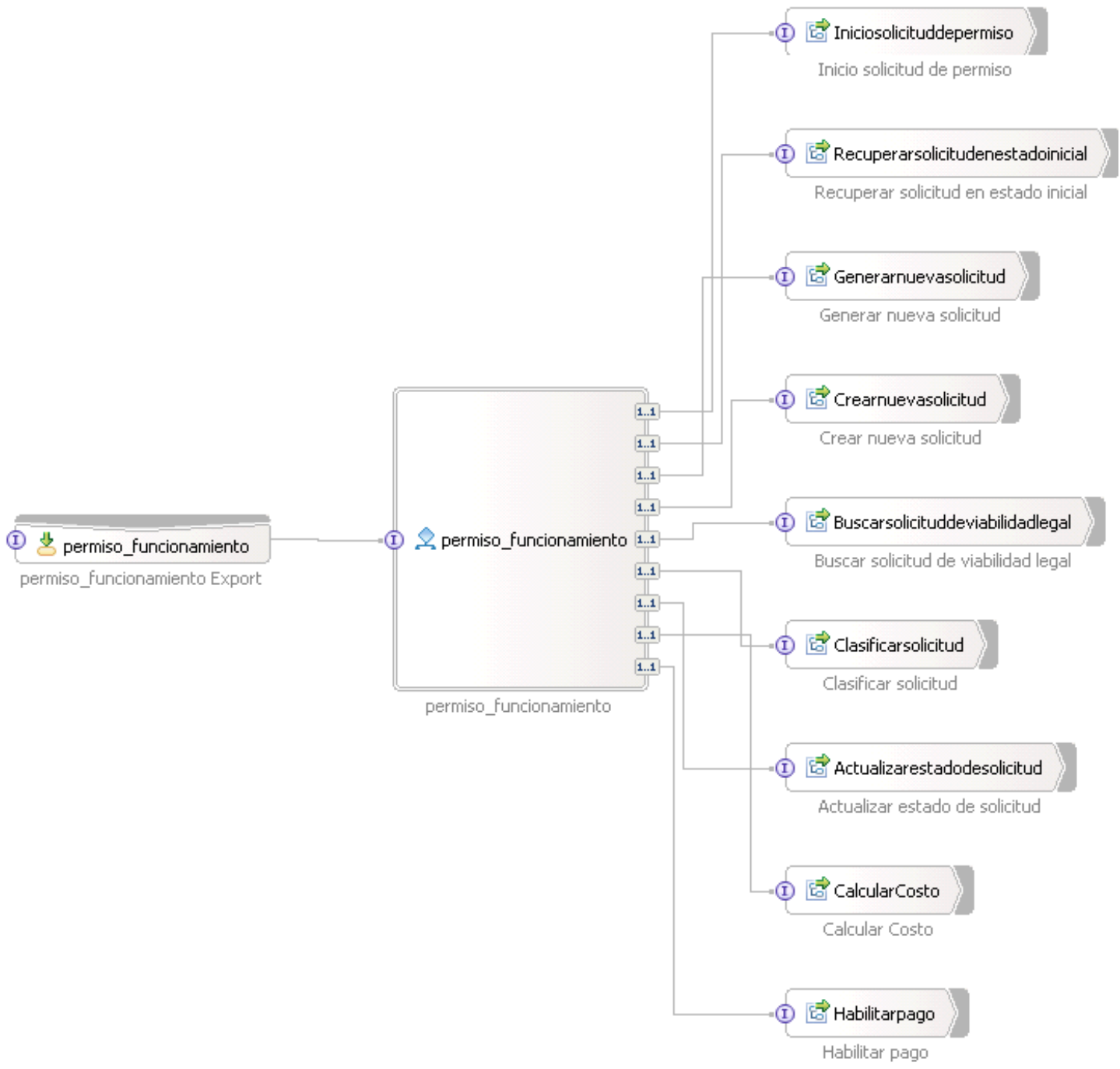

Figura 6.11. Diagrama de ensamblado de componentes del proceso Permiso de Funcionamiento

\section{Implementación de componentes 7-IC}

En el marco que se plantea en este caso de estudio, la implementación de los componentes se transformará en la codificación de clases Java para los servicios nuevos y la invocación a Web Services para el caso en que el servicio se encuentre ya resuelto por otras aplicaciones existentes, como es el caso del CalcularCosto o HabilitarPago. 


\section{Caso de Estudio}

En la figura 6.12 se ve el diagrama de ensamblado de cada componente del proceso Permiso de Funcionamiento y su mapeo al tipo de implementación. En la figura se encuentra marcada la diferencia gráfica según el tipo de implementación de cada componente.

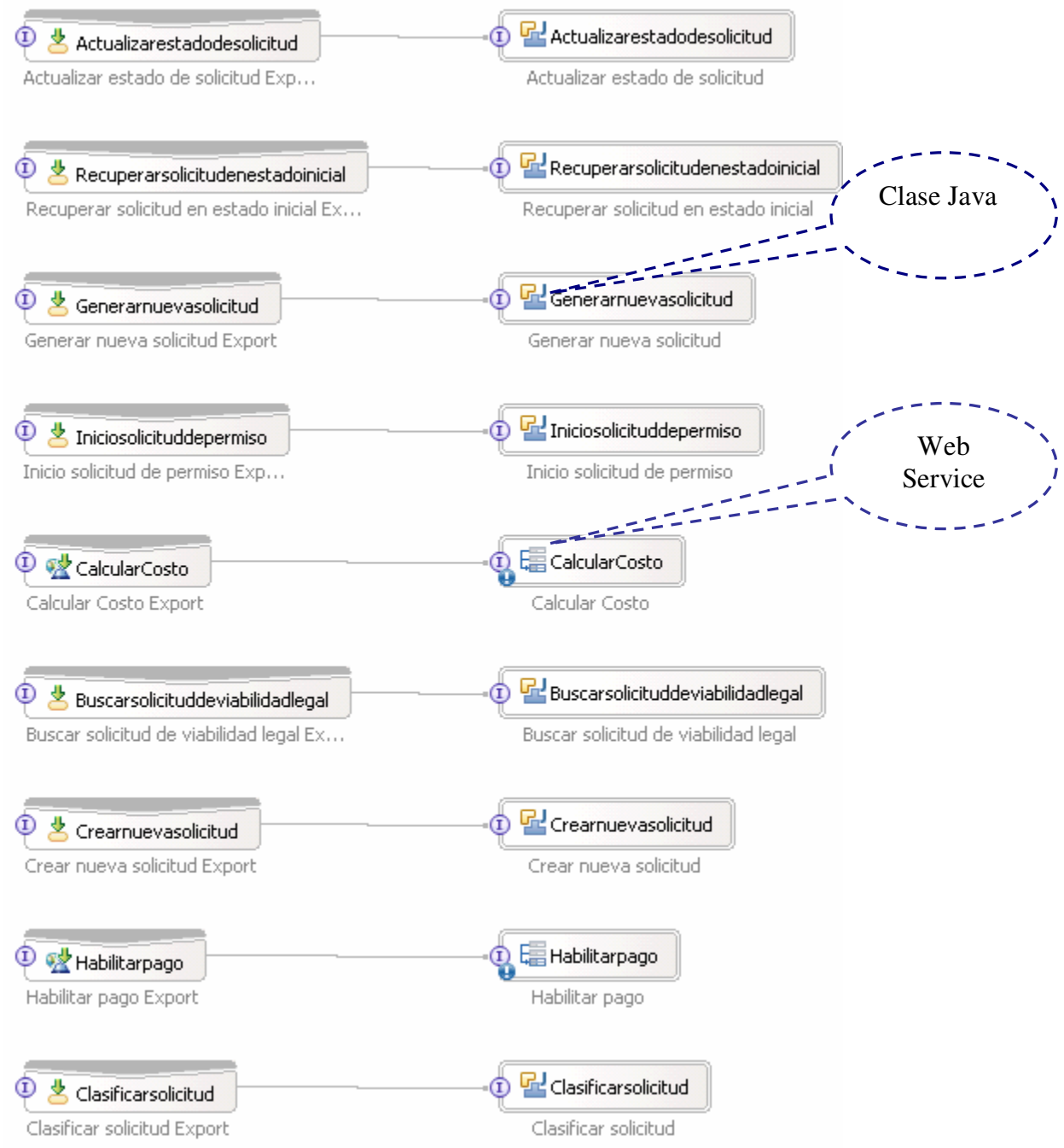

Figura 6.12. Diagrama de implementación de componentes

A partir de este diagrama de ensamblado se realiza la programación de cada componente o bien la invocación al Web Service correspondiente.

Esta etapa es la que más vinculación tiene con las diferentes herramientas de desarrollo basadas en BPM.

La idea subyacente es que el entorno de ejecución de estos componentes sea un motor de procesos que posea la infraestructura necesaria para mantener la corrida del proceso, tal y como fue modelado en las etapas anteriores. 


\subsection{Lecciones aprendidas y estado actual de la tecnologia}

Durante el desarrollo del caso de estudio presentado se analizaron, evaluaron y utilizaron distintos productos de BPM para poder abordar la solución de cada una de las etapas propuestas en la metodología.

El proceso de "Permiso de Funcionamiento" fue desarrollado en su totalidad en la herramienta IBM WebSphere BPM que se analiza también en esta sección. Previo a ello se realizaron algunos pasos de la etapa de modelado de procesos en diversos modeladores basados en BPMN como JBoss jBPM (https://www.jboss.com/products/jbpm/) y BizAgi Process Modeler (http://www.bizagi.com/).

Asimismo se analizó la implementación de Web Services en tecnología Java, utilizando el motor de ejecución de BPEL provisto por JBoss jBPM.

Como resultado de la aplicación de cada tecnología se pudieron apreciar diversos aspectos que deben tenerse en cuenta en la evaluación y uso de un BMPS. Estos aspectos se definen como un conjunto de requisitos a cumplir y que son de interés a la hora de elegir una herramienta que permita gestionar más adecuadamente los cambios y el impacto de sus procesos en el área de tecnología.

Asimismo, se clasificaron tres de las herramientas de BPM más populares del mercado actual, se analizaron los requisitos exigidos y se determinaron cuales de las etapas de la metodología propuesta estaban cubiertas por cada componente de la herramienta.

En los siguientes puntos se describen los requisitos a cumplir por las herramientas de BPM.

\section{- Soporte para todo el ciclo de vida de los procesos}

Este requisito mide las etapas del ciclo de vida y los roles de los actores en un proceso de negocio. Las etapas son: modelado, ensamblado, despliegue y el soporte de roles que faciliten la tarea del analista del negocio (para el modelado), del arquitecto de componentes (para el ensamblado) y del desarrollador (para el despliegue). Es fundamental determinar si la herramienta soporta todas las fases y lo hace unificadamente, sin necesidad de importación/exportación de archivos. El soporte unificado también garantiza una actualización consistente en todos los archivos fuentes teniendo en cuenta los cambios frecuentes en las múltiples fases.

En cuanto al soporte de roles es muy provechoso contar con múltiples visiones de un mismo proceso de negocio delimitando las actividades habilitadas para cada caso.

- Simulación en tiempo real y optimización

Entendemos por simulación en tiempo real y optimización como la manera de medir el rendimiento de los modelos utilizando datos operacionales en tiempo real o bien registros históricos que permitan evaluar comportamiento ante distintos escenarios.

Para poder realizar simulaciones es preciso poder definir parámetros de costo y tiempo de cada actividad y especificar también la probabilidad de los diferentes caminos de los procesos.

Soporte para monitoreo

Una vez desplegado el proceso y puesto en ejecución es preciso contar con herramientas que capturen métricas o KPIs para analizar rendimiento y también para construir dashbords para entender cuellos de botella y retardos de los procesos y tomar acciones correctivas.

\section{- Soporte para SOA}

Este aspecto evalúa en qué medida la herramienta brinda soporte para acoplarse a una arquitectura orientada a servicios. El soporte del lenguaje BPEL (Business Process Execution Language) y la adhesión al estándar SCA (Service Component Architecture) [51] garantizan que los procesos de negocios se transformen en los 


\section{Caso de Estudio}

consumidores de los servicios ofrecidos por SOA. Frecuentemente las organizaciones cuentan con un activo tecnológico desarrollado y estable que requiere ser integrado en términos de procesos de negocio.

- Integración con IDEs

Esta caracteristica mide la capacidad de integración con un IDE tanto de la comunidad de software libre como propietaria. Los entornos de desarrollo cuentan con definición de múltiples visiones, editores contextuales, compiladores, depuradores y ejecutores integrados, y paletas de componentes gráficas para arrastrar-soltar que agilizan la producción de software. Las herramientas analizadas pueden cubrir todas las etapas del ciclo de vida del software hasta su implementación. En este caso es importante medir en qué grado la herramienta BPM posee un entorno de desarrollo propio o la capacidad de integrarse alguno existente y popular dentro de la comunidad de desarrolladores.

\section{- Soporte a tareas humanas}

Las herramientas de BPM con soporte para interacción humana (human task) permiten resolver partes de extensos procesos que poseen partes automatizadas y otras no. El objetivo es dar soporte para la interacción humana pero automatizando el control de las actividades ejecutadas de esta manera, según el modelo de procesos.

A continuación se describen de manera esquemática las tres herramientas elegidas para evaluar los requisitos exigidos y su grado de aplicación en cada etapa del marco metodologico propuesto.

- JBoss Enterprise SOA Platform que incluye una arquitectura orientada a servicios (SOA) y está compuesta por las siguientes componentes open source [52]: JBoss Enterprise Eervice Bus (ESB) (orquestación de servicios), JBoss jBPM (modelado), JBoss Rules (motor de reglas) y JBoss Enterprise Application Platform (despliegue y ejecución) para integrar aplicaciones, servicios, transacciones y componentes de negocios, dentro de procesos de negocios automatizados [53]. En la figura 6.13 se muestra cada componente en el contexto de la arquitectura de JBoss.

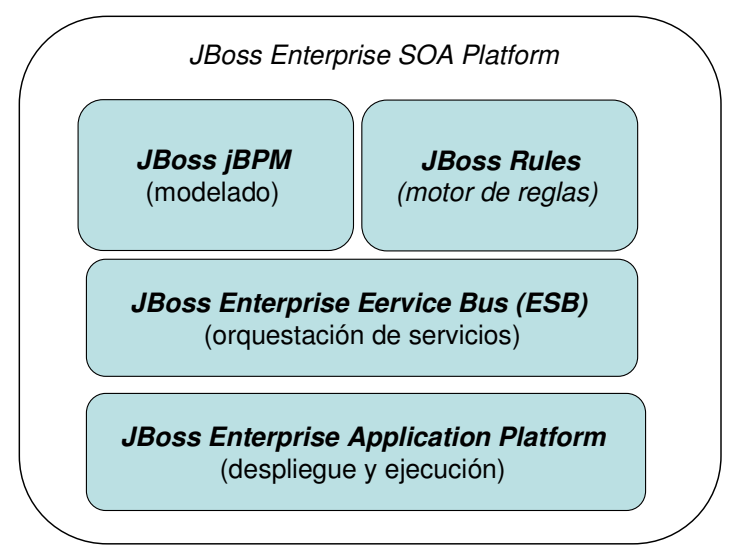

Figura 6.13. Componentes de JBoss Enterprise SOA Platform

- Oracle BPM, integrada por dos productos, Oracle BPA y Oracle SOA Suite. El primero cuenta con las siguientes componentes: Oracle Business Process Architect (modelado y simulación), Oracle Business Process Publisher (publicación de proceso de negocios), Oracle Business Process Repository y Oracle Business Process Repository Server (repositorio de procesos para trabajo colaborativo). El segundo producto, cuenta con las siguientes componentes Oracle BPEL Process Designer (implementación y 


\section{Caso de Estudio}

despliegue), Oracle BPEL Process Manager (ejecuta y soporta tareas humanas e interacciones de contenido), Orcacle Enterprise Service Bus (transformación y ruteo), Oracle Business Activity Monitoring (monitoreo) y Oracle Business Rules (motor de reglas) [54]. En la figura 6.14 se muestra cada componente en el contexto de la arquitectura de Oracle BPM.

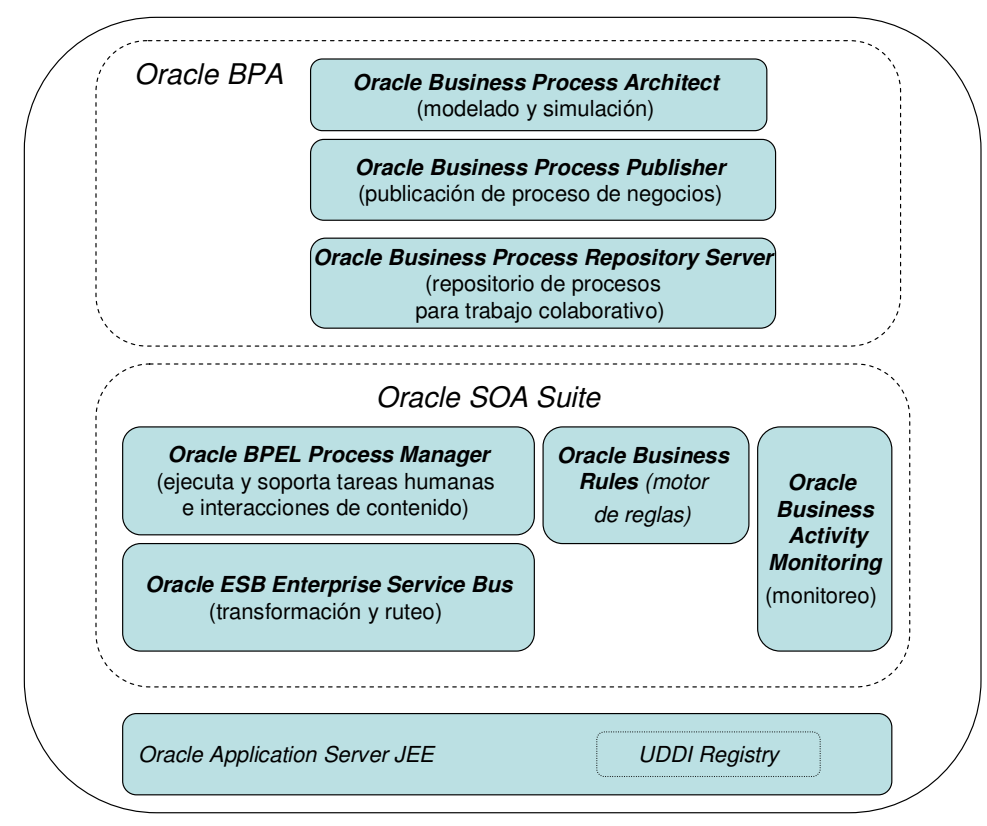

Figura 6.14. Componentes de Oracle BPM

- IBM WebSphere BPM, integrada por los siguientes productos: WebSphere Process Server (ejecución), WebSphere Enterprise Service Bus (orquestación de servicios), WebSphere Integration Developer (implementación y despliegue), WebSphere Service Registry \& Repository (registra y cataloga servicios bajo la idea de "gobierno" SOA), WebSphere Business Services Fabric (ensamblado y composición de servicios), WebSphere Business Modeler (modelado), WebSphere Business Monitor (monitoreo) [39]. La figura 6.15 muestra cada componente en el contexto de la arquitectura de IBM WebSphere BPM.

\footnotetext{
${ }^{6}$ Peter Weill de MIT define gobierno como "especificar las decisiones correctas y la rendición de cuentas
} para fomentar el comportamiento esperado en el uso de IT" 


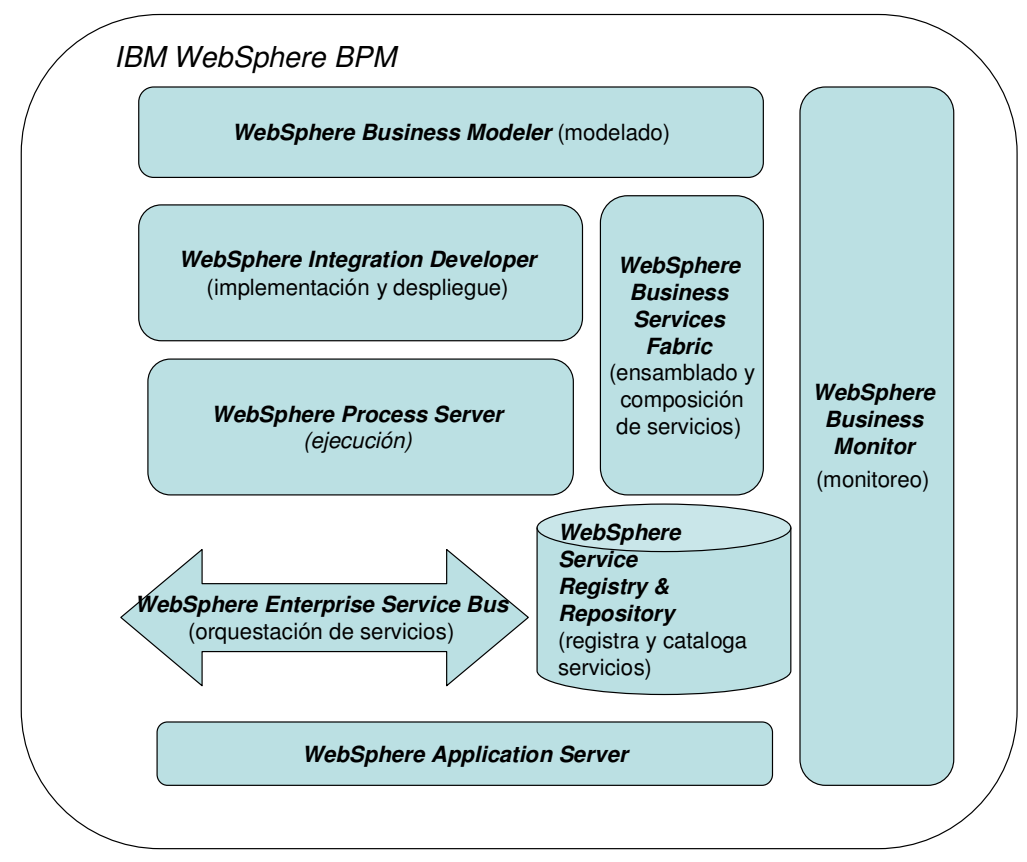

Figura 6.15. Componentes de IBM WebSphere BPM

En las Tablas 6.4 y 6.5 se comparan las tres herramientas mencionadas. En las columnas se visualizan los requisitos definidos previamente y en cada celda se indica el componente que la lleva a cabo o bien la tecnología que la resuelve. Ubicadas sobre cada uno de los requisitos se indica la etapa de la metodología que se ve afectada por cada una de los requisitos y, en consecuencia, estaría enmarcada en la solución tecnológica para dicho requisito.

Tabla 6.4- Comparación de herramientas (1era parte)

\begin{tabular}{|c|c|c|c|c|}
\hline & \multicolumn{2}{|r|}{ Ciclo de vida } & \multirow{2}{*}{$\begin{array}{c}\text { Simulacion en } \\
\text { Tiempo Real }\end{array}$} & \multirow{2}{*}{$\begin{array}{l}\text { Monitoreo } \\
8\end{array}$} \\
\hline & (3) 4 & $\begin{array}{c}\text { Ejecucion y Despliegue } \\
67\end{array}$ & & \\
\hline JBPM & \multicolumn{2}{|c|}{$\begin{array}{c}\text { jBPM Graphical Process Designer: } \\
\text { realizan el modelado, desarrollo y } \\
\text { desplegado de los procesos de } \\
\text { negocios en JPDL. }\end{array}$} & No da soporte & $\begin{array}{c}\mathrm{jBPM} \\
\text { Console, }\end{array}$ \\
\hline $\begin{array}{c}\text { Oracle Suite 10g } \\
\text { (BPA \& SOA) }\end{array}$ & $\begin{array}{c}\text { Orable BPA } \\
10 \mathrm{~g}\end{array}$ & $\begin{array}{l}\text { WebSphere Process } \\
\text { Server basado sobre } \\
\text { WebSphere } \\
\text { Application Server }\end{array}$ & Orable BPA $10 \mathrm{~g}$ & $\begin{array}{c}\text { JDeveloper } \\
10 \mathrm{~g} \text { y Oracle } \\
\text { SOA Suite } \\
10 \mathrm{~g}\end{array}$ \\
\hline $\begin{array}{c}\text { IBM WebSphere } \\
\text { BPM }\end{array}$ & $\begin{array}{c}\text { WebSphere } \\
\text { Business } \\
\text { Modeler }\end{array}$ & $\begin{array}{l}\text { WebSphere Process } \\
\text { Server basado sobre } \\
\text { WebSphere } \\
\text { Application Server }\end{array}$ & \begin{tabular}{l|} 
WebSphere \\
Business Monitor \\
se integra con \\
WebSphere \\
Business \\
Modeler y \\
permite crear \\
simulaciones en \\
el modelador con \\
datos del monitor
\end{tabular} & $\begin{array}{l}\text { WebSphere } \\
\text { Business } \\
\text { Monitor }\end{array}$ \\
\hline
\end{tabular}




\section{Caso de Estudio}

Tabla 6.5 - Comparación de herramientas (2da parte)

\begin{tabular}{|c|c|c|c|}
\hline & $\begin{array}{l}\text { Soporte SOA } \\
5\end{array}$ & $\begin{array}{c}\text { Integración con IDEs } \\
67\end{array}$ & $\begin{array}{c}\text { Soporte a Tareas Humanas } \\
3\end{array}$ \\
\hline JBPM & $\begin{array}{l}\text { Cuenta con componentes } \\
\text { "ESB service" dentro del } \\
\text { diseñador de procesos para } \\
\text { utilizar servicios que están } \\
\text { disponibles en el ESB pero } \\
\text { no cuenta con soporte para } \\
\text { BPEL }\end{array}$ & $\begin{array}{l}\text { Eclipse con plug-in } \\
\text { http://www.eclipse- } \\
\text { plugins.info/eclipse/plugi } \\
\text { n_details.jsp?id=1028 } \\
\text { http://sourceforge.net/pro } \\
\text { jects/jbpm/ }\end{array}$ & Task Node de JPDL \\
\hline $\begin{array}{c}\text { Oracle Suite 10g } \\
\text { (BPA \& SOA) }\end{array}$ & $\begin{array}{l}\text { Utiliza como lenguaje de } \\
\text { ejecución a BPEL. }\end{array}$ & JDeveloper 10g & $\begin{array}{l}\text { Oracle BPEL process manager } \\
\text { provee soporte para la } \\
\text { participación humana en los } \\
\text { procesos fin-a-fin. Las } \\
\text { características del flujo de } \\
\text { trabajo humano incluye una } \\
\text { aplicación de lista de } \\
\text { trabajo, personalizables y } \\
\text { basadas en roles }\end{array}$ \\
\hline $\begin{array}{c}\text { IBM WebSphere } \\
\text { BPM }\end{array}$ & $\begin{array}{l}\text { WebSphere Business } \\
\text { Service Fabric: incluye el } \\
\text { ESB, el servidor de } \\
\text { procesos y WebSphere } \\
\text { Integration Developer }\end{array}$ & $\begin{array}{l}\text { IDE propia basada en } \\
\text { Eclipse. WebSphere } \\
\text { Integration Developer } \\
\text { que se ejecuta sobre } \\
\text { Rational Applicaition } \\
\text { Developer (RAD) el cual } \\
\text { se monta sobre Eclpse }\end{array}$ & $\begin{array}{l}\text { A traves de una de las } \\
\text { componentes de WebSphere } \\
\text { Process Server (Human Task) }\end{array}$ \\
\hline
\end{tabular}

Entre las lecciones aprendidas como resultado del desarrollo de este trabajo, notamos que es de mucha importancia contar con herramientas para BPM integradas que permitan mantener el contexto de trabajo entre los distintas etapas. Por otra parte, la adherencia a los estándares constituye también un aspecto de gran importancia asi como también el tipo de licenciamiento de la herramienta.

De todos modos, el estado del arte en esta materia indica que aún hay un largo camino por recorrer ya que las organizaciones recién comienzan a transitarlo y la industria del software aún continua ensayando alternativas que sean capaces de dar la respuesta que el mercado requiere, tal como lo indican las publicaciones en la materia como "Enterprise IT management resources for CIOs SearchCIO.com" (http://searchcio.techtarget.com/), "TheServerSide.Com Your Entreprise Java Community" (http://www.theserverside.com/) y "SearchSOA.Com Essential SOA and Web Service Resource for enterprise IT professionals" (http:// searchsoa.techtarget.com/)

\subsection{Conclusiones}

En la práctica, una buena solución BPM debería poder ejecutar un proceso de modelado que involucre al área de negocios, sin la necesidad de que el área de tecnología de la organización tenga que programar una sola línea de código y así obtener como solución algo equivalente a un workflow tradicional. Luego el área de tecnologia deberia tomar este workflow e implementar los formularios de entrada (de interacción con usuarios) y los "servicios" (las actividades automatizadas) para completarlo en un flujo BPM.

Hacer que un modelo se convierta en un proceso ejecutable requiere de varias tecnologias habilitantes. Cuando estas tecnologias se proveen juntas se la llama BPMS (Business Process Management Suite). Los componentes tecnológicos de esta suite son:

- Motores de Orquestación: coordinan la secuencia de actividades según los flujos y reglas del modelo de procesos.

- Herramientas de Análisis y Business Intelligence: analizan la información producto de la ejecución del proceso en tiempo real. 


\section{Caso de Estudio}

- Motores de Reglas: ejecutan reglas que permiten abstraer las políticas y decisiones de negocio de las aplicaciones subyacentes.

- Repositorios: mantienen los componentes y recursos de los procesos (definiciones, modelos, reglas) disponibles para su reutilización en múltiples procesos.

- Herramientas de Simulación y Optimización: permiten a los administradores del negocio comparar el nuevo diseño de procesos con el desempeño operacional actual.

- Herramientas de Integración: permiten integrar el modelo con otros sistemas, como los sistemas legados de la empresa.

El actual interés en BPM es el combustible del área de tecnología para las arquitecturas orientadas a servicios. La idea principal de la orientación a servicios es capturar la funcionalidad del negocio más relevante y proveerla con el suficiente grado de detalle para que pueda ser consumida. Para favorecer dicho consumo, los servicios deben ser registrados y publicados, además de contar con interfaces bien definidas basadas en lenguajes estándares como XML. Por otra parte, si bien BPM muchas veces se describe como una metodología despegada de la implementación, en la medida en que la solución BPM se ajuste mejor a la plataforma de desarrollo redunda en facilidades para la documentación, depuración y mantenimiento posterior [43].

En el desarrollo de este caso de estudio hemos mostrado la aplicación de cada una de las etapas de la metodología integradora propuesta que tiene como finalidad disminuir la brecha entre el modelado de procesos y el de servicios, viendo a los primeros como componentes de software que orquestan servicios dentro de un entorno de ejecución propio.

El concepto de integración subyacente en la metodología se pone de manifiesto tanto en el hilo conductor que se mantiene en cada etapa como en la noción de componer funcionalidades (nuevas o ya existentes) para alcanzar un objetivo común que fue fijado por cada uno de los procesos modelados.

En el pròximo capitulo presentamos las conclusiones de esta tesis y un análisis de los trabajos relacionados con la misma. 


\section{Conclusiones y trabajos relacionados}

En este capítulo se presenta el resultado del análisis realizado sobre los trabajos relacionados con esta tesis, fundamentalmente en términos de propuestas metodológicas.

Los trabajos analizados han resultado todos inspiradores en algún sentido en lo relacionado a mejorar aspectos de las metodologias que permitan construir un marco metodológico integrado y abarcativo de todo el ciclo de vida de los proyectos, fundamentado en el enfoque orientado a procesos y servicios.

Por último, planteamos las conclusiones a las que hemos podido arribar luego de finalizado este trabajo.

\subsection{Trabajos relacionados}

En cuanto a los trabajos relacionados con esta propuesta, se analizaron algunas metodologias y su alcance, en el marco de la propuesta presentada.

La metodología de Delgado [1][2] cubre únicamente el modelado de procesos e identificación de servicios, no considerando ni la especificación de requisitos ni la etapa de implementación de los servicios. Por otra parte no se ve la utilidad en hacer evolucionar la metodología hacia un esquema de derivación automática, habida cuenta que existen muchas herramientas que cuentan con servicios implementados que sólo deben orquestarse adecuadamente.

SOMA (Service-oriented modeling and architecture) es un método para desarrollar el ciclo de vida del software creado por IBM para diseñar y construir soluciones basadas en SOA. Es un método que define técnicas clave y provee de tareas o actividades detalladas para guiar el análisis, diseño, implementación, testeo y desarrollo de componentes de servicios [11]. Es un método muy completo pero altamente enfocado a la arquitectura de los servicios desde un punto de vista de IT, dejando de lado una vez más, la tarea de especificación de requisitos y una integración del ciclo de vida del software con el ciclo de vida de los procesos.

Por su parte, SoaML (Service oriented architecture Modeling Language) [9] se crea en respuesta al RFP de UPMS (UML Profile and Metamodel for Services) para servicios y describe un perfil de UML y un metamodelo para el diseño de servicios dentro de una arquitectura orientada a servicios. El objetivo de SoaML es dar soporte a las actividades de modelado y diseño de servicios ajustándose al enfoque de desarrollo dirigido por modelos. SoaML resulta una herramienta parcial comparada con nuestra propuesta, dado que se enfoca solamente en las etapas de modelado y diseño y además se aplica únicamente a los servicios, no abarcando el ciclo de vida de los procesos. De todos modos, resulta un aporte interesante a la hora de formalizar nuestra metodología dado que provee una forma estándar para construir y modelar soluciones SOA usando UML.

La metodología presentada por Weske en [6] se plantea sobre el ciclo de vida de los procesos pero presenta una modalidad típica en cascada, donde cada etapa se sucede a la anterior con una leve iteración hacia la fase de diseño. La metodología es iterativa e incremental y reúne los conocimientos acerca de los procesos de negocio y su entorno. Esta metodología ha constituido un marco de referencia para el trabajo presentado, a la que se aplicó una mejora 
al contraponer los ciclos de vida de los procesos con los de desarrollo de software.

Observando sólo el aspecto de identificación y especificación de requisitos, podemos mencionar la visión de Errecalde y Marcos en [16] que resulta completa y adecuada pero únicamente dentro del marco del desarrollo de software orientado a aspectos. Nuestra propuesta respecto de la Ingeniería de requisitos (el diseño participativo de procesos [12]) trasciende la metodología de desarrollo y resulta más adecuada en términos de diseños orientados a procesos y servicios.

En la misma línea anterior, en [35] se presenta una guía metodológica integrada para especificar requisitos de datos en un sistema de información orientado a procesos. Esta guía integra dos enfoques:

- el análisis de procesos de negocio y el propósito de un sistema de información, centrándose en el modelado organizacional para la captura y especificación de requisitos funcionales.

- la derivación de modelos de datos a partir de requisitos funcionales.

La finalidad de la propuesta es ayudar a los analistas de sistemas a la hora de especificar los requisitos de datos de un sistema de información a partir de sus requisitos funcionales, los cuales se especifican en base a los procesos de negocio que una organización quiere ejecutar.

Si bien resulta que la propuesta es sólida, no presenta un aspecto innovador respecto de la metodología utilizada en este trabajo para la etapa de especificación de requisitos como lo es el "diseño participativo de proceso" y, por otro lado, conserva la característica de muchas propuestas de estar muy orientada a analistas tecnológicos y no de negocios.

En [36] se presenta el modelado de negocio como medio para entender la estructura y dinámica de las organizaciones, visualizar sus problemas e identificar mejoras potenciales, asegurar que el cliente, los usuarios y los desarrolladores tengan un entendimiento común de la organización para la posterior derivación de los requisitos de sistema.

Este trabajo relacionado tiene en cuenta los elementos necesarios para modelar negocios interorganizacionales: objetivos, interacciones entre las organizaciones y procesos de negocio. Además modela el negocio a distintos niveles de abstracción, desde el nivel más estratégico al más operacional y proporciona trazabilidad tanto horizontal (entre los tres tipos de modelos) como vertical (entre los distintos niveles de abstracción). La propuesta es validada con un prototipo MDA con tecnología Eclipse que permite dibujar los modelos y mantener la trazabilidad entre ellos.

La propuesta es adecuada para ser considerada en la etapa de identificación y especificación de requisitos de nuestro modelo, pero resulta dificil de integrar en un enfoque orientado a procesos y servicios ya que pone el acento en la derivación de requisitos del sistema, sin considerar el "enganche" con fases posteriores del ciclo de vida de los sistemas.

En [37] se presenta también un modelo integrado para requisitos que especializa los modelos de casos de uso introduciendo una regla de "elicitación"7 de requisitos (requerimientos que deben ser extraidos u obtenidos con esfuerzo

7 Si bien no se cuenta con una etimología en español, una acepción posible puede ser: "Investigaciones sociológicas, psicológicas o sociales (y también en espionaje civil o industrial) para referirse a una investigación en que el sujeto investigado no es consciente de serlo" 
desde las fuentes), que exige una descripción más rigurosa de los flujos de información intercambiados entre el sistema y las entidades externas o actores. Del análisis de este trabajo relacionado se puede concluir que: no considera la idea de servicio, deriva sobre el modelo de objetos tradicional, resulta adecuado como mecanismo para identificar y especificar requisitos pero desde un enfoque formal y muy micro, dejando dudas acerca de su aplicabilidad en problemas a gran escala. No queda claro qué significa que el caso de uso "se ejecuta". Los modelos de casos de uso no tienen este concepto y no está claro cómo lo logran. Por último, resulta muy orientado a la solución, careciendo de visión integral del problema, la organización y el proyecto.

En [38] se aborda el concepto de modelado de metas construido mediante heurísticas en base a modelos de procesos en la forma de BPMN. A partir del modelo de metas, mediante un proceso de refinamiento y de etiquetado de metas, se obtiene un modelo de requisitos en la forma de casos de uso. Una vez más estamos en presencia de una aproximación para derivar requisitos utilizando, en este caso, modelos de procesos en BPMN.

Los aportes más importantes de este trabajo relacionado radican en que enriquece el enfoque de desarrollo basado en metas con un modelo de procesos, dando intervención temprana al área de tecnología. Por otra parte, ofrece trazabilidad entre las estrategias de negocios y los sistemas de información de una organización.

Parece buena alternativa para la ingeniería de requisitos porque es participativa como el enfoque de [12]. También es orientada a procesos pero sólo deriva casos de uso y no hay vinculación entre procesos y servicios.

Finalizando el análisis de trabajos relacionados básicamente con la especificación y análisis de requisitos, se puede mencionar la metodología TROPOS [40] [41] que sustenta la metodología presentada en [36].

TROPOS es una metodología orientada a agentes para análisis de requerimientos de Web Services que resulta adecuada para razonar sobre aspectos no funcionales de los Web Services como la calidad de servicio (QoS).

TROPOS se basa en dos características clave: por un lado la noción de agente usada en todas las fases de desarrollo de software desde los análisis tempranos de requerimientos hasta la implementación real y por el otro, el gran énfasis que pone la metodología en el análisis de requerimientos tempranos, que precede a la especificación de requerimientos, de modo que los desarrolladores pueden capturar y analizar los objetivos de los analistas de negocio. Esta perspectiva da lugar a un análisis más refinado y a un tratamiento uniforme de requerimientos funcionales y no-funcionales.

Una vez más, nos encontramos con una metodología adecuada pero incompleta para su aplicación en el marco metodológico presentado en este trabajo. Su alcance a los Web Services y a los requerimientos de QoS que a ellos se apliquen, resulta un aspecto muy parcial de la orientación a servicios y además no integra este concepto con la orientación a procesos.

En [47] se aborda la idea de contar con un ambiente de ejecución dinámico para descubrimiento, composición, mediación e invocación de Servicios Web para lo cual es preciso contar con descripciones semánticas tanto de servicios como de procesos. El trabajo plantea un conjunto de escenarios que tienen en cuenta la idea de BPM con vistas a definir una metodología para ingeniería de Servicios Web Semánticos. Sin duda resulta muy interesante esta linea de investigación y podría convertirse en la evolución que debería tener el marco metodológico presentado en este trabajo hacia etapas futuras.

En la misma linea que se acaba de mencionar, encontramos en [48] un trabajo cuyo aporte principal es soportar un despliegue automático de Web Semánticas respecto de los workflows que se describen en el modelado de negocios 
tradicional. Una vez más esta referencia constituye sin duda un posible bloque constructor para la metodología que presentamos, pero tiene un alcance parcial sobre la misma, que cubre un espectro más amplio en el desarrollo de proyectos dentro de una organización.

\subsection{Lineas de trabajo futuras}

Uno de los aspectos de interés que surge como consecuencia de la realización de esta tesis es el de estudiar la aplicación de BPM al concepto de redes sociales con Web 2.0 y "cloud computing".

En [55] se define como Web 2.0 como una segunda generación de comunidades basadas en Web y una alternativa al hospedaje de servicios (tales como redes sociales y wikis) que facilitan la creatividad, colaboración y mecanismos de intercambio entre usuarios.

Por otra parte, en [56] se plantea que las redes sociales se han transformado en uno de los fenómenos tecnológicos más dinámicos siendo sin duda Internet quien lo facilita. Si bien comenzó como un fenómeno meramente social, las organizaciones ya lo están vislumbrando como una herramienta poderosa para compartir información y favorecer el trabajo en grupo.

En este sentido, en [56] se hace hincapié en la presencia de las "3 C" del concepto de groupwhere, pero en una red social (colaboración, comunicación y coordinación). El autor afirma que las redes sociales tradicionales carecen del aspecto de "coordinación" siendo BMP y los workflow mecanismos válidos para aportar este aspecto a las redes sociales.

Vinculados a estos tópicos de redes sociales y Web 2.0 no puede estar ajeno el concepto de "cloud computing" o virtualización planteados en [60] y [61]. La idea subyacente en "cloud computing" es que aporta un nivel superior de eficiencia para distribuir y desplegar recursos de IT bajo demanda. La incorporación de conceptos como virtualización, despliegue bajo demanda, distribución de recursos por Internet y software open source, cambian el enfoque no sólo para el desarrollo de aplicaciones, sino también para su despliegue, mantenimiento y fundamentalmente su interoperabilidad.

En este sentido, mientras la arquitectura de tres capas de las aplicaciones basadas en Web revolucionó el desarrollo del software en su momento, la virtualización en "nubes" ha dado origen a nuevos niveles como lo son: las aplicaciones, los servicios y la infraestructura [61]. Surgen así los conceptos de SaaS (Software as a Service), PaaS (Platform as a Service) y IaaS (Infraestructre as a Services), enunciados según su nivel de abstracción.

El concepto de PaaS aplicado a BPM y el de SaaS aplicado a arquitecturas basadas en servicios, pueden ampliar la propuesta metodológica de este trabajo hacia el aprovechamiento de la red como recurso escalable y como medio para desarrollo y despliegue.

Como otra línea de trabajo posible se pueden analizar las posibilidades de automatizar algunas actividades vinculadas con esta metododologia, abordando este tema tanto desde la perspectiva de "process mining" y también desde los procesos de negocio semánticos (SBPM). Las referencias [48], [47], [58] y [59] constituyen un punto de partida para el tratamiento de esta linea de trabajo.

Por último, puede resultar de interés abordar temas vinculados a calidad de servicio y SLA como punto de referencia para profundizar la idea de mejoramiento continuo y afianzarla dentro de estándares de calidad [56]. Esta línea de trabajo puede contribuir también a la mejora del marco metodológico planteado para sumar valor a los productos generados por las etapas de Definición e Implementación de Componentes. 


\subsection{Conclusión final}

Los modelos tradicionales en el mundo de la tecnología de información y la ingenieria de software resultan insuficientes porque son pobres en su integración y se orientan a describir datos y transacciones. La tendencia es hacia un paradigma orientado a procesos, donde las aplicaciones cubren la actividad global de la empresa y las herramientas son los BPMS (Sistemas de Gestión de Procesos de Negocio).

Por otra parte, la tecnología de Servicios Web como el estándar de computación distribuida más adoptado de la historia de la industria y su orquestación y coreografia como workflow, no puede estar ajena.

En este trabajo se delinea una nueva visión global que identifica las etapas y su interacción, para cubrir tanto el ciclo de vida de los procesos de negocio como los del software de una manera unificada. Esta propuesta metodológica tiene como objetivo final facilitar la construcción de procesos de mejora continua y flexibilidad ante los cambios.

Para comprobar el grado de aplicación posible del marco metodológico propuesto se abordó un caso de estudio donde resultó necesario realizar una reingeniería de los procesos de una organización, identificar roles y actores intervinientes en dichos procesos estableciendo la actividad que desempeñan. Se definió también el escenario tecnológico requerido para el funcionamiento de una Ventanilla Única siguiendo las siguientes premisas: contar con una base de datos registral única de trámites, poseer acceso al sistema informático desde cualquier punto geográfico e integrar el sistema con sistemas legados existentes en la organización y que requieran ser invocados para la concreción del trámite.

En este marco, podemos decir que se encuentra un terreno propicio para abordar el problema con un enfoque orientado a procesos y a servicios bajo el concepto de un modelo de integrabilidad.

En particular, en lo referente a la característica propia del problema, que es el funcionamiento de un sistema de Ventanilla Única, podemos decir que el mismo presenta particularidades propias en cuanto a la definición de circuitos que pueden presentar cierta complejidad en el manejo de condiciones excepcionales. Un trámite puede resultar trivial cuando sigue el circuito estándar, pero puede presentar caminos alternativos excepcionales que requieran un tratamiento especial sin dejar de pertenecer al flujo de trabajo propio de dicho trámite.

En este sentido, el enfoque orientado a procesos y los métodos que lo guían absorben muy bien este escenario planteado ya que justamente descansan en el concepto de contar con un conjunto de actividades regidas por restricciones o reglas que condicionan su coordinación.

El enfoque orientado a procesos favorece la reingeniería de los procesos de regulación de actividad económica logrando, además, explicitar el conocimiento implícito en dichos procesos (estén estos vigentes o surjan como resultado de la reingenieria) e insertar el circuito de trámites en un proceso de mejora continua capaz de absorber los cambios regulatorios que pudieran producirse.

Por su parte, el enfoque orientado a servicios nos permite identificar funcionalidades transversales y reusar gran parte del activo de la organización existente en sistemas legados, definiendo un modelo de integración que facilite el acceso desacoplado a dichos activos.

Es importante tener en cuenta que ya hace más de una década que la metáfora de Internet ha impactado fuertemente en la manera en que se construye software desde el punto de vista tecnológico y metodológico. Sin embargo, el concepto de "cloud computing" y virtualización, representa sin lugar a dudas un punto de inflexión para el valor que posee la computación en red. En este sentido se impone la necesidad de contar con nuevos modelos de programación, nuevas infraestructuras y nuevos modelos de negocios. 


\section{Conclusiones y Trabajos Relacionados}

La propuesta metodológica presentada en este trabajo favorece la exposición de servicios, tanto nuevos como generados a partir de activos de software, para ser orquestados y consumidos por procesos de negocios corporativos. Este modelo ayuda a las organizaciones a integrarse con sus pares, con sus clientes y con sus proveedores más allá de las tecnologías e infraestructuras subyacentes, pero haciendo uso del valor que aportan las nuevas tendencias de computación en red.

Para finalizar, esta cita de Winston Churchill resume claramente las ideas esbozadas en este trabajo: "Para mejorar hay que cambiar, para ser perfecto hay que cambiar con frecuencia". 


\section{Referencias}

[1] Delgado, Andrea, "Desarrollo de Software orientado a servicios basado en procesos de Negocio". Memorias de la XII Conferencia Iberoamericana de Ingeniería de Requisitos y Ambientes de Software (IDEAS 2009). ISBN 978-958-44-5028-9. 2009

[2] Delgado, Andrea. "Desarrollo de Software con enfoque en el Negocio", Taller sobre Procesos de Negocio e Ingeniería de Software (PNIS'07). Zaragoza, España Workshop realizado en el marco de las XII Jornadas de Ingeniería del Software y Bases de Datos (JISBD’07) en el II Congreso Español de Informática (CEDI). 2007

[3] Erl, Thomas. "SOA Principles of Service Design". Prentice Hall. ISBN-13: 9780132344821. 2007. Pag.25-119

[4] Eric NewComer - Grez Lomow, "Understanding SOA with Web Services". AddisonWesley. Pag 1-159. ISBN. 0-321-18086-0. Pearson. 2005

[5] Scott McKorkle, "Model-Driven SOA - Achieve Higher Productivity Gains throughout the Design Process". Telelogic White Paper. 2007

[6] Weske Mathias, "Business Process Management: Concepts, Languages, Architectures". Springer, Pag 3-67. ISBN 978-3-540-73521-2. 2008

[7] Stephen A.White, "Introduction to BPMN". IBM Corporation. http://www.bpmn.org/Documents/Introduction\%20to\%20BPMN.pdf . 2004 (al $16 / 10 / 2009)$

[8] Business Process Modeling Notation (BPMN) Version 1.2 OMG http:/ /www.omg.org/spec/BPMN/ 1.2. 2009. (al 16/10/2009)

[9] Unified Modeling Language (UML), version 2.2 OMG http://www.omg.org/technology/documents/formal/uml.htm. 2009. (al $16 / 10 / 2009)$

[10] Service oriented architecture Modeling Language (SoaML) - Specification for the UML Profile and Metamodel for Services (UPMS). OMG Document. 2008

[11] A. Arsanjani, S. Ghosh, A. Allam, T. Abdollah, S. Ganapathy, K. Holley. "SOMA: A method for developing service-oriented solutions". IBM SYSTEMS JOURNAL, VOL 47, N 3. 2008

[12] Gustavo Giorgetti. "Transformando. Capitulo: Administrando la Complejidad." Editorial Eudeba ISBN 950-231289-9. 2003

[13] Ali Arsanjani, Ph.D. "Service-oriented modeling and architecture". http://www.ibm.com/developerworks/webservices/library/ws-soa-design 1/. 2004. (al 16/10/2009)

[14] Olaf Zimmermann, Pal Krogdahl, Clive Gee. "Elements of Service-Oriented Analysis and Design". http://www-128.ibm.com/developerworks/library/ws-soa-design 1/. 2004. (al 16/10/2009)

[15] Olaf Zimmermann, Frank Mueller. "Web Services project roles". http://www128.ibm.com/developerworks/library/ws-roles/. 2004. (al 16/10/2009)

[16] Gladis Errecalde, Claudia Marcos "Una Ontología de Aspectos para la Ingeniería de Requisitos". Memorias de la XII Conferencia Iberoamericana de Ingeniería de Requisitos y Ambientes de Software (IDEAS 2009). ISBN 978-958-44-5028-9. 2009.

[17] Sheina Dana. "Realising the promise of SOA and BPM". Ovum. SearchCIO. 2008

[18] Hurwitz Judith, Bloor Robin, Baroudi Carol, Kaufman Marcia."Service Oriented Architecture For Dummies”. Wiley Publishing, Inc.. 2007. Pag. 5-61 ISBN-10: 0-47005435-2

[19] Bell Michel. "Service-Oriented Modeling. Services Analysis, Design and Architecture". John Wiley \& Sons, Inc., ISBN 978-0-470-14111-3. 2008

[20] Pulier Eric, Taylor Hugo. "Understanding Enterprise SOA". Manning Publications Co. ISBN 1-932394-59-1. 2006. Pag 1-73.

[21] Juric Matjaz B., Loganathan Ramesh, Poornachandra Sarang, Frank Jennings "SOA Approach to Integration XML, Web services, ESB, and BPEL in real-world SOA projects". Packt Publishing. ISBN 978-1-904811-17-6. 2007

[22] Martin Owen and Jog Raj. "BPMN and Business Process Management Introduction to the New Business Process Modeling Standard”. Popkin Software. 2003

[23] BPM Group Snoop Consulting. "BPM Group”. Junio 2008. http://crm.snoop.com.ar/tikiwiki/tiki-index.php?page=BPMGroup

[24] Bea Whitepaper. "Extending the Business Value SOA through Business Process Management". 2006

[25] Oracle Whitepaper. "Bringing SOA Value Patterns to Life". 2007 
[26] IBM Global Technology Services. "How service-oriented architecture (SOA) impacts your IT infrastructure". 2008

[27] Manuel Imaz "Curso Introducción a SOA/BPM" organizado por SADIO. 2008

[28] BPEL Tutorial http://go.techtarget.com/r/8638480/2744320. 2009 (al 16/10/2009)

[29] Oracle Whitepaper. "SOA Governance: Framework and Best Practices". 2007

[30] Scott McKorkle "Model-Driven SOA. Achieve Higher Productivity Gains throughout the Design Process". Telelogic White Paper. 2007

[31] Lombardi. "What is the difference between workflow engines and BPM suites?" publicado por SearchSOA.com. 2008

[32] ESB Best-Practices - Fiorano Software and Affiliates http://www.fiorano.com/docs/ESB_Best_Practices.pdf. 2009(al 30/07/2009)

[33] IBM RedBook. "Patterns: Implementing an SOA Using an Enterprise Service Bus". 2004. Pag 73-90

[34] Fiorano Site."The Mission of Application Integration" http://www.fiorano.com/products/products_application_integration_mission.php. 2009 (al 30/07/2009)

[35] de la Vara J., Fortuna M., Sánchez J., Werner C., Borges M. "Modelado de Requisitos de Datos para Sistemas de Información basados en Procesos de Negocio". Memorias de la XII Conferencia Iberoamericana de Ingenieria de Requisitos y Ambientes de Software (IDEAS 2009). ISBN 978-958-44-5028-9. 2009.

[36] Bocanegra J., Peña J., Ruiz Cortez A.. "Modelado de Negocio Interorganizacional: Una Aproximación para la Trazabilidad entre Objetivos, Modelos Organizacionales y Procesos de Negocio". Memorias de la XII Conferencia Iberoamericana de Ingeniería de Requisitos y Ambientes de Software (IDEAS 2009). ISBN 978-958-44-5028-9. 2009.

[37] Fortuna M., Werner C, Borges M.”Um Modelo Integrado de Requisitos com Casos de Uso". Memorias del X Workshop Iberoamericano de Ingeniería de Requisitos y Ambientes de Software (IDEAS`07) Caracas, Venezuela ISBN: 978-980-325-323-3, Isla de Margarita, del 7 al 11 de Mayo 2007

[38] De la Vara Gonzalez J., Anes Alcolea D., Sánchez Díaz J. "Construcción de modelos de requisitos a partir de modelos de procesos y de metas" Memorias del X Workshop Iberoamericano de Ingeniería de Requisitos y Ambientes de Software (IDEAS`07) Caracas, Venezuela ISBN: 978-980-325-323-3, Isla de Margarita, del 7 al 11 de Mayo 2007

[39] IBM TechWorks. "An IBM Proof of Technology. Discovering the value of WebSphere Business Process Management for your organization”. International Business Machines Corporation 2007, 2008.

[40] D. Lau and J. Mylopoulos. "Designing web services with tropos". In ICWS ?04: Proceedings of the IEEE International Conference on Web Services, page 306, 2004.

[41] M. Aiello and P. Giorgini. Applying the Tropos Methodology for Analysing Web Services Requeriments and Reasoning about Quality of Services. Technical Report,University of Trento., 2004.

[42] Stephen A.White, "Using BPMN to Model a BPEL Process". IBM Corporation. 2004.

[43] Diaz J, Bazán P., Queiruga C, Gotelli G, Rodríguez F. "Entornos para usar BPM en aplicaciones JAVA: un análisis comparativo" publicado en XI Workshop de Investigadores en Ciencias de la Computación WICC. Universidad Nacional de San Juan. Argentina. Mayo 2009.http:/ /www.wicc2009.com.ar/index.php?option=com_content\&view=article\&id= 61\&Itemid=74. ISBN 978-950-605-570-7

[44] Pau Giner, Victoria Torres, Vicente Pelechano: Bridging the Gap between BPMN and WS-BPEL. M2M Transformations in Practice. MDWE 2007

[45] Rational Software Modeler http:// publib.boulder.ibm.com/infocenter/rsmhelp/v7r5m0/index.jsp?topic=/com.i bm.xtools.transform.cfm.wbm.doc/topics/ccwbmtransf.html. (al 16/10/2009)

[46] Transformation to SOA: Part 1. From business process to service model architecture using IBM WebSphere Business Modeler and IBM Rational Software Architecthttp://www.ibm.com/developerworks/rational/library/07/1225_bennettbalaba/. 2007 (al 16/10/2009)

[47] Mick Kerrigan, Barry Norton, Elena Simperl, Dieter Fensel. "SemanticWeb Service Engineering for Semantic Business Process Management”. ACM, 2009.

[48] Li Guo, Yun-Heh Chen-Burger, Dave Roberston. "Mapping a Business Process Model to a Semantic Web Service Model”. IEEE International Conference on Web Services (ICWS'04). 2004 


\section{Referencias}

[49] Peter Y. Xu.. "Transactionally integrate Web services with BPEL processes in WebSphere Process Server"

http://www.ibm.com/developerworks/websphere/library/techarticles/0703_xu/070 3_xu.html. 2007. (al 16/10/2009)

[50] Morgenthal JP. "Enterprise Application Integration with XML and Java". Prentice Hall. ISBN 0-13-085135-3. 2001. Pag 1-86

[51] Open SOA

http://www.osoa.org/display/Main/Service+Component+Architecture+Home

[52] Open Source Initiative http://www.opensource.org/docs/definition.php

[53] Red Hat JBoss Community. “JBoss Enterprise SOA Platform datasheet”. Julio 2008.

[54] Oracle Corporation. "Oracle Business Process Architect, Quick Start Guide Release 10.1.3.4". Abril 2008.

[55] Oracle White Paper. "Business Process Management, Service-Oriented Architecture, and Web 2.0: Business Transformation or Train Wreck?". 2008. http://whitepapers.techrepublic.com.com/abstract.aspx?docid=992727 (al 23/11/2009)

[56] Kahn Rashid. "Social Networking and BPM of the Future". BpTrends Column. Setiembre 2009. http://bptrends.com/publicationfiles/TEN-COL-BPMA_Global_View--Social\%20Networking\%20and\%20BPM\%20of\%20the\%20Future.pdf (al 23/11/2009)

[57] Ruz C., Baude, F. "Enabling SLA monitoring for component-based SOA applications" XXVIII International Conference of the Chilean Computing Science Society (SCCC). Santiago, Chile. Noviembre 2009.

[58] Macias-Garcia, Sosa-Sosa, Lopez-Arevalo, Tello-Leal. "Data integration with a semantic Web approach". XXI Encuentro Chileno de Computación (ECC). Santiago, Chile. Noviembre 2009.

[59] Calderón G., Sepúlveda M. "Conformance Checking in business processes in order to identify failure sources”. XXVIII International Conference of the Chilean Computing Science Society (SCCC). Santiago, Chile. Noviembre 2009.

[60] Sun MicroSystems. "Take your business to higher level". Abril 2009. https://slx.sun.com/files/Cloud_Computing_Brochure_2009.pdf (al 23/11/2009)

[61] Sun Microsystems. "Introduction to Cloud Computing Architecture". Junio de 2009. http://www.sun.com/featured-articles/CloudComputing.pdf (al 23/11/2009) 


\section{Anexo 1}

\section{Anexo 1. Contexto Global}

\section{A.1.1 Aspectos Conceptuales}

El Diagrama de Contexto permite visualizar las interacciones entre los procesos objeto de la reingeniería (regulación de la actividad económica del partido) y las instancias con que éste debe relacionarse para lograr su objetivo. Este instrumento fue desarrollado con la específica finalidad de representar de manera muy resumida los aspectos esenciales de los procesos de gestión mencionados, proporcionando categorias que permiten interpretar en un mismo lenguaje tanto la lógica actual de funcionamiento como la propuesta.

El Diagrama de contexto describe el funcionamiento de la gestión de regulación de los permisos de funcionamiento para comercios e industrias en las siguientes cinco etapas:

1. Visibilidad, etapa en la cual el emprendedor accede a información, en forma presencial o no, y puede obtener asesoramiento por parte de un informante especializado.

2. Viabilidad legal de la actividad desarrollada por el comercio o industria, es la etapa en la cual el interesado puede obtener a partir de información minima solicitada, un informe que indica la viabilidad legal de obtener un permiso de funcionamiento para una determinada actividad económica en una región, así como las condiciones requeridas para iniciar el trámite.

3. Permiso de Funcionamiento para la actividad desarrollada por un comercio o industria, etapa en la cual, a solicitud del interesado, pueden obtenerse de acuerdo con la naturaleza del trámite, permisos de funcionamiento precarios o bien definitivos, lo cual implica un derecho para la puesta en funcionamiento de una actividad económica en la región.

4. Modificación del estado del permiso de funcionamiento de la actividad a desarrollar, etapa en la cual los interesados pueden obtener cambios en el estado de los permisos de funcionamiento. Las aprobaciones de las modificaciones también podrian tener carácter de provisorias o definitivas.

5. Finalización del desarrollo de la actividad que lleva a cabo el comercio o industria, etapa en la que se deja de realizar dicha actividad y es notificada al organismo regional por iniciativas de los titulares del permiso de funcionamiento o por solicitud del dueño de la propiedad donde se realizaba la actividad. En esta etapa se certifican la finalización de la actividad mediante documentos en los que constan el desistimiento del trámite, el cese de la actividad o la baja de oficio, según corresponda.

En el diseño se contemplan los siguientes niveles de instancias decisorias: a) instancia local, en aspectos sobre los cuales el organismo dispone de 
atribuciones regulatorias y b) instancias externas, constituidas por los niveles de gobierno nacional y provincial.

\section{Esquema de roles de gestión}

El modelo conceptual que se expresa en el diagrama de contexto presupone la existencia de roles mediante los cuales se articulan las interacciones entre los actores. Estos roles permiten asignar responsabilidades de manera horizontal en las gestiones que, como la presente, deben funcionar bajo modelos de red en los cuales las relaciones jerárquicas entre los actores son determinadas por las estructuras organizativas de cada momento y en las que, además, deben intervenir áreas que no tienen dependencias jerárquicas entre sí, como es el caso de las responsables de las gestiones de permisos de funcionamiento, catastral, tributaria y territorial, entre otras.

Los roles han sido clasificados en externos e internos al organismo y se describen a continuación:

\section{Roles externos}

\section{E1 Solicitante de información}

Cualquier ciudadano que pueda acceder a la web o presentarse a solicitar información por escrito o verbalmente sobre actividades desarrolladas por comercios e industrias de la región.

E2 Solicitante de trámite

Personas fisicas o jurídicas o sus apoderados que presenten solicitudes de viabilidad legal, de permiso de funcionamiento, de modificación o de finalización de actividades desarrolladas por comercios o industrias, debiendo para ello cumplir los requisitos de la nueva normativa local y externa vigentes.

\section{Roles internos ${ }^{8}$}

Se describe a continuación el alcance de las responsabilidades de cada rol interno.

\section{AI Atención inicial a usuarios}

a. Proporcionar información a solicitantes de información.

b. Prestar a solicitantes de trámite el servicio de ingreso de los datos cuando corresponda.

c. Recibir solicitudes de viabilidad legal y habilitación de solicitantes de trámite.

d. Aprobar inicio de trámites.

e. Clasificar solicitudes de trámite con los clasificadores primarios.

f. Derivar trámites a Responsables de Trámite (RT) con la previa aprobación del Supervisor de Gestión, cuando corresponda.

Los tipos de roles de AP se pueden clasificar en:

\section{AI.1 Orientación a usuarios}

Se aplica cuando es preciso por razones de demanda puntual de trabajo para el cumplimiento de las funciones a) y b)

AI.2 Recepción de trámites

Se aplica cuando es preciso por razones de demanda puntual de trabajo para el cumplimiento de las funciones c) a f)

\section{A Asesor}

\footnotetext{
${ }^{8}$ Una misma persona puede cumplir más de un rol y varias personas pueden cumplir un mismo rol.
} 
Proporciona asesoramiento especializado a solicitantes de información en materia de:

a. Cuestiones relacionadas con el mercado y el organismo.

b. Oportunidades económicas de exportación y otras.

c. Requerimientos y procesos de los trámites (de manera análoga a la del AP, y eventualmente más especializada en aspectos técnicos).

Aunque el asesor debe estar en condiciones de desempeñar el rol de Atención Primaria, no es así a la inversa, pues se requieren de aptitudes personales y, especialmente, conocimientos sobre gestión empresarial, desarrollo económico local y mercado.

\section{RT Responsable de Trámite}

a. Seguimiento de trámites asignados desde la presentación de la solicitud hasta su finalización o desistimiento.

b. Interlocución con los informantes internos para activación del trámite.

c. Realización de gestiones ante organismos externos.

d. Aprobación técnica de las etapas intermedias y final de los trámites.

e. Puede incluir las funciones de Atención Inicial si es necesario.

Según el esquema que se adopte, todos o sólo algunos de los trámites podrían hallarse a cargo de Responsables de Trámite. Los trámites que no se hallen a cargo de un RT serían supervisados directamente por el Supervisor de Gestión.

\section{IES Informante de estado de situación}

a. Proporcionar al RT o al SG, a través del sistema de permisos de funcionamiento, informaciones específicas de sus áreas, necesarias para el procesamiento del trámite, surgidas de terceros sistemas o gestiones de su especialidad. Tiene responsabilidad sobre la validez de las informaciones. En el caso del IES.4 Mesa de Entradas, la información es la carátula de expediente con el número correspondiente.

b. Proporcionar al RT y SG asesoramiento e información sobre su especialidad, que resulten necesarios.

Los tipos de roles de IES se pueden clasificar en:

\section{IES. 1 IES Catastral \\ IES. 2 IES Territorial \\ IES. 3 IES Tributario \\ IES. 4 IES Mesa de entradas \\ IES. 4 IES Tesoreria}

\section{SG Supervisor de gestión}

a. Autorizar administrativamente etapas o finales de trámites previa aprobación técnica de RTs.

b. Asumir el rol de RT cuando el trámite no está asignado a dicho rol.

c. Obtener de terceras instancias las autorizaciones en caso necesario para el avance de los trámites.

d. Asignar trámites a RTs.

e. Supervisar la gestión completa de visibilidad, prefactibilidad y habilitación en cuanto a la naturaleza de actividades económicas que se hayan establecido mediante la estructura organizativa vigente.

\section{VF Verificador físico}

a. Proporcionar al RT o al SG, a través del sistema de habilitaciones, informaciones específicas necesarias para el procesamiento del 
trámite, surgidas de las verificaciones realizadas por demanda del proceso de habilitación.

Los Verificadores Físicos pueden introducir información sobre los tipos de verificaciones para los que se hallen habilitados.

RAF Responsable de archivo físico

a. Mantener y custodiar los documentos del archivo fisico en poder de la gestión de habilitaciones, hasta su entrega al responsable definitivo.

b. Administrar la entrega de documentos a distintos responsables que los necesiten.

c. En los casos en que se decida, realizar la digitalización de documentos para su consulta directa por el sistema.

\section{AF Administrador funcional}

a. Administrar acceso de usuarios al sistema.

b. Mantener la configuración del sistema, incluyendo la administración de las tablas de codificación.

\section{A.1.2. Criterios de interacción con usuarios en que se basa la hipótesis inicial de ventanillas que da lugar al diagrama de contexto.}

El criterio rector de la interacción subyacente en el Diagrama de Contexto, al que se alude usualmente con el concepto de "ventanilla única" es el de la interacción del rol Solicitante con la menor cantidad posible de interlocutores diferentes para completar cada gestión. En realidad, la "ventanilla única" en sentido estricto se encuentra sólo en los procesos en los que no hay impedimentos para que puedan llevarse a cabo con un mismo interlocutor. Cuando la concentración de funciones en una misma ventanilla resulta poco manejable, el proceso puede agilizarse, según convenga, de dos maneras: o bien redundando ventanillas (v.g. en mostradores de check in en aeropuertos $u$ hoteles) o bien agregando ventanillas especializadas en determinados aspectos (v.g. cajas diferenciadas de la atención en mostrador en los comercios). En este caso, a partir del análisis realizado hasta el momento en el proceso de reingenieria, parece razonable que la gestión pueda realizarse, para los trámites normales, con sólo tres ventanillas, una general y dos especializadas:

- Ventanilla principal de atención (que será percibida, a cualquier efecto, como la "ventanilla única") por cumplir las funciones de acceso y derivación en todas las gestiones,

- Ventanilla especializada "Caja" (o Tesorería) y

- Ventanilla especializada "Asesoramiento especializado" para casos en los que ello se requiera.

En este modelo se asume que, a cualquier efecto, desde el punto de vista del rol Solicitante los RTs atienden a través de la ventanilla única, más allá de que, por razones prácticas, pueden realizarse interacciones en lugares diferentes del inicial (por ejemplo, oficinas de RTs en front office o back office).

El esquema de tres ventanillas para la interacción con el usuario externo, permite establecer la secuencia básica de circulación de los usuarios, la cual siempre debería responder, salvo casos excepcionales, al siguiente esquema:

$1^{\circ}$ ) Contacto inicial con la Ventanilla Principal (para visibilidad, inicio o modificaciones posteriores de cualquier trámite)

$2^{\circ}$ ) Cuando correspondiera, paso por ventanillas especializadas Caja o Asesoramiento especializado

$3^{\circ}$ ) Salida sin retornar a la Ventanilla Principal 
En tal sentido, el flujo de la circulación de los usuarios debe ser unidireccional en trámites normales.

\section{A.1.3. Criterios tecnológicos y de procesos en que se basa el diagrama de contexto.}

La concepción del proceso de gestión del desarrollo económico local y la nueva lógica expuesta a través de Diagrama de Contexto, con la creación de los roles antes enunciados, posee no sólo una serie de implicaciones administrativas y organizativas, sino que también subyacen en este nuevo modelo una serie de criterios y un escenario tecnológico distinto para su funcionamiento. Los mismos se pueden sintetizar en los siguientes documentos:

- Escenario tecnológico: contempla la existencia de una base de datos única para toda la gestión, con la que los responsables y usuarios interactuarán a través de un sistema operable en la web según roles.

- Articulación de responsabilidades: se establece según una tabla de roles genéricos que permita independizar todo lo posible la gestión de cambios de estructuras y normativas, asi como disponer de flexibilidad para la asignación de roles a personas físicas en determinados momentos, con relativa independencia de otros aspectos de sus puestos de trabajo (por ejemplo, el rol SG se refiere solamente a las funciones del coordinador y aprobador de determinadas actividades dentro de los procesos según tipos de trámites, mientras que el de Director de un área como Comercio, Industria, Regulación, etc., incluye otras funciones adicionales. Asimismo, para determinados trámites, podría asignarse el rol SG a determinadas personas que no son titulares de unidades).

- Simultaneidad de actividades limitada sólo por precedencias técnicas o restricciones normativas, de modo que, a partir del inicio de un trámite, las notificaciones para las actividades siguientes se realicen siempre en paralelo.

- Archivo de documentación física estático en el área responsable de la gestión de habilitaciones, en el que, salvo excepciones, los documentos físicos que se depositen se mantengan hasta el momento en el que el archivo sea enviado a Mesa de Entradas para cumplir con las disposiciones normativas correspondientes. La minimización de la necesidad de extracción de documentos del archivo físico, además de la información con que se cuente en la propia base de datos, depende en buena medida de la posibilidad práctica de digitalización.

- No redundancia de cumplimiento de requisitos por parte de usuarios como, por ejemplo, la reiteración de presentación de documentos e informaciones en trámites de modificación cuando han sido presentados anteriormente.

\section{A.1.4. Criterios derivados de las politicas}

El Diagrama de Contexto, por otra parte, presupone la aplicación de una serie de criterios derivados de las politicas definidas por el organismo bajo estudio, que pueden resumirse en los siguientes enunciados: 
a. Gestión según Tipos de Trámite definidos de acuerdo al grado de regulación requerido a partir del nivel de riesgo, que el Estado tiene la obligación de prevenir, a fin de garantizar las condiciones del medio ambiente y la seguridad de las personas.

b. Flexibilidad en el grado de regulación establecido, mediante la posibilidad de cambiar siempre que las circunstancias lo aconsejen y la normativa lo permita, el tipo de trámite que corresponda a cada ámbito, sin por ello cambiar la lógica de las reglas de negocio del sistema.

c. Establecimiento de compatibilidades entre ámbitos que minimice o simplifique la necesidad y frecuencia de trámites del tipo modificación. Al igual que el anterior, este criterio es llevado a la práctica mediante el análisis de los riesgos inherentes y la razonabilidad de cada tipo de compatibilidad, pudiendo existir distintos niveles en esta relación, los que modifican la aplicación de este criterio.

d. No disminuir requisitos cuando ello implique no prevención de riesgos, más allá del grado de complejidad del trámite resultante. 


\section{Anexo 1. Contexto Global}

\section{A.1.5. Diagrama de contexto}

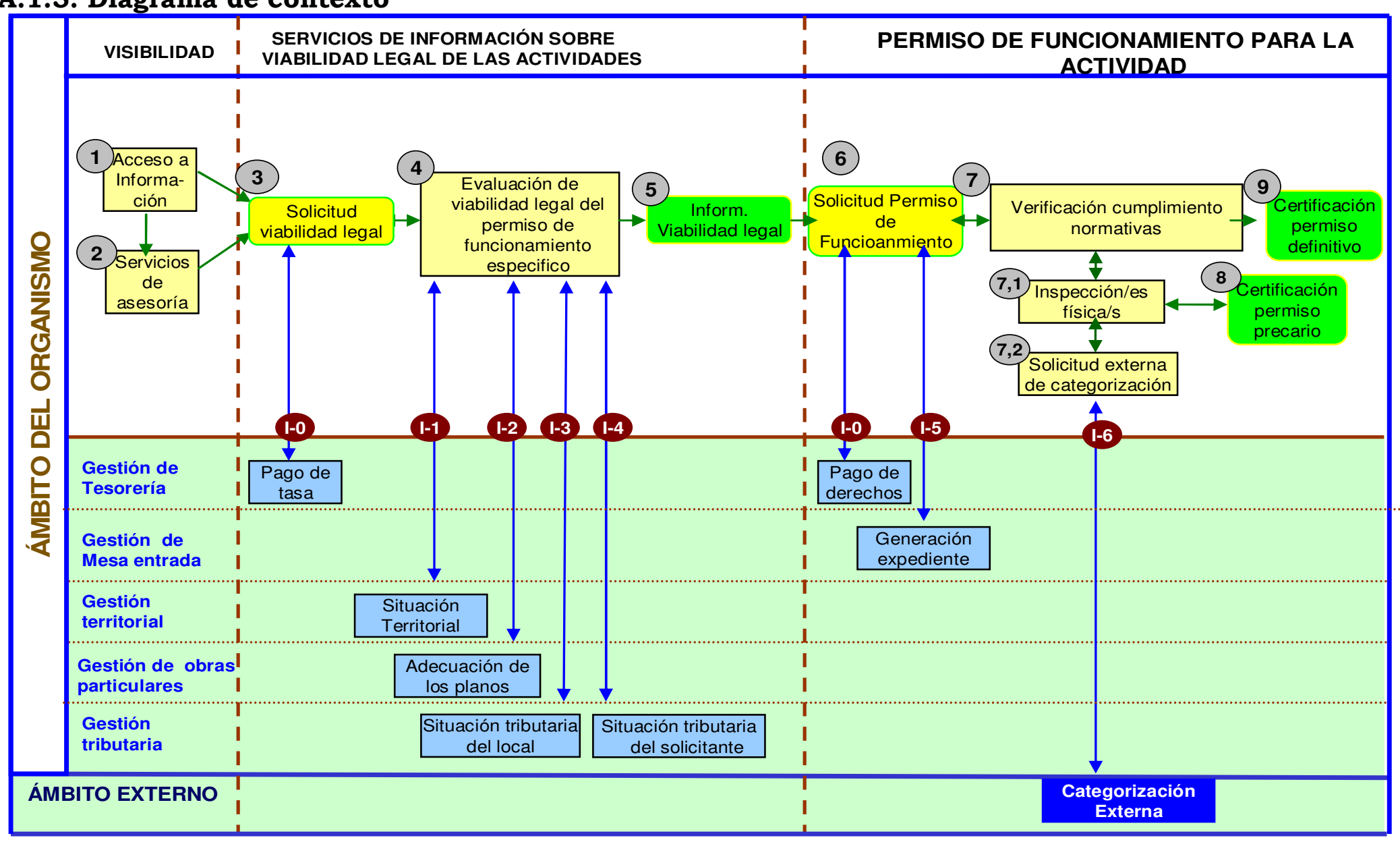




\section{Referencias del Diagrama de Contexto}

a) $\mathrm{N}^{\circ}$ : Actividad o subproceso genérico.

b) Color amarillo: solicitudes de usuarios externos.

c) Color verde: productos para usuarios externos.

d) I- $\mathrm{N}^{\circ}$ : interfaces con gestores responsables de procesos paralelos a la gestión de desarrollo económico.

e) Visibilidad: facilidades de acceso a información sobre relaciones de los actores económicos con el estado y/o el mercado por cualquier medio (internet, folletos, personalmente, etc.)

f) Servicios de asesoría: tiempo/persona de personal asignado a atender demandas de usuarios relacionadas con el estado y/o el mercado.

g) Servicio de información sobre viabilidad legal: informaciones sobre condiciones en las que serian normativamente viables habilitaciones específicas en términos que bajen la incertidumbre y el riesgo decisorio de actores económicos.

h) Flechas azules: interacciones del proceso de permisos de funcionamiento con el contexto institucional.

g) Flechas verdes: flujo del proceso dentro de la gestión de permisos de funcionamiento.

i) Gestión: conjunto de procesos genéricos necesarios para que el Estado cumpla su función regulatoria o prestadora de servicios, con independencia de cómo se hallen asignadas en una estructura organizativa determinada (ej: gestión catastral, gestión de obras particulares, gestión de uso del suelo, etc.) 


\section{Anexo 2}

\section{Anexo 2. Modificaciones Propuestas}

A partir de los criterios ya identificados en la reingeniería y expresados como fundamentación del diagrama de contexto, pueden identificarse las modificaciones propuestas a partir de la reingeniería de procesos, las que pueden ser clasificadas, según sus características, en los siguientes grupos:

- Modificaciones generales, que impactan en todos los procesos y trámites, tendrán principalmente implicancias normativas, ya que son las que fijan la lógica general de los procesos y para su implementación requerirán de ajustes normativos.

- Modificaciones específicas, asociadas a un determinado proceso.

\section{A.2.1 Modificaciones generales}

Se propone el establecimiento de niveles de regulación mediante instrumentos técnicos y propuestas de mejora en las reglas de negocio de los procesos. En principio, se estima hasta el momento necesario que las normas a desarrollar incluyan, como minimo los siguientes:

\section{Instrumentos Técnicos}

Clasificador de Especie o Género de la Actividad desarrollada por el Comercio o Industria (EACyI): Este instrumento técnico, cuyo nivel más detallado es el Ámbito, regularía la aplicación, sin perjuicio de otros, de los siguientes aspectos:

- Identificación de los ámbitos que son objeto de regulación de la actividad económica local a los efectos normativos y operativos.

- Aplicación según el ámbito, de las regulaciones que resultan de las normas territoriales vigentes en el partido (p.e. Código de Ordenamiento Urbano).

- Aplicación según el ámbito de las regulaciones que resultan de las normas externas vigentes.

- Calificación del riesgo ambiental y social asignado por el Estado regional a cada ámbito según sus dimensiones, a los efectos de la regulación de la actividad.

- Establecimiento de los aspectos a fiscalizar y exigencias de prevenciones y medidas precautorias para las actividades económicas según su nivel de riesgo.

- Exigencia de requisitos a cargo del actor que desea realizar una actividad económica en el partido.

Clasificador de Tipos de Trámites (TT): Este instrumento debe establecer los requerimientos de requisitos aplicables a cada ámbito que surgen del apartado anterior. Para el clasificador de tipos de Trámites se tomaron en cuenta, los siguientes aspectos:

- Nivel de exigencia de requisitos según fases del proceso (viabilidad legal, permiso de funcionamiento, modificaciones y finalización).

- Nivel de exigencia de requisitos según nivel de riesgo ambiental, socioeconómico y regulaciones externas.

A partir de los mencionados aspectos, para cada proceso, se determinaron variantes de requerimientos de acuerdo a los niveles de regulación deseados. Esto implica distintos niveles de simplificación, de acuerdo al nivel de riesgo de cada actividad económica, o sea para distintos niveles de riesgo (ambiental o social) distintos niveles de complejidad del trámite (cantidad de requisitos). 
Instrumento de evaluación del riesgo contextual: Este instrumento técnico debe establecer, entre otros, los siguientes aspectos a regular:

- Variables e indicadores con los que deberá ser evaluado el nivel de riesgo ambiental y social intrínseco de los ámbitos según dimensiones para el desarrollo de la actividad del comercio o industria en condiciones normales y el real en casos concretos con el objeto de otorgar permiso de funcionamiento y posterior fiscalización.

- Niveles máximos admisibles de riesgo en cada variable y medidas específicas de prevención exigibles para garantizar que dicho nivel no sea superado. Estos niveles máximos, cuando se hallen también regulados por otras normas vigentes locales o externas, podrian ser establecidos en valores de mayor seguridad en casos específicos por razones derivadas de la evaluación del riesgo realizada por el organismo.

- Peso relativo de las variables de riesgo en caso de que algún aspecto de política u otro se regulara según el índice de riesgo (como, por ejemplo, se aplica en la categorización de industrias en PBA).

\section{Mejora en las reglas de negocio de los procesos}

Minimización y simplificación de la necesidad interpretativa: La parte dispositiva de la normativa deberia incluir, sin perjuicio de otros aspectos:

- Alcance regulatorio de la actividad económica y su relación con las otras gestiones locales (p.e. tributos, planeamiento, etc.).

- Alcance y aplicación de los instrumentos técnicos.

- Alcance de las responsabilidades asumidas por el Estado local y por los responsables de actividades económicas entre sí y frente a la sociedad.

- Proceso aplicable y esquema de distribución de responsabilidades de gestión que permita la actualización flexible de aspectos que corresponda o convenga que sean decididos por el Ejecutivo (tales como modificaciones de estructuras organizativas, actualización de clasificadores en niveles operativos, como rubros o indicadores, asignación de tipos de procesos a rubros dentro de ciertos límites, etc.) de modo que se garantice la máxima flexibilidad en el plano operativo al tiempo que preserve la continuidad y sostenibilidad de las reglas de juego y los sistemas de gestión que las soportan.

Distinción entre procesos propios de la regulación de la actividad económica frente a otras gestiones regionales: Se requiere distinguir entre las gestiones propias de la regulación y las de otras gestiones del organismo (ordenamiento territorial, gestión tributaria, fiscalización e inspección, entre otras). El sector encargado de la regulación, deberá solicitar información a otras áreas del organismo $\mathrm{y}$, en base a dicha información, $\mathrm{y}$ a la normativa correspondiente, tomar decisiones respecto de los procesos que tiene a su cargo. Esto no implica que no deba existir colaboración entre áreas, los responsables de la regulación deberán poner a disposición de terceras áreas cualquier información útil que permita facilitar sus tareas.

Eliminar pases improductivos: Se trata de eliminar aquellos pases improductivos o formales, que actualmente se realizan por meros requerimientos formales (Normas de reglamentación de procesos administrativos), pero que no tienen justificación técnica. Para ellos se intenta que las gestiones que implican solicitudes de información entre áreas del municipio se realicen previamente a la confección del expediente.

Reducción del número de interacciones del solicitante: Se trata de evitar que el solicitante del trámite deba realizar gestiones en distintas áreas del organismo, para ello, todas las gestiones con terceras áreas será resuelta de manera interna o incorporadas al espacio físico de la ventanilla única. 


\section{Anexo 2. Modificaciones Propuestas}

\section{A.2.2. Modificaciones especificas}

\begin{tabular}{|c|c|c|c|c|c|c|c|c|c|c|c|c|}
\hline \multirow{2}{*}{$\begin{array}{l}\text { PRO } \\
\text { CE } \\
\text { SOS }\end{array}$} & \multirow{3}{*}{$\begin{array}{l}\text { SITUACIÓN ACTUAL } \\
\text { (SEGÚN LINEA DE BASE) }\end{array}$} & \multicolumn{11}{|c|}{ MODIFICACIONES PROPUESTAS } \\
\hline & & \multirow[b]{2}{*}{ Descripción de la modificación } & \multirow[b]{2}{*}{ Ventaja de la modificación } & \multicolumn{3}{|c|}{$\underset{*}{\operatorname{Implicancia}}$} & \multicolumn{5}{|c|}{$\begin{array}{l}\text { Naturaleza } \\
\text { de la mejora** }\end{array}$} & \multirow[b]{2}{*}{$\begin{array}{l}\text { Afecta a los } \\
\text { trámites tipo }\end{array}$} \\
\hline$\frac{\text { gृ }}{\frac{\pi}{\pi}}$ & & & & 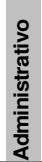 & 竞 & 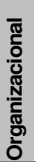 & & 产 & & 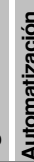 & 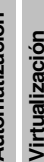 & \\
\hline \multirow[t]{4}{*}{$\frac{\pi}{\frac{\pi}{6}}$} & 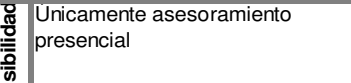 & {$\left[\begin{array}{l}\text { Se proponen tres formas de asesoramiento: a) } \\
\text { asesoramiento automatizado online, b) Asesoramiento a } \\
\text { distancia (telefónico y por e-mail) y c) presencial }\end{array}\right.$} & $\begin{array}{l}\text { Se incorporan medios de consulta que evitan el traslado de } \\
\text { los emprendedores hasta dependencias municipales }\end{array}$ & $\mathbf{x}$ & & $\mathbf{x}$ & & & & & $\mathrm{x}$ & $\begin{array}{l}\text { 1.1, 1.2, 2.1, } \\
2.2,2.3,3.1 \\
3.2\end{array}$ \\
\hline & $\begin{array}{l}\text { Información brindada sin } \\
\text { estandarización, la respuesta } \\
\text { depende en gran parte de la } \\
\text { persona que asesora }\end{array}$ & $\begin{array}{l}\text { Todo el asesoramiento se realiza, en primera instancia, en } \\
\text { base a la misma herramienta informática sin importar la } \\
\text { forma de interacción. }\end{array}$ & $\begin{array}{l}\text { Se minimizan las asimetrías de información y el número de } \\
\text { respuestas posibles que puede obtener el emprendedor, } \\
\text { permite sistematizar las respuestas sin importar la forma en } \\
\text { que se canalice la consulta }\end{array}$ & $\mathbf{x}$ & & & & & & $\mathrm{x}$ & $\mathrm{k}$ & $\begin{array}{l}1.1,1.2,2.1 \\
2.2,2.3,3.1 \\
3.2\end{array}$ \\
\hline & $\begin{array}{l}\text { Únicamente se provee } \\
\text { información necesaria para } \\
\text { habilitar }\end{array}$ & $\begin{array}{l}\text { En los casos de asesoramiento presencial y a distancia, se } \\
\text { podría agregar a la información automatizada de sistema } \\
\text { datos adicionales, útiles para la toma de decisiones y para la } \\
\text { gestión de la actividad (p.e técnicas de gestión) por parte del } \\
\text { emprendedor. }\end{array}$ & $\begin{array}{l}\text { Mejora las posibilidades de éxito del emprendedor al recibir } \\
\text { información adicional para la toma de decisiones }\end{array}$ & $\mathrm{x}$ & & $\mathbf{x}$ & $\mathbf{x}$ & & & & & $\begin{array}{l}1.1,1.2,2.1 \\
2.2,2.3,3.1 \\
3.2\end{array}$ \\
\hline & $\begin{array}{l}\text { No se lleva un control del número } \\
\text { de consultas que se realizan }\end{array}$ & En todos los casos se registrarán las consultas realizadas & $\begin{array}{l}\text { Permite tener información útil para el control de gestión y la } \\
\text { toma de decisiones por parte del municipio }\end{array}$ & $\mathbf{x}$ & & $\mathbf{x}$ & & & & $x$ & $\mathrm{k}$ & $\begin{array}{l}\text { 1.1, 1.2, 2.1, } \\
2.2,2.3,3.1 \\
3.2\end{array}$ \\
\hline & 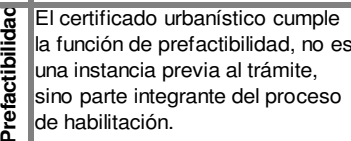 & $\begin{array}{l}\text { El informe de prefactibilidad reemplaza el urbanístico y se } \\
\text { incorporara esta fase como previa al inicio de la habilitación }\end{array}$ & $\begin{array}{l}\text { Se evita el inicio de trámites de habilitación que son } \\
\text { inviables, generando una instancia previa de información a } \\
\text { los solicitantes que permita determinar su posibilidad de } \\
\text { iniciar la actividad económica sin haber realizado gastos } \\
\text { previos de instalación (alquileres, modificaciones, etc.) }\end{array}$ & $\mathbf{x}$ & $\mathbf{X}$ & $\mathbf{x}$ & $\mathbf{x}$ & & & & & $\begin{array}{l}1.1,1.2,2.1 \\
2.2,2.3,3.1 \\
3.2\end{array}$ \\
\hline & \begin{tabular}{|l} 
Los requisitos para iniciar el \\
trámite no son sólo los \\
necesarios para la prefactibilidad.
\end{tabular} & $\begin{array}{l}\text { El informe es único sin importar la naturaleza de actividad y } \\
\text { con los mismos requisitos mínimos para todos los } \\
\text { emprendedores }\end{array}$ & $\begin{array}{l}\text { Permite tener un informe de factibilidad con requisitos } \\
\text { mínimos, bajando los costos de transacción del } \\
\text { emprendedor }\end{array}$ & $\mathbf{x}$ & $\mathbf{X}$ & & $\mathrm{x}$ & & & & & $\begin{array}{l}1.1,1.2,2.1 \\
2.2,2.3,3.1 \\
3.2\end{array}$ \\
\hline & $\begin{array}{l}\text { El trámite es iniciado en distintos } \\
\text { lugares (p.e. industria y comercio) } \\
\text { y requiere de la interacción del } \\
\text { solicitante con varias áreas del } \\
\text { municipio (p.e. catastro, } \\
\text { planeamiento y tributos) }\end{array}$ & $\begin{array}{l}\text { El proceso se inicia, para todos los solicitantes en un único } \\
\text { lugar y se gestiona en el mismo espacio físico en su } \\
\text { totalidad }\end{array}$ & $\begin{array}{l}\text { Reduce el número de interacciones y personal con el que el } \\
\text { emprendedor debe interactuar. }\end{array}$ & $\mathbf{x}$ & $\mathbf{x}$ & $\mathbf{x}$ & & $\mathbf{x}$ & $\mathbf{x}$ & & & $\begin{array}{l}1.1,1.2,2.1 \\
2.2,2.3,3.1 \\
3.2\end{array}$ \\
\hline
\end{tabular}




\section{Anexo 2. Modificaciones Propuestas}

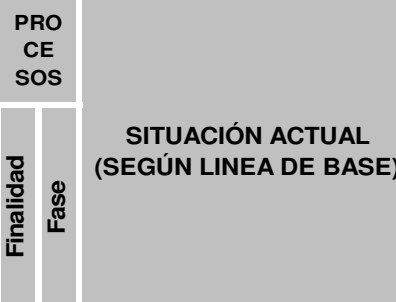

Actualmente el urbanístico qued detenido en cada área hasta que
se subsanan los inconvenientes detectados, este certificado no informa los requisitos necesario para iniciar el proceso de habilitación.

\section{Actualmente, en el caso de ser} una industria, se entrega el instructivo de la provincia y aplicalvo enun CD en todos casos, al inicio del trámite.

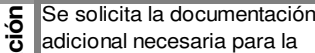
habilitación una vez que se presenta el urbanístico completo

垔

Actualmente el solicitante tiene un número identificatorio por cada expediente, no cuenta con un identificador único

\section{No se otorga habilitación} funcionamiento inmediata en ningún caso.

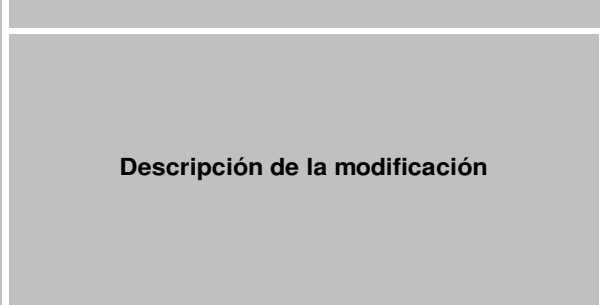

El informe de prefactibilidad le indicará al emprendedor la posibilidad de iniciar el trámite de habilitación o la negativa,
dado que no cumple los requisitos mínimos, y le indicará las alternativas para subsanar los posibles inconvenientes a fin de continuar el proceso de habilitación.

Se indicará en el informe de prefactibilidad desde que sitio web puede bajar el aplicativo del Gobierno de la Provincia para la calegorización junto con un instruclivo. En caso de no copia en el momento.

En la propuesta de reingeniería los requisitos necesarios para la habilitación de una actividad económica estan incluidos en el informe de prefactibilidad.

Sin importar el número de expedientes asociados al trámite el solicitante recibe un único número identificatorio para seguimiento de trámite

En el caso de los trámites de baja complejidad (1.1 y 1.2) completando la documentación y realizando el pago de tasas y timbrados correspondientes se le entrega en el mona
solicitante una licencia provisoria de funcionamiento

solicitante una licencia provisoria de funcionamiento

En el caso 1.1 el período para la entrega de la habilitación
definitiva se encuentra vinculado únicamente con el tiempo necesario para la caratulación del expediente y la aprobación de la habilitación definitiva por parte del supervisor.

\section{MODIFICACIONES PROPUESTAS}

\begin{tabular}{|l|l|l|l|l|l|l|l|l|l|l|}
\hline \multicolumn{2}{|c|}{ Ventaja de la modificación } & \multicolumn{2}{|c|}{ Implicancia } & \multicolumn{2}{|c|}{ Naturaleza } \\
de la mejora
\end{tabular}




\section{Anexo 2. Modificaciones Propuestas}

\begin{tabular}{|l|l}
\hline $\begin{array}{l}\text { PRO } \\
\text { CE } \\
\text { SOS }\end{array}$ & \begin{tabular}{l}
\multicolumn{1}{c}{ SITUACIÓN ACTUAL } \\
(SEGÚN LINEA DE BASE)
\end{tabular} \\
\hline $\begin{array}{l}\text { I. Para realizar los pagos, es } \\
\text { necesario dirigirse a otras áreas } \\
\text { del municipio (p.e. ventanilla } 1 \text { y } \\
\text { mesa de entrada) }\end{array}$ \\
\hline $\begin{array}{l}\text { No se entrega habilitación } \\
\text { provisoria sin inspección para } \\
\text { comercios mayores de 50 metros } \\
\text { cuadrados. }\end{array}$ \\
\hline $\begin{array}{l}\text { Actualmente, en el caso de } \\
\text { incumplimientos reiterados en } \\
\text { presentación de documentación y } \\
\text { requisitos derivados de la } \\
\text { inspección, para realizar alguna } \\
\text { acción se notifica a Inspección } \\
\text { General. }\end{array}$ \\
\hline $\begin{array}{l}\text { El solicitante debe ir hasta mesa } \\
\text { de entrada para la caratulación de } \\
\text { expedientes, debiendo realizar } \\
\text { gestiones en distintas áreas del } \\
\text { municipio. }\end{array}$ \\
\hline $\begin{array}{l}\text { El expediente circula por las } \\
\text { distintas áreas e incluso fuera del } \\
\text { municipio (inspecciones) }\end{array}$ \\
\hline $\begin{array}{l}\text { Actualmente los inspecciones se } \\
\text { distinguen por la naturaleza de la } \\
\text { actividad (industria o comercio), } \\
\text { pero no por el nivel de impacto } \\
\text { (riesgo) de la actividad. }\end{array}$ \\
\hline
\end{tabular}

\begin{tabular}{|c|c|c|c|c|c|c|c|c|c|c|}
\hline \multicolumn{11}{|c|}{ MODIFICACIONES PROPUESTAS } \\
\hline \multirow[b]{2}{*}{ Descripción de la modificación } & \multirow[b]{2}{*}{ Ventaja de la modificación } & \multicolumn{3}{|c|}{$\underset{\star}{\stackrel{*}{*}(m p l i c a n c i a}$} & \multicolumn{5}{|c|}{$\begin{array}{l}\text { Naturaleza } \\
\text { de la mejora** }\end{array}$} & \multirow[b]{2}{*}{$\begin{array}{l}\text { Afecta a los } \\
\text { trámites tipo }\end{array}$} \\
\hline & & 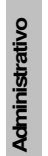 & 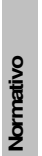 & 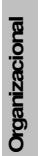 & 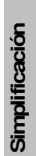 & : & $\begin{array}{l}\frac{8}{8} \\
\frac{\pi}{8} \\
\frac{8}{2} \\
\end{array}$ & 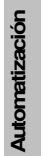 & 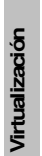 & \\
\hline $\begin{array}{l}\text { Se propone incorporar una ventanilla de pago en el sector de } \\
\text { habilitaciones, que cobre en una sola instancia todos los } \\
\text { cargos referidos al trámite de habilitación }\end{array}$ & $\begin{array}{l}\text { Evita que el contribuyente tenga que realizar varios pagos en } \\
\text { lugares y momentos diferentes. }\end{array}$ & $\mathbf{x}$ & $\mathbf{x}$ & $\mathbf{x}$ & & $\mathbf{x}$ & $\mathbf{x}$ & $\mathbf{x}$ & & $\begin{array}{l}1.1,1.2,2.1 \\
2.2,2.3,3.1 \\
3.2\end{array}$ \\
\hline $\begin{array}{l}\text { En el caso de los trámites tipo } 1.2 \text {, la licencia de } \\
\text { funcionamiento, se otorga sin inspección previa }\end{array}$ & $\begin{array}{l}\text { Reduce drásticamente los tiempos en que el emprendedor } \\
\text { puede iniciar la actividad, reduciendo costos y pérdidas. }\end{array}$ & $\mathbf{x}$ & $\mathbf{x}$ & & $\mathbf{x}$ & & $\mathbf{x}$ & & & 1.1, y 1.2 \\
\hline $\begin{array}{l}\text { En caso de informes de verificación con aprobación nula o el } \\
\text { incumplimiento en la entrega de documentación solicitada, } \\
\text { para la que se dio plazos (p.e. libreta sanitaria) el supervisor } \\
\text { tiene la atribución de revocar la licencia y notificar a } \\
\text { Inspección General para que verifique que el local no está en } \\
\text { funcionamiento y/o aplique las sanciones correspondientes }\end{array}$ & $\begin{array}{l}\text { Reduce tiempo en los plazos de resolución y otorga al sector } \\
\text { de habilitaciones atribuciones adicionales que le dan mayor } \\
\text { poder de coerción, con lo que antes no contaba. }\end{array}$ & $\mathbf{x}$ & $\mathbf{x}$ & $\mathbf{x}$ & $\mathbf{x}$ & $\mathbf{x}$ & & & & $\begin{array}{l}1.1,1.2,2.1 \\
2.2,2.3,3.1 \\
3.2\end{array}$ \\
\hline $\begin{array}{l}\text { La solicitud de caratulación y asignación del número/s de } \\
\text { expediente/s es realizada por el responsable de trámite vía } \\
\text { remisión de los documentos recibidos a mesa de entrada }\end{array}$ & $\begin{array}{l}\text { Reduce el número de interacciones y personal con el que el } \\
\text { emprendedor debe interactuar. }\end{array}$ & $\mathbf{x}$ & & $\mathbf{x}$ & $\mathbf{x}$ & & $\mathbf{x}$ & & & $\begin{array}{l}1.1,1.2,2.1 \\
2.2,2.3,3.1 \\
3.2\end{array}$ \\
\hline $\begin{array}{l}\text { El expediente se encuentra en el archivo físico de } \\
\text { documentación de respaldo de la gestión, y no se traslada } \\
\text { entre áreas del municipio y sólo se envía al Archivo Municipal } \\
\text { cuando se tiene el recibo de recepción de la habilitación } \\
\text { definitiva firmado. }\end{array}$ & $\begin{array}{l}\text { Evita la circulación de papeles y reduce el tiempo de gestión } \\
\text { permitiendo simultaneidad de gestiones. }\end{array}$ & $\mathbf{x}$ & & & & & $\mathbf{x}$ & $\mathbf{x}$ & & $\begin{array}{l}1.1,1.2,2.1 \\
2.2,2.3,3.1 \\
3.2\end{array}$ \\
\hline $\begin{array}{l}\text { Para los tipos de proceso de complejidad media y alta se ha } \\
\text { diferenciado el tipo de verificación que se realiza en dos: a) } \\
\text { inspección ocular o inspección básica b) inspección técnica o } \\
\text { de requisitos específicos }\end{array}$ & $\begin{array}{l}\text { Permite diferenciar distintos niveles de calificación entre los } \\
\text { verificadores y reducir costos al municipio, así como } \\
\text { identificar con mayor exactitud los alcances de las } \\
\text { verificaciones de acuerdo al nivel de criticidad de impacto } \\
\text { (riesgo) }\end{array}$ & $\mathbf{x}$ & $\mathbf{x}$ & $\mathbf{x}$ & $\mathbf{x}$ & $\mathbf{x}$ & & & & $\begin{array}{l}2.1,2.2,2.3 \\
3.1 \text { y } 3.2\end{array}$ \\
\hline $\begin{array}{l}\text { En el caso del trámite tipo } 2.3 \text { incorpora la obligatoriedad de } \\
\text { obtener previamente una habilitación provisoria a partir de } \\
\text { una verificación básica. La habilitación definitiva solo es } \\
\text { posible obtenerla luego de una inspección especializada que } \\
\text { verifique las correctas condiciones efectivas de } \\
\text { funcionamiento del establecimiento. }\end{array}$ & $\begin{array}{l}\text { Permite identificar con mayor exactitud los alcances de las } \\
\text { verificaciones de acuerdo al nivel de impacto (riesgo), } \\
\text { mejorando la capacidad regulatoria del municipio }\end{array}$ & $\mathbf{x}$ & $\mathbf{x}$ & & $\mathbf{x}$ & & & & & 2.3 \\
\hline
\end{tabular}




\section{Anexo 2. Modificaciones Propuestas}

\begin{tabular}{|c|c|c|c|c|c|c|c|c|c|c|c|c|}
\hline \multirow{2}{*}{$\begin{array}{l}\text { PRO } \\
\text { CE } \\
\text { SOS }\end{array}$} & \multirow[b]{3}{*}{$\begin{array}{l}\text { SITUACIÓN ACTUAL } \\
\text { (SEGÚN LINEA DE BASE) }\end{array}$} & \multicolumn{11}{|c|}{ MODIFICACIONES PROPUESTAS } \\
\hline & & & \multirow[b]{2}{*}{ Ventaja de la modificación } & \multicolumn{3}{|c|}{$\underset{\star}{\operatorname{Implicancia}}$} & \multicolumn{5}{|c|}{$\begin{array}{l}\text { Naturaleza } \\
\text { de la mejora }{ }^{\star \star}\end{array}$} & \multirow[b]{2}{*}{$\begin{array}{l}\text { Afecta a los } \\
\text { trámites tipo }\end{array}$} \\
\hline \multirow[t]{2}{*}{ क्ष } & & Descripción de la modificación & & $\frac{?}{\underbrace{}_{0}}$ & $\overbrace{2}^{2}$ & 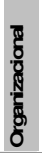 & $\begin{array}{l}\frac{\delta}{8} \\
\frac{8}{2} \\
\frac{\sum_{n}^{2}}{\omega}\end{array}$ & $\begin{array}{l}\frac{\delta}{8} \\
\frac{8}{8} \\
\frac{6}{5}\end{array}$ & $\frac{\delta}{\frac{\delta}{8}}$ & 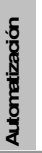 & $\frac{\frac{\delta}{6}}{\frac{6}{2}}$ & \\
\hline & $\begin{array}{l}\text { Las verificaciones son realizadas } \\
\text { unicamente por inspectores } \\
\text { municipales. }\end{array}$ & $\begin{array}{l}\text { Se incorpora la opción de presentación de certificados } \\
\text { emitidos por instancia profesional competente, lo cual } \\
\text { remplaza, en los casos en que el municipio considere viable, } \\
\text { la inspección técnica municipal. }\end{array}$ & Reduce costos y recursos municipales & & $\mathbf{x}$ & $\mathrm{x}$ & $\mathrm{x}$ & & & & & $\begin{array}{l}1.2,2.1,2.2 \\
2.3,3.1 \text { y } 3.2\end{array}$ \\
\hline \multirow{8}{*}{$\begin{array}{l}\frac{9}{4} \\
\frac{1}{8} \\
8 \\
8 \\
8 \\
\frac{8}{8} \\
\frac{1}{8} \\
2\end{array}$} & $\begin{array}{l}\text { La modificación implica un nuevo } \\
\text { inicio de trámite, excepto en el } \\
\text { caso de cambio de titularidad. }\end{array}$ & $\begin{array}{l}\text { La modificación se considera un cambio de estado en la } \\
\text { habilitación. }\end{array}$ & $\begin{array}{l}\text { Baja el costo del contribuyente al no tener que realizar todo } \\
\text { el trámite desde el inicio nuevamente. }\end{array}$ & $\mathbf{x}$ & $\mathbf{x}$ & $\mathrm{x}$ & $\mathbf{x}$ & & $\mathbf{x}$ & $\mathbf{x}$ & $\mathrm{x}$ & $\mathrm{M} 1, \mathrm{M} 2$, у M3 \\
\hline & $\begin{array}{l}\text { Para hacer un cambio de estado } \\
\text { se debe presentar toda la } \\
\text { documentación y los requisitos } \\
\text { nuevamente. }\end{array}$ & $\begin{array}{l}\text { Se permite realizar la modificación (anexo rubro, cambio de } \\
\text { titularidad, ampliación de superficie) presentando solamente } \\
\text { documentación adicional a la ya presentada. }\end{array}$ & $\begin{array}{l}\text { Reduce los costos de transacción y los tiempos de } \\
\text { resolución para el solicitante. }\end{array}$ & $\mathbf{x}$ & $\mathbf{x}$ & & $\mathbf{x}$ & & & & & M1, M2, y M3 \\
\hline & & $\begin{array}{l}\text { La información originalmente presentada por el solicitante es } \\
\text { rescatada directamente desde el sistema, sin necesidad de } \\
\text { desarchivar el expediente }\end{array}$ & $\begin{array}{l}\text { Reduce los costos de transacción y los tiempos de } \\
\text { resolución para el solicitante y el municipio }\end{array}$ & $\mathbf{x}$ & $\mathbf{x}$ & & & & $\mathbf{x}$ & $\mathrm{x}$ & & M1, M2, у M3 \\
\hline & & $\begin{array}{l}\text { En los casos de baja complejidad de trámite y con } \\
\text { compatibilidad primaria de rubro, se realiza el trámite de } \\
\text { manera automática solamente completando la información y } \\
\text { llenando una declaración jurada, sin verificación ocular. }\end{array}$ & $\begin{array}{l}\text { Minimiza los tiempos de aprobación de las modificaciones, } \\
\text { reduciendo costos para el municipio y el solicitante. }\end{array}$ & $\mathbf{x}$ & $\mathbf{x}$ & $\mathbf{x}$ & $\mathbf{x}$ & & $\mathbf{x}$ & $\mathbf{x}$ & & M1 \\
\hline & $\begin{array}{l}\text { Normalmente para hacer un } \\
\text { cambio de estado se requiere una } \\
\text { inspección previa. }\end{array}$ & $\begin{array}{l}\text { En los casos de baja complejidad y media complejidad no se } \\
\text { requiere de una verificación previa, sólo se requiere en los } \\
\text { casos de actividades de alto riesgo (M3) }\end{array}$ & $\begin{array}{l}\text { Minimiza los tiempos de aprobación de las modificaciones, } \\
\text { reduciendo costos para el municipio y el solicitante. }\end{array}$ & $\mathbf{x}$ & $\mathbf{x}$ & $\mathbf{x}$ & $\mathbf{x}$ & & $\mathbf{x}$ & & & M1 у M2 \\
\hline & $\begin{array}{l}\text { Para realizar la modificación se } \\
\text { requiere nuevamente todas las } \\
\text { consultas a otras áreas del } \\
\text { municipio. }\end{array}$ & $\begin{array}{l}\text { Salvo excepciones, la gestión completa se realiza en el } \\
\text { sector de habilitaciones sin necesidad de nuevas consultas a } \\
\text { los informantes, de las realizadas en la prefactibilidad previa } \\
\text { a la habilitación. }\end{array}$ & $\begin{array}{l}\text { Evita la interacción con terceras áreas de municipio y reduce } \\
\text { los tiempos de resolución de trámite. }\end{array}$ & $\mathbf{x}$ & $\mathbf{x}$ & & & $\mathbf{x}$ & $\mathbf{x}$ & & & $\mathrm{M} 1, \mathrm{M} 2$, у M3 \\
\hline & $\begin{array}{l}\text { Para realizar los pagos, es } \\
\text { necesario dirigirse a otras áreas } \\
\text { del municipio (p.e. ventanilla } 1 \text { y } \\
\text { mesa de entrada) }\end{array}$ & $\begin{array}{l}\text { Se propone incorporar una ventanilla de pago en el sector de } \\
\text { habilitaciones, que cobre en una sola instancia todos los } \\
\text { cargos referidos al trámite. }\end{array}$ & $\begin{array}{l}\text { Evita que el contribuyente tenga que realizar varios pagos en } \\
\text { lugares y momentos diferentes. }\end{array}$ & $\mathbf{x}$ & & $\mathbf{x}$ & & $\mathbf{x}$ & $\mathbf{x}$ & & & $\mathrm{M} 1, \mathrm{M} 2$, у M3 \\
\hline & $\begin{array}{l}\text { Para obtener el cambio de } \\
\text { titularidad era necesario } \\
\text { previamente que Fiscalización y } \\
\text { Apremio, realice una auditoria } \\
\text { para determinar tributos de oficio. }\end{array}$ & $\begin{array}{l}\text { Se propone no esperar dictamen de Fiscalización y Apremio, } \\
\text { sino sólo notificar del cambio para que este sector realice } \\
\text { sus gestiones de manera independiente al área de } \\
\text { habilitación. }\end{array}$ & $\begin{array}{l}\text { Separa los procesos de habilitación de los de fiscalización } \\
\text { tributaria, reduciendo los tiempos de resolución del trámite. }\end{array}$ & $\mathbf{x}$ & $\mathbf{x}$ & & $\mathbf{x}$ & & $\mathbf{x}$ & $\mathbf{x}$ & & M1, M2, y M3 \\
\hline
\end{tabular}


Referencias

-128 . 